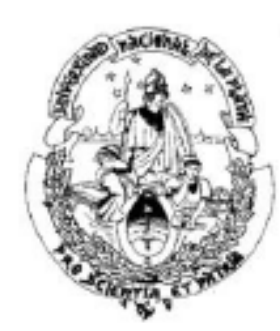

\title{
ECOLOGÍA TRÓFICA DE LOS MONOS AULLADORES NEGROS Y DORADOS (ALOUATTA CARAYA, ATELIDAE) EN EL GRADIENTE LATITUDINAL DE LA SELVA DE INUNDACIÓN DEL RÍO PARANÁ MEDIO
}

\author{
Gustavo Rotta \\ Tesis Doctoral \\ en \\ Ciencias Naturales
}

Directores

Dr. Héctor Ricardo Ferrari - Dr. Pablo Augusto Scarabotti

Facultad de Ciencias Naturales y Museo

Universidad Nacional de La Plata 


\section{RESUMEN}

\section{Ecología trófica de los monos aulladores negros y dorados (Alouatta caraya, Atelidae) en el gradiente latitudinal de la selva de inundación del río Paraná Medio}

Los monos aulladores (Alouatta spp), poseen una distribución geográfica amplia y continua que se extiende desde el sur de México hasta el norte de Argentina. Son herbívoros arborícolas, con una dieta compuesta principalmente por hojas y frutos de árboles y lianas. El objetivo de este trabajo fue analizar la ecología alimentaria, la organización social y uso del espacio de Alouatta caraya, en el extremo sur de su rango geográfico para explorar los factores limitantes que determinan su distribución. El área de estudio abarcó cuatro localidades ubicadas a lo largo de un tramo de 300 kilómetros de selva de inundación del río Paraná comprendido entre la localidad de Paranacito (27³6'33'S, 58 54'29”O) en la provincia de Chaco, al norte y Esquina $\left(30^{\circ} 03^{\prime} 21^{\prime \prime}\right.$ S, 59 $\left.34^{\prime} 25^{\prime \prime} \mathrm{O}\right)$ en la Provincia de Corrientes, al sur. En cada sitio se realizaron estimaciones de la disponibilidad de alimentos por medio del análisis fenológico mensual, a lo largo de un ciclo anual. La composición dietaria de la especie fue evaluada por medio de los métodos de observación directa, análisis microhistológico y macroscópico de heces. El análisis climático demostró que la especie se encuentra limitada a sitios con más de $19.5^{\circ} \mathrm{C}$ de temperatura media anual y con precipitaciones de más de $1000 \mathrm{~mm}$ anuales. Los relevamientos de la vegetación mostraron una reducción en la riqueza de especies vegetales hacia los sitios del sur del gradiente. El análisis fenológico de las especies vegetales consumidas por Alouatta caraya no mostró diferencias claras en la variación estacional en la disponibilidad de estructuras vegetales utilizadas como alimento entre los sitios de estudio, aunque se observó una mayor variación estacional en la diversidad de los recursos hacia el sur. La dieta estuvo integrada mayormente por hojas $(74,7 \%)$ y en menor medida por frutos $(17,7 \%)$ y flores $(7,6 \%)$. Las 5 especies más importantes en la dieta (de un total de al menos 36 especies) fueron Inga affinis, Octoea diospyrifolia, Albizia inundata Banara arguta y Nectandra angustifolia. Las mayores diferencias en la composición de la dieta ocurrieron primariamente entre las localidades y secundariamente entre diferentes períodos dentro de cada localidad. Las distintas clases de edad y sexo evidenciaron escasas diferencias en la composición dietaria, mostrando variaciones aproximadamente sincrónicas a través de las estaciones. Se registró una variación estacional mucho más marcada en el consumo de frutos en relación al consumo de hojas. Se observó que la estacionalidad en el consumo de frutos fue mayor en el sitio del 
extremo sur, sugiriendo la presencia de un período crítico en la disponibilidad de alimento. Las poblaciones de aulladores mostraron grupos mayormente multimacho de gran tamaño (media $=12.3$ individuos) y los valores de densidad y área de acción se mantuvieron estables a lo largo del gradiente estudiado. El sitio del sur mostró una leve disminución en el número de inmaduro-infantes por hembra madura en comparación con los otros sitios. Los cambios en la estabilidad y la persistencia de las poblaciones de Alouatta caraya en el extremo sur de su distribución pueden resultar de una combinación de factores asociados al aumento en la rigurosidad climática, y la mayor estacionalidad en la disponibilidad de alimento que afectarían de diversas maneras las variables demográficas de la especie.

Palabras clave: aullador negro y dorado, Alouatta caraya, ecología alimentaria, microhistología.

\section{ABSTRACT \\ Feeding ecology of the black and gold howler monkey (Alouatta caraya, Atelidae) along the latitudinal gradient of the flooded forest of the Middle Paraná River}

Howler monkeys (Alouatta) have a broad and continuous geographic distribution that extends from the south of Mexico to the north of Argentina. They are arboreal herbivores, with a diet consisting mainly of the leaves and fruit of trees and vines. The objective of this work was to analyze the feeding ecology, social organization, and habitat use and ranging patterns of Alouatta caraya in the southern extreme of the species' geographic range to explore the limits that determine its distribution. The area of study included four study sites along a 300 kilometer stretch of flooded forest of the Middle Paraná River between the localities of Paranacito (27036'33"S, 58 $\left.54^{\prime} 29^{\prime \prime} \mathrm{W}\right)$ in the province of Chaco to the north, and Esquina ( $\left.30^{\circ} 03^{\prime} 21^{\prime \prime} \mathrm{S}, 59^{\circ} 34^{\prime} 25^{\prime \prime} \mathrm{W}\right)$ in the province of Corrientes to the south. A climatic analysis demonstrated that the species was found only at study sites with an average annual temperature greater than $19.5^{\circ} \mathrm{C}$ and an annual precipitation greater than $1000 \mathrm{~mm}$. Estimates of food availability were determined at each study site by analyzing monthly phenological data through an annual cycle. The species' dietary composition was evaluated through direct observation, and microhistological and macroscopic analysis of feces. The analysis of vegetation showed a reduction in plant species richness in study sites located in the southern part of the gradient. Although the phenological analysis of plant species consumed by 
Alouatta caraya showed no clear differences in seasonal availability between study sites, a greater seasonal variation in the diversity of resources was shown in study sites towards the south. The diet was composed mainly of leaves (74.7\%) and, to a lesser extent, of fruits $(17.7 \%)$ and flowers $(7.6 \%)$. The five most frequent plant species in the diet (of a total of more than 36 species consumed) were Inga affinis, Octoea diospyrifolia, Albizia inundata, Banara arguta, and Nectandra angustifolia. The largest differences in diet composition occurred primarily between study sites and secondarily between different periods within each study site. Age and sex classes showed scarce differences in diet composition, demonstrating variations which were synchronous among the seasons. There was a marked seasonal variation in the consumption of fruit in relation to the consumption of leaves. Seasonality of the consumption of fruit was greater in the most southern study site, suggesting the presence of a critical period in food availability. The howler populations in the study area were composed mainly of multi-male groups of large size (average of 12.3 individuals). Values of density and range remained stable along the study gradient. The southern site showed a slight reduction in the ratio of immature-infant individuals per mature female in comparison with the other sites. The changes in the stability and the persistence of populations of Alouatta caraya in the southern extreme of its distribution may result from a combination of factors associated with an increase in the severity of climate and greater seasonal variation in the availability of food that would affect the demographic variables of the species in diverse ways.

Key words: Black and gold howler, Alouatta caraya, feeding ecology, microhistology. 


\section{AGRADECIMIENTOS}

Deseo agradecer en primer lugar a mis directores por la orientación para la concretar este proyecto: A Gabriel Zunino, por guiarme durante los primeros años del doctorado, por sus comentarios y dedicación, por transmitirme sus conocimientos en el campo y mediante publicaciones y cursos. A Heckhard Heymann por sus comentarios críticos del plan de tesis y su apoyo académico en los comienzos del doctorado. A Ricardo Ferrari por orientarme con consejos, críticas, comentarios y correcciones, por su presión para que avance, por ayudarme a visualizar los objetivos y por acompañar con humor esta trayectoria. También por compartir su pasión por la Etología, lo que fue de gran estímulo en mis primeros años de facultad y que continúa hasta el presente. A Pablo Scarabotti, por su dedicación, por brindarse a dirigir esta tesis con un entusiasmo creativo, inspirador e inagotable, por orientarme cuando no hallaba salida a los problemas que iban surgiendo, por exigirme y ayudarme a encontrar las herramientas para avanzar. También por dejarme una enseñanza de vida al encarar las dificultades sin temor, con el tesón y empuje necesario para concreción de un trabajo como este, actitud que adopté como guía para mi desempeño profesional, académico y personal. Por asumir este desafío, ampliando sus horizontes ecológicos y motivando mi interés por ir más profundo en la comprensión de los datos y en la historia natural de los animales.

A investigadores y técnicos de la Estación Biológica de Corrientes, Museo Argentino de Ciencias Naturales, Instituto de Botánica del Nordeste, Facultad de Humanidades y Ciencias Universidad Nacional del Litoral, Facultad de Ciencias Naturales y MuseoUniversidad Nacional de La Plata e Instituto Nacional de Limnología, Dirección de Ordenamiento Territorial-Ministerio de la Producción de Santa Fe, por su colaboración al desarrollo de la tesis: Gabriela Núñez Montellano, Martín Kowalewski, Patricio Ramírez Llorens, Mercedes Arbo, Ana González, Aurelio Schinini, Walter Medina, José Tarragó, Natalia Dolce, Andrea Panseri, Mariana Sosa, Romina Rebozzio, Gabriela Elías, David Iriart, Stela Vaira, Federico Giri, Liliana Tauber, Cecilia Vera Candioti, Alba Imof, Romina Ghirardi, Mirta Arriaga, Mónica Stampacchio, Dolores Montero, Roberto Gómez, Ana Arambarri, Luciana Oklander, Silvana Peker, Carolina Ramírez, Andrés Bortoluzzi, José

Pensiero, Gustavo Marino, Miguel Blanco, Ramón Poló Romero, Ángel Chupali Martínez y Teodoro Baroncho Martínez, Matildo Ezequiel Martínez. Un particular agradecimiento a 
esos fieles compañeros caninos, Charli, Bronco, Nata y Lobo, siempre presentes en los sitios de estudio.

A los miembros del jurado, Dra. María C. Baldovino, Dra. Ingrid Holzmann y Dr. Martín M. Kowalewski, por sus comentarios y apoyo en la última etapa de elaboración de mi tesis.

A los propietarios de las áreas donde se realizó el trabajo de campo por el permiso y comodidades brindadas: Don Iki Karlen, Don Willy Cowper Coles y Don Antonio Perrotta, y a los baquianos: Don Antonio, Don Gómez y Don Mario. A David Ávalos, Francisco Ostolaza y Arnoldo Romer de la Municipalidad Goya y a la Prefectura Naval de Esquina por facilitar el acceso a los sitios de estudio. A Don José Secotto del Instituto Nacional de Tecnología Agropecuaria por el apoyo logístico dispensado y contactos personales para los primeros muestreos en Bella Vista.

A mis asistentes de campo y laboratorio: Javier López, Luciana Sinica, Vanina Botta, Ángeles Daveta, Josefina Vera Candioti, Pablo y Carolina Debarbora, Amparo Pérez Rueda, Jésica Ramírez, Danielle Cole, Griselda Urich y Martín Ortiz, por su valiosa y desinteresada colaboración para la concreción del proyecto.

A mis amigos, por aguantar mis descargas de furia, ausencias, frustraciones, alegrías y avances en la tesis. Gracias Sabino Tomás, Martín Tibu Perotti, Maxi Chiche Curli, Gonzalo Goni Ferreyra, Federico Guasuncho Arguello, Walter Wini Santana, Juani Metal Giancarelli, Sebastián Valle y Ale Díaz. A Germán el Loco Cheli, Mariano Codesido, Fernando Biganzoli, Gonzalo el Vasco Ruiz, Seba Garrizon Cirignoli, Darío Podestá, Patrick, Hérnan, Leandro, Beti, Laura, Marce, Ale P, Ale G, Virginia, Paula, Andrea y Lui. A los señores peñistas: Leo, Diego, Ale, Maxi, Martín, Huguito y Mingo. Un agradecimiento muy especial a Gabi Nuñez, por acompañarme en esta gran experiencia.

A esa gran familia formada por primos, tíos y sobrinos, y por supuesto a Mamama y Papapa!. Gracias Pinitos por estar siempre y colaborar de una u otra forma con este trabajo.

A mi familia, por el apoyo incondicional: Gracias Má, Pá, Pablo, Guille, Inés y Ceci, y a mis cuñaditos queridos Ale, Lauri y Guillegacho!.

Por último, deseo expresar mi agradecimiento al Consejo Nacional de Investigaciones Científicas y Técnicas, a la Agencia Nacional de Promoción Científica y Tecnológica y a Idea Wild, por las becas, subsidios y equipamientos otorgados para la realización del doctorado. 


\section{INDICE GENERAL}

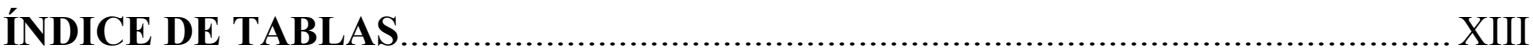

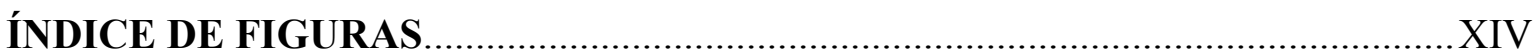

\section{CAPÍTULO I \\ INTRODUCCIÓN GENERAL}

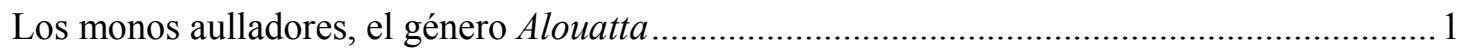

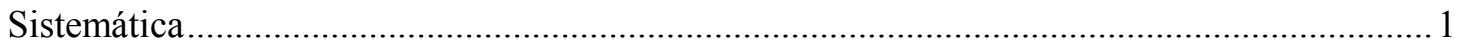

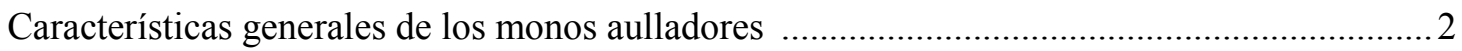

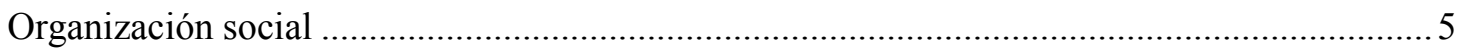

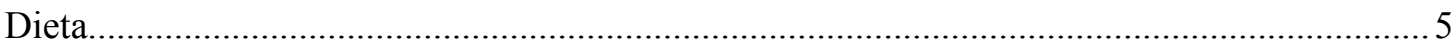

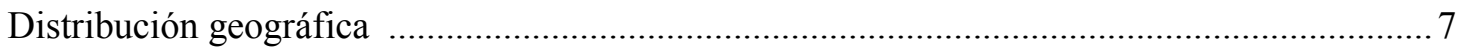

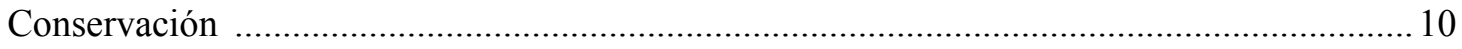

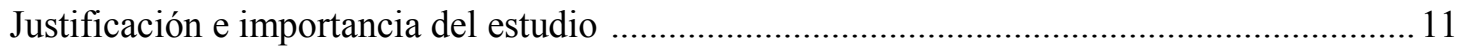

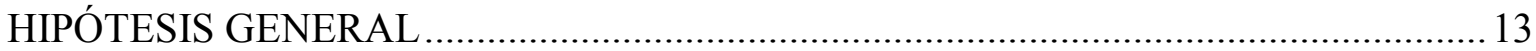

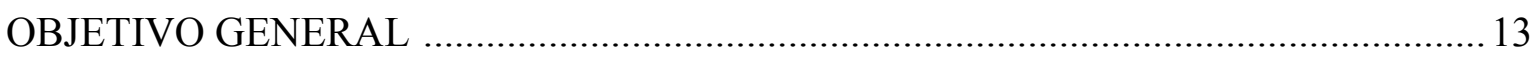

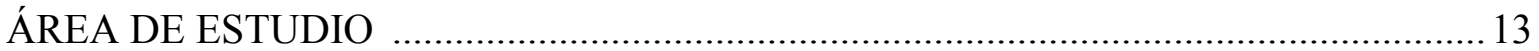

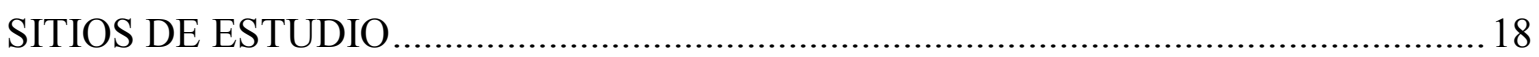

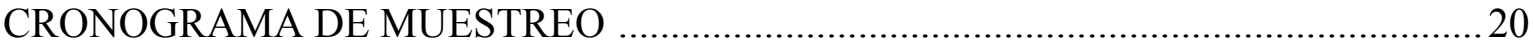

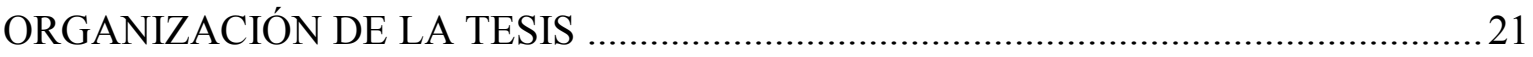

\section{CAPÍTULO II}

VARIACIÓN CLIMÁTICA Y DISPONIBILIDAD DE RECURSOS TRÓFICOS DE Alouatta caraya EN EL EXTREMO SUR DE SU DISTRIBUCIÓN GEOGRÁFICA

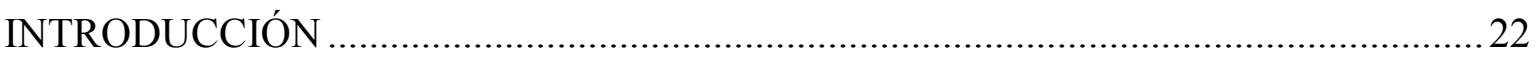

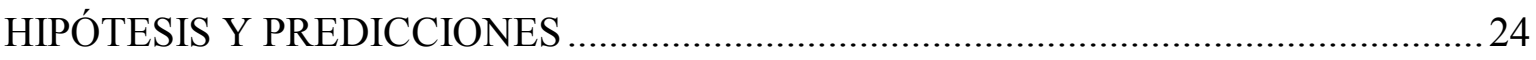

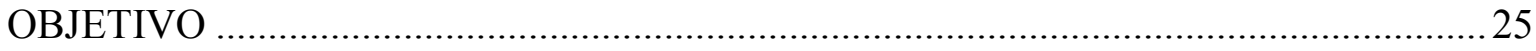

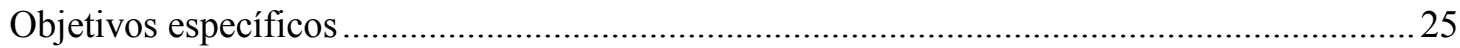

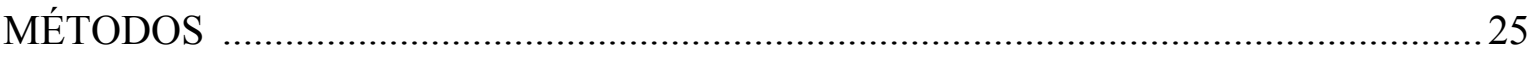


La temperatura y las precipitaciones en cada sitio de estudio ................................................2

Clasificación del clima en la selva de inundación y tierra firme ..............................................26

CARACTERIZACIÓN DE LA VEGETACIÓN DEL ÁREA DE ESTUDIO ....................27

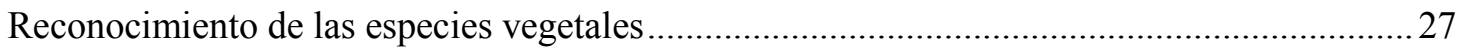

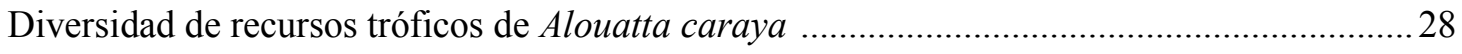

Disponibilidad media mensual de recursos tróficos para Alouatta caraya ................................29

Variación espacial de los grupos principales de recursos alimentarios ....................................... 31

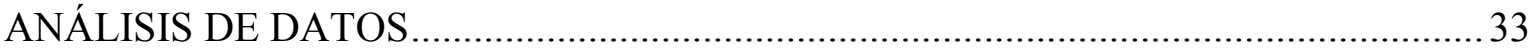

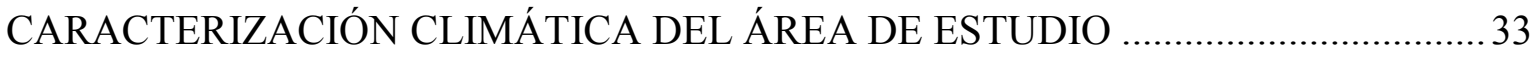

La temperatura y las precipitaciones en cada sitio de estudio ..................................................33

Clasificación del clima en la selva de inundación y en tierra firme ...........................................33

CARACTERIZACIÓN DE LA VEGETACIÓN DEL ÁREA DE ESTUDIO .................... 33

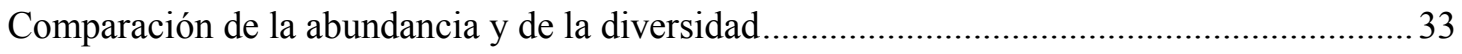

Comparación de la composición de especies consumibles en cada sitio de estudio...................34

Disponibilidad de recursos tróficos analizada con el método de escalamiento multidimensional

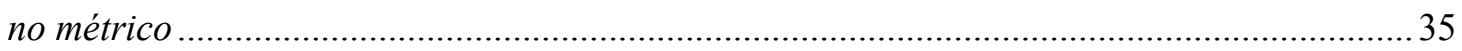

Asociación entre la variación espaciotemporal de los recursos tróficos y el clima ....................36

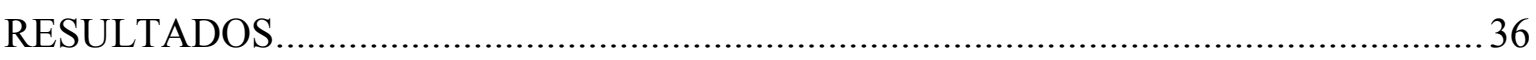

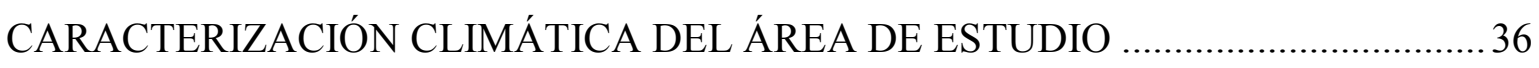

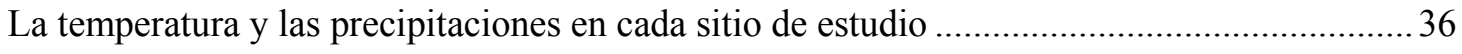

Clasificación del clima en selva de inundación y en tierra firme …............................................ 37

CARACTERIZACIÓN DE LA VEGETACIÓN DEL ÁREA DE ESTUDIO .................... 39

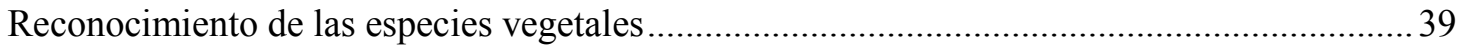

Diversidad de recursos tróficos de Alouatta caraya .................................................................... 39

Comparación de la abundancia y la diversidad entre sitios ....................................................... 43

Comparación de la composición de especies consumibles en cada sitio de estudio...................44

Disponibilidad media mensual de recursos tróficos para Alouatta caraya ...............................45

Disponibilidad de recursos tróficos analizada con el método de escalamiento multidimensional

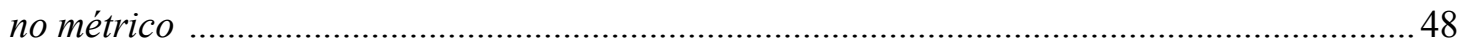

Asociación entre la variación espaciotemporal de los recursos tróficos y el clima ....................50

Variación espacial de los grupos principales de recursos alimentarios ...................................50

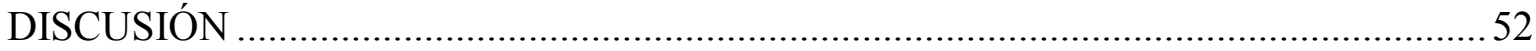




\section{CAPÍTULO III}

VARIACIÓN LATITUDINAL DEL COMPORTAMIENTO TRÓFICO DE Alouatta caraya EN EL EXTREMO SUR DE SU DISTRIBUCIÓN GEOGRÁFICA

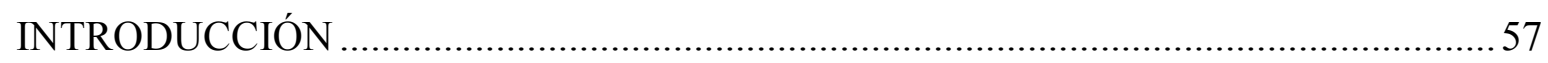

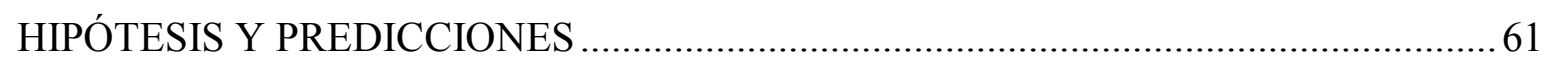

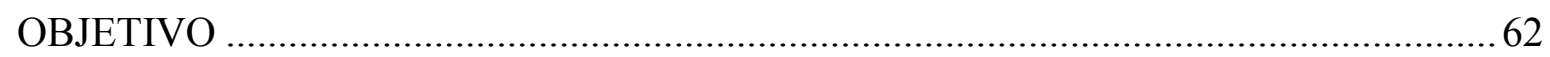

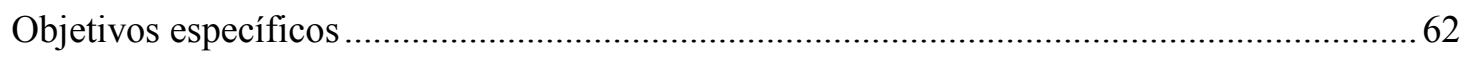

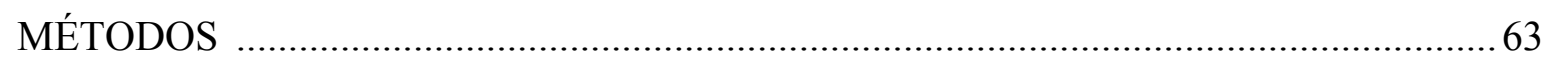

Descripción de la composición de la dieta en base a la utilización de 3 métodos ......................63

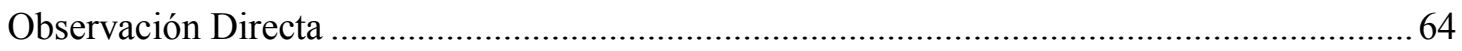

Colecta y tratamiento de muestras fecales para microhistología y macroscopía ........................65

ANÁLISIS MICROHISTOLÓGICO DE HECES .......................................................... 65

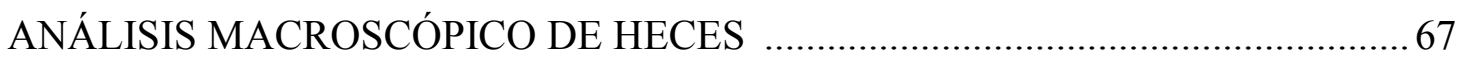

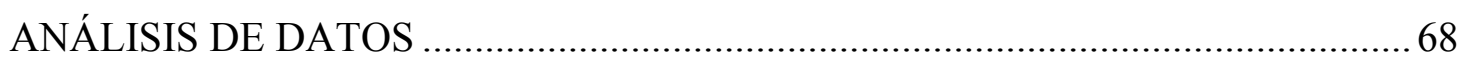

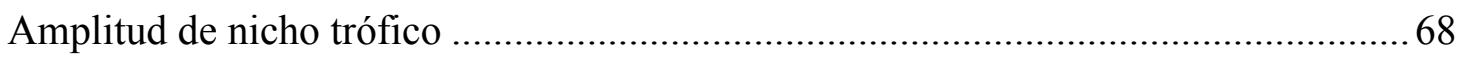

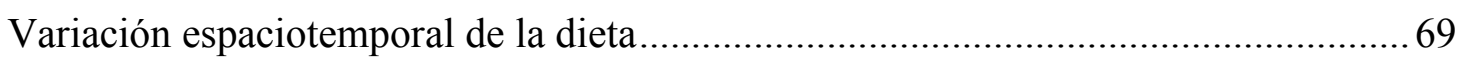

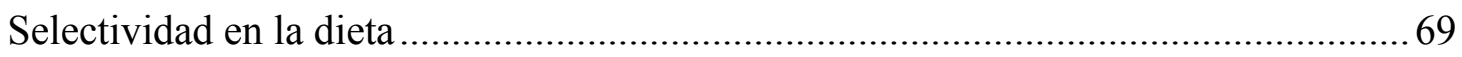

Variación espaciotemporal de la disponibilidad de los recursos tróficos y la

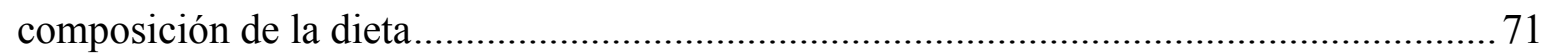

Asociación entre la disponibilidad de recursos y la composición de la dieta ................71

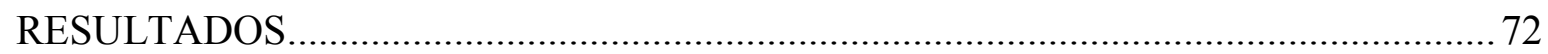

Descripción de la composición de la dieta en base al uso de 3 métodos de análisis....72

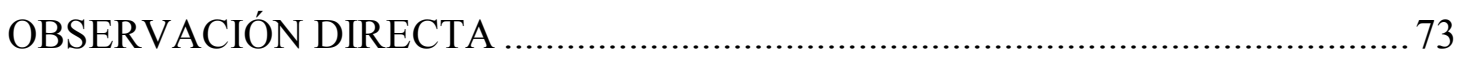

Colecta y tratamiento de muestras fecales para microhistología y macroscopía ........... 74

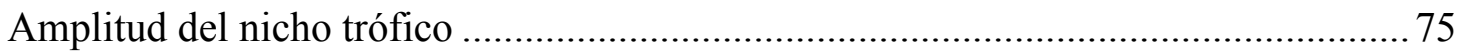

ANÁLISIS MICROHISTOLÓGICO DE HECES ........................................................ 76

Variación espaciotemporal en la composición de la dieta folívora ..................................76

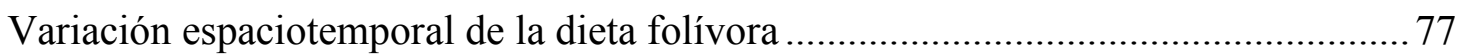

Variación espaciotemporal de la dieta folívora entre clases de edad/sexo.....................79

ANÁLISIS MACROSCÓPICO DE HECES …………………………………....... 81

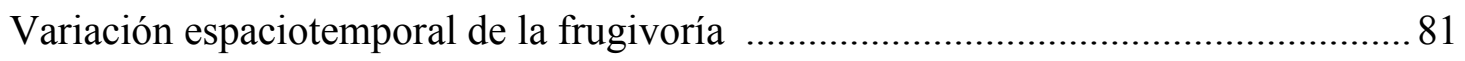

Variación espaciotemporal en la composición de la dieta frugívora...............................82

Variación espaciotemporal de la dieta frugívora entre clases de edad/sexo ................. 85 
Variación espaciotemporal de la disponibilidad de los recursos tróficos y la composición de la dieta

Asociación entre la disponibilidad de recursos tróficos y la composición de la dieta .90 DISCUSIÓN .91

Descripción general de la composición de la dieta ................................................... 91

Alimentación de las diferentes clases de edad y sexo ................................................ 94

Folivoría y frugivoría en Alouatta caraya .................................................................. 94

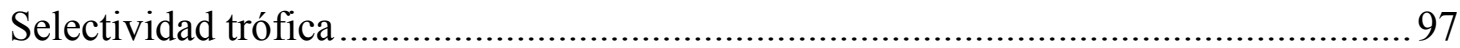

Variación espaciotemporal en la amplitud del nicho trófico ........................................ 99

Composición de la dieta y disponibilidad de recursos tróficos de Alouatta caraya .. 100

\section{CAPÍTULO IV}

VARIACIÓN EN LA ORGANIZACIÓN SOCIAL, USO DEL ESPACIO Y

DENSIDAD DE Alouatta caraya EN EL GRADIENTE LATITUDINAL DE LA SELVA DE INUNDACIÓN DEL RÍO PARANÁ MEDIO

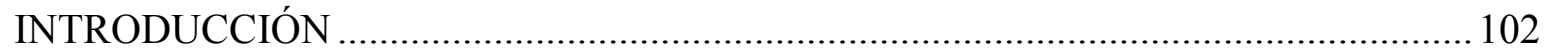

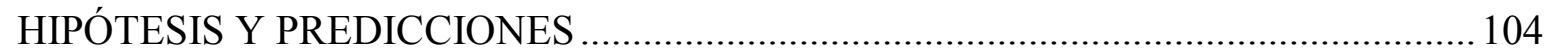

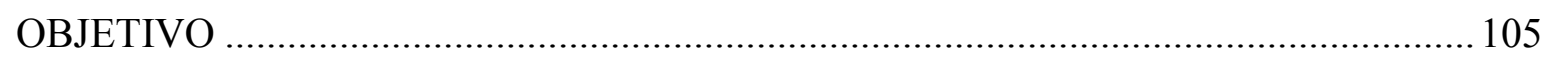

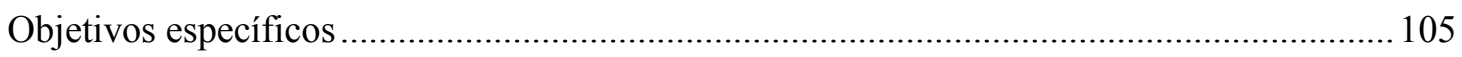

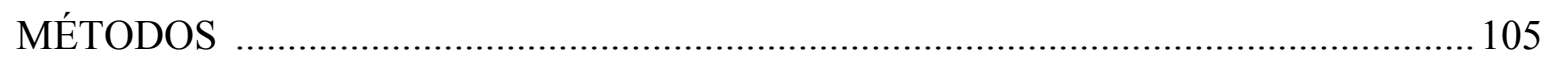

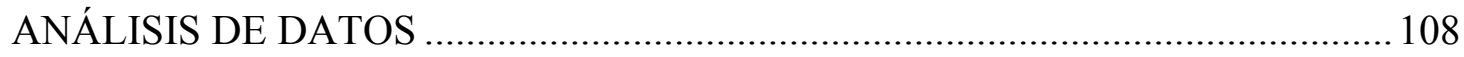

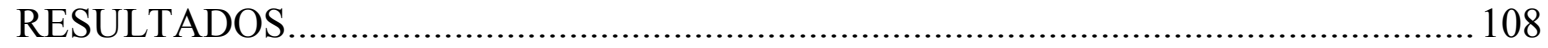

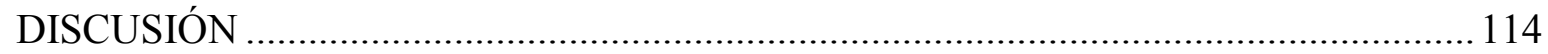

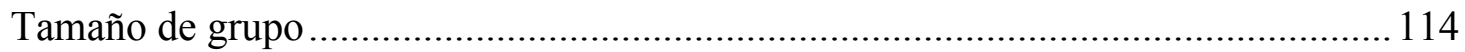

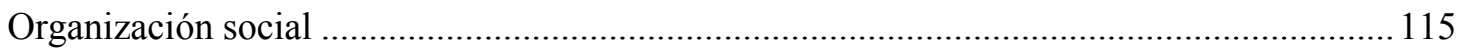

Relación Inmaduro-infantes por Hembra madura ……....................................................... 116

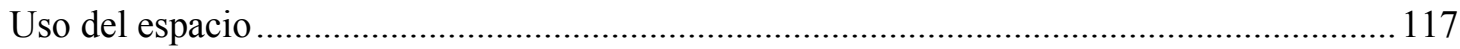

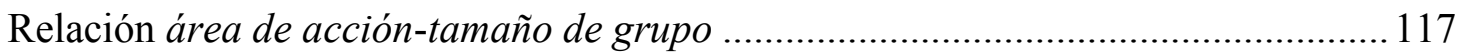




\author{
CAPÍTULO V \\ DISCUSIÓN GENERAL Y CONCLUSIONES \\ FACTORES QUE AFECTAN LA ABUNDANCIA DE LOS AULLADORES EN EL \\ EXTREMO SUR DE SU DISTRIBUCIÓN GEOGRÁFICA \\ Mortalidad
}

BIBLIOGRAFÍA .......................................... 127

ANEXO 1. Registro fotográfico de forrajeo de recursos tróficos de Alouatta caraya 154

ANEXO 2. Cuadro comparativo de las características anatómicas foliares, clave dicotómica y microfotografías para la determinación por microhistología de especies consumidas por Alouatta caraya 155

ANEXO 3. Semillas de especies consumidas por Alouatta caraya, detectadas por análisis macroscópico de muestras fecales 166

ANEXO 4. Frecuencia relativa porcentual de especies de la dieta de hojas, frutos y flores de Alouatta caraya, determinada por observación directa, microhistología y macroscopía. 167

ANEXO 5. Índice de disponibilidad de especies utilizadas como recurso alimentario por Alouatta caraya 168

Nota: en la presente tesis, se utiliza letra cursiva para resaltar las denominaciones correspondientes a nombres de análisis, índices, variables, vocablos en latín y de clasificaciones de grupos de especies vegetales. 


\section{ÍNDICE DE TABLAS \\ CAPÍTULO I}

Tabla I-1. Pesos corporales de diferente sexo de aulladores (Alouatta spp.)

Tabla I-2. Número de especies que conforman la mayor parte de la dieta de distintas especies de aulladores.

Tabla I-3. Fechas de muestreo de especies vegetales y de material fecal, y registro de comportamiento trófico de Alouatta caraya

\section{CAPÍTULO II}

Tabla II-1. Variables bioclimáticas utilizadas y sus referencias. 27

Tabla II-2. Número de individuos de especies consumibles por Alouatta caraya. 40

Tabla II-3. Área basal de especies que conforman la dieta de Alouatta caraya. 43

Tabla II-4. Resultados del ANOVA permutacional comparando las diferencias de abundancia de individuos, riqueza y diversidad medias de especies consumibles por Alouatta caraya

Tabla II-5. Abundancia de individuos, riqueza y diversidad de especies vegetales consumibles por Alouatta caraya.

Tabla II-6. Grupos de especies vegetales utilizadas como recursos por Alouatta caraya 51

Tabla II-7. Riqueza, abundancia y área basal de los grupos de especies vegetales aportantes de recursos tróficos para Alouatta caraya

\section{CAPÍTULO III}

Tabla III-1. Número de muestras fecales de Alouatta caraya colectadas por mes y estación ......66

Tabla III-2. Amplitud de nicho trófico de distintas clases de edad/sexo de Alouatta caraya .79

\section{CAPÍTULO IV}

Tabla IV-1. Tamaño de grupo de Alouatta caraya, en la selva de inundación del río Paraná Medio/Superior y en otros sitios 104

Tabla IV-2. Organización/composición social y uso del espacio de Alouatta caraya 110

Tabla IV-3: Resultados del análisis de la varianza de variables de la organización social comparada de Alouatta caraya.

Tabla IV-4. Área de acción media, área y densidad ecológica y de solapamiento de las áreas de acción de grupos de Alouatta caraya 


\section{ÍNDICE DE FIGURAS \\ CAPÍTULO I}

Figura I-1. Sistemática del género Alouatta según UICN-Cortés Ortiz et al. (2015) ...................... 1

Figura I-2. Individuos de distintas clases de edad y sexo de Alouatta caraya ................................. 4

Figura I-3. Distribución geográfica de Alouatta spp................................................................ 8

Figura I-4: Distribución geográfica de Alouatta caraya en Sudamérica y en Argentina............... 10

Figura I-5. Aspecto general de selva de inundación del río Paraná Medio...................................... 15

Figura I-6. Área de estudio en la selva de inundación del río Paraná Medio ................................ 19

\section{CAPÍTULO II}

Figura II-1. Área de estudio con ecorregiones, isóclinas, e isohietas, y ubicación de los sitios de estudio en selva de inundación del río Paraná Medio y en tierra firme .......................................26

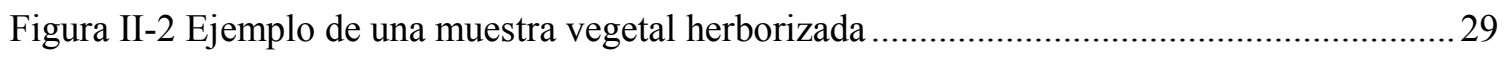

Figura II-3. Climatogramas de 4 sitios de estudio en la selva de inundación del río Paraná Medio, en el período histórico y en el período de muestreo

Figura II-4. Análisis de componentes principales basado en 19 variables ambientales aplicadas a 4 puntos georreferenciados en la selva de inundación del río Paraná Medio y 8 en tierra firme.. 38

Figura II-5. Área basal de 33 especies consumibles por Alouatta caraya.

Figura II-6. Simulación del número de especies vegetales registradas a medida que se incrementa el número individuos en 4 sitios del río Paraná Medio.....

Figura II-7. Dendrograma de similitud porcentual obtenido mediante el índice de Bray-Curtis de especies consumibles por Alouatta caraya

Figura II-8. Índice de disponibilidad media de hoja joven, hoja madura, fruto, flor y estructuras tróficas totales de las especies componentes de la dieta de Alouatta caraya

Figura II-9. Diversidad de Shannon (H) calculados a partir de los valores de disponibilidad de las estrucuturas vegetales de las especies componentes de la dieta de Alouatta caraya.... 48

Figura II-10. Disponibilidad de los recursos alimentarios de Alouatta caraya en la selva de inundación del Paraná Medio.

\section{CAPÍTULO III}

Figura III-1. Semillas extraídas de muestras fecales de Alouatta caraya, dispuestas en recipientes herméticos, cápsulas de Petri con sustrato de Sphagnum sp y algodón/papel secante, en cámara de germinación y en macetas con tierra fértil en vivero 68

Figura III-2. Frecuencia relativa porcentual de especies componentes de la dieta folívora y frugívora de Alouatta caraya determinada por observación directa, análisis microhistológico y macroscópico de heces

Figura III-3. Consumo porcentual anual de estructuras vegetales por Alouatta caraya, registrado por observación directa

Figura III-4. Amplitud del nicho trófico estacional y latitudinal de individuos de diferentes clases de edad y sexo de Alouatta caraya . 
Figura III-5. Selectividad estacional y latitudinal de especies componentes de la dieta folívora de Alouatta caraya

Figura III-6. Dendrograma de similitud de la dieta folívora estacional de Alouatta caraya, en tres sitios de la selva de inundación del río Paraná Medio

Figura III-7. Dendrograma de similitud de la dieta folívora estacional entre clases de edad y sexo de Alouatta caraya.

Figura III-8. Variación estacional porcentual de muestras fecales con semillas de Alouatta caraya

Figura III-9. Frecuencia relativa porcentual del número de semillas-especies halladas en muestras fecales de Alouatta caraya.

Figura III-10. Selectividad estacional de especies componentes de la dieta frugívora de Alouatta caraya

Figura III-11. Dendrograma de similitud de la dieta frugívora de Alouatta caraya en 3 sitios de la selva de inundación del río Paraná Medio.

Figura III-12. Dendrograma de similitud de la dieta frugívora estacional entre clases de edad y sexo de Alouatta caraya

Figura III-13. Similitud del consumo y la disponibilidad estacional de recursos tróficos para Alouatta caraya.

Figura III-14. Gráfico de dispersión de los valores de similitud de la dieta y de disponibilidad de recursos tróficos 91

\section{CAPÍTULO IV}

Figura IV-1. Grupos unimacho y multimacho de Alouatta caraya

Figura IV-2. Organización/composición social media de Alouatta caraya registrada en la selva de inundación del río Paraná Medio....

Figura IV-3. Composición social media de Alouatta caraya registrados en 3 sitios de la selva de inundación del río Paraná Medio..... 111

Figura IV-4. Área de acción de grupos de Alouatta caraya en la selva de inundación del río Paraná Medio 113

\section{CAPÍTULO V}

Figura V-1. Diagrama de flujo que integra los procesos que afectan la dinámica poblacional de Alouatta caraya en el extremo sur de su distribución geográfica. 126 


\section{CAPÍTULO I}

\section{INTRODUCCIÓN GENERAL}

\section{Los monos aulladores, el género Alouatta}

\section{Sistemática}

Según Schneider (2000), los monos del nuevo mundo o primates neotropicales están agrupados en el Infraorden Platyrrhini e incluidos en la Superfamilia Ceboidea, la cual se divide en tres familias: Pitheciidae, Cebidae y Atelidae. El género Alouatta ha sido tradicionalmente incluido dentro de la familia Cebidae (Hershkovitz 1977), sin embargo, según investigaciones moleculares recientes, se ha revelado su parentesco con Ateles, Brachyteles y Lagothrix (Subfamilia Atelinae) (Schneider 2000, Schneider et al. 2001, Groves 2001).

Para el género Alouatta, llamados comúnmente monos aulladores, se considera la existencia de diferente número de especies según la interpretación de distintos autores, y su taxonomía aún sigue en debate (Gregorin 2006, Rylands y Mittermeier 2009). Para la presente tesis se tuvo en cuenta la clasificación de Cortés Ortiz et al. (2015) que reconocen la existencia de 12 especies (Figura I-1).

Reino Animalia

Filo Chordata

Clase Mammalia

Orden Primates

Suborden Haplorrhini

Infraorden Simiiformes

Parvorden Platyrrhini

Suborden Anthropoidea

Superfamilia Ateloidea

Familia Atelidae

Subfamilia Atelinae

Alouatta arctoidea

Alouatta belzebul

Alouatta caraya

Alouatta discolor

Alouatta guariba

Alouatta macconnelli

Alouatta nigerrima

Alouatta palliata

Alouatta pigra

Alouatta sara

Alouatta seniculus

Alouatta ululata

Figura I-1. Sistemática del género Alouatta según UICN-Cortés Ortiz et al. (2015). 


\section{Características generales de los monos aulladores}

Los monos aulladores, definidos como animales arborícolas relativamente grandes y de hábitos diurnos, restringen la mayoría de sus actividades a los estratos superiores de los bosques (Milton 1980, Crockett 1998), aunque también se ha observado su locomoción por el suelo, principalmente para recorrer distancias entre parches de bosque, donde se tornan más vulnerables a depredadores como los felinos (Leopardus pardalis, Puma concolor, Panthera onca), canidos (Eira barbara, Canis lupus familiaris), serpientes constrictoras (Boa constrictor) y águilas (Harpia harpyja, Spizaetus ornatus) (Carpenter 1934, Heymann 1987, Neville et al. 1988, Bicca Marques y Calegaro Marques 1995, Tello et al. 2002, Miranda et al. 2005, Bianchi y Mendes 2007, Ludwig et al. 2007).

En cuanto a su morfología, los aulladores poseen una cola muscular prensil generalmente usada para soportar el cuerpo durante la alimentación y como un apoyo adicional durante la locomoción (Di Fiore y Campbell 2007). Presentan una característica excepcional entre los primates que consiste en el desarrollo de un hueso hioides de gran tamaño (mayor en machos que en hembras), el cual actúa como una caja de resonancia amplificando las vocalizaciones típicas del género producidas con mayor intensidad por los machos (Schön Ybarra 1986, Crockett y Einsenberg 1987). Estos sonidos pueden viajar grandes distancias a través de la densa vegetación selvática, un medio en el cual las vibraciones sonoras son absorbidas rápidamente (Bradbury y Vehrencamp 1998). Sus funciones son presumiblemente informar la localización y composición del grupo (Kinzey 1997) y regular el espaciamiento entre grupos (Whitehead 1989), la defensa de los recursos (Sekulic 1983, Aguiar et al. 2003, Defler 2003), como así también evitar el acceso a las hembras por machos externos al grupo (Sekulic 1983).

El género Alouatta es uno de los de mayor tamaño entre los géneros de monos neotropicales, con un peso corporal que varía entre las especies que lo componen, siendo mayor en los machos que en las hembras (Von Ihering 1914, Treves 2001, Di Fiore y Campbell 2007). El aullador negro y dorado (Alouatta caraya), tiene un marcado dimorfismo sexual en cuanto al peso medio entre hembras y machos maduros (Tabla I-1). 
Tabla I-1. Pesos corporales de diferente sexo de aulladores (Alouatta spp.). Referencias: N: Número de individuos, Dimorfismo sexual (razón entre la media del peso de machos y de hembras).

\begin{tabular}{|c|c|c|c|c|c|c|c|c|}
\hline \multirow{2}{*}{ Especie } & \multicolumn{3}{|c|}{ Peso de machos } & \multicolumn{3}{|c|}{ Peso de hembras } & \multirow{2}{*}{$\begin{array}{c}\text { Dimorfismo } \\
\text { sexual }\end{array}$} & \multirow{2}{*}{ Fuente } \\
\hline & Media & Rango & $\mathbf{N}$ & Media & Rango & $\mathbf{N}$ & & \\
\hline A. belzebul & 7,27 & $6,54-8,00$ & 27 & 5,52 & $4,85-6,20$ & 26 & 1,32 & 1 \\
\hline A. caraya & 6,80 & $4,00-9,60$ & 19 & 4,60 & $3,80-5,40$ & 13 & 1,48 & 1 \\
\hline A. caraya & 6,42 & - & 58 & 4,33 & - & 117 & 1,48 & 2 \\
\hline A. caraya & 6,65 & $3,80-9,50$ & 4 & 4,10 & $3,50-4,70$ & 4 & 1,47 & 3 \\
\hline A. guariba & 6,17 & $5,20-7,15$ & 4 & 4,55 & $4,10-5,00$ & 3 & 1,36 & 1 \\
\hline A. macconelli & 6,20 & $5,20-7,10$ & 4 & 4,50 & $4,10-5,00$ & 3 & 1,38 & 1 \\
\hline A. palliata & 7,15 & $4,50-9,80$ & 56 & 5,35 & $3,10-7,60$ & 67 & 1,34 & 1 \\
\hline A. pigra & 11,35 & $11,11-11,59$ & 2 & 6,43 & $6,29-6,57$ & 4 & 1,76 & 4 \\
\hline A. seniculus & 7,20 & $5,40-9,00$ & 61 & 5,60 & $4,20-7,00$ & 61 & 1,29 & 1 \\
\hline
\end{tabular}

Fuente: 1. Ford y Davis 1992, 2: Rumiz 1990, 3. Wallace y Rumiz 2010, 4. Ford 1994.

Alouatta caraya no sólo tiene dimorfismo sexual en cuanto al tamaño corporal, sino también en la coloración (Coppo y Resoagli 1978, Rumiz 1990, Kinzey 1997). Los individuos de ambos sexos son de color marrón claro al nacer, produciéndose un oscurecimiento gradual en los machos a medida que alcanzan la madurez, hasta llegar al color negro a los 3 o 4 años de edad, y con el escroto cubierto de pelos amarillentoanaranjados, mientras que las hembras mantienen el color marrón toda su vida (Thorington et al. 1984). La clasificación en categorías de edad/sexo se basa en diferencias de tamaño corporal, coloración, genitales y asociación con otros individuos (ej. madres con sus crías) (Rumiz 1990, Muñoz et al. 2005, Zunino et al. 2007). En esta tesis se utilizaron las categorías que se describen a continuación:

-Infantes: individuos de hasta 1 año de edad de color marrón claro, dependientes gran parte del tiempo de la madre para el transporte y la alimentación.

-Hembras inmaduras: individuos juveniles, destetados y no cargados por progenitores, de pelaje marrón claro, y subadultos, de 3 a 4-5 años, de tamaño similar o menor a las hembras adultas y apariencia más delgada y vulva no pigmentada.

-Machos inmaduros: individuos juveniles, destetados y no cargados por progenitores, con distintos grados de oscurecimiento en su coloración, y subadultos, de 4-5 años, de tamaño algo menor que los adultos, de color negro parduzco y testículos no contrastantes con pelaje circundante.

-Hembras maduras: individuos adultos mayores a 4-5 años, reproductivamente maduras, pelaje marrón con la espalda más oscura y grisácea, labios vulvares anchos e irregularmente pigmentados, con crías y/o desarrollo mamario y pezones conspicuos que indican que han amamantado. 
-Machos maduros: individuos adultos mayores a 4-5 años, reproductivamente maduros, de mayor tamaño que las hembras, con desarrollo total de genitales, de pelaje color negro, y anaranjado alrededor del escroto (Figura I-2).

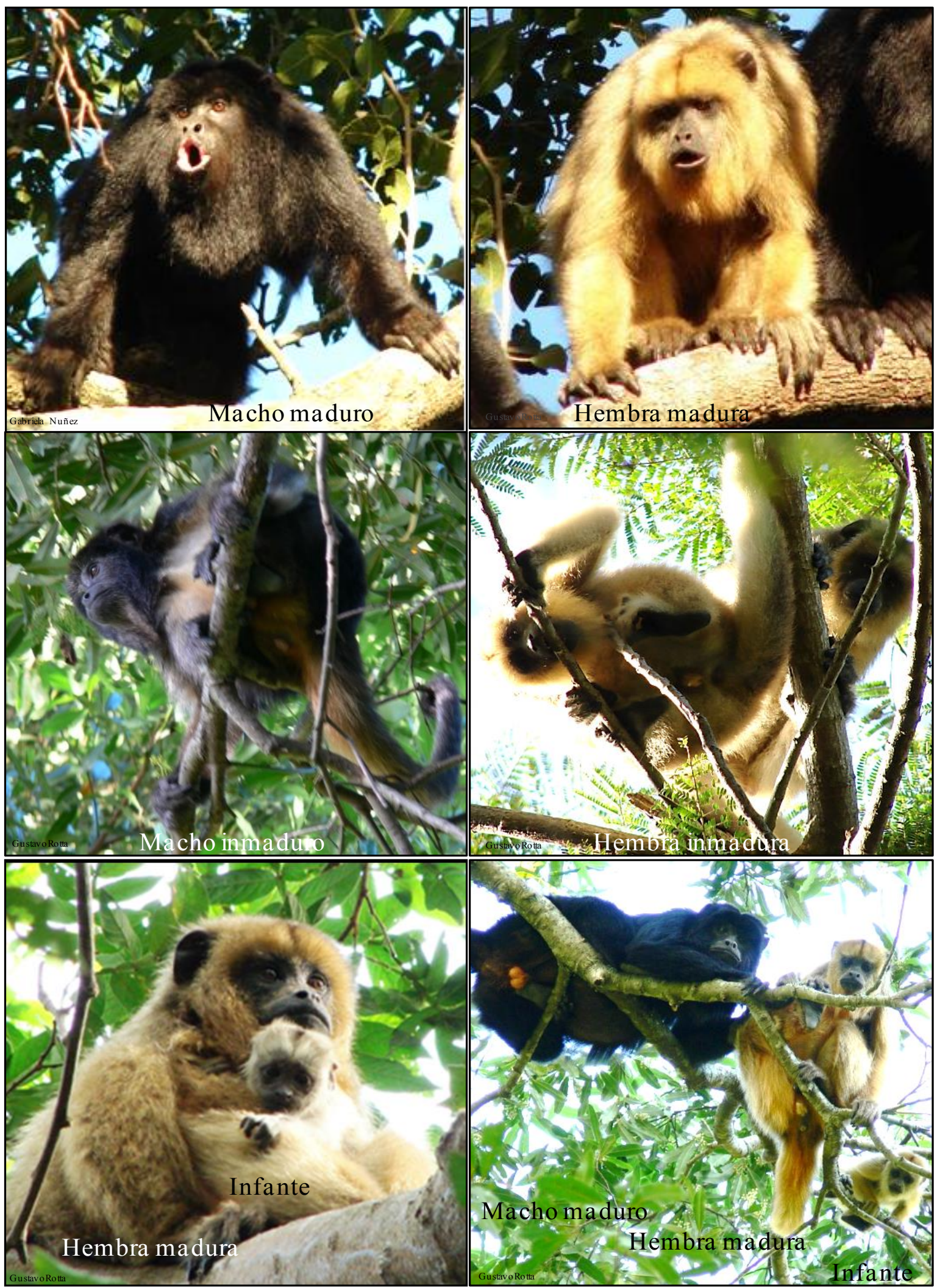

Figura I-2. Individuos de distintas clases de edad y sexo de Alouatta caraya, registrados en la selva de inundación del río Paraná Medio, en el período abril de 2007-marzo de 2008. 


\section{Organización social}

Los aulladores forman grupos de tamaño y composición variable, de acuerdo con la especie, con la calidad del ambiente y con el patrón de dispersión de los machos y hembras, que al migrar pueden formar nuevos grupos o integrarse a uno nuevo (Kinzey 1997, Brockett et al. 2000, Ostro et al. 2001). Se encuentran organizaciones unimacho, multimacho, o con machos en gradiente de edades (Eisenberg 1979), que se describen en el capítulo IV.

El género Alouatta presenta diferentes patrones de reproducción, con especies que exhiben un cierto grado de estacionalidad en los nacimientos posiblemente asociada a períodos con mayor disponibilidad de alimento durante la etapa del destete (ej. A. seniculus) (Crockett y Rudran 1987) como así también, especies que presentan nacimientos sin una concentración estacional (ej. A. guariba) (Strier et al. 2001). En A. caraya, se ha evidenciado estacionalidad en los nacimientos en ambientes fragmentados (Kowalewski y Zunino 2004), pero no se ha manifestado en ambientes continuos de selva de inundación (Pavé et al. 2012). La gestación tiene una duración de 180 a 194 días dependiendo de la especie, y el cuidado y transporte de la cría es exclusivo de la madre (Rumiz 1990, Kinzey 1997, Strier et al. 2001, Kowalewski y Zunino 2004, Kowalewski y Garber 2010).

\section{Dieta}

Los aulladores se han definido como herbívoros (folívoros-frugívoros), con una dieta rica en fibras, compuesta de hojas, frutos, flores, brotes, lianas y raíces de epifitas (Milton 1980, Crockett y Eisenberg 1987, Londoño y Gómez Posada 2003, Di Fiore y Campbell 2007). Basan su dieta principalmente en el consumo de hojas, particularmente jóvenes, durante todo el año y de cantidades considerables de frutos y flores cuando estos recursos están disponibles, por lo que son caracterizados como frugívoros oportunistas (Milton 1980, Bonvicino 1989, Mendes 1989, Chiarello 1994). También se ha observado la ingesta de insectos, semillas, corteza, raíces y madera en descomposición (Simmen y Sabatier 1996, Pina 1999, Santamaría Gómez 1999, De Marques 2001, Pinto 2001, 2002). A su vez, se ha registrado diferente número de especies consumidas en relación con la ubicación del sitio de estudio y la especie de aullador, y en algunos estudios también se identificaron las especies vegetales que conformaron la mayor parte de la dieta (cercana al 70\%) (Tabla I-2). 
Tabla I-2. Número de especies (spp.) vegetales que conforman la mayor parte de la dieta (expresada en porcentaje), de distintas especies de aulladores (Alouatta spp.).

\begin{tabular}{|c|c|c|c|c|}
\hline Especie & $\mathrm{N}^{\circ}$ total spp. & $N^{0}$ spp. $\operatorname{con}>\%$ en la dieta & Sitio de estudio & Fuente \\
\hline A. palliata & 27 & $4>73$ & Veracruz-México & 1 \\
\hline A. palliata & 31 & $8>70$ & Tabasco-México & 2 \\
\hline A. palliata & 57 & $8>71$ & Nicaragua & 5 \\
\hline A. palliata & 96 & $15>81$ & Costa Rica & 6 \\
\hline A. palliata & 73 & $7>50$ & Panamá & 7 \\
\hline A. palliata & 95 & $12>66$ & Costa Rica & 8 \\
\hline A. palliata & 65 & $5>61$ & Costa Rica & 8 \\
\hline A. pigra & 74 & $12>70$ & Belice & 3 \\
\hline A. pigra & 85 & $5>75$ & Belice & 4 \\
\hline A. seniculus & 195 & $19>36$ & Guayana francesa & 9 \\
\hline A. seniculus & 56 & $2>66$ & Venezuela & 10 \\
\hline A. seniculus & 33 & $1>50$ & Venezuela & 10 \\
\hline A. seniculus & 35 & $6>50$ & Colombia & 11 \\
\hline A. guariba & 52 & $9>50$ & San Pablo-Brasil & 12 \\
\hline A. guariba & 27 & - & Rio Grande do Sul-Brasil & 13 \\
\hline A. caraya & 27 & $3>50$ & Rio Grande do Sul-Brasil & 14 \\
\hline A. caraya & 17 & $5>73$ & Paraná-Brasil & 15 \\
\hline A. caraya & 16 & $5>72$ & Paraná-Brasil & 15 \\
\hline A. caraya & 23 & $5>92$ & Corrientes-Argentina & 16 \\
\hline A. caraya & 12 & $6>88$ & Corrientes-Argentina & 16 \\
\hline A. caraya & 18 & $2>65$ & Corrientes-Argentina & 17 \\
\hline A. caraya & 13 & - & Chaco-Argentina & 18 \\
\hline A. caraya & 70 & $5>74$ & Chaco-Argentina & 19 \\
\hline A. caraya & 22 & $3>64$ & Chaco-Argentina & 20 \\
\hline A. caraya & 26 & - & Corrientes -Argentina & 21 \\
\hline A. caraya & 31 & $5>73$ & Chaco-Argentina & 22 \\
\hline A. caraya & 26 & $5>74$ & Santa Fe-Argentina & 22 \\
\hline A. caraya & 23 & $4>75$ & Santa Fe-Argentina & 22 \\
\hline
\end{tabular}

Fuente: 1: Estrada 1984, 2: Fuentes et. al.2003, 3: Silver et. al.1998, 4: Marsh 1999, 5: Williams Guillén 2003, 6: Glander 1975, 7: Milton 1980, 8: Stoner 1996, 9: Julliot y Sabatier 1993, 10: Orihuela et. al. 2005, 11: Alvis Rojas 2012, 12: Galetti et al.1994, 13: Prates et al.1990, 14: Bicca Marques y Calegaro Marques 1994a, 15: Ludwig et al. 2008, 16: Rumiz et. al. 1986, 17: Zunino 1987, 18: Bazzalo 2001, 19: Kowalewski 2007, 20: Bravo y Sallenave 2003, 21, Fernández et al. 2012, 22: Este estudio.

Los aulladores negros y dorados (Alouatta caraya) son principalmente folívoros, aunque consumen diferentes frutos cuando están disponibles (Zunino 1986, 1987), siendo además importantes agentes dispersores de semillas de algunas especies vegetales (Bravo y Zunino 2000). Para esta especie se han observado variaciones en la dieta de acuerdo con la disponibilidad espacial y temporal de los recursos del área (Rumiz et al. 1986). 
Si bien se han realizado investigaciones sobre la dieta, densidad y organización social de la especie en selva de inundación del río Paraná Medio (Bravo y Zunino 1998, Bazzalo 2001, Zunino et al. 2001, Kowalewski y Zunino 2004, Bravo y Sallenave 2003, Kowalewski 2007), no se han efectuado estudios sobre cambios en dichas variables a lo largo de un gradiente latitudinal en el extremo sur de su distribución. En la presente tesis, se ahonda en el análisis de la disponibilidad temporal y latitudinal de recursos alimentarios, selectividad trófica, diferencias dietarias entre clases de edad/sexo, y su relación con el uso del espacio y la organización social de $A$. caraya. De esta forma, se profundiza en los efectos de factores potencialmente determinantes de la distribución geográfica poblacional de los aulladores.

\section{Distribución geográfica}

Las poblaciones de aulladores se encuentran en bosques perennes, semideciduos, montanos, selvas en galería y de inundación (Eisenberg 1979, Crockett y Eisenberg 1987, Chapman y Balcomb 1998). Se piensa que la distribución de los monos aulladores está principalmente relacionada con su flexibilidad ecológica y adaptabilidad a diferentes condiciones ambientales (Eisenberg et al. 1972, Eisenberg 1979). La mayoría de las especies además, habitan fragmentos de bosque cerca de áreas con actividad agrícola o ganadera (Crockett 1998, Zunino et al. 2007), reflejando su tolerancia a ambientes disturbados por lo que, probablemente sólo los cambios drásticos en el ambiente donde habitan, o los disturbios directos sean la causa de su desaparición en un área determinada (Cortés Ortiz et al. 2003).

La distribución del género Alouatta se extiende desde el estado de Veracruz, en el sur de México, hasta las provincias de Corrientes y Santa Fe en el noreste de Argentina, y hasta el estado de Río Grande do Sul en el sur de Brasil (Kinzey 1997, Nowak 1999, Printes et al. 2001). Este género, el de mayor distribución geográfica entre los primates neotropicales (Hirsch et al. 2002), habita además el mayor rango de ambientes forestales húmedos y sub-húmedos del trópico y subtrópico, desde el nivel del mar hasta los 3000 metros de altura (Crockett y Eisenberg 1987), aunque las diferentes especies varían en las preferencias de hábitat (Crockett 1998) (Figura I-3). 


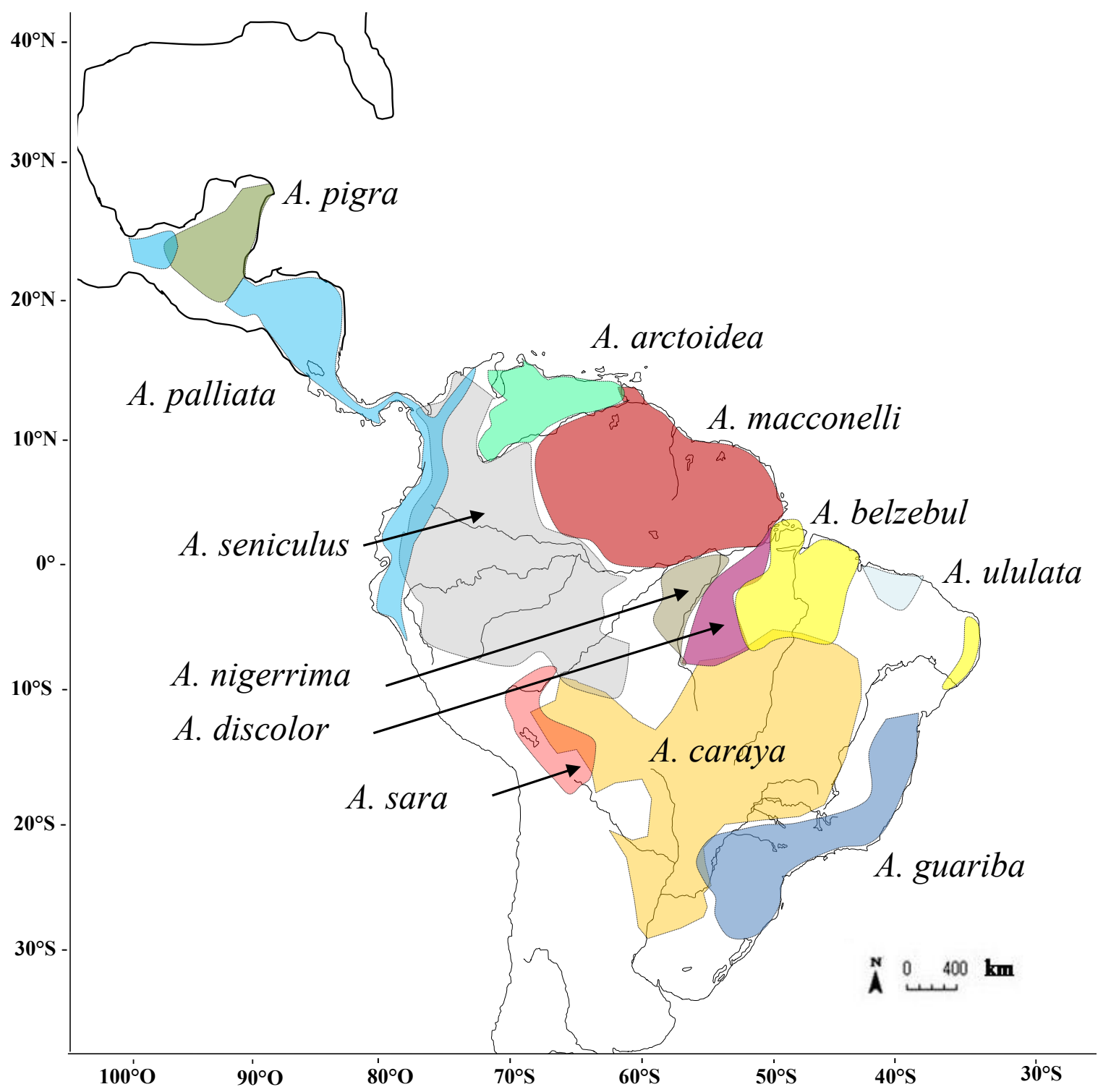

Figura I-3. Distribución geográfica del género Alouatta (modificado de UICN-Cortés Ortiz et. al 2015).

Alouatta caraya se distribuye por bosques ribereños y de interior en las ecorregiones de Caatinga, Cerrado, Chaco y Pantanal, algunas zonas del Bosque Atlántico y Campos (noreste de Bolivia, gran parte del Paraguay, estados de Mato Grosso, Goiás, Minas Gerais, São Paulo, Paraná y Río Grande do Sul) (Bicca Marques 1990, Eisenberg y Redford 1999, Hirsch et al. 2002 Gregorin 2006, Aguiar et al. 2007ab). Esta especie alcanza las selvas del noreste argentino, las cuales conforman un gran mosaico de fisonomías interconectadas que se suceden desde la Selva Paranaense (provincia de Misiones), el Bosque Chaqueño (este de las provincias de Formosa y Chaco, norte de Corrientes y noreste de Santa Fe), la selva de inundación de los ríos Paraná, Paraguay y Uruguay y las selvas en galería que acompañan a sus afluentes (Cabrera 1939, 1976, Rumiz 1990, Brown y Zunino 1994, Zunino et al. 2001, Di Bitetti 2003). 
Hacia el extremo sur de su distribución, Alouatta caraya llega aproximadamente a los $29^{\circ} 03^{\prime} \mathrm{S}$ por tierra firme, al sudoeste de la provincia de Corrientes (Piantanida et al. 1984), y hasta los $29^{\circ} 30^{\prime} \mathrm{S}$ por la selva de inundación del río Paraná, al noreste de la provincia de Santa Fe en cercanía de la localidad de Romang (Pautasso 2008), pudiendo extenderse más al sur con la ocurrencia de grandes crecientes del río (Zunino com. pers.).

El área de distribución de Alouatta caraya descripta por Zunino et al. (1995), se basa en estudios a largo plazo realizados en la región y fueron corroborados por observaciones personales en la presente tesis. Otros autores consideran que la especie se extendería hasta latitudes mayores, alcanzando el extremo sur de Corrientes, el noreste de Entre Ríos y el norte de Uruguay (Villalba et al. 1995, Hirsch et al. 2002, Fernández Duque et al. 2008). Sin embargo esta distribución se basa en registros aislados, probablemente debido a la liberación realizada por el hombre de individuos provenientes de otras regiones, o bien se trataría de poblaciones no estables (Fallabrino et al. 2009). Una revisión de puntos de registro realizada por Holzmann (2012), actualizó el conocimiento de la distribución de A. caraya en toda su extensión, coincidiendo en buena medida con lo expresado por Zunino et al. (1995) para la distribución en Argentina, y poniendo de manifiesto que la distribución más austral de la especie está representada en el área de estudio considerada en esta tesis y en el sur de Brasil (Figura I-4). 


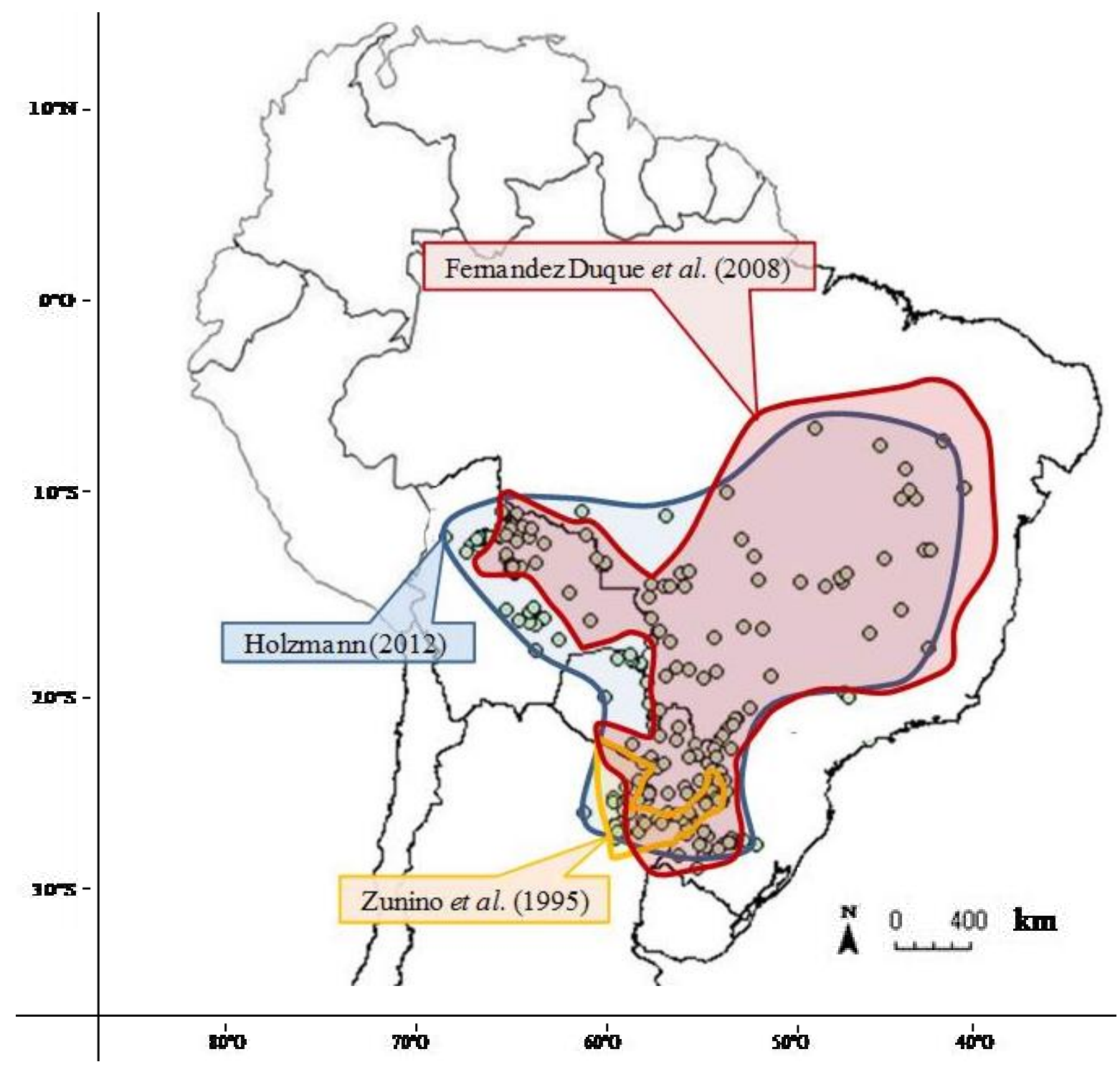

Figura I-4. Distribución geográfica de Alouatta caraya en Argentina según Zunino et al. (1995), en Sudamérica según Fernández Duque et al. (2008) y Holzmann (2012-confeccionada por unión de puntos de registros compilados).

\section{Conservación}

La situación poblacional de Alouatta caraya es categorizada como de preocupación menor por la Unión Internacional para la Conservación de la Naturaleza (UICN), y sin problemas de conservación a escala mundial (Fernández Duque et al. 2008), aunque su población es considerada en declive para algunas áreas, y clasificada como vulnerable para Argentina (Ojeda et al. 2012), al igual que para el estado de Río Grande do Sul-Brasil en peligro para los estados de Paraná y San Pablo-Brasil (Codenotti et al. 2002, De Marques 2003, Machado et al. 2005). Estas diferencias en las categorizaciones pueden deberse a su gran distribución geográfica, versatilidad y adaptabilidad a sobrevivir en hábitats muy degradados, con niveles moderados de deforestación y fragmentación y en bosques secundarios (Crockett y 
Eisenberg 1987, Crockett 1998, Clarke et al. 2002, Bicca Marques 2003, Zunino et al. 2007). En el sur de su rango geográfico en Argentina, se la considera amenazada por el desmonte indiscriminado en las provincias de Santa Fe, Chaco, Formosa y Corrientes (Brown y Zunino 1994). Otra amenaza a las poblaciones silvestres de $A$. caraya es su tráfico para el mercado de mascotas, siendo la especie más comercializada de los monos autóctonos (Bertonatti 1995), a pesar de estar prohibida su caza por la ley nacional $N^{0} 22421$, e incluida en el Apéndice II de la Convención sobre el Comercio Internacional de Especies Amenazadas de Fauna y Flora Silvestres (CITES 1975, UNEP-WCMC 2013).

\section{Justificación e importancia del estudio}

El extremo sur de la distribución de Alouatta caraya en Argentina, presenta al río Paraná como principal agente formador del paisaje. Éste, junto con el río Paraguay, nacen en latitudes tropicales y corren hacia latitudes subtropicales templadas, por lo que la biota de los mismos tiene elementos tropicales que contrastan con los biomas templados que atraviesan (Arzamendia y Giraudo 2009). En su trayectoria hacia el sur funcionan como corredores de la distribución de especies, cambiando gradualmente sus condiciones ambientales hasta tornarse extremas o marginales para las mismas (Ascunce et al. 2007, Giraudo 2008). Las poblaciones marginales tienen mayor riesgo de extinción y a menudo son genéticamente menos diversas que las del centro de la distribución, debido a que ocupan hábitats menos favorables y con densidades menores (Lawton 1993).

La disponibilidad de alimento puede ser uno de los factores que limita geográficamente a las poblaciones de animales (Dunbar 1987). La calidad, abundancia y diversidad de los principales ítems alimenticios de Alouatta caraya (hojas y frutos), dependen del estadio sucesional y estacionalidad de los diferentes tipos de ambientes (Peres 1997), así como de la temperatura y de las precipitaciones entre otro factores posibles (Ramírez 2009). Es decir, que la disminución poblacional de $A$. caraya hacia el sur puede asociarse con el empobrecimiento de la vegetación, determinado por el descenso de la temperatura y de las precipitaciones (Cabrera 1957, Zunino et al. 1995).

Por otro lado, la selva de inundación del río Paraná presenta una menor estacionalidad climática comparada con lo observado en tierra firme (ej. monte chaqueño, espinal correntino), posiblemente como resultado del efecto estabilizador de la temperatura por parte del río (Neiff et al. 1985). Esto, posibilita una mayor disponibilidad de recursos alimentarios y una distribución más prolongada de los aulladores hacia el sur por las islas del Paraná que por tierra firme (Brown y Zunino 1994, Zunino et al. 1996, 2001). 
Cabe destacar la presencia en Argentina de una especie emparentada a la aquí estudiada, Alouatta guariba clamitans, de gran similitud en su nicho ecológico e incluso simpátrica con Alouatta caraya (Parque Provincial El Piñalito, provincia de MisionesHolzmann 2012), que ha sido catalogada como en peligro crítico de extinción (Ojeda et al. 2012). Por lo cual, se considera importante la obtención de información ecológica que pueda ser útil también para la elaboración de planes de conservación de esta especie.

La selva de inundación del río Paraná Medio constituye un hábitat ideal para evaluar los cambios adaptativos que ocurren en las poblaciones de Alouatta caraya debido a que representa el extremo sur del rango geográfico de la especie, que a su vez constituye uno de los primates más australes del mundo. Estudios previos han notado que los ambientes de selva de inundación sustentan mayores densidades de aulladores en relación a sitios cercanos de tierra firme, debido a una mayor disponibilidad de recursos alimentarios en los primeros (Rumiz et al. 1986, Zunino et al. 1995). Tanto en la cuenca del Plata como en la del Amazonas, los aulladores son más abundantes en la selva de inundación que en tierra firme (Peres 1997). Sin embargo, la posición latitudinal del área de estudio determina que los organismos estén expuestos comparativamente a una mayor estacionalidad térmica (aún considerando el efecto atemperador del río Paraná) y por ende a períodos de mayor rigurosidad climática en relación a otros sitios del neotrópico habitados por primates no humanos. En esta región, la especie no posee depredadores naturales ni se encuentra en competencia por los recursos con otros mamíferos arborícolas, por lo que dichos factores no serían importantes en la demografía de la especie en este sector. Cabe destacar que en todo el extremo sur de su área de distribución, la especie no se encuentra en contacto con otros primates (Holzmann 2012). Por estos motivos, el sistema bajo estudio representa un modelo interesante para analizar las variables que afectan la distribución de los primates a latitudes más elevadas (en la zona de contacto de las regiones subtropicales y templadas).

Por su parte, Alouatta caraya representa un buen modelo para estudiar los cambios adaptativos en respuesta a gradientes ambientales debido a su plasticidad trófica. Crockett y Eisenberg (1987) describen a A. caraya como una especie colonizadora, mostrando la capacidad de adaptarse a condiciones variadas. En este sentido, las especies con mayor plasticidad fenotípica pueden utilizar un rango más amplio de condiciones ecológicas, mostrando mayor resiliencia a cambios estacionales en la disponibilidad de recursos (Miner et al. 2005, Kowalewki 2007). En base a su plasticidad, es esperable que la especie exhiba cambios adaptativos, tales como variaciones en la ecología alimentaria y uso del espacio, 
que informen acerca de las presiones selectivas a las que está sometida en el límite sur de su distribución.

\section{HIPÓTESIS GENERAL}

A lo largo del gradiente latitudinal de la selva de inundación del río Paraná Medio, Alouatta caraya presenta cambios progresivos en el comportamiento trófico, en la organización social y en el uso del espacio, como respuesta a la escasez de recursos y al aumento de la rigurosidad climática asociadas a la determinación del extremo sur de su distribución.

\section{OBJETIVO GENERAL}

El objetivo general de esta tesis fue investigar la relación de Alouatta caraya y su ambiente, a través de un análisis de los cambios en la composición de la dieta, la organización social y la densidad poblacional, y su asociación a las variaciones de las condiciones climáticas y disponibilidad de recursos alimentarios, a lo largo de un gradiente latitudinal, ubicado en la selva de inundación del río Paraná Medio, límite austral de su distribución geográfica.

\section{ÁREA DE ESTUDIO}

El río Paraná es el segundo río más largo de Sudamérica con 3940 km de longitud, naciendo en la conjunción de los ríos Paranaíba y Grande, cuyas cabeceras y área superior se encuentran en el Escudo Cristalino central de Brasil (Bonetto y Hurtado 1998) entre los estados de San Pablo, Mina Gerais y Mato Grosso drenan una cuenca de $2.800 .000 \mathrm{~km}^{2}$ (Iriondo y Paira 2007). Por sus características geomorfológicas e hidrológicas diferenciales, es zonificado en tres grandes tramos: el Paraná Superior, el Paraná Medio y el Delta. Esta tesis se focalizó en el segmento del Paraná Medio, el cual se extiende unos $600 \mathrm{~km}$ desde su confluencia con el río Paraguay en la localidad de Paso de la Patria (provincia de Corrientes) hasta la ciudad de Diamante (provincia de Entre Ríos) donde se inicia el Delta (Bonetto y Drago 1968).

La morfología del río Paraná Medio está influenciada en su margen oeste, por la unión con el río Paraguay, su principal afluente. Este contribuye con una gran cantidad de nutrientes en suspensión y sedimentos andinos transportados a través del río Bermejo (Carignan y Neiff 1992). Dichos sedimentos se concentran cerca de la margen oeste del Paraná Medio (Bonetto y Orfeo 1984), mientras que la margen este contiene una mayor 
concentración de sedimentos en suspensión procedentes del Paraná Superior (Orfeo 1995). La planicie aluvial del Paraná Medio con abundantes lagunas, madrejones y zanjones (Bó 2006), resulta asimétrica ya que la mayor parte de esta se ubica en el lado oeste del río (Orfeo y Stevaux 2002). Desde la confluencia con el río Paraguay hasta los $28^{\circ} 10^{\prime} \mathrm{S}$, la planicie de inundación se amplía de 13 a 45 km (Iriondo 2007). El canal principal del Paraná Medio incluye numerosas barras e islas, formadas por la acumulación de sedimentos o por el retroceso erosivo que aísla partes de la llanura aluvial en el canal (Orfeo y Stevaux 2002). $\mathrm{Su}$ régimen hidrológico se caracteriza por un pulso anual con inundaciones en verano y niveles mínimos en primavera (Orfeo y Stevaux 2002). Se han detectado períodos de aguas relativamente altas y bajas, varios pulsos pequeños en el ciclo anual, o bien varios pulsos de inundación o de estiaje relacionados con fenómenos climáticos naturales como el niño o la niña, aunque también se los asocia al manejo hidráulico que se realiza en las altas cuencas (Bó 2006).

La selva de inundación se incluye en la provincia fitogeográfica Paranaense y se extiende, en Argentina de norte a sur a lo largo de los ríos Paraná y Paraguay (Cabrera 1976, Franceschi y Lewis 1979, Lewis y Franceschi 1979). Esta selva, con una disminución de la riqueza florística a medida que se extiende hacia el oeste y hacia el sur (Carnevali 1994), se asienta sobre las islas y riberas y está caracterizada por especies vegetales con una alta tasa de recuperación y resistencia a las inundaciones prolongadas (Neiff et al. 1985, Neiff y Reboratti 1989, Fernandes Corrêa y Furch 1992, Tundisi 1994). Algunos árboles viven con el suelo cubierto por agua durante meses sin alteraciones importantes (Neiff et al. 1985). Con inundaciones de mayor magnitud, las partes más altas de las islas quedan cubiertas por el agua (Rumiz et al. 1986, Brown y Zunino 1994). Se destaca que los efectos del régimen del pulso de inundación sobre la vegetación fluvial dependen no solo de la posición topográfica, sino de otros aspectos de la dinámica de los sistemas fluviales, tales como la arquitectura geomorfológica, la carga de sedimentos y la dinámica del canal, aspectos que explican la diferenciación florística de la llanura de inundación del río Paraná (Marchetti y Aceñolaza 2012).

La gran cantidad de islas modeladas con una dinámica de los ciclos de crecientes y bajantes, constituyen una combinación muy compleja de hábitats con influencia de las selvas Misionera y Amazónica, del Pantanal y de otros tipos de vegetación con las que limita en su recorrido (Ecorregiones del Chaco, del Espinal y Pampeana). Sus principales tipos de vegetación quedan representados por una selva subtropical empobrecida, bosques en galería, sauzales, alisales, ceibales y timbozales, diversos tipos de sabanas inundables y vegetación 
palustre y flotante (Pensiero et al. 2005). La selva de inundación se caracteriza por presentar distintas comunidades vegetales como los bosques pioneros o maduros (dominados por Salix humboldtiana), bosques en galería con un estrato arbóreo alto (de Albizia inundata, Inga affinis, Nectandra angustifolia, Ocotea diospyrifolia, Geoffroea spinosa, Banara arguta) y un estrato más bajo (de Croton urucurana, Cecropia pachystachya, Pouteria gardneriana), arbustales (de Celtis sp., Psychotria carthagenensis, Eugenia moraviana Solanum glaucophyllum, Mimosa pigra y Baccharis salicifolia) y vegetación palustre (de Panicum elephantipes, Ludwigia peploides). Son frecuentes las enredaderas (Ipomoea sp. y Mikania micrantha) como así también epifitos vasculares (cactáceas, bromeliáceas, piperáceas, orquídeas y helechos), briófitos y líquenes (Beltzer y Neiff 1992, Eskuche 2004, Marchetti et al. 2013) (Figura I-5).

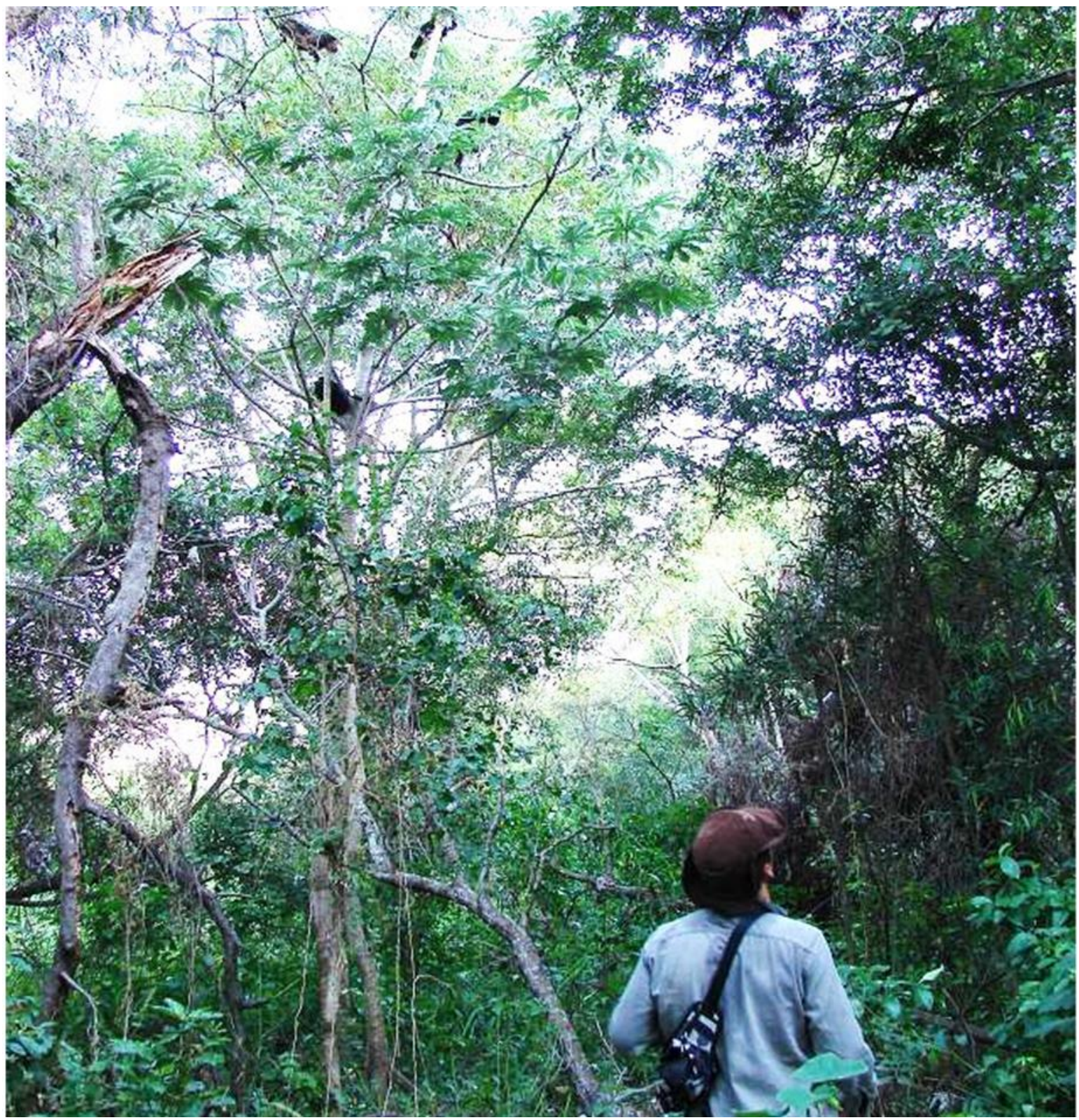

Figura I-5. Aspecto general de selva de inundación del río Paraná Medio en el área de estudio. 
Debido a las características del río Paraná, la selva de inundación se encuentra fragmentada a diferentes escalas espaciales. A gran escala, el paisaje de la llanura se encuentra fragmentado por los ambientes lóticos que separan diferentes sectores de la planicie, denominados islas. A menor escala, dentro de estas islas, la selva de inundación se halla distribuida en sitios con mayor nivel topográfico que permite el establecimiento de árboles de gran porte. Estos sitios, denominados albardones, existen sólo en las zonas marginales de las islas o en los márgenes de antiguos causes que representan áreas con mayor sedimentación. De este modo, la selva de inundación, se encuentra en forma de cordones o manchones irregulares que siguen el contorno de las zonas más elevadas de la planicie. Estos manchones de selva se encuentran separados por zonas más bajas cubiertas por arbustales, pastizales y vegetación acuática que alcanzan el margen del cuerpo de agua (Marchetti y Aceñolaza 2012).

Las actividades antrópicas se extienden a lo largo del Paraná Medio, formando grandes conglomerados urbanos e industriales, algunos de ellos correspondientes a las ciudades capitales y puertos de varias provincias, lo que implica una intensa intervención en la cuenca a fin de proveer bienes y servicios a las mismas (Basadonna 2002, Salvatori et al. 2002, Zuidwijk 2002). La acción del hombre en la selva marginal o ribereña en ambientes de tierra firme, tanto por la explotación maderera como por el uso ganadero conduce a toda la comunidad boscosa a un estado de disclímax, transformando la selva primitiva densa de difícil transitabilidad en otra de sotobosque abierto y masa forestal de clases diamétricas inferiores (Carnevali 1994). La situación en el valle de inundación y su sistema de islas es algo diferente debido a que ha sido menos afectado por la acción antropogénica. El sistema del río Paraguay-Paraná Medio-Río de la Plata constituye un eje potámico no regulado por represas, de más de $3700 \mathrm{~km}$, desde sus fuentes en los cerros del oeste del escudo brasílico hasta el estuario del Río de La Plata. Este hecho permite el mantenimiento de una amplia diversidad de hábitats en un estado relativamente prístino (Quirós et al. 2007). Por lo tanto, es un área interesante sobre la cual se pueden aplicar teorías ecológicas y explicar la dinámica y el funcionamiento de un sistema muy complejo, sobre la base de factores naturales (Ezcurra de Drago et al. 2007).

El área de estudio se encuentra incluida dentro de un humedal protegido a nivel internacional, constituido por los sitios Ramsar Humedales Chaco (Provincia de Chaco) y Jaaukanigás (Provincia de Santa Fe). En su valle de inundación e islas, la producción ganadera bovina sobre los pastizales naturales es la principal actividad económica, practicada por productores radicados en la zona de tierras altas, al oeste del humedal. Las 
crecidas del río hacen necesario el retiro de la hacienda y constituyen un limitante a la producción continua, como así también para el uso y la conservación de instalaciones. La pesca y la caza son actividades corrientes y de importancia con destino utilitario directo, comercial o deportivo, desarrolladas sin ordenamiento y en escala de difícil estimación. La utilización forestal es relativamente escasa, limitándose a las especies nativas, especialmente maderas blancas y cañas, permaneciendo como desafío un desarrollo más racional y productivo (Cordiviola de Yuan et al. 2001).

Los sitios de estudio se ubicaron en áreas de selva con bajo impacto de actividades antrópicas (escasa presencia de ganado y sin tala), con una distribución natural de los parches de selva, semejante entre los sitios, sin barreras antrópicas de importancia, aunque el sitio Paranacito presentó un camino rural de tierra poco transitado, que pudo haber alterado mínimamente el movimiento de los aulladores.

El clima general de la cuenca del río Paraná es tropical húmedo en el noreste cambiando a subtropical húmedo en el sur y desértico subtropical hacia el oeste. Las heladas y la nieve son inexistentes o irrelevantes (Paoli et al. 2000).

El clima de la selva de inundación del Paraná Medio se define como subtropical húmedo, con ocurrencia de 1 a 5 tormentas por mes, y una nubosidad moderada (100-120 días/año). Cuenta con inviernos suaves (media del mes de julio de $15^{\circ} \mathrm{C}$ ) y veranos calurosos (media del mes de enero de $27,5^{\circ} \mathrm{C}$ ) (Iriondo y Paira 2007). La influencia constante de vientos del noreste causa precipitaciones entre 1000 y $1300 \mathrm{~mm}$ anuales, con un alto porcentaje de humedad del aire que reduce la oscilación diaria de la temperatura (Centro Editor de América Latina 1982).

Cabe destacar que el clima del área se asocia a la influencia del gran volumen de agua que se moviliza en dirección norte-sur, unos $20.000 \mathrm{~m}^{3} / \mathrm{s}$ que fluyen a cerca de $1 \mathrm{~m} / \mathrm{s}$, por los canales, lagos, pantanos y fundamentalmente por el canal principal del río, lo que produce también un importante transporte de calor desde el trópico a la región templada (Iriondo 2007).

Por otro lado, según el sistema de zonas de vida de Holdridge (1967), el área de estudio es clasificada como de bosque con clima subtropical húmedo, limitado al sur y al oeste con una zona de vida de bosque subtropical seco (Leemans 1990). 


\section{SITIOS DE ESTUDIO}

El estudio fue llevado a cabo en la selva de inundación del río Paraná Medio, en 4 sitios ubicados a lo largo de un gradiente geográfico latitudinal de $300 \mathrm{~km}$, en una secuencia lineal, con una separación de $100 \mathrm{~km}$ entre si aproximadamente. Están emplazados en cercanía de

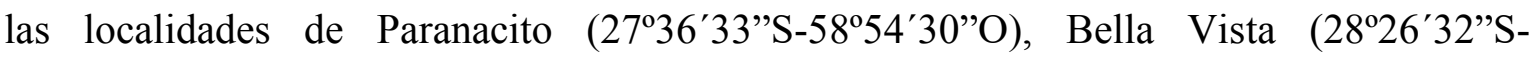

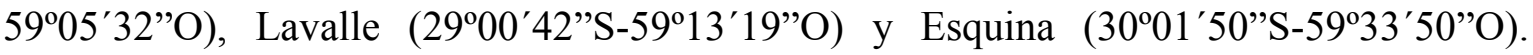
Paranacito, Bella Vista y Lavalle presentan poblaciones estables de Alouatta caraya, y el sitio ubicado más al sur, Esquina, no tiene registros de la especie. Este último sitio, se incluyó a fin de analizar condiciones ambientales donde el período de menor temperatura (invierno), podría asociarse a una disminución crítica en la disponibilidad de los recursos alimentarios de $A$. caraya, y a la ausencia de poblaciones estables de la especie (Figura I-6). 


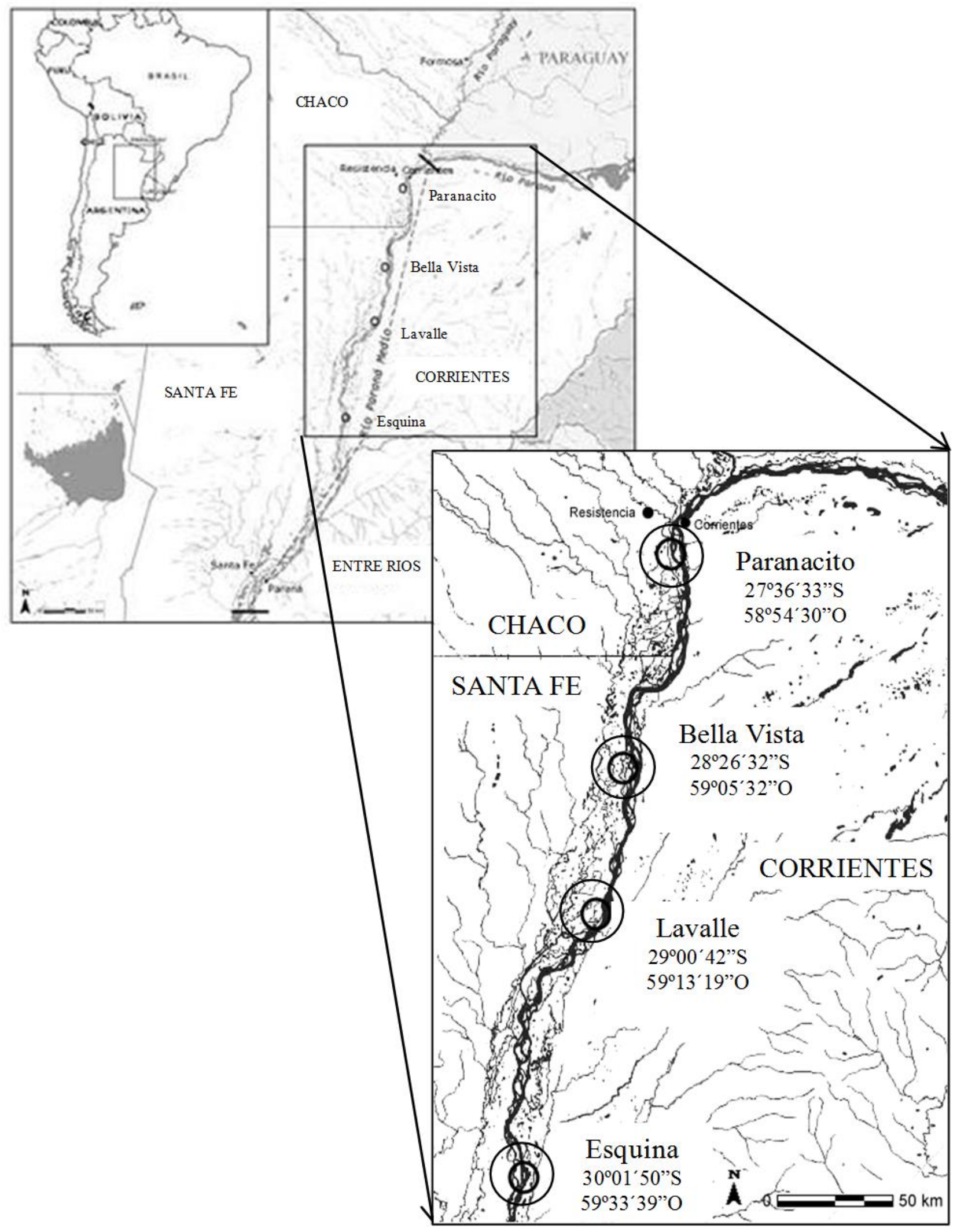

Figura I-6. Área y sitios de estudio (Paranacito, Bella Vista, Lavalle y Esquina) ubicados en la selva de inundación del río Paraná Medio. 


\section{CRONOGRAMA DE MUESTREO}

El trabajo de campo fue realizado desde abril de 2007 a marzo de 2008, con una duración total de 121 días completos de muestreo, concretándose 37 días de muestreo en cada uno de los sitios con presencia de Alouatta caraya (Paranacito, Bella Vista y Lavalle) y 10 días de muestreo en el sitio donde no habita la especie (Esquina). En los 3 primeros sitios mencionados, se realizó un seguimiento fenológico anual de especies utilizadas como recurso trófico por los aulladores, mientras que en Esquina se realizó sólo durante la estación invernal. La mayoría de los muestreos se concretaron en la primera quincena de cada mes, contando con una primera campaña de 4 días en cada sitio y de 3 días de duración las restantes. A fin de estudiar la dieta por análisis de material fecal se colectaron heces de los aulladores durante todas las campañas concretándose 111 días de muestreo. Además se realizó un registro de comportamiento trófico por observación directa durante las últimas dos campañas de cada estación climática, concretándose 24 días de muestreo (Tabla I-3).

Tabla I-3. Fechas de muestreo de especies vegetales y de material fecal, y registro de comportamiento trófico de Alouatta caraya, en 4 sitios de la selva de inundación del río Paraná Medio (Paranacito, Bella Vista, Lavalle y Esquina). Referencia: registros por observación directa (en negrita).

\begin{tabular}{c|cccc}
\hline Sitio & Paranacito & Bella Vista & Lavalle & Esquina \\
\hline \multirow{5}{*}{$\begin{array}{c}\text { Fechas } \\
\text { de }\end{array}$} & 06 al 09/04/2007 & 10 al 13/04/2007 & 14 al 17/04/2007 & - \\
& $\mathbf{0 3}$ al 05/05/2007 & $\mathbf{0 6}$ al 08/05/2007 & 09 al 11/05/2007 & - \\
& $\mathbf{0 5}$ al 07/06/2007 & $\mathbf{0 8}$ al 09/06/2007 & $\mathbf{1 1}$ al 13/06/2007 & - \\
muestreo & 14 al 16/07/2007 & 17 al 19/07/2007 & 20 al 22/07/2007 & 09 al 12/07/2007 \\
& $\mathbf{0 6}$ al 08/09/2007 & $\mathbf{1 0}$ al 12/09/2007 & $\mathbf{1 3}$ al 15/09/2007 & 16 al 18/09/2007 \\
& 14 al 16/10/2007 & 17 al 19/10/2007 & 20 al 22/10/2007 & - \\
& $\mathbf{1 2}$ al 14/11/2007 & $\mathbf{1 5}$ al 17/11/2007 & $\mathbf{1 8}$ al 20/11/2007 & - \\
& $\mathbf{1 0}$ al 12/12/2007 & $\mathbf{1 3}$ al 15/12/2007 & $\mathbf{1 6}$ al 18/11/2007 & - \\
& 11 al 13/01/2008 & 08 al 10/01/2008 & 05 al 07/01/2008 & - \\
& $\mathbf{0 9}$ al 11/02/2008 & $\mathbf{1 2}$ al 14/02/2008 & $\mathbf{1 5}$ al 17/02/2008 & - \\
& $\mathbf{1 6}$ al 18/03/2008 & $\mathbf{1 3}$ al 15/03/2008 & $\mathbf{1 0}$ al 12/03/2008 & - \\
\hline
\end{tabular}




\section{ORGANIZACIÓN DE LA TESIS}

En el capítulo inicial se realiza una introducción general al tema de la tesis, con una descripción de la sistemática de Alouatta caraya, su morfología, dieta, organización social y el estado de conservación. Se describen las características ambientales del área de estudio en su carácter de gradiente latitudinal ubicado en el sur de la distribución geográfica de la especie. Se plantea el objetivo y la hipótesis general de la tesis, así como el cronograma de muestreo para concretar el trabajo de campo.

En el segundo capítulo se desarrolla el tema sobre factores determinantes de la distribución geográfica de las especies. Se analiza la variación clima (temperatura y precipitaciones) y su relación con la disponibilidad espaciotemporal de recursos tróficos de Alouatta caraya en la porción más austral de su distribución, en la selva de inundación del río Paraná Medio. Además, se contrastan las características climáticas conocidas para tierra firme a la misma latitud que los sitios estudiados en la selva de inundación.

En el tercer capítulo se estudia el comportamiento trófico de Alouatta caraya a lo largo del gradiente latitudinal, mediante el uso de 3 métodos diferentes (observación directa, análisis macroscópico y microhistológico de heces). Se analiza la selectividad, la similitud dietaria y la amplitud de nicho trófico entre distintas clases de edad/sexo, así como la variación espaciotemporal de la disponibilidad de los recursos tróficos y su relación con la composición de la dieta.

El capítulo cuarto abarca los temas de variación en la organización social, el uso del espacio y la densidad poblacional de Alouatta caraya en relación con la variación de la disponibilidad de recursos alimentarios a lo largo del gradiente latitudinal estudiado.

En el quinto capítulo se realiza un cierre de la tesis con discusiones generales, dando conexión a los resultados obtenidos en los capítulos precedentes. Se ofrece una visión integradora de la relación entre las variables ambientales y las del comportamiento trófico, organización social, uso del espacio y densidad de los aulladores, a lo largo del gradiente latitudinal. Por último se arriba a las conclusiones finales de la tesis. 


\section{CAPÍTULO II}

\section{VARIACIÓN CLIMÁTICA Y DISPONIBILIDAD DE RECURSOS TRÓFICOS DE Alouatta caraya EN EL EXTREMO SUR DE SU DISTRIBUCIÓN GEOGRÁFICA}

\section{INTRODUCCIÓN}

La diversidad y distribución de especies disminuye gradualmente hacia el clima frío de los polos, sugiriendo que la influencia de la baja temperatura podría ser la explicación más simple para ambos (Stevens 1992, Brown y Lomolino 1998). Las condiciones ambientales de temperatura como así también de precipitaciones, pueden influir directamente sobre la complejidad vegetal e indirectamente sobre la diversidad y distribución de especies animales (Pianka 1966). Los cambios de diversidad a lo largo de gradientes latitudinales han sido ampliamente discutidos en la literatura para diversos taxa y ambientes (Wallace 1878, Fischer 1960, Simpson 1964, Rosenzweig 1995), como por ejemplo, en estudios de aves (Picidae y Psitacidae) en el continente americano (Koleff y Gaston 2001), de moluscos (Prosobranchia, Bivalvia y Placophora) en el sudeste del océano Pacífico (Valdovinos et al. 2003), de reptiles en México (Flores-Villela et. al 2005) o de primates (Cercopithecidae) en África Central, Sudeste de Asia e Indonesia (Böhm y Mayhew 2005). La latitud presenta un importante número de gradientes ambientales (ej. gradientes de temperatura, aislamiento, estacionalidad) que covarían e interactúan determinando, entre otras variables, los patrones de diversidad y de distribución de especies. Un gran número de hipótesis han sido sugeridas como causas de las variaciones de biodiversidad a lo largo de estos gradientes (Rahbek 1995, Rosenzweig 1995, Lomolino 2001, Whittaker et al. 2001, Willig et al. 2003), como por ejemplo la teoría de Biogeografía de islas de MacArthur y Wilson (1967), la hipótesis de Muestreo de Kaspari et al. (2000), la hipótesis de Fuera de los Trópicos de Jablonski et al. (2006), la teoría Neutral de la Biodiversidad y la Biogeografía de Hubbell (2001) o la hipótesis de Efectos Fuente-Sumidero (Grytnes et al. 2008).

La disminución en la diversidad vegetal al aumentar la latitud, podría significar una disminución en la disponibilidad de recursos tróficos para algunas especies animales, afectando su distribución. No obstante, los gradientes de diversidad latitudinal, o altitudinal, dependen finalmente de factores históricos, geográficos, bióticos, abióticos, y estocásticos (Schemske 2002, Willig et al. 2003) (por ej.: variaciones climáticas, heterogeneidad 
ambiental, topografía, disponibilidad de energía, competencia e interacciones biológicas), lo que se relaciona con cambios en la geometría, estructura interna y localización de los rangos de especies en tiempo evolutivo y ecológico (Schemske 2002, Willig et al. 2003). Así, lo que determina la diversidad biológica no es, claramente, la latitud per se, sino las variables ambientales correlacionadas con la misma (Hawkins y Diniz Filho 2004).

Para comprender muchos patrones ecológicos y biogeográficos es necesario analizar los mecanismos que determinan las distribuciones de las especies y sus límites a lo largo de gradientes ambientales (Gaston 1990, 2003, Holt 2003, Parmesan et al. 2005). Sin embargo, estos mecanismos son poco conocidos, sobre todo porque estos límites surgen de las interacciones complejas entre una gran variedad de factores físicos, bióticos e históricos (Holt 2003, Parmesan et al. 2005, Goldberg y Lande 2007) que incluyen, entre otros, aspectos del medio físico (Gaston 1990, 2003, Holt 2003, Parmesan et. al. 2005) (ej.: la temperatura), flujo génico, adaptación local e interacciones entre especies (Caughley et al. 1988, Kirkpatrick y Barton 1997, Holt 2003, Case et al. 2005, Goldberg y Lande 2007). Se ha comprobado que el clima es un factor limitante clave en la distribución de las especies (Root 1988, Jeffree y Jeffree 1994). La influencia de la temperatura y otros factores sobre la amplitud geográfica de las especies parece ser más compleja que la simplificación del factor latitudinal (Jetz y Rahbek 2002). Además, debe tenerse en cuenta que los factores climáticos podrían determinar directamente la complejidad vegetal de un área, mientras que sólo indirectamente determinan la diversidad faunística (Pianka 1966). Es decir, el mantenimiento de poblaciones de animales, depende de una disponibilidad adecuada de recursos alimenticios (Dunbar 1987, Hemingway y Bynum 2005). Las poblaciones animales están limitadas principalmente por estos recursos, resultando los patrones actuales de distribución de las especies, producidos por la cantidad de recursos disponibles en períodos de escasez, tanto en el pasado como en el presente (Cant 1980).

Las selvas tropicales y subtropicales del Neotrópico albergan una alta diversidad y biomasa de primates. El norte de Argentina es habitado por 5 especies de primates: Sapajus cay $(=$ Cebus apella paraguayanus $=$ Cebus libidinosus $)$ y Sapajus nigritus $(=$ Cebus apella nigritus $=$ Cebus nigritus), Alouatta caraya, Alouatta guariba clamitans y Aotus azarae (Rylands et al 2012, Lynch et al. 2011, Zunino et al. 1995, Silva et al. 2001) que encuentran en esta zona, el límite austral de su distribución. Los límites de la distribución de los primates pueden estar dados por una conjunción de factores climáticos (con efectos directos sobre la vegetación) y barreras geográficas (Peres y Janson 1999, Lehman 2000, Bennet et al. 2001). Se ha propuesto que entre los factores que determinan los límites de las distribuciones de los 
primates del sur de América del sur, se hallan la marcada estacionalidad de los ambientes subtropicales con bajas temperaturas en el invierno, la predominancia de árboles deciduos y la disminución de la diversidad de especies vegetales lo cual hace que sea difícil mantener una dieta folívora (Printes et al. 2001). Un escenario oportuno para evaluar e hipotetizar sobre los factores que estarían limitando la distribución de los primates neotropicales, lo conformarían las condiciones del gradiente latitudinal, ubicado en el rango más austral de los monos aulladores (Alouatta spp.), en las selvas del noreste de Argentina, donde habita $A$. caraya. La disminución poblacional de esta especie hacia el sur podría asociarse con el empobrecimiento de la vegetación, determinado por el descenso de las precipitaciones y la temperatura (Cabrera 1957) y un incremento en la estacionalidad (Zunino et al. 1995). Sin embargo no se han realizado estudios teniendo en cuenta estos factores y otros, como la respuesta de las especies vegetales a diversas condiciones ambientales del gradiente, lo que puede aportar interesantes datos sobre la disponibilidad de recursos alimentarios para la subsistencia de los aulladores.

\section{HIPÓTESIS Y PREDICCIONES}

La variación climática, relacionada con los cambios en temperatura y precipitaciones, a lo largo del gradiente latitudinal del extremo sur de distribución de Alouatta caraya, condicionará la disponibilidad de recursos alimentarios para esta especie y posiblemente limitará su distribución.

Se predice que a lo largo del gradiente latitudinal norte-sur de la distribución de Alouatta caraya en el río Paraná Medio, las temperaturas y precipitaciones disminuirán y aumentará la estacionalidad climática, lo que haría reducir la disponibilidad de recursos alimentarios para esta especie, afectando su distribución hacia latitudes mayores. A su vez se pondrá de manifiesto una disminución aún más marcada de los recursos alimentarios en el sitio ubicado más al sur del área de estudio donde no se observan poblaciones estables de la especie. Por esto, hacia latitudes superiores de la distribución geográfica de A. caraya, se espera:

-una disminución en la diversidad, riqueza y abundancia de especies vegetales utilizadas como recurso alimenticio por Alouatta caraya.

-una disminución y una mayor variación estacional, en la disponibilidad de estructuras vegetales consumidas por Alouatta caraya (hoja, fruto, flor). 


\section{OBJETIVO}

Evaluar la variación espaciotemporal en la disponibilidad de recursos alimenticios de las especies vegetales consumidas por Alouatta caraya y su relación con la variación climática latitudinal en la selva de inundación del río Paraná Medio, extremo sur de su distribución geográfica poblacional.

\section{Objetivos específicos}

-Analizar las variaciones climáticas de temperatura y precipitaciones a lo largo del gradiente de distribución de Alouatta caraya y en sitios no habitados por la especie.

-Estudiar la diversidad de especies usadas como recurso trófico por Alouatta caraya, en cada sitio de estudio.

-Analizar la variación espaciotemporal en la diversidad de especies consumidas y disponibilidad de recursos alimenticios.

-Investigar la relación entre las variaciones climáticas de temperatura-precipitaciones y los cambios en diversidad-disponibilidad de los recursos alimenticios.

\section{MÉTODOS}

\section{CARACTERIZACIÓN CLIMÁTICA DEL ÁREA DE ESTUDIO}

\section{La temperatura y las precipitaciones históricas y de muestreo en los sitios de estudio} de la selva de inundación

La información climática fue obtenida de registros de estaciones meteorológicas del Servicio Meteorológico Nacional (SMN) para los sitios Paranacito y Bella Vista, del Instituto Nacional de Tecnología Agropecuaria (INTA) para el sitio Lavalle y de Aguas de Corrientes para el sitio Esquina. Dicha información se utilizó para analizar las variaciones de temperatura y precipitaciones mensuales medias a lo largo del gradiente. Debido a que las condiciones climáticas inusuales (años con características climáticas extremas) pueden generar patrones fenológicos atípicos en las especies, es importante conocer si los muestreos se realizaron en un año típico o extraordinario. 


\section{Clasificación del clima en la selva de inundación y tierra firme}

Se analizaron algunas condiciones climáticas de sitios habitados y no habitados por la especie, a fin de lograr un acercamiento al conocimiento de los determinantes ecológicos del rango de distribución de Alouatta caraya.

Las condiciones de la selva de inundación del río Paraná difieren de las de tierra firme a la misma latitud, por tal motivo, se realizó un análisis de clasificación del clima considerando las coordenadas de 12 puntos georrenferenciados: 4 correspondientes a los sitios muestreados en la selva de inundación, y en la misma latitud, 100 kilómetros hacia tierra firme de cada uno de estos, 1 punto hacia el este y otro punto hacia el oeste (Figura II$1)$.

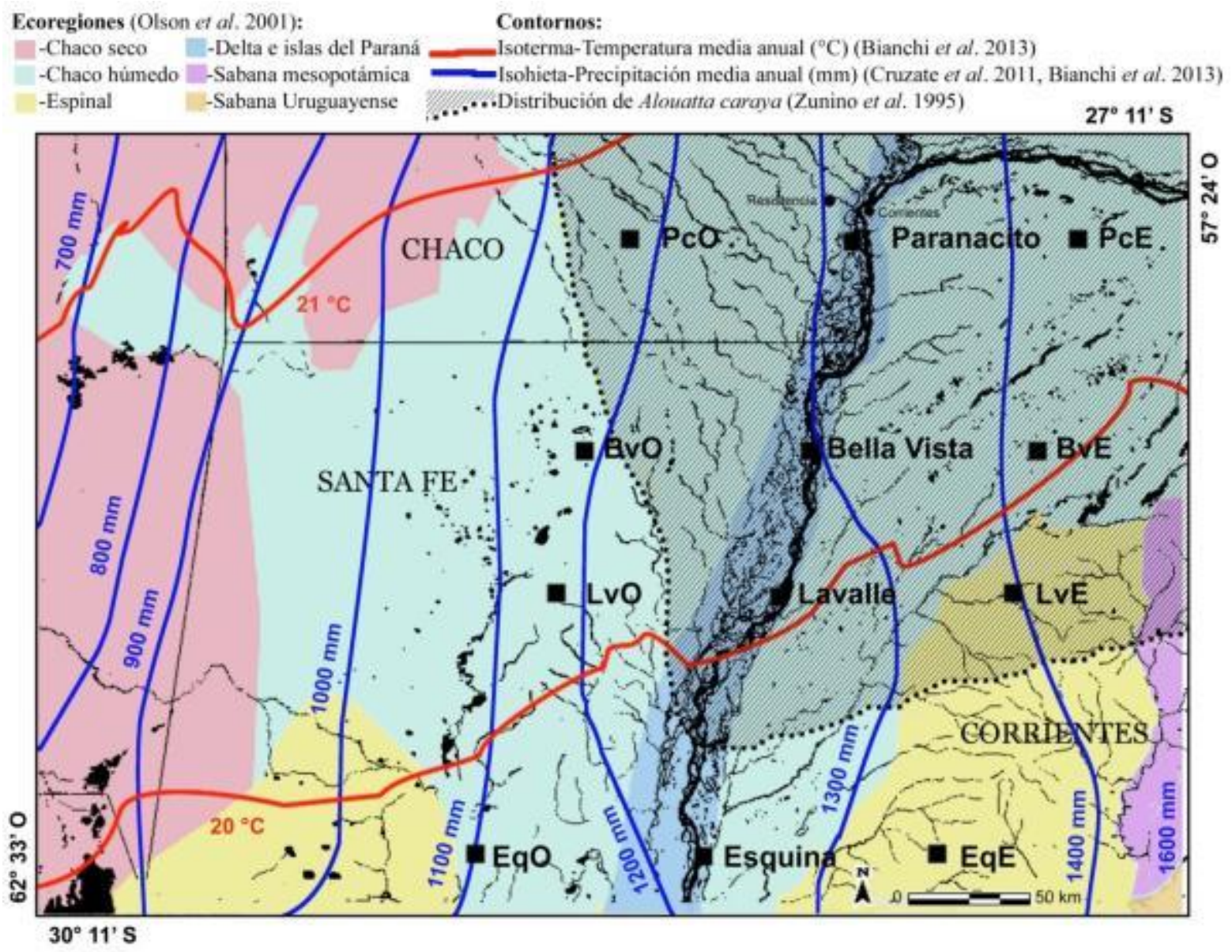

Figura II-1. Área de estudio con ecorregiones, isoclinas, e isohietas, y ubicación de los sitios de estudio en selva de inundación del río Paraná Medio (Paranacito, Bella Vista, Lavalle, Esquina) y sitios equidistantes de comparación en tierra firme, $100 \mathrm{~km}$ al este y al oeste $(\mathrm{PcO}, \mathrm{PcE}, \mathrm{BvO}, \mathrm{BvE}$, LvO, LvE, EqO y EqE).

Se consideraron 19 variables ambientales, obtenidas de la base de datos publicada de WorldClim (Hijmans et al. 2005) (http://www.worldclim.org), que surgen de una interpolación de datos climáticos observados entre los años 1950 y 2000 en diferentes 
estaciones meteorológicas utilizando latitud, longitud y elevación como variables independientes (Hutchinson 2004) (Tabla II-1).

Tabla II-1. Variables bioclimáticas utilizadas y sus referencias.

\begin{tabular}{lc}
\hline \multicolumn{1}{c}{ Variable } & Referencia \\
\hline Temperatura media anual & TMA \\
Rango medio diurno de temperatura & RMD \\
Isotermalidad & IST \\
Estacionalidad de temperatura & ET \\
Temperatura máxima en el mes más cálido & TMxMC \\
Temperatura mínima en el mes más frío & TMnMF \\
Rango de temperatura anual & RTA \\
Temperatura media en la estación más húmeda & TMdEH \\
Temperatura media en la estación más seca & TMdES \\
Temperatura media en la estación más cálida & TMdEC \\
Temperatura media en la estación más fría & TMdEF \\
Precipitación anual & PA \\
Precipitación en el mes más húmedo & PMH \\
Precipitación en el mes más seco & PMS \\
Estacionalidad de precipitaciones & EP \\
Precipitación en la estación más húmeda & PEH \\
Precipitación en la estación más seca & PES \\
Precipitación en la estación más cálida & PEC \\
Precipitación en la estación más fría & PEF \\
\hline
\end{tabular}

\section{CARACTERIZACIÓN DE LA VEGETACIÓN DEL ÁREA DE ESTUDIO}

\section{Reconocimiento de las especies vegetales}

Para el reconocimiento e identificación de las especies vegetales del área de estudio, se colectaron 574 muestras vegetales procurando reunir la mayor cantidad de especies posible para confeccionar un herbario según la metodología propuesta por Katinas (2001). Se seleccionaron muestras no dañadas por insectos, con flores y/o frutos para facilitar la posterior determinación. Cada ejemplar fue fotografiado, se le asignó un número y se registró la localidad, la fecha, características del entorno y de la planta (altura, olores, color de las flores, presencia de látex). Estos fueron prensados acomodando el espécimen en una hoja de papel de diario y cortando los frutos voluminosos longitudinalmente para facilitar su secado. Se apilaron en prensas de madera hasta una altura manejable (40 $\mathrm{cm}$ aproximadamente), se expusieron al calor del sol, y si conservaban mucha humedad se cambiaba el papel de diario, aprovechando a arreglar la disposición de los mismos.

En laboratorio, las muestras que aún permanecían húmedas fueron secadas en estufa a $50{ }^{\circ} \mathrm{C}$ hasta 3 días y posteriormente descontaminadas (larvas, insectos, huevos, etc.) 
utilizando un freezer a $-18{ }^{\circ} \mathrm{C}$ durante aproximadamente 10 días (Katinas 2001). Se realizó una etiqueta de herbario con los datos obtenidos al momento de la colecta colocando el nombre de la institución, localidad de colecta, el hábitat y observaciones, el nombre del colector, el número y la fecha de colección. Los especímenes fueron determinados mediante material bibliográfico, comparación con ejemplares de herbarios del Instituto de Botánica del Nordeste (Herbario Corrientes-IBONE) y del Museo Argentino de Ciencias Naturales (Herbario Buenos Aires-MACN) en cuyas colecciones fueron depositados. Para la denominación taxonómica de las especies se utilizó la clasificación del Instituto de Botánica Darwinion (IBODA) (Figura II-2).

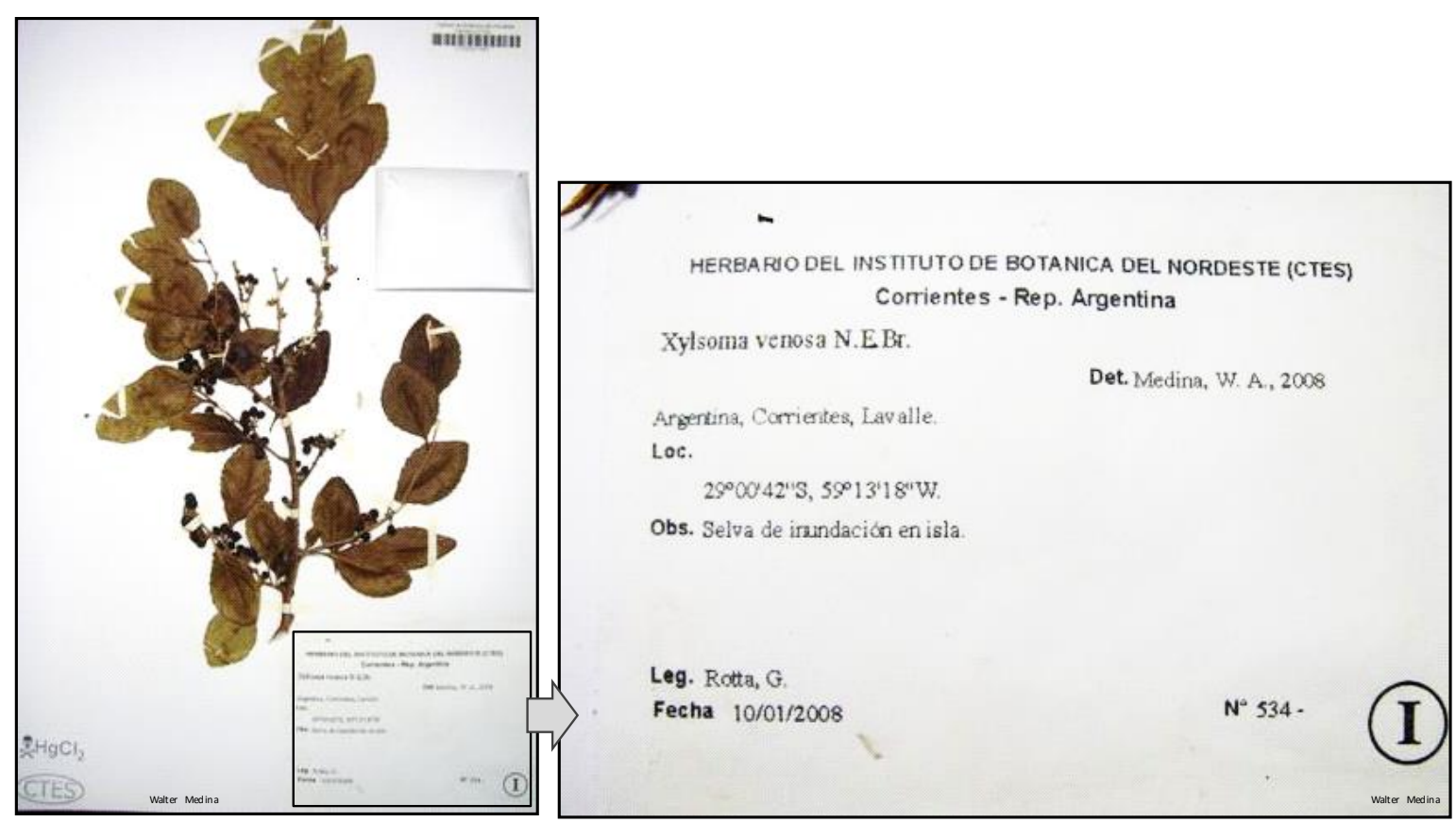

Figura II-2. Ejemplo de una muestra vegetal herborizada y depositada en el herbario del IBONE, con detalle de la etiqueta. Referencias: Leg.: identificación del colector, Det.: identificación de quien realizó la determinación, Loc.: localidad, Obs.: observaciones y $\mathrm{N}^{\mathrm{o}}$ : número de colección.

\section{Diversidad de recursos tróficos de Alouatta caraya}

Para analizar la diversidad de especies usadas como recurso trófico por Alouatta caraya, en cada sitio de estudio, se delimitó una parcela de una hectárea, ubicada sobre albardones marginales al canal principal o brazos secundarios del río Paraná, donde comúnmente se encuentran los bosques más desarrollados de la planicie de inundación (Marchetti et al. 2013). La parcela fue subdividida en 25 cuadrantes de $20 \mathrm{~m}$ de lado (Dallmeier 1992, Condit 1998), a fin de facilitar la cuantificación de la frecuencia de individuos de las especies vegetales, y evitar repeticiones durante los conteos. Cada cuadrante fue recorrido exhaustivamente registrándose la identidad de cada especie. 
Se registraron las especies vegetales consideradas como recurso trófico, teniendo en cuenta citas bibliográficas de estudios efectuados en la región (ej. Rumiz et al. 1986, Zunino 1986, 1989, Bravo y Sallenave 2003) y observaciones personales, confeccionándose una lista de 37 especies. Una especie se consideró consumible si al menos una de sus estructuras (hojas, flores o frutos) formaba parte de la dieta de los aulladores. La evaluación de la disponibilidad de estas especies se realizó tanto en los sitios con presencia de Alouatta caraya (Paranacito, Bella Vista y Lavalle), como en el sitio ubicado al sur del gradiente estudiado (Esquina), donde no habitan los aulladores.

\section{Disponibilidad media mensual de recursos tróficos para Alouatta caraya}

Para obtener información sobre la disponibilidad y la estacionalidad de los recursos alimenticios, se realizó un análisis fenológico de las especies más importantes en la dieta de los aulladores (Rumiz et al. 1986, Zunino 1989) en los distintos sitios de muestreo del gradiente latitudinal. De las 37 especies consumibles registradas en el área de estudio, 4 especies de consumo ocasional no pudieron ser cuantificadas adecuadamente debido a su forma de vida (2 especies epifitas: Tillandsia meridionalis y Rhipsalis lumbricoides) o porque su consumo fue determinado en la fase final del estudio (Panicum sp., Solanum aculeatissimum).

A fin de realizar el muestreo fenológico se seleccionaron aleatoriamente 10 ejemplares por especie con un DAP mayor a $10 \mathrm{~cm}$. Para el caso de lianas, se consideraron ejemplares con DAP superior a 0,5 cm de DAP, y en el caso de especies con ejemplares de menor diámetro se adoptó un criterio de agrupamiento, considerando una cantidad de ejemplares cuya sumatoria alcanzase $\operatorname{los} 0,5 \mathrm{~cm}$ de DAP. Cuando no se hallaron los 10 individuos por especie dentro de las parcelas, se completó el registro con ejemplares situados fuera de las mismas, o bien se utilizaron menos individuos por especie.

Cada ejemplar fue identificado con una chapa de aluminio numerada y fijada al tronco a fin de facilitar su seguimiento fenológico a lo largo del año de muestreo. Se midió la altura de los individuos con el uso de un clinómetro cuando se hallaron en lugares abiertos, y en ocasiones de baja visibilidad en el interior del monte, se tomó una referencia de altura conocida y se contó cuántas veces cabía la misma en la altura del individuo. La circunferencia del tronco a la altura del pecho (CAP) fue medida con el uso de una cinta métrica. En el caso de los cañaverales de Guadua sp. se midió la circunferencia del grupo de individuos. 
A partir de los valores de CAP se calculó el área basal por ser un indicador de la capacidad del individuo para producir estructuras vegetales en general (Chapman et al. 1992, 1994), siguiendo la siguiente fórmula:

$$
A B=\frac{C A P^{2}}{4 \pi}
$$

Como medida de abundancia de cada especie, se utilizó la sumatoria de las áreas basales de todos los individuos presentes en la parcela expresando los valores en $\mathrm{m}^{2} / \mathrm{ha}$ (Matteucci y Colma 1982). Este índice permite considerar no sólo la abundancia numérica sino también el tamaño de los árboles.

Mensualmente en cada sitio de estudio se estimó la abundancia de 4 estructuras vegetales (hojas jóvenes, hojas maduras, frutos y flores), mediante la división imaginaria de la copa del árbol en cuatro cuadrantes iguales y el registro de la abundancia de cada fenofase de acuerdo con una escala subjetiva de 0 a 4 , en donde 0 representa la ausencia de una fase específica (la estructura vegetal) y 4 cuando la copa se encuentra al $100 \%$ de su estadio fenológico (Rudran 1978, Rumiz et al. 1986, Chapman et al. 1994, Smith Ramírez y Armesto 1994, Sun et al. 1996, Talora y Morellato 2000). Las hojas jóvenes fueron distinguidas de las hojas maduras en función de su color, su menor tamaño y mayor brillo (Chiarello 1994).

En el sitio ubicado más al sur del gradiente, Esquina, donde no se presenta Alouatta caraya, el seguimiento fenológico mensual se limitó sólo a los 3 meses de invierno, con el objetivo de determinar la disponibilidad alimentaria de la especie, en el período más crítico del año. El invierno representa el período más seco y de menor temperatura, con lo cual es esperable registrar menor disponibilidad de estructuras alimentarias (Ramírez 2009). Cabe destacar que el hecho de realizar un muestreo de menor extensión temporal no incide sobre los valores de abundancia de individuos, ya que todos los ejemplares con un DAP mayor a $10 \mathrm{~cm}(0,5 \mathrm{~cm}$ en lianas) fueron contabilizados e identificados en los 4 sitios de estudio. Si bien este diseño no permite observar todo el rango de variación de la disponibilidad de recursos de Esquina, se considera que la extensión de tiempo elegida fue suficiente para determinar la presencia de condiciones críticas en la disponibilidad de recursos.

Para cada estructura vegetal se promediaron los valores fenológicos de los individuos de cada especie obteniéndose el índice fenológico por especie (IF) en cada sitio a lo largo del año. A fin de obtener un índice de disponibilidad (IDi) de cada tipo de fenofase, los 
valores mensuales fenológicos de cada especie (IFi) fueron multiplicados por el área basal de las mismas (ABi) (Placci 1995, Kowalewski y Zunino 2004).

$$
I D_{i}=\mathrm{IF}_{i} \times \mathrm{AB}_{i}
$$

Los índices de disponibilidad fueron comparados entre meses y sitios, a fin de analizar la variación temporal de los recursos alimenticios a lo largo del gradiente. Del conjunto de datos originales y a fin de evitar datos aleatorios o casuales de consumo, que podrían llevar a resultados sesgados en el análisis, se consideraron sólo aquellas especies que sumadas en conjunto conformaban hasta el $70 \%$ de la dieta folívora y frugívora comprobada por microhistología y macroscopía, respectivamente. Debido a que sólo 4 especies suministraron flores en toda el área se consideró el 100\% de las especies registradas por observación directa (Figura III-3, Anexo 4). Alouatta caraya, como oportunista, tendería a consumir los recursos alimentarios disponibles, ya sean hojas, flores o frutos. En consecuencia, también se analizó la disponibilidad de todas las estructuras vegetales que componen el $70 \%$ de la dieta, realizando la sumatoria de los valores del índice de disponibilidad para cada mes.

\section{Variación espacial de los grupos principales de recursos alimentarios}

Las especies vegetales fueron categorizadas según la consistencia del tallo, el patrón de ramificación, la altura y la longevidad, combinando la clasificación de las formas de vida utilizada por Ramírez (2009), y por González et al. (2002). Además para evaluar la utilidad del vegetal para brindar soporte a los aulladores y condicionar el acceso a los recursos tróficos, se tuvieron en cuenta características como el porte, el tamaño de las ramas, y la presencia de espinas en los tallos (Fleagle 1999, Defler 2004, 2010). A su vez, para caracterizar las especies utilizadas como recurso trófico por Alouatta caraya se analizaron rasgos morfológicos de las hojas, tales como presencia de tricomas, grosor de la cutícula, presencia de cristales en el mesófilo y presencia de compuestos secundarios (taninos, saponinas) evidentes mediante las técnicas de microhistología ya descriptas. Estos rasgos están descriptos para cada especie vegetal en el Anexo 2. Para las especies que suministran frutos, se consideró la coloración, la carnosidad y el tamaño de las semillas, que son reconocidas como características importantes para su selectividad (Julliot 1996ab). 
En base a los rasgos mencionados y a criterios utilizados en otros estudios (Julliot 1996ab, Stevenson et al. 2000) se definieron grupos de especies que pueden proporcionar a los aulladores recursos de propiedades comparables (ej. hojas y frutos):

-Árboles de gran porte con oferta de hojas y frutos $(A G P H F)$ : plantas leñosas con fuste no ramificado cercano al suelo con diámetro a la altura del pecho (DAP) mayor a $10 \mathrm{~cm}, \mathrm{y}$ altura superior a 15 metros, de nivel emergente, con ramas anchas, horizontales e inermes, utilizados frecuentemente como soporte. Hojas con escasos tricomas y de regeneración rápida (mayor abundancia de hoja joven). Frutos carnosos, coloridos y con semillas pequeñas.

-Higueras: ejemplares de gran porte, de nivel emergente, perennifolias, con producción de hojas voluminosas y frutos de muy buena calidad producidos en asincronía con otras especies (Milton 1980, Terborgh 1986, Stevenson et al. 2000), consideradas claves en la dieta de los aulladores (ej. 32\% de la dieta de Alouatta palliata-Estrada 1984 y de Alouatta pigra-Silver et. al. 1998).

-Árboles de mediano porte $(A M P)$ : árboles medianos raramente usados como soporte (algunos con espinas), con hojas de regeneración rápida y gran producción de frutos carnosos y coloridos.

-Palmeras: de mediano porte, con hojas grandes y perennes de muy baja regeneración (no consumidas) y con frutos muy carnosos y coloridos.

-Árboles de gran porte con oferta de hojas $(A G P H)$ : plantas leñosas con fuste no ramificado cercano al suelo con diámetro a la altura del pecho (DAP) mayor a $10 \mathrm{~cm}$, de nivel medio y emergente del bosque, utilizados frecuentemente como soporte, con hojas de buena calidad (regeneración medianamente rápida) y portadoras de escasos tricomas, y sin aporte de frutos. -Lianas: plantas leñosas o con tallos ligeramente leñosos mayores a $0,5 \mathrm{~cm}$ de DAP, de alturas variables, trepadoras, anuales o perennes, con hojas de baja renovación, unas especies con frutos algo coloridos y carnosos, y otras con frutos secos.

-Arbustos y árboles de pequeño porte (ARAPP): plantas leñosas con tallo ramificado cercano al suelo, con una altura mayor a 1,60 $\mathrm{m}$ y menor a $5 \mathrm{~m}$, arbustos del sotobosque o árboles del nivel bajo del dosel, raramente utilizados como soporte debido a su baja altura y sus tallos y ramas delgados.

-Cañas: gramíneas de gran porte, perennes, con tallos leñosos, rectos, ramificación basal, y formando conjuntos de ejemplares apretados. Fue el considerado el DAP grupal, si superaba los $10 \mathrm{~cm}$. Con tallos portadores de espinas y hojas con abundantes cristales de sílice. 
-Otros: .Pastos: gramíneas rastreras anuales o perennes, sub-leñosas de escasa altura hasta 1-3 m.

.Epifitas: plantas que crecen sobre otro vegetal que le sirve de soporte.

Cabe señalar que para los análisis de diversidad no fueron consideradas aquellas especies que presentaban gran dificultad para su cuantificación como el arbusto Solanum aculeatissimum, la gramínea Panicum sp. y las epifitas.

\section{ANÁLISIS DE DATOS}

\section{CARACTERIZACIÓN CLIMÁTICA DEL ÁREA DE ESTUDIO}

\section{La temperatura y las precipitaciones históricas y de muestreo en los sitios de estudio} de la selva de inundación

Para cada sitio de estudio, se compararon las temperaturas y precipitaciones medias mensuales correspondientes al período de estudio (abril 2007-marzo 2008) e históricas (1991-2001).

\section{Clasificación del clima en la selva de inundación y en tierra firme}

Se realizó un análisis de componentes principales (ACP) para las variables ambientales (Tabla II-1), consideradas para el gradiente latitudinal en la selva de inundación y en tierra firme, con los datos ambientales de los 12 puntos georrenferenciados.

\section{CARACTERIZACIÓN DE LA VEGETACIÓN DEL ÁREA DE ESTUDIO}

\section{Comparación de la abundancia y de la diversidad de especies}

La diversidad de especies vegetales consumibles para cada sitio de estudio se calculó en función del número de especies cuantificadas en los diferentes cuadrantes por parcela (riqueza) y el número total de individuos relevados de cada especie en los diferentes cuadrantes por parcela (abundancia), por aplicación de la ecuación de Shannon-Wiener (Pielou 1966):

$$
H^{\prime}=-\Sigma p_{i} \log p_{i}
$$

Donde: $p_{i}=\mathrm{n}_{i} / \mathrm{N}_{\mathrm{t}}$ ( $\mathrm{n}_{i}$ : número de individuos del taxón $i, \mathrm{~N}_{\mathrm{t}}$ : número total de individuos). 
El índice de Shannon-Wiener se utilizó también para estimar el efecto que posee la variación fenológica de las estructuras en la diversidad de recursos disponibles para los aulladores. Como dato de abundancia, se utilizaron los valores de IDi de las estructuras de cada una de las especies a lo largo del año.

La abundancia de individuos y la diversidad de especies vegetales de cada sitio fue comparada con un ANOVA permutacional mediante el software EcoSim (Gotelli y Entsminger 2001), utilizando como réplicas los diferentes cuadrantes por parcela. EcoSim posee un algoritmo de permutación que intercambia los valores de diversidad aleatoriamente entre las columnas pertenecientes a cada sitio y en cada proceso calcula un valor de pseudoF esperado por azar. Este proceso es repetido unas 1000 veces y se construye un histograma de valores de pseudo-F esperados por azar que es propio del conjunto de datos analizados (a diferencia de los métodos paramétricos clásicos, donde los estadísticos esperados son obtenidos de una tabla estadística teórica). Finalmente a partir de la matriz de datos original (no permutada), se calcula un valor de pseudo-F que es comparado con la población de estadísticos esperados por azar. Apartir de la proporción de estadísticos pseudo $\mathrm{F}$ esperados por azar mayores al estadístico observado se obtiene un valor de $\mathrm{P}$ que indica la probabilidad de tipo I de la prueba (Gotelli y Entsminger 2001).

Como análisis complementario, se comparó la riqueza de especies entre los 4 sitios, utilizando el método de rarefacción EcoSim 7.0 (Gotelli y Entsminger 2001). Este método permite controlar el efecto del número diferente de individuos sobre la riqueza de especies a lo largo del gradiente.

\section{Comparación de la composición de especies consumibles en cada sitio de estudio}

A fin de clasificar los sitios de estudio en base a la composición de especies vegetales, se confeccionó un dendrograma, elaborado a través de un análisis realizado con el método de agrupamiento por pares de promedios no ponderados (UPGMA, según la denominación en inglés) utilizando el índice de similitud de Bray-Curtis (1957).

$$
B C_{a b}=\frac{2 p N}{a N+b N}
$$

Donde

$a N=$ número total de individuos en el sitio A

$b N=$ número total de individuos en el sitio $\mathrm{B}$

$p N=$ sumatoria de la abundancia más baja de las especies presentes en ambos sitios entre ambos sitios 
La significancia estadística de los grupos determinados por el UPGMA, fue estimada mediante el método Bootstrap. Dicho método consiste en la creación de una matriz ficticia a partir del remuestreo de las columnas de las especies de la matriz original de forma aleatoria y con reposición. Esto da lugar a que algunas columnas de las especies aparezcan duplicadas y otras sean excluidas por el proceso de remuestreo. A partir de cada una de las matrices ficticias resultantes se crea un dendrograma, donde se registran los nodos observados. Este proceso es repetido 1000 veces calculando al final el porcentaje de veces que aparecen los nodos observados en la matriz original. Si un nodo del dendrograma aparece en más del 50\% de los remuestreos, se considera que éste es fiable (Soltis y Soltis 2003). En el contexto de este trabajo, cada nodo representa un grupo de muestras con composición de recursos tróficos siginificativamente más similar entre ellas que con el resto de las muestras.

\section{Disponibilidad de recursos tróficos analizada con el método de escalamiento multidimensional no métrico}

Debido a sus características contrastantes, las hojas jóvenes y maduras, las flores y los frutos representan diferentes estados de recursos independientemente de la especie de la que provengan. Es decir, la disponibilidad de estos 4 estados fenológicos en una misma especie podría ser equivalente a poseer 4 recursos diferentes, y comparable a poseer un único estado fenológico en 4 especies diferentes. En base a lo mencionado, se realizó un análisis integrador a fin de comparar la variación espaciotemporal en la disponibilidad de los recursos. Al igual que otros métodos de ordenamiento, el método de escalamiento multidimensional no métrico (NMDS, según su denominación en inglés) permite diferenciar los sitios y los meses de muestreo, no sólo en base a la abundancia sino también a la composición de los recursos tróficos disponibles (tipo de especies y estructuras).

En un primer paso, se elaboró una matriz incluyendo la abundancia de todos los estados fenológicos de todas las especies en cada sitio por mes (12 meses por sitio, a excepción de Esquina con 3 meses de la estación invernal). Para comparar las relaciones de similitud entre los meses de cada sitio se realizó un análisis de ordenamiento utilizando el método NMDS. Este es un caso especial de ordenación que no asume relaciones lineales o distancias métricas, es más tolerante a los datos faltantes y a menudo puede resumir más información en menor cantidad de ejes en comparación con otras técnicas (Manly 1986). El análisis con NMDS se origina con una matriz de similitudes entre las muestras construida a partir de índices de distancia ecológica (índice de Bray-Curtis), a continuación, se asigna 
una ubicación de cada elemento a un espacio $n$-dimensional, donde $n$ consiste de un número de dimensiones que se especifica a priori (generalmente 2 dimensiones). Finalmente es posible calcular el índice de estrés, que indica en qué grado las distancias obtenidas en las dimensiones seleccionadas se corresponden con la matriz de distancias original. Para construir la matriz de similitudes se utilizó el índice de similitud de Bray-Curtis, que es frecuentemente usado en este tipo de análisis (Legendre y Legendre 1998).

\section{Asociación entre la variación espaciotemporal de los recursos tróficos y el clima}

A fin de analizar si la variación espaciotemporal de los recursos se asocia a variaciones climáticas en el período de muestreo, o a períodos más prolongados, se realizaron correlaciones lineales, utilizando los datos correspondientes a la sumatoria de la disponibilidad mensual de las estructuras vegetales alimentarias (hojas, flores y frutos) por cada sitio, y los datos del período de muestreo (2007-2008) y los datos promedio de temperatura y precipitaciones del período histórico (1991-2001) de cada sitio del gradiente. Este análisis permite dimensionar si los resultados observados pueden ser medianamente constantes en el tiempo, o si se deben a respuestas particulares climáticas del año en que se realizó el muestreo.

\section{RESULTADOS}

\section{CARACTERIZACIÓN CLIMÁTICA DEL ÁREA DE ESTUDIO}

\section{La temperatura y las precipitaciones históricas y de muestreo en los sitios de estudio} de la selva de inundación

Para los 4 sitios de estudio del gradiente, se pudo apreciar una gran similitud entre la temperatura y precipitaciones medias mensuales históricas (1991-2001) y las del período de muestreo (2007-2008, para Esquina sólo los meses del invierno de 2007).

Los sitios de estudio presentaron veranos cálidos con una temperatura media anual máxima en el mes de enero e inviernos con una temperatura media anual mínima en el mes de julio. Para los 4 sitios del gradiente, entre mayo y agosto, las temperaturas fueron menores.

En cuanto a las precipitaciones, en el período histórico aumentaron su magnitud desde enero hasta abril, y se presentaron registros menores desde mayo hasta setiembre, mientras que en el período de muestro, se observó un año más seco, con mayor registro en 
el mes de octubre en todos los sitios, a excepción de Bella Vista, donde se observó un pico en el mes de abril. A su vez, en Paranacito se destacó una diferencia en el registro de precipitaciones de aproximadamente $100 \mathrm{~mm}$ menos para el mes de mayo y $100 \mathrm{~mm}$ más para setiembre, comparado con lo registrado en Bella Vista y Lavalle (Figura II-3).
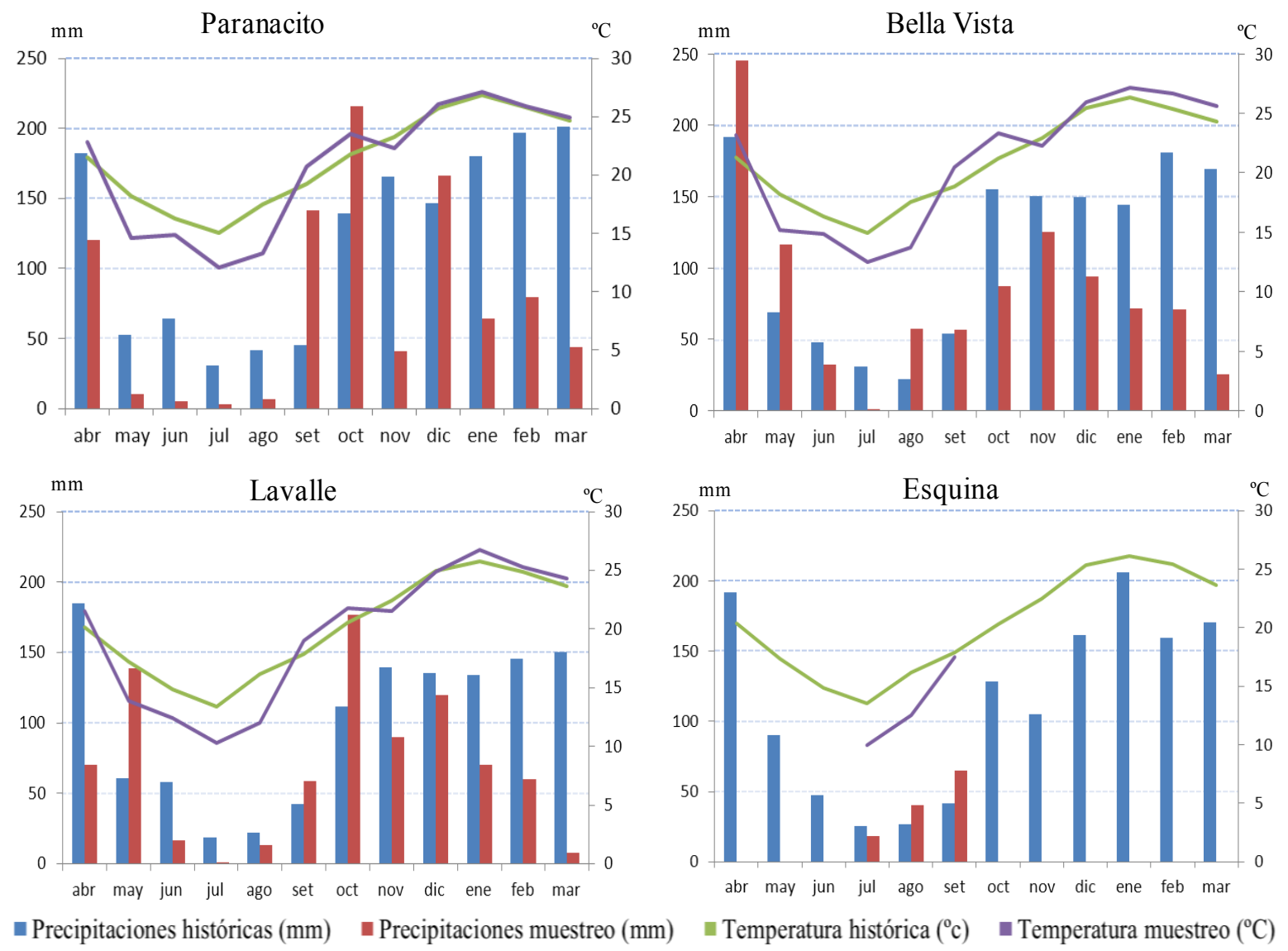

- Precipitaciones históricas $(\mathrm{mm}) \quad$ Precipitaciones muestreo $(\mathrm{mm})$

- Temperatura histórica $\left({ }^{\circ} \mathrm{c}\right) \quad$ Temperatura muestreo $\left({ }^{\circ} \mathrm{C}\right)$

Figura II-3. Climatogramas de 4 sitios de estudio ubicados en la selva de inundación del río Paraná Medio (Paranacito, Bella Vista, Lavalle y Esquina), en el período histórico desde 1991 a 2001 y en el período de muestreo desde abril de 2007 a marzo de 2008 (julio a setiembre en Esquina).

\section{Clasificación del clima en selva de inundación y en tierra firme}

El análisis de componentes principales (ACP) puso de manifiesto diferentes relaciones entre las variables bioclimáticas y los sitios ubicados en selva de inundación y tierra firme.

El eje II se correlacionó positivamente con las precipitaciones en el mes más húmedo, precipitaciones en la estación más húmeda, con la isotermalidad y la temperatura máxima en el mes más cálido, y negativamente con la estacionalidad en la temperatura. A su vez al eje I se correlacionó positivamente las variables precipitación en el mes más seco, precipitación en la estación más seca y precipitación en la estación más fría, y valores negativos con las variables rango medio diurno, estacionalidad de precipitaciones y rango de temperatura anual (Figura II-4). Los sitios ocuparon diferentes sectores del diagrama y se segregaron de este a oeste sobre el eje I y de norte a sur sobre el eje II. De esta manera, se 
puede afirmar que el eje I del ACP describe la estacionalidad en las precipitaciones, observándose mayormente sobre el eje este-oeste del área de estudio, y el eje II describe la variación en la temperatura y las precipitaciones anuales, lo que se observa a lo largo del eje norte-sur del área de estudio.

Los sitios con presencia de Alouatta caraya se ubicaron en la parte superior derecha del diagrama, asociándose a mayores temperaturas y precipitaciones, y a una menor estacionalidad climática.

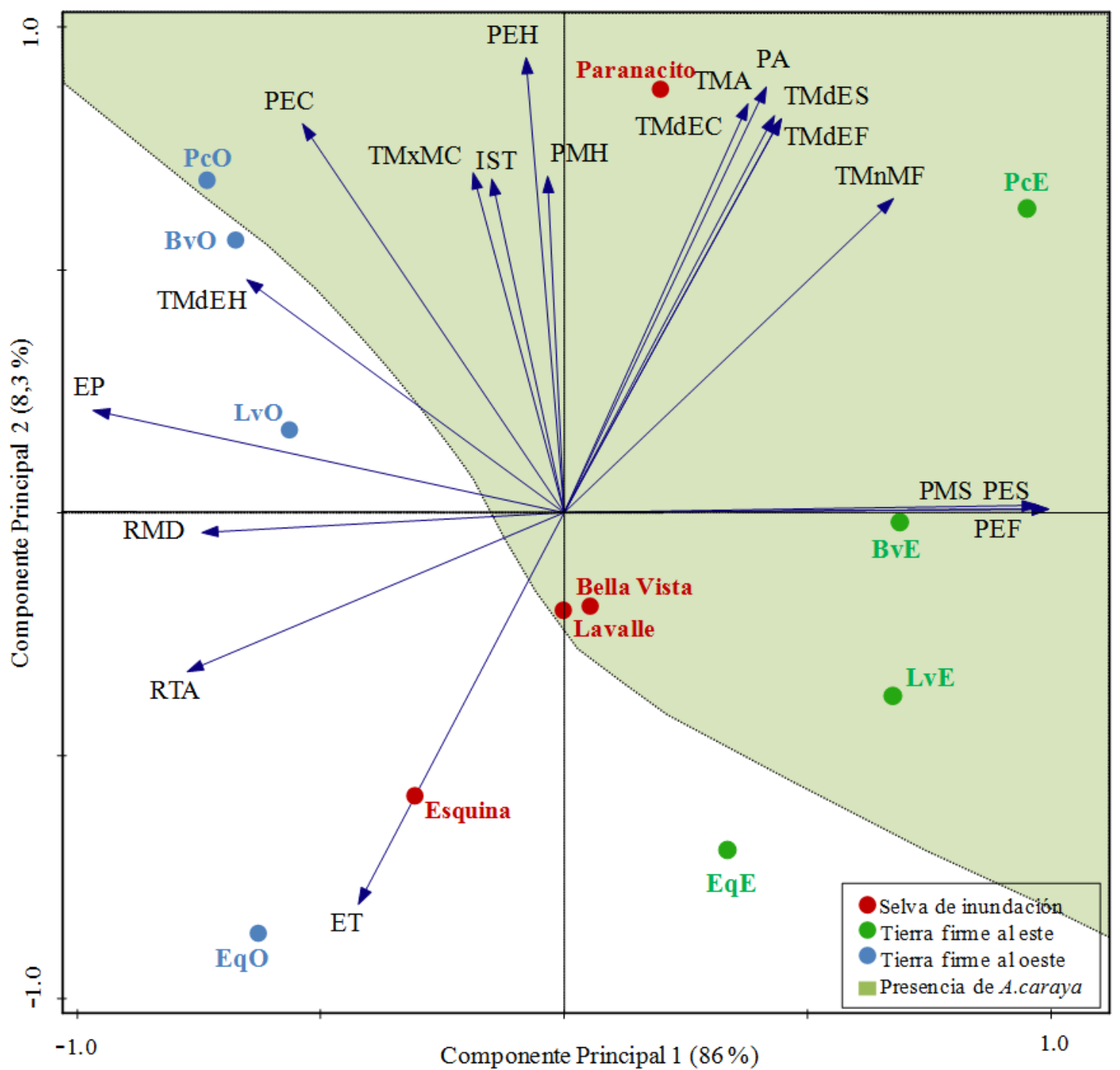

Figura II-4. Análisis de componentes principales basado en 19 variables ambientales aplicadas a 4 puntos georreferenciados en la selva de inundación del río Paraná Medio (Paranacito, Bella Vista, Lavalle y Esquina) y 8 puntos $100 \mathrm{~km}$ hacia tierra firme (al oeste: $\mathrm{PcO}, \mathrm{BvO}, \mathrm{LvO}, \mathrm{EqO}$, y al este: $\mathrm{PcE}, \mathrm{BvE}, \mathrm{LvE}, \mathrm{EqE})$. Referencias: $\mathrm{PMH}$ : precipitación en el mes más húmedo, $\mathrm{PEH}$ : precipitación en la estación más húmeda, IST: isotermalidad, TMxMC: temperatura máxima en el mes más cálido, ET: estacionalidad de temperatura, PMS: precipitación en el mes más seco, PES: precipitación en la estación más seca, PEF: precipitación en la estación más fría, RMD: rango medio diurno, EP: estacionalidad de precipitaciones RTA: rango de temperatura anual, TMA: temperatura media anual, TMnMF: temperatura minima en el mes más frío, TMdEH: temperatura media en la estación más húmeda, TMdES: temperatura media en la estación más seca, TMdEC: temperatura media en la estación más cálida, TMdEF: temperatura media en la estación más fría, PA: precipitación anual, PMS: precipitación en el mes más seco, PEC: precipitación en la estación más cálida. 


\section{CARACTERIZACIÓN DE LA VEGETACIÓN DEL ÁREA DE ESTUDIO}

\section{Reconocimiento de las especies vegetales}

El análisis de las 574 muestras colectadas, permitió reconocer una cantidad de 37 especies que constituyen recursos alimenticios para los aulladores en el área de estudio.

\section{Diversidad de recursos tróficos de Alouatta caraya}

Las 37 especies mencionadas se distribuyeron en 24 familias, destacándose las familias Fabaceae con 5 especies, Sapindaceae y Myrtaceae con 3 especies cada una, seguidas por las familias Moraceae, Lauraceae, Flacourtiaceae, Poaceae y Rubiaceae con 2 especies cada una y 16 familias más con 1 especie cada una.

De las especies registradas, el 48,7\% fueron árboles ( $A G P H, A G P H F, A M P), 21,6 \%$ lianas, 18,9\%, arbustos y árboles de pequeño porte (ARAPP), 5,4\% epifitas, 2,5 cañas y 2,5 pastos. Se observó una disminución gradual del número de especies de las principales formas de vida (árboles y lianas), hacia el sur del gradiente (Tabla II-2). 
Tabla II-2. Número de individuos de 37 especies consumibles por Alouatta caraya, presentes en parcelas de una hectárea en 4 sitios de la selva de inundación del río Paraná Medio (Paranacito: Pc, Bella Vista: Bv, Lavalle: Lv, Esquina: Eq) en el período abril 2007-marzo 2008. Referencias: $A G P H F$ : Árboles de gran porte con oferta de hojas y frutos, $A M P$ : Árboles de mediano porte, $A G P H$ : Árboles de gran porte con oferta de hoja, ARAPP: Arbustos y árboles de pequeño porte, Cañas, *: especies a las que se les hizo seguimiento fenológico, $X$ : no cuantificada.

\begin{tabular}{|c|c|c|c|c|c|c|c|}
\hline Familia & Especie & $\begin{array}{l}\text { Forma } \\
\text { de vida }\end{array}$ & $\begin{array}{l}\text { Estructura vege } \\
\text { tal consumible }\end{array}$ & Pc & $\mathbf{B v}$ & $\mathbf{L v}$ & $\mathbf{E q}$ \\
\hline Euphorbiaceae & Croton urucurana* & $A G P H$ & hoja, flor & 30 & 77 & 69 & 49 \\
\hline Fabaceae & Inga affinis* & $A G P H F$ & hoja, fruto, flor & 26 & 32 & 40 & 30 \\
\hline Fabaceae & Albizia inundata* & $A G P H F$ & hoja, fruto & 23 & 33 & 6 & 30 \\
\hline Lauraceae & Nectandra angustifolia* & $A G P H F$ & hoja, fruto & 1 & 22 & 48 & 2 \\
\hline Salicaceae & Salix humboldtiana* & $A G P H$ & hoja & 1 & 19 & 31 & 13 \\
\hline Celtidiaceae & Celtis chichape* & $A M P$ & hoja, fruto & 3 & 2 & 40 & 4 \\
\hline Sapindaceae & Paullinia elegans* & Liana & hoja, fruto & 1 & 15 & 7 & 9 \\
\hline Flacourtiaceae & Xylosma venosa* & $A M P$ & hoja, fruto & 1 & 4 & 4 & 2 \\
\hline Convolvulaceae & Ipomoea cairica* & Liana & hoja & 1 & 6 & 1 & 7 \\
\hline Malpighiceae & Stigmaphyllon bonariense* & Liana & hoja & 1 & 1 & 12 & 2 \\
\hline Rubiaceae & Machaonia brasiliensis & $A R A P P$ & hoja, fruto & 26 & 14 & 11 & \\
\hline Poaceae & Guadua sp.* & Caña & hoja & 17 & 11 & 8 & 2 \\
\hline Asteraceae & Tessaria integrifolia* & $A R A P P$ & hoja, fruto, flor & 1 & 31 & 14 & \\
\hline Flacourtiaceae & Banara arguta* & $A G P H F$ & hoja, fruto & 1 & 19 & 4 & \\
\hline Cecropiaceae & Cecropia pachystachya* & $A M P$ & hoja, fruto & 1 & 8 & 1 & \\
\hline Bignoniaceae & Dolichandra unguis cati & Liana & hoja & 2 & $\mathrm{x}$ & 1 & 2 \\
\hline Myrtaceae & Psidium guajava & $A R A P P$ & fruto & 1 & 1 & & 2 \\
\hline Moraceae & Ficus luschnathiana & Higuera & fruto & 1 & 1 & 1 & \\
\hline Fabaceae & Geoffroea spinosa* & $A G P H$ & hoja & 15 & & 3 & \\
\hline Phyllanthaceae & Phyllanthus chacoensis* & $A G P H$ & hoja & 1 & 8 & & \\
\hline Rubiaceae & Psychotria carthagenensis & $A R A P P$ & fruto & & 1 & 1 & \\
\hline Cucurbitaceae & Melothria candolleana & Liana & fruto & & 1 & 1 & \\
\hline Fabaceae & Erythrina crista galli* & $A G P H$ & hoja & & 1 & 1 & \\
\hline Fabaceae & Peltophorum dubium* & $A G P H$ & hoja & 44 & & & \\
\hline Hippocrateaceae & Pristimera andina* & Liana & hoja, fruto & 41 & & & \\
\hline Lauraceae & Ocotea diospyrifolia* & $A G P H F$ & hoja, fruto, flor & 41 & & & \\
\hline Arecaceae & Copernicia alba* & Palmera & hoja, fruto & 41 & & & \\
\hline Sapindaceae & Sapindus saponaria* & $A G P H$ & hoja & 20 & & & \\
\hline Myrtaceae & Eugenia moraviana* & $A R A P P$ & hoja & 11 & & & \\
\hline Vitaceae & Cissus palmata & Liana & fruto & & $\mathrm{x}$ & $\mathrm{x}$ & 3 \\
\hline Myrtaceae & Eugenia uniflora & $A R A P P$ & fruto & & & & 3 \\
\hline Moraceae & Sorocea sprucei & $A R A P P$ & hoja & 1 & & & \\
\hline Sapindaceae & Houssayanthus incanus & Liana & hoja, fruto & & 1 & & \\
\hline Solanaceae & Solanum aculeatissimum & $A R A P P$ & fruto & $\mathrm{x}$ & $\mathrm{x}$ & $\mathrm{x}$ & \\
\hline Poaceae & Panicum sp. & Pasto & fruto & $\mathrm{x}$ & $\mathrm{X}$ & & \\
\hline Cactaceae & Rhipsalis lumbricoides & Epifita & fruto & $\mathrm{x}$ & & & \\
\hline Bromeliaceae & Tillandsia meridionalis & Epifita & hoja & $\mathrm{X}$ & & & \\
\hline \multicolumn{4}{|c|}{ Ejemplares por parcela de 1 hectárea } & 353 & 308 & 304 & 160 \\
\hline \multicolumn{4}{|c|}{ Total de especies consumibles: 37} & 31 & 26 & 23 & 15 \\
\hline \multicolumn{4}{|c|}{ Especies con seguimiento fenológico*: 23} & 19 & 15 & 16 & 11 \\
\hline
\end{tabular}


En 4 de estas 37 especies consumibles, no fueron cuantificados el número de individuos, ni calculados sus DAP, debido a su condición (epifita de tamaño pequeño, gramínea o arbusto muy abundante) por lo que la comparación del área basal se realizó con 33 especies. Esto permitió observar diferencias en la estructura de la vegetación, resultando con mayor aporte las especies: Guadua sp., Inga affinis, Croton urucurana, Albizia inundata, Salix humboldtiana, Geoffroea spinosa y Nectandra angustifolia

El área basal total (sumatoria de áreas basales de todas las especies) resultó mayor en Lavalle, seguida por Paranacito, Bella Vista y Esquina. No obstante, considerando solamente las especies conformantes del 70\% de la dieta, el valor de las áreas basales resultó mayor en Esquina y Lavalle que en Paranacito y Bella Vista. Si bien los 4 sitios presentan una fisonomía semejante de la vegetación, consistente en un bosque aluvial de un estadio sucesional avanzado, el mayor área basal observado en Esquina y Lavalle podría asociarse a la presencia de un bosque con ejemplares de mayor edad (Figura II-5). No se observó una intensidad de tala selectiva que pudiera generar estos resultados, ni que la misma fuera considerablemente diferente entre los sitios. A su vez, la escasa presencia humana, debido a la dificultad de acceso y mantención de estructuras, no tendría un impacto importante. 


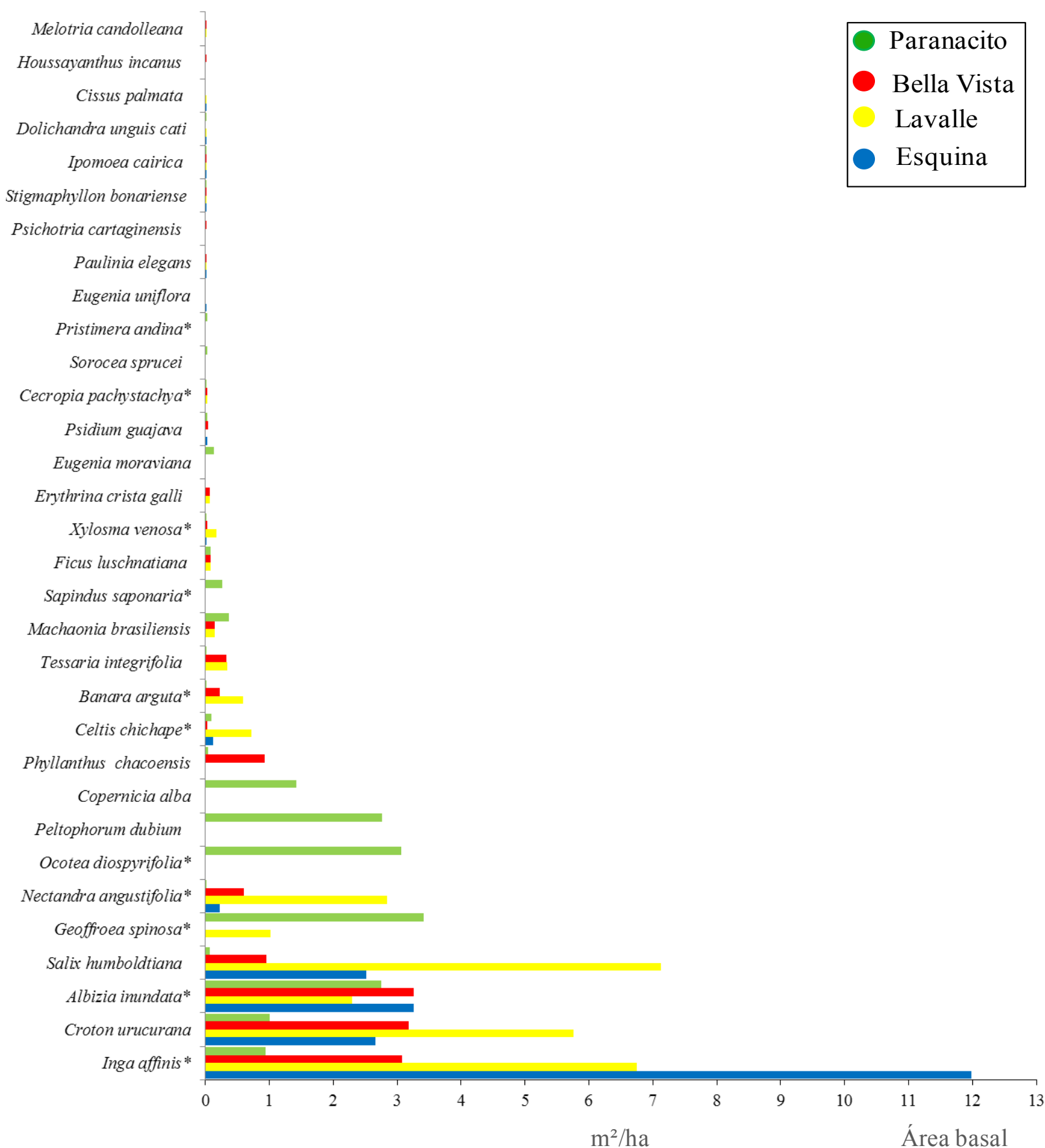

Figura II-5. Área basal de 33 especies consumibles de Alouatta caraya, en 4 sitios de la selva de inundación del río Paraná Medio (Paranacito, Bella Vista, Lavalle y Esquina) en el período abril 2007-marzo 2008. Nota: no se representaron los valores de Guadua sp. para diferenciar mejor el valor de las demás especies, *especies conformantes del $70 \%$ de la dieta.

Del 100\% de las 33 especies, se diferenció el gran aporte de Guadua sp. al área basal total, del de las especies que contribuyen al 70\% de la dieta de los aulladores ( 11 especies), las que resultaron relativamente similares entre sí (Tabla II-3). 
Tabla II-3. Área basal de especies que conforman la dieta de Alouatta caraya en 4 sitios de la selva de inundación del río Paraná Medio (Paranacito, Bella Vista, Lavalle y Esquina), en el período abril 2007-marzo 2008. Referencia: entre paréntesis se detalla el valor del área basal de Guadua sp.

\begin{tabular}{lcccc}
\hline \% especies de la dieta / sitio & Paranacito & Bella Vista & Lavalle & Esquina \\
\hline $\mathbf{7 0 \%}$ de la dieta-11 especies & 10,3 & 7,4 & 14,4 & 15,6 \\
$\mathbf{1 0 0 \%}$ de la dieta-33 especies & $168(151)$ & $145,7(132)$ & $172(144)$ & $120(99)$ \\
\hline
\end{tabular}

\section{Comparación de la abundancia y la diversidad entre sitios}

La abundancia de individuos de especies vegetales disponibles como recursos alimentarios, expresada como densidad de individuos presentes en las parcelas, registró un valor mayor en Paranacito, seguido por Bella Vista, Lavalle y Esquina. A su vez, el ANOVA realizado arrojó diferencias significativas entre sitios, y el test de Tukey reflejó que Esquina fue significativamente diferente del resto de los sitios, con menor abundancia de individuos de especies vegetales consumibles. A su vez, la riqueza de especies consumibles, resultó significativamente diferente entre los sitios, presentando Esquina una riqueza menor que el resto de los sitios (Tabla II-4 y II-5).

La diversidad de especies vegetales consumibles según el índice Shannon-Wiener disminuyó entre los sitios del gradiente latitudinal hacia el sur poniendo de manifiesto que Esquina presentó un número de especies significativamente menor que el resto de los sitios. Se utilizó la corrección de Bonferroni para las pruebas de comparaciones múltiples (Tabla II-4 y II-5).

Tabla II-4. Resultados del ANOVA permutacional comparando las diferencias de abundancia de individuos, riqueza y diversidad medias de especies vegetales consumibles por Alouatta caraya, entre 4 sitios de la selva de inundación del río Paraná Medio (Paranacito, Bella Vista, Lavalle y Esquina).

\begin{tabular}{lccc}
\hline Variable & Abundancia individuos & Riqueza & Diversidad \\
\hline Pseudo F simulados & 31,92 & 33,59 & 6,99 \\
Media de los Pseudo-F simulados & 1,05 & 1,06 & 0,95 \\
Varianza de los Pseudo-F simulados & 0,82 & 0,79 & 0,58 \\
P (observado $<=$ esperado) & 1,00 & 1,00 & 1,00 \\
P (observado $>=$ esperado) & 0,00 & 0,00 & 0,00 \\
\hline
\end{tabular}

Tabla II-5. Abundancia de individuos, riqueza y diversidad de especies vegetales consumibles por Alouatta caraya, según el índice Shannon-Wiener, en 4 sitios de la selva de inundación del río Paraná Medio (Paranacito, Bella Vista, Lavalle y Esquina). Referencias: Test de Tukey, letras diferentes (a $\mathrm{y} \mathrm{b})$ indican diferencias significativas entre sitios $(p<0.05)$.

\begin{tabular}{lccc}
\hline Sitio & Abundancia individuos & Riqueza & Diversidad \\
\hline Paranacito & $353 \mathrm{~b}$ & $31 \mathrm{~b}$ & $2,62 \mathrm{~b}$ \\
Bella Vista & $308 \mathrm{~b}$ & $26 \mathrm{~b}$ & $2,48 \mathrm{~b}$ \\
Lavalle & $304 \mathrm{~b}$ & $23 \mathrm{~b}$ & $2,34 \mathrm{~b}$ \\
Esquina & $160 \mathrm{a}$ & $15 \mathrm{a}$ & $2,02 \mathrm{a}$ \\
\hline
\end{tabular}


La comparación de la diversidad de cada sitio, mediante el método de rarefacción, considerando el mismo número de individuos registrados (160) en los distintos sitios, resultó un 6\% mayor hacia el norte del gradiente (Paranacito y Bella Vista) (Figura II-6).

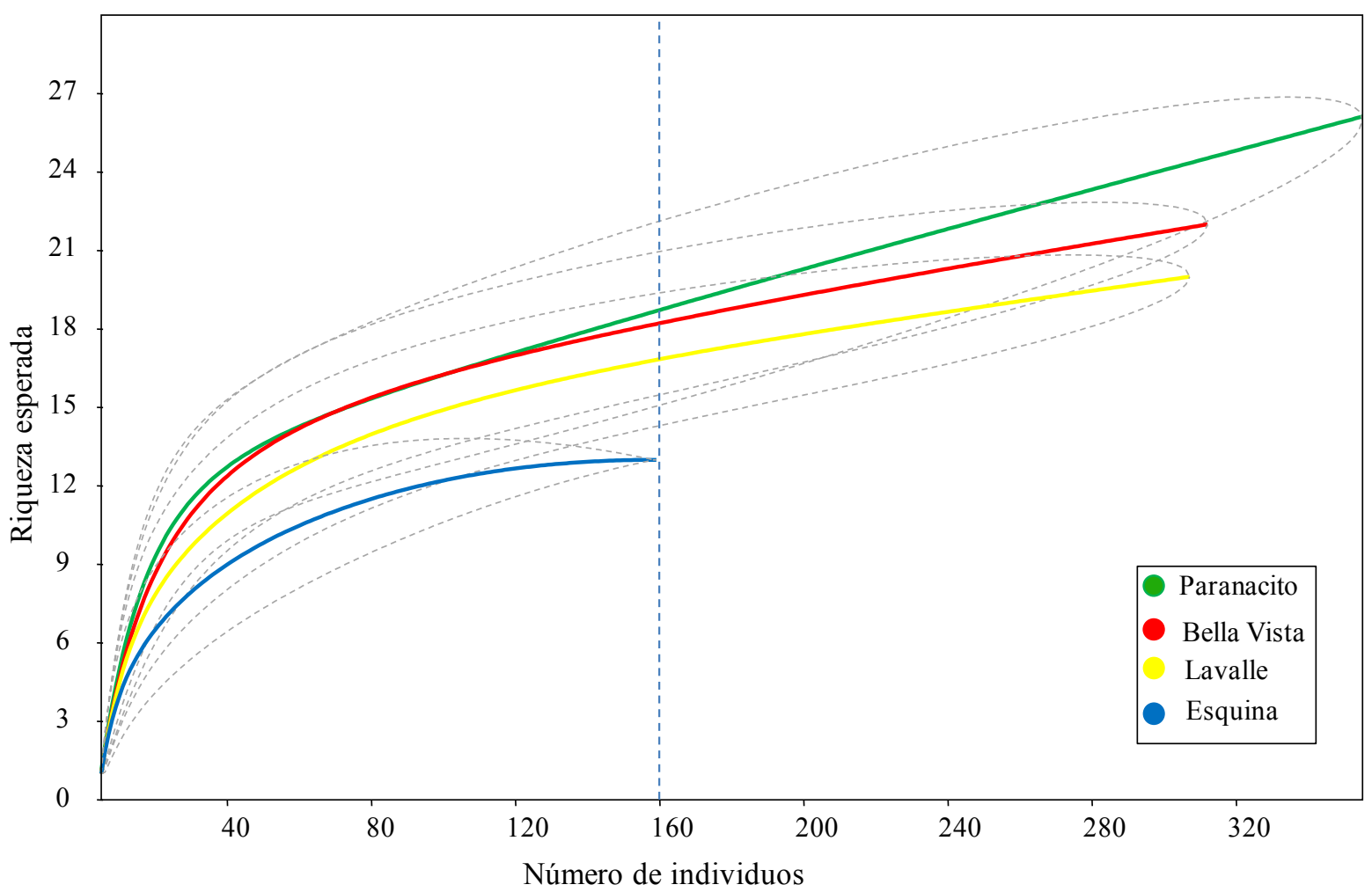

Figura II-6. Simulación del número de especies vegetales registradas a medida que se incrementa el número individuos en 4 sitios del río Paraná Medio (Paranacito, Bella Vista, Lavalle y Esquina). La línea vertical representa el punto de comparación de la riqueza de especies entre los sitios para un mismo número de individuos.

\section{Comparación de la composición de especies consumibles en cada sitio de estudio}

El análisis realizado con los datos de presencia de las 37 especies consumibles registradas en el área de estudio, evidenció que Paranacito presentaba la mayor cantidad de especies exclusivas (9), seguido por Bella Vista (1) y Esquina (1), mientras que Lavalle no presentó ninguna especie en exclusividad (Figura II-7).

Por otro lado, el análisis de similitud del número de especies compartidas reflejó un alto nivel de semejanza entre sitios, identificándose que los sitios Bella Vista y Lavalle tuvieron el mayor grado de similitud, con el 90\% de las especies en común, los cuales compartieron a su vez el 74\% de la riqueza de especies con Paranacito y el 65\% con Esquina (Figura II-7). 


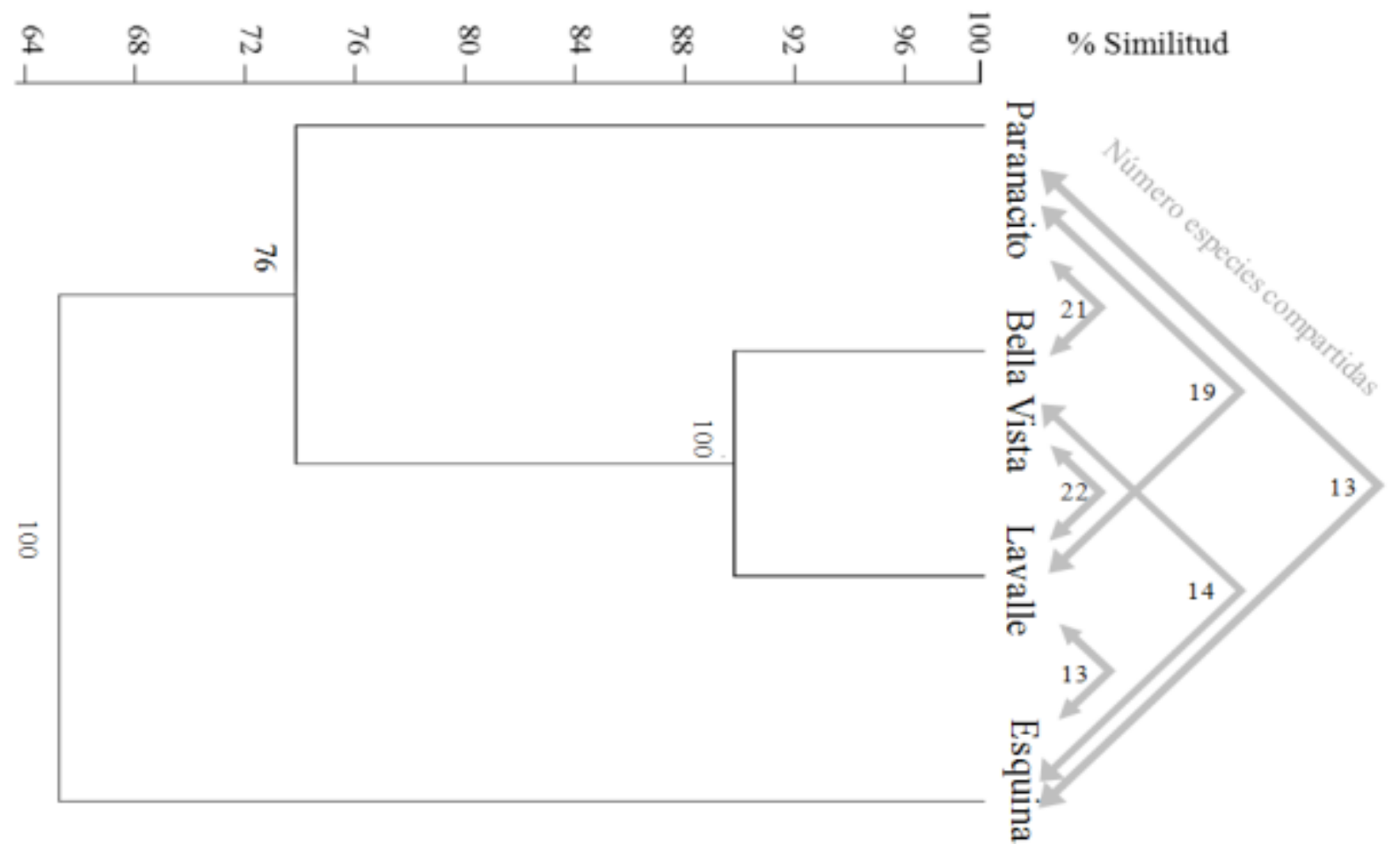

Figura II-7. Dendrograma de similitud porcentual obtenido mediante el índice de Bray-Curtis de especies consumibles por Alouatta caraya, en 4 sitios de la selva de inundación del río Paraná Medio (Paranacito, Bella Vista, Lavalle y Esquina) en el período abril 2007-marzo 2008. Referencias: el número debajo de los nodos es el porcentaje de remuestreos que sustentan el grupo (Felsenstein 1985), y el número de especies compartidas entre sitios se representa a la derecha del gráfico.

\section{Disponibilidad media mensual de recursos tróficos para Alouatta caraya}

La fenología de las especies más importantes, es decir, de aquellas conformantes del 70\% de la dieta de Alouatta caraya en el área de estudio (Figura II-8), evidenció, mediante el índice de disponibilidad IDI, variaciones en la producción de estructuras vegetales alimentarias a lo largo del período de muestreo:

La disponibilidad de hoja joven mostró en Lavalle y Paranacito valores generalmente superiores a los de Bella Vista y Esquina. Se destacaron picos máximos en los meses de octubre y noviembre para los 3 sitios con presencia de aulladores. El período invernal mostró la menor disponibilidad de este recurso, en el mes de agosto en Esquina, Lavalle y Bella Vista, y en setiembre en Paranacito (Figura II-8A).

La disponibilidad de hoja madura resultó en Lavalle y Paranacito con valores superiores a los de Esquina y Bella Vista, resultando esta última con los menores valores para todo el año. Se observó una disminución progresiva invernal (julio a setiembre) con valores menores en Bella Vista y Esquina, y continuando el decrecimiento hasta octubre (Figura II-8B). 
La disponibilidad de fruto, manifestó una mayor disponibilidad general en Lavalle a lo largo del año de muestreo, una menor disponibilidad en Bella Vista y Paranacito. A su vez, se registró una menor disponibilidad general en los meses de inverno, con valores más bajos en Paranacito y Bella Vista (Figura II-8C).

La disponibilidad de flor, presentó valores marcadamente variables en el año de muestreo, presentando mayor registro en los meses de primavera, y menor en los meses de invierno en los 4 sitios, resultando con valores intermedios en Paranacito y Esquina, y con valores cercanos a cero en Lavalle y Bella Vista (Figura II-8D).

La sumatoria de disponibilidad de todas las estructuras alimentarias en cada sitio, puso de manifiesto, valores mayores en Lavalle y Paranacito, y menores en Bella Vista a lo largo del año. Se observó una disminución general de los recursos tróficos, en la parte final del otoño, acentuándose durante el invierno, período en el que se registraron valores menores en Bella Vista y Esquina. A esta etapa, le siguió un aumento de la disponibilidad de recursos a comienzos de la primavera y estabilización de las curvas durante el verano (Figura II-8E). La contribución relativa de las estructuras de cada una de las especies, a la disponibilidad total se muestra en el Anexo 5. 

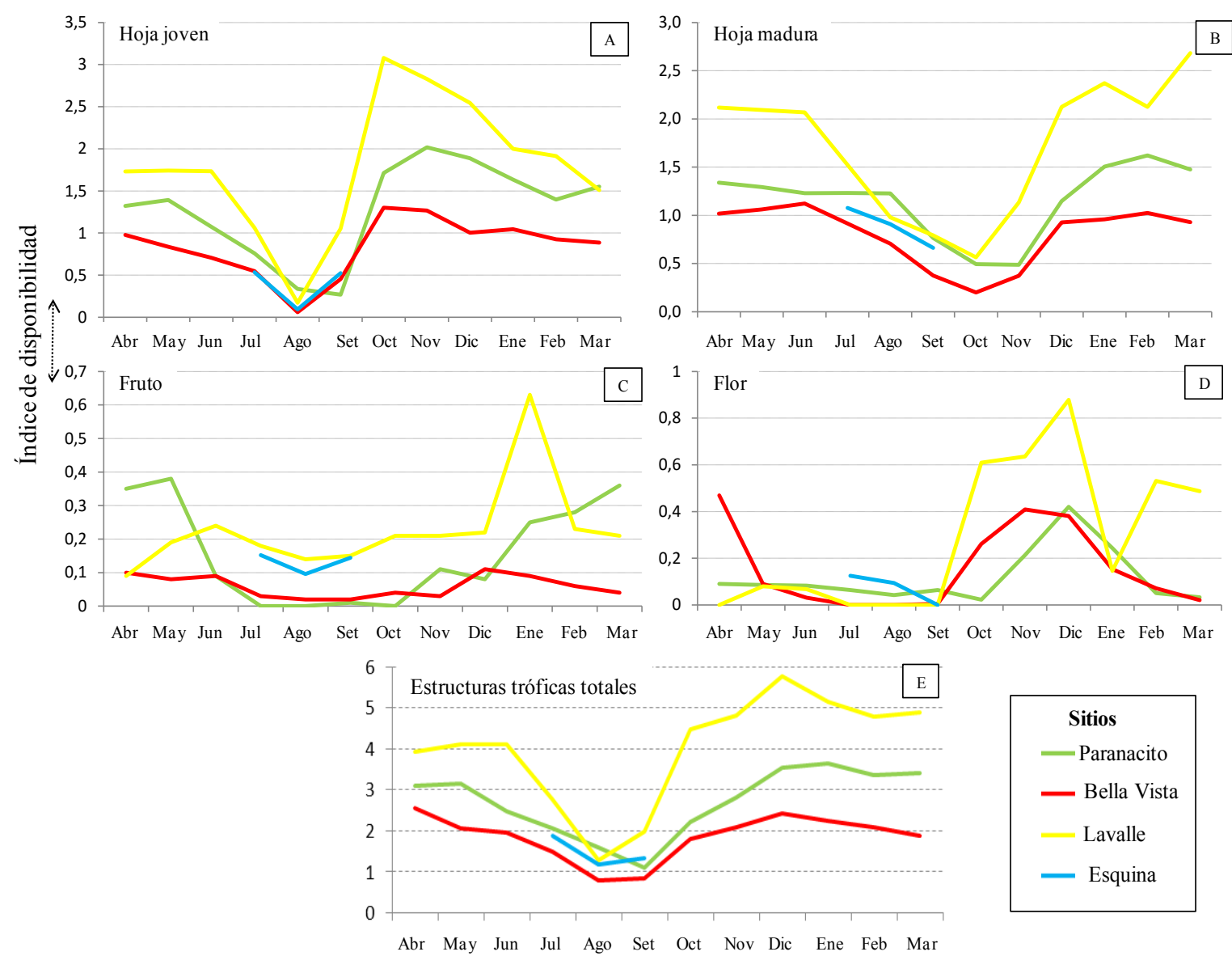

Figura II-8. Índice de disponibilidad media de estrucuturas vegetales de las especies componentes del $70 \%$ de la dieta de Alouatta caraya, en 4 sitios de la selva de inundación del río Paraná Medio: Paranacito, Bella Vista y Lavalle en el período abril de 2007-marzo de 2008, y en Esquina en el período julio-setiembre de 2007.

Los índices de diversidad de Shannon-Wiener $(\mathrm{H})$ calculados a partir de los valores de disponibilidad (IDi) de cada una de las estructuras mostraron diferencias entre los sitios y las estaciones.

Tanto para hoja joven como para hoja madura, los valores de diversidad fueron menores y mostraron mayor estacionalidad hacia el sur. Los valores de diversidad de fruto y flor presentaron una marcada estacionalidad en todos los sitios, aunque fueron ligeramente superiores en Paranacito y Bella Vista (Figura II-9). 

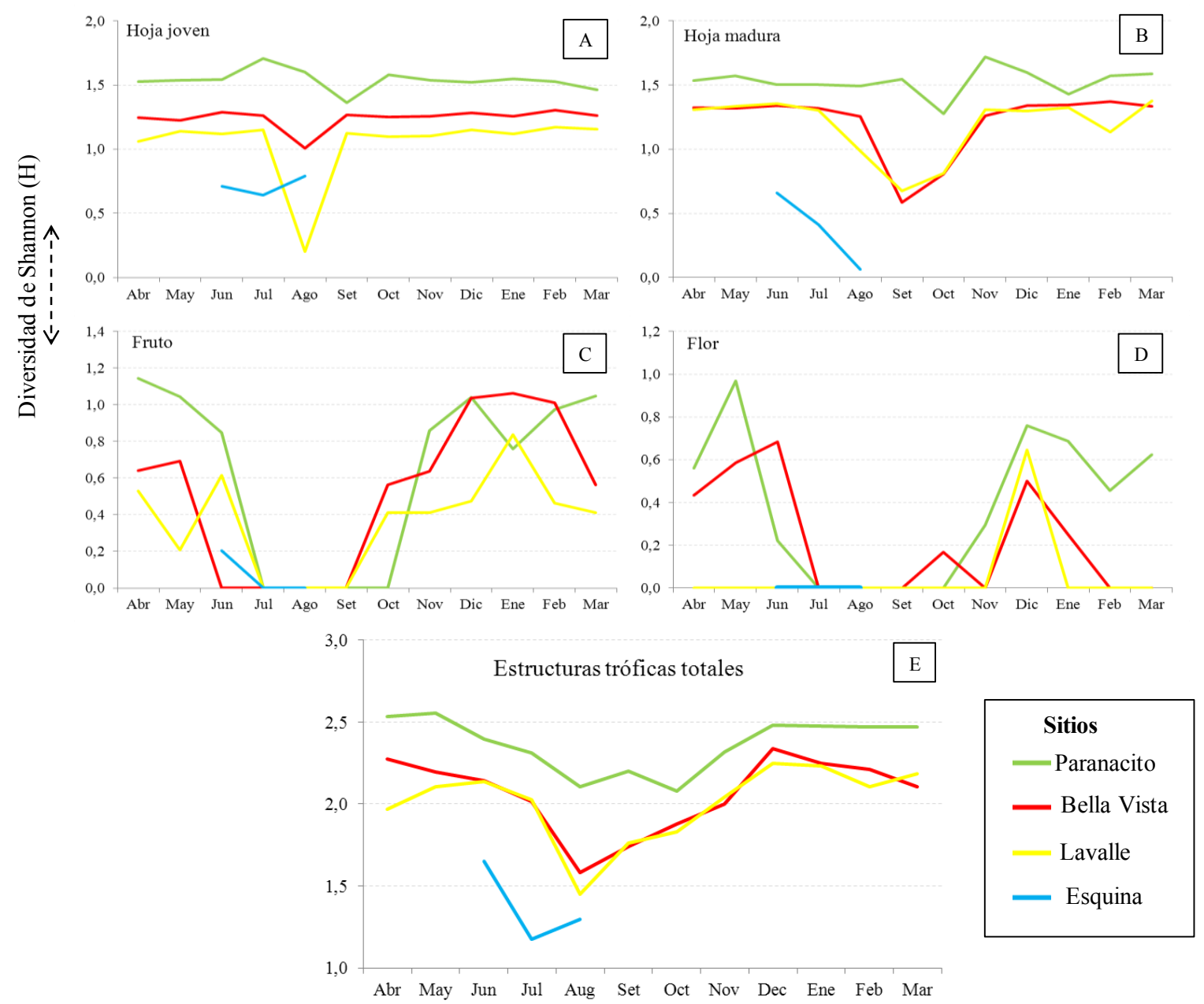

Figura II-9. Diversidad de Shannon (H) calculados a partir de los valores de disponibilidad de las estrucuturas vegetales de las especies componentes de la dieta de Alouatta caraya en 4 sitios de la selva de inundación del río Paraná Medio: Paranacito, Bella Vista y Lavalle en el período abril de 2007-marzo de 2008, y en Esquina en el período julio-setiembre de 2007.

\section{Disponibilidad de recursos tróficos analizada con el método de escalamiento multidimensional no métrico}

Este método permitió identificar gráficamente la disponibilidad media mensual de todos los recursos alimentarios de cada estructura en cada uno de los sitios del gradiente latitudinal. Se observó hacia la derecha de la dimensión 2 (vertical) del diagrama, en los cuadrantes superior e inferior la disposición de las muestras correspondientes a Paranacito (ubicado al norte del gradiente de muestreo) y hacia la izquierda, cercanas a dicha dimensión y abarcando los cuadrantes superior e inferior, se distribuyeron las muestras de Bella Vista, seguidas hacia la izquierda por las muestras de Lavalle, y por último, en el extremo superior izquierdo, se ubicaron las muestras de Esquina (correspondientes a los meses de invierno en el extremo sur del área de estudio) (Figura II-10).

Las muestras de cada sitio se dispusieron en agrupamientos elongados verticalmente, reconociéndose las muestras de primavera, presumiblemente con mayor disponibilidad de 
recursos, en el extremo inferior de estos agrupamientos, mientras que las muestras de invierno se dispusieron en el extremo superior del diagrama. Estos resultados se encontraron en coincidencia con las variaciones en la disponibilidad total mostrados por cada estructura. A su vez, se observó que los 3 meses de invierno del sitio localizado más al sur (Esquina) tuvieron una ubicación más distal en el gráfico que los respectivos meses de los restantes sitios. Estos resultados pusieron de manifiesto una diferenciación en cuanto a la disponibilidad de recursos tróficos, lo que puede relacionarse con una variación importante en cuanto a composición y cantidad de los mismos, destacándose un período más prolongado de escasez durante la estación más crítica (invierno), en el sitio ubicado hacia el sur del gradiente. Como indicador de estacionalidad, se obtuvo un bajo índice de estrés de 0,1248, lo que representa un menor forzamiento de los datos y mayor fiabilidad del indicador. La variación de la disponibilidad quedó explicada por la dimensión 1 en un 73,06\% y por la dimensión 2 en un 14,07\% (Figura II-10).

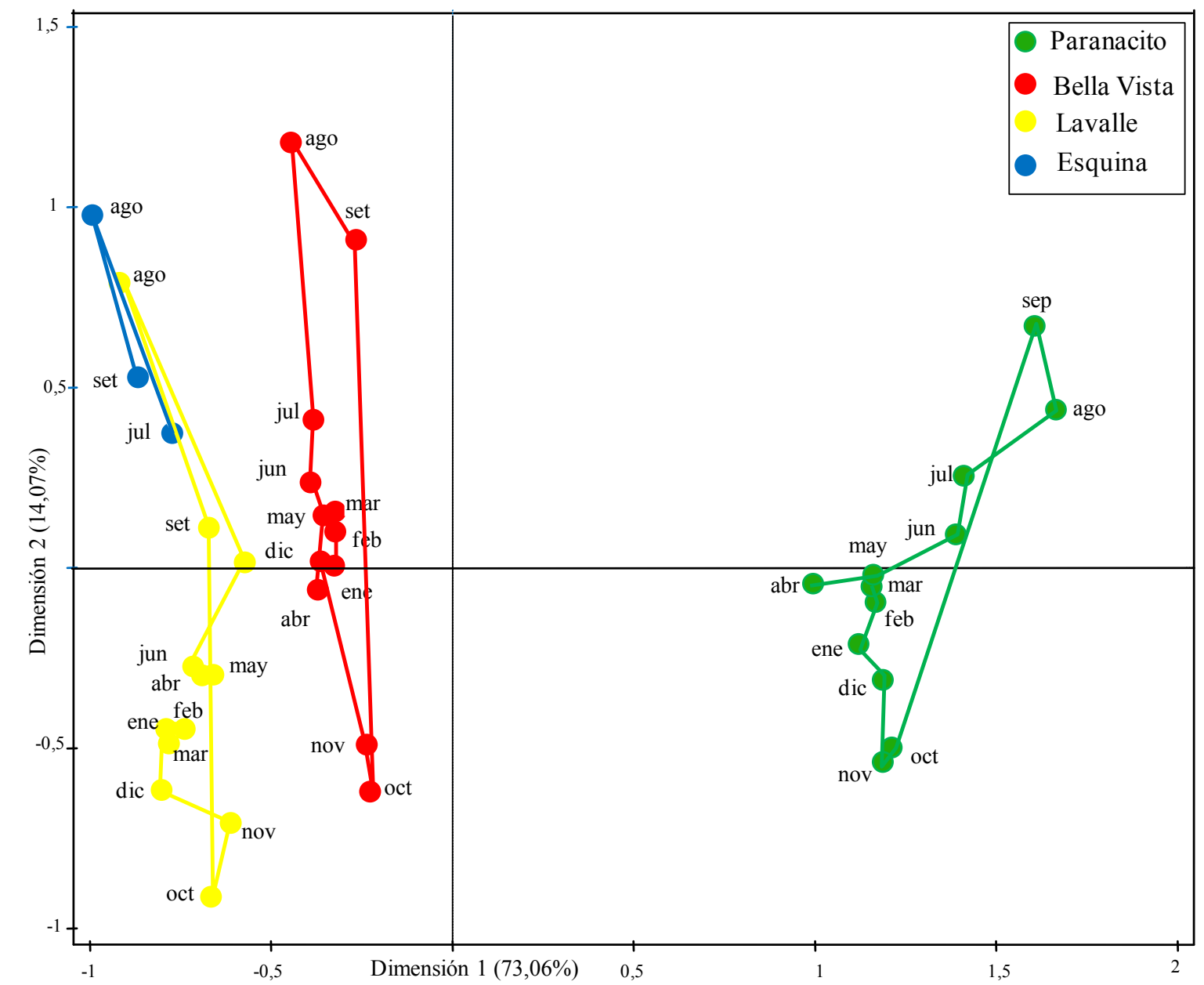

Figura II-10. Disponibilidad de los recursos alimentarios de especies componentes del $70 \%$ de la dieta de Alouatta caraya en 3 sitios de la selva de inundación del Paraná Medio: Paranacito, Bella Vista, Lavalle desde abril 2007 a marzo 2008, y en Esquina desde julio a setiembre de 2007, de acuerdo con el análisis de escalamiento multidimensional no métrico. Referencia: entre paréntesis: porcentaje explicado de la variación de la disponibilidad por cada dimensión, estrés: 0,1248. 


\section{Asociación entre la variación espaciotemporal de los recursos tróficos y el clima}

La disponibilidad de recursos tróficos estuvo correlacionada significativamente con la temperatura del período histórico y del período de muestreo, y con la precipitación del período histórico $(\mathrm{r}=0.41,0.45,0.48$ respectivamente; $p<0.05)$, mientras que no estuvo correlacionada significativamente con la precipitación del período de muestreo $(\mathrm{r}=0.17$; $p=0.35$ ). Estos resultados estarían indicando que el desarrollo vegetal ocurre en mayor asociación a la temperatura y a las precipitaciones promedio históricas, y con menor relación al patrón particular de precipitaciones de una única temporada.

\section{Variación espacial de los grupos principales de recursos alimentarios}

A lo largo del gradiente estudiado se observaron algunos cambios en la riqueza, abundancia y área basal de los principales grupos de recursos alimentarios, que son presentados de manera descriptiva a continuación y con mayor detalle en las tablas II-6 y II-7:

El grupo de árboles de gran porte con oferta de hojas y frutos (AGPHF), presentó mayor riqueza de especies en los sitios del norte del gradiente, registrándose 5 especies en Paranacito, 4 especies en Bella Vista y Lavalle y sólo 3 especies en Esquina pertenecientes a este grupo. La abundancia de este grupo fue menor en el sitio del sur aunque debido a la presencia de ejemplares de gran tamaño, la sumatoria de las áreas basales fue mayor en este sitio.

Las higueras (Ficus sp.), consideradas excelentes fuentes de recursos para los primates (Stevenson et al. 2000), fueron registradas sólo en Paranacito, Bella Vista y Lavalle, pero no se presentaron en Esquina. Estas plantas fueron de presencia ocasional y registraron muy baja abundancia en general.

En el grupo de árboles de mediano porte $(A M P)$, se encontraron especies importantes por su oferta de hojas y frutos. Este grupo presentó más especies en los sitios del norte, pero no se observó un patrón claro respecto de la abundancia ni del área basal.

El grupo de las palmeras, un recurso valioso por su aporte de frutos de muy buena calidad, estuvo representado únicamente por Copernicia alba, que fue abundante en Paranacito no se registró en los demás sitios.

El grupo formado por árboles de gran porte con oferta de hojas (AGPH), considerados valiosos por su uso como soporte, presentó mayor riqueza y abundancia en los tres sitios del norte. Sin embargo, el área basal total de este grupo no mostró un patrón claro en el área de estudio. Cabe destacar que Sapindus saponaria, una especie importante por su aporte de hojas como recurso trófico, fue registrada solamente en Paranacito. 
El grupo conformado por lianas presentó mayor riqueza, abundancia y área basal en los sitios ubicados al norte del gradiente respecto de Esquina.

La riqueza, la abundancia y el área basal de las especies de arbustos y árboles de pequeño porte $(A R A P P)$ disminuyeron hacia el sur del área de estudio.

Las cañas (Guadua sp.) son utilizadas ocasionalmente como soporte por los aulladores (Hernández 2014) y representan recursos tróficos de menor calidad. Fueron abundantes en todos los sitios, presentándose en grandes agrupaciones de individuos (cañaverales) lo que tornó imposible la determinación exacta de su abundancia (Tabla II-7). Tabla II-6. Grupos de especies vegetales utilizadas como recursos por Alouatta caraya en la selva de inundación del río Paraná Medio.

\begin{tabular}{|c|c|c|}
\hline Grupos & Familia & Especie \\
\hline \multirow{5}{*}{$\begin{array}{l}\text { Árboles de gran porte } \\
\text { con oferta de hojas y frutos } \\
\quad(A G P H F)\end{array}$} & Lauraceae & Nectandra angustifolia \\
\hline & Lauraceae & Ocotea diospyrifolia \\
\hline & Fabaceae & Albizia inundata \\
\hline & Fabaceae & Inga affinis \\
\hline & Flacourtiaceae & Banara arguta \\
\hline Higueras & Moraceae & Ficus luschnatiana \\
\hline \multirow{3}{*}{$\begin{array}{l}\text { Árboles de mediano porte } \\
\qquad(A M P)\end{array}$} & Cecropiaceae & Cecropia pachystachya \\
\hline & Celtidiaceae & Celtis chichape \\
\hline & Flacourtiaceae & Xylosma venosa \\
\hline Palmeras & Arecaceae & Copernicia alba \\
\hline \multirow{7}{*}{$\begin{array}{l}\text { Árboles de gran porte } \\
\text { con oferta de hojas } \\
\quad(A G P H)\end{array}$} & Sapindaceae & Sapindus saponaria \\
\hline & Fabaceae & Geoffroea spinosa \\
\hline & Fabaceae & Peltophorum dubium \\
\hline & Fabaceae & Erythrina crista galli \\
\hline & Salicaceae & Salix humboldtiana \\
\hline & Phyllanthaceae & Phyllanthus chacoensis \\
\hline & Euphorbiaceae & Croton urucurana \\
\hline \multirow{5}{*}{ Lianas } & Hippocrateaceae & Pristimera andina \\
\hline & Sapindaceae & Paullinia elegans \\
\hline & Cucurbitaceae & Melothria candolleana \\
\hline & Malpighiceae & Stigmaphyllon bonariense \\
\hline & Convolvulaceae & Ipomoea cairica \\
\hline \multirow{7}{*}{$\begin{array}{l}\text { Arbustos o árboles de } \\
\text { pequeño porte } \\
\qquad(A R A P P)\end{array}$} & Myrtaceae & Psidium guajava \\
\hline & Myrtaceae & Eugenia uniflora \\
\hline & Myrtaceae & Eugenia moraviana \\
\hline & Rubiaceae & Psychotria carthagenensis \\
\hline & Rubiaceae & Machaonia brasiliensis \\
\hline & Asteraceae & Tessaria integrifolia \\
\hline & Moraceae & Sorocea sprucei \\
\hline Cañas & Poaceae & Guadua sp. \\
\hline
\end{tabular}


Tabla II-7. Riqueza, abundancia y área basal de los grupos de especies vegetales aportantes de recursos para Alouatta caraya en 4 sitios de la selva de inundación del río Paraná Medio (Paranacito: Pc, Bella Vista: Bv, Lavalle: Lv y Esquina: Eq. Referencias: $A G P H F$ : Árboles de gran porte con oferta de hojas y frutos, $A M P$ : Árboles de mediano porte, $A G P H$ : Árboles de gran porte con oferta de hoja, $A R A P P$ : Arbustos y árboles de pequeño porte.

\begin{tabular}{|c|c|c|c|c|c|c|c|c|c|c|c|c|}
\hline \multirow[b]{2}{*}{ Grupo / Sitio } & \multicolumn{4}{|c|}{ Riqueza de especies } & \multicolumn{4}{|c|}{ Abundancia } & \multicolumn{4}{|c|}{ Área basal } \\
\hline & Pc & Bv & Lv & $\mathbf{E q}$ & Pc & Bv & $\mathbf{L v}$ & $\mathbf{E q}$ & Pc & Bv & $\mathbf{L v}$ & Eq \\
\hline$A G P H F$ & 5 & 4 & 4 & 3 & 92 & 106 & 98 & 62 & 6,774 & 7,160 & 12,469 & 15,470 \\
\hline Higueras & 1 & 1 & 1 & 0 & 1 & 1 & 1 & 0 & 0,079 & 0,085 & 0,082 & 0 \\
\hline$A M P$ & 3 & 3 & 3 & 2 & 5 & 14 & 45 & 6 & 0,115 & 0,076 & 0,926 & 0,135 \\
\hline Palmeras & 1 & 0 & 0 & 0 & 41 & 0 & 0 & 0 & 1,419 & 0 & 0 & 0 \\
\hline$A G P H$ & 6 & 4 & 4 & 2 & 111 & 105 & 104 & 62 & 7,568 & 5,121 & 13,981 & 5,171 \\
\hline Lianas & 4 & 4 & 4 & 3 & 44 & 23 & 21 & 18 & 0,025 & 0,011 & 0,004 & 0,001 \\
\hline$A R A P P$ & 5 & 4 & 3 & 2 & 40 & 47 & 26 & 5 & 0,577 & 0,535 & 0,489 & 0,053 \\
\hline Cañas & 1 & 1 & 1 & 1 & --- & --- & --- & --- & 151,28 & 131,68 & 144,05 & 99,00 \\
\hline
\end{tabular}

\section{DISCUSIÓN}

El análisis de los datos climáticos en este capítulo permitió observar que los límites de la distribución de Alouatta caraya en su extremo sur estarían asociados a un gradiente de disminución de las temperaturas y precipitaciones y a un incremento en su estacionalidad, a lo largo del río Paraná Medio. Hacia el sur, el límite de distribución de la especie coincide aproximadamente con la isoterma de $19,5^{\circ} \mathrm{C}$ y hacia el oeste con la isohieta de $1100 \mathrm{~mm}$. A su vez, tanto hacia el sur como hacia el oeste se observaron incrementos en la estacionalidad climática lo que generaría condiciones desfavorables para la presencia de la especie. La temperatura y las precipitaciones podrían tener un efecto directo o indirecto (a través del efecto sobre la disponibilidad de recursos) sobre la supervivencia de las poblaciones de $A$. caraya. Ambas posibilidades se discuten a continuación.

La mayor frecuencia de eventos de bajas temperaturas en los sitios del sur podrían constituir un factor limitante de manera directa para las poblaciones de aulladores. Sin embargo, existen casos de translocación de individuos de la especie fuera de su área de distribución donde se ha observado que toleran hasta $-8,8{ }^{\circ} \mathrm{C}$ de temperatura ambiente, e incluso períodos de nevadas, manteniendo en estas condiciones, poblaciones viables (Lindbergh 1976, Giudice y Ascunce 1998, Bruno 2011). En el valle aluvial del río Paraná, el efecto atemperador de las grandes masas de agua circundantes que se mueven desde el norte (Iriondo 2007), determina que estas temperaturas extremas nunca ocurran en el área de estudio. Otro factor a tener en cuenta es que la mayoría de los nacimientos ocurren durante los meses más fríos de otoño e invierno y el destete de los infantes se alcanza durante el fin de la primavera (Zunino 1986, 1996). Considerando que se trata de animales endotermos, la 
mayor relación superficie-volumen de los infantes determinaría una mayor tasa de pérdida de calor (Randall et al. 2002) haciéndolos más susceptibles a la mortalidad por el frío. Sin embargo, durante las primeras fases del desarrollo, los infantes cuentan con la protección de la madre para reducir la pérdida de calor y con el suministro de energía a través de la lactancia. En consecuencia, la acción directa de las bajas temperaturas parecería no ser un factor crucial en la determinación del límite sur del área de distribución de la especie.

Por otra parte, la mayor estacionalidad y menor volumen de precipitaciones hacia el sur y hacia el oeste, podrían determinar períodos de escasez hídrica afectando la disponibilidad de agua para los aulladores. No obstante, la presencia de cuerpos de agua permanentes y el continuo exceso hídrico en el valle aluvial del río Paraná (Iriondo y Paira 2007) haría que los aulladores dispongan de agua durante todo el año. Además, según se ha reportado para otras especies del género, los aulladores obtienen la mayor parte de sus requerimientos hídricos a partir de su dieta (Glander 1979, Figueiredo 1993). Esto sugiere que la disminución en las precipitaciones no tenga un efecto directo en la supervivencia de la especie en el área de estudio.

No obstante, la temperatura y las precipitaciones podrían tener un efecto indirecto en la distribución de Alouatta caraya, a través de su influencia sobre la vegetación. Los cambios en la abundancia de las diferentes especies vegetales a lo largo del gradiente climático podrían afectar la disponibilidad de hábitat y de recursos tróficos para la especie, lo que ha sido citado como una variable determinante de la abundancia y distribución de los aulladores (Zunino et al. 1995, Milton 1996, Chapman et al. 1999). A lo largo del gradiente latitudinal estudiado, se observó un descenso de la temperatura media, que podría afectar de manera negativa la supervivencia y la producción de estructuras vegetales de las plantas (McWilliam 1978, Whiteman 1980, Zyalalov 2004). La disminución de la temperatura y de las precipitaciones, pueden generar cambios en las características de las plantas como el aumento en sus defensas físicas y químicas, diminución de su digestibilidad y de su palatabilidad afectando así su consumo (Glander 1975, Johnson et al. 1985).

Varios autores sostienen que el factor más importante que determina la calidad del hábitat para los aulladores es la densidad de especies vegetales más comúnmente utilizadas como recursos alimenticios (Gaulin et al. 1980, Stoner 1996). Mediante el análisis de rarefacción, pudo observarse que el número de especies consumibles resultó inferior hacia los sitios ubicados al sur del gradiente estudiado. Lo observado es esperable dada la tendencia general de disminución de la diversidad de especies hacia latitudes superiores. Algunas especies se registraron en los 3 sitios ubicados al norte del gradiente, como Ficus 
sp., Cecropia pachystachya, Banara arguta, Solanum aculeatissimum, pero no se registraron en el sitio ubicado más al sur (Esquina). En conjunto, las lauráceas (Ocotea diospyrifolia y Nectandra angustifolia) que son reconocidas como recurso trófico para los aulladores fueron abundantes en los 3 sitios del norte y estuvieron pobremente representadas en el sitio ubicado más al sur del gradiente. Las 6 especies mencionadas, que suministran hojas y frutos de gran calidad, mostraron mínima abundancia o estuvieron ausentes en el sitio ubicado más al sur (Esquina) de gradiente estudiado, lo que podría afectar el equilibrio dietario de Alouatta caraya.

En este capítulo se observó que diversas especies vegetales de distribución más tropical como Cecropia pachystachya, Banara arguta, Sapindus saponaria, Ocotea diospyrifolia (López Villalba et al. 1987, Ferrucci 1998, Pensiero et al. 2005), redujeron su abundancia o desaparecieron hacia el extremo sur del gradiente. En los sitios donde estuvieron presentes, estas especies constituyeron la mayor parte de la dieta de los aulladores (capítulo III). Algunas especies vegetales mostraron patrones de distribución entre los sitios que fueron coincidentes con la presencia de Alouatta caraya. Por ejemplo, las higueras (Ficus sp.), que consideradas un recurso trófico clave para los aulladores (Estrada y Coates Estrada 1986, Zunino 1989, Silver et al. 1998) y determinantes de la biomasa de primates en el Neotrópico (Stevenson et al. 2000), estuvieron presentes en los tres sitios del norte, pero no fueron registradas en el sitio más austral del gradiente, Esquina.

Entre los distintos grupos de recursos evaluados, la diversidad y abundancia de lianas decrece junto con la latitud a mayor magnitud que otras formas de vida vegetal (Gentry 1991, D’Arcy et al. 2006). En concordancia con esta observación, las lianas mostraron una disminución marcada en su abundancia y área basal a lo largo del gradiente. Las lianas contribuyen a la diversidad general de las selvas, estructurando y facilitando el movimiento de especies animales arborícolas y conforman una parte importante de la dieta para muchas especies de primates, aves e insectos (Gentry 1991, Gerwing y Vidal 2002). En los bosques secundarios, las lianas colonizan rápidamente los claros y pueden constituir un alimento de importancia para los aulladores. Las hojas de las lianas pueden tener una relación de proteína/fibra más favorable y con menor concentración de inhibidores de la digestión en comparación con las hojas de los árboles (Martins 2009), además de presentar frutos disponibles en períodos donde los árboles no fructifican (Morellato y Leitão Filho 1996).

Si bien se observaron diferencias en la abundancia de la mayoría de los árboles de gran porte hacia el sur del gradiente, no se evidenció un patrón claro en los datos de área basal, sugiriendo que los aulladores podrían acceder a un volumen semejante de recursos 
(aunque con menor diversidad de especies) en todos los sitios estudiados. Las especies más abundantes y constituyentes centrales de la dieta como Albizia inundata e Inga affinis, en conjunto con otras especies de árboles de gran porte, presentaron un área basal comparable en los cuatro sitios analizados. Es importante tener en cuenta que este conjunto de especies representó casi el 70\% de la abundancia y más del 90\% del área basal (excluyendo a Guadua sp.) de las especies vegetales disponibles como recurso para los aulladores. Por este motivo, el patrón observado en los árboles de gran porte podría barrer con las diferencias observadas en otros grupos de especies de mucha menor abundancia. Siguiendo esta línea de argumentación, las diferencias en la disponibilidad de recursos tróficos a lo largo del gradiente serían mas bien de tipo cualitativo que cuantitativo. En este sentido, es interesante discutir la importancia que pueden tener ciertos recursos de menor abundancia en el balance nutricional de la dieta de los aulladores. En Alouatta pigra, Brosimiun alicastrum, proporcionó proteína cruda en abundancia y observándose como un elemento esencial en la dieta de poblaciones del sureste de México (Milton 1980), para una dieta balanceada, ya que en baja proporción puede provocar alteración de la población microbiana celulolítica gastrointestinal, resultando en trastornos y en la principal causa de muerte (Oftedal et al. 1991, Duarte Quiroga y Estrada 2003, Anaya Lira et al. 2010). Un acercamiento más ajustado de este aspecto, demandaría la ejecución de estudios sobre el valor nutricional y toxicológico de las distintas especies vegetales utilizadas como recursos por los aulladores.

Sitios con la misma composición de especies vegetales a lo largo de un gradiente climático, podrían poseer una oferta de recursos diferentes, producto del efecto de las condiciones climáticas sobre la disponibilidad de estructuras vegetales (hoja, flor, fruto). La mayor estacionalidad en la temperatura observada hacia el sur del gradiente podría determinar cambios en la fenología de las plantas (menor floración, fructificación y producción de hoja joven) generando períodos críticos para los herbívoros (Lundberg y Palo 1993). En este capítulo, se observó que la variación temporal en la disponibilidad de las estructuras alimenticias estuvo íntimamente relacionada a la estacionalidad climática. Las estructuras hoja joven, flor y fruto, fueron mucho menos abundantes durante el invierno y la primavera, mientras que la hoja madura estuvo disponible durante períodos más prolongados a lo largo del año. La disponibilidad de estructuras vegetales agrupada entre las especies mostró un comportamiento estacional muy semejante entre los 4 sitios, lo que en principio indicaría que el aumento de la estacionalidad térmica hacia el sur no tiene un efecto claro sobre la fenología de las plantas. Sin embargo, la variación fenológica de las plantas determinó una menor diversidad de recursos disponibles hacia el sur. Si bien los aulladores 
disponen de un volumen de alimento semejante a lo largo del gradiente, se observa una simplificación del recurso alimentario disponible en cuanto a las especies que lo componen. Si se considera que cada especie aporta nutrientes diferentes a la dieta de los aulladores (Zunino 1986), estos cambios estarían indicando un deterioro de la calidad de la oferta trófica en los sitios ubicados hacia el sur del gradiente.

En resumen, se puede afirmar que la temperatura y las precipitaciones no tendrían un efecto directo sobre la distribución de las poblaciones de aulladores ya que los mismos poseen una gran tolerancia al frío y cuentan con abundante disponibilidad de agua durante todo el año. La composición y fenología de la vegetación mostró patrones espaciales y temporales en coincidencia con la variación climática latitudinal y estacional respectivamente. Estos cambios en la vegetación se pueden interpretar como variaciones en la abundancia y diversidad de recursos tróficos que funcionan como potenciales determinantes de la distribución de Alouatta caraya en el extremo sur de su área geográfica. En el presente capítulo no se encontraron resultados concluyentes que indiquen un límite claro en la disponibilidad de recursos para la especie, sino una disminución gradual en la diversidad de la vegetación hacia el sur. Si bien la abundancia de recursos estimada a través del área basal no mostró diferencias entre los sitios para las especies más importantes, en los sitios del sur se observó una disminución más marcada en la diversidad de recursos disponibles en los meses más fríos del año. Para ponderar la influencia de los cambios en la vegetación sobre la disponibilidad de recursos para los aulladores sería importante desarrollar estudios sobre el valor nutritivo de las especies consumidas por los aulladores y estimar la abundancia de recursos no sólo en base a la biomasa en pie sino a la productividad de las estructuras (Stevenson et al. 2000). 


\section{CAPÍTULO III}

\section{VARIACIÓN LATITUDINAL DEL COMPORTAMIENTO TRÓFICO DE Alouatta caraya EN EL EXTREMO SUR DE SU DISTRIBUCIÓN GEOGRÁFICA}

\section{INTRODUCCIÓN}

Los límites en la distribución geográfica de los organismos son determinados fundamentalmente por la reducción en la disponibilidad de recursos y los cambios en las condiciones ambientales (Gaston 2009), los cuales presentan variaciones latitudinales (Janson y Chapman 1999, Stevenson et al. 2008). En este contexto, además de las condiciones ambientales, varios autores mencionan la importancia de la disponibilidad de recursos tróficos en la distribución y abundancia de muchas especies de primates herbívoros (Isbell 1991, Mendes Pontes 1999, Snaith y Chapman 2007). La mayor estacionalidad puede conducir a una carencia de importantes especies vegetales básicas en la dieta de los aulladores, viéndose forzados a utilizar otras especies que aseguren sus necesidades energéticas. Esto, puede tener considerables efectos negativos a nivel de estrés y fisiológico para los aulladores, con graves consecuencias para su supervivencia al corto, mediano y largo plazo (Martínez Mota 2004, Estrada et al. 2006). El estudio de los patrones de uso de los recursos tróficos de una especie de primate a medida que se aproxima a su límite de distribución puede echar luz sobre los factores que determinan los límites de su rango geográfico.

De manera general, el comportamiento trófico de los mamíferos herbívoros es considerado como uno de los más complejos, en comparación con el de otros vertebrados (Belovsky 1978, Owen Smith y Novellie 1982). Además del consumo de gran abundancia de alimentos (Westoby 1978), requieren de la ingestión de distintos ítems alimentarios, y de diferentes especies vegetales para mantener un balance nutricional (Belovsky 1984). Dentro de los primates herbívoros, las diferentes especies de aulladores, incluyen en su dieta; hojas, flores, frutos, ramas tiernas de árboles y lianas, raíces de epifitas y bulbos de orquídeas (Milton 1998, Stevenson et al. 2000, Palacios y Rodríguez 2001, Londoño y Gómez Posada 2003). Con un intestino posterior de gran longitud como única especialización asociada a la folivoría, son calificados como folívoros conductuales, con un patrón dietario altamente selectivo caracterizado por la ingesta de una gran variedad de especies, y la capacidad de 
evitar compuestos secundarios mediante la ingesta de hojas jóvenes de mayor valor nutricional (con una razón baja de fibras/proteínas) (Glander 1982, Estrada 1984, Milton 1984).

La dieta frugívora de los aulladores tiene como factor crítico la maduración de los frutos, lo que afecta sus preferencias alimentarias (Garber 1984). Los frutos maduros son recursos con alto nivel de energía, ricos en carbohidratos no estructurales y azúcares simples, rápidamente hidrolizables en un intestino largo, aunque los frutos inmaduros, ricos en fibra y compuestos secundarios, también son incluidos en la dieta. Lo mencionado anteriormente refleja cierta tolerancia a alimentos ricos en fibra y un posible rechazo a agentes antibióticos presentes en frutos maduros, potencialmente desfavorables para la composición de la microflora intestinal (Janzen 1978).

Los aulladores también fueron denominados folivoros facultativos, con una dieta frugívora cuando es posible y folívora cuando es necesaria dada la disponibilidad limitada de frutos a lo largo del tiempo (Silver et al. 1998). Los rasgos conductuales antes mencionados, permiten a los aulladores subsistir con una dieta relativamente de baja calidad (Garber 1987), es decir una dieta basada en un alto porcentaje por hojas (Estrada 1984, Chiarello 1993, Williams Guillen 2003, Bravo y Sallenave 2003), las que representan alimentos de escaso valor nutritivo, debido a su alto contenido de fibra (de difícil o lenta digestión) y al bajo contenido de carbohidratos no estructurales (azúcares hidrolizables para uso de energía rápidamente disponible). La disminución en la calidad de la dieta se intensifica en períodos de escasez, cuando los aulladores se alimentan de los recursos más abundantes pero no necesariamente más nutritivos, y evitan el desgaste energético por la búsqueda de alimentos de mayor calidad, motivo por el cual fueron denominados minimizadores de viaje (Milton 1980).

Por otro lado, se ha observado que la dieta de los animales es variable entre especies y entre individuos, acorde a modificaciones en el metabolismo dependientes del tamaño corporal, de la edad y sexo, de la fisiología digestiva (ej. crecimiento de los juveniles, mayor tamaño de los machos, reproducción y lactancia para las hembras), del resultado de la mezcla de nutrientes consumidos, así como del uso del hábitat y las tácticas de forrajeo (Clutton Brock y Harvey 1977, Bicca Marques y Calegaro Marques 1993, 1995, Milton 2006). Si bien los patrones de actividad de los aulladores varían entre las clases de edad y sexo, para varias especies en latitudes tropicales la dieta ha resultado equivalente entre las mismas (Bicca Marques y Calegaro Marques 1995, Glander y Teaford 1995, Pavelka y Knopff 2004, Prates y Bicca Marques 2008). En este sentido, Alouatta caraya, debido a su marcado 
dimorfismo sexual en tamaño (Tabla I-1) y a las condiciones ambientales del extremo sur de su distribución (clima subtropical con mayor estacionalidad y menor diversidad vegetal relativa) podría manifestar una diferenciación dietaria entre las clases de edad/sexo, no registrada en latitudes inferiores. Por su mayor estructura mandibular y su mayor tamaño corporal, los machos maduros podrían tener acceso a un mayor espectro de recursos tróficos, lo que haría esperar una mayor diversidad de especies incluidas en la dieta. Por su parte, los estadios juveniles tendrían preferencia por especies con mayor digestibilidad y menor contenido de compuestos secundarios y por aquellas que contengan mayor energía para el crecimiento. A su vez, los modelos nutricionales desarrollados para estimar abundancia de poblaciones de primates han considerado sólo estrategias alimentarias de clases de edad maduras (Ej. Oates et al. 1990, Ganzhorn 1992, Chapman et al. 2002) por lo que sería importante incorporar a las clases inmaduras, ya que son las que tienen más probabilidades de ser afectados por el estrés nutricional.

Una medida descriptiva de la diversidad de recursos alimentarios consumidos por un organismo es la amplitud de nicho trófico, la que puede ser interpretada como su grado de especialización (Pianka 1976), es decir una medida en que una especie consuma un espectro cada vez más reducido de los recursos disponibles de su ambiente, tenderá a ser más especialista y su nicho será más reducido (Levins 1968, Colwell y Futuyma 1971). Adicionalmente, si se dispone de información sobre la disponibilidad ambiental de recursos, la evaluación de la amplitud de nicho trófico podría informar sobre la reducción del espectro trófico en períodos de escasez de alimentos.

En los últimos años, el estudio de la Ecología nutricional ha buscado integrar aportes de la ecología, la nutrición, la etología, la morfología, la fisiología, la historia de vida y biología evolutiva, a fin de lograr una unificación conceptual de la disciplina (Raubenheimer et al. 2009, Raubenheimer 2011). Entre los marcos teóricos más satisfactorios para unificar la disciplina, se encuentra el marco teórico geométrico (geometric framework, según la denominación en inglés). Esta perspectiva es un marco teórico que permite explorar gráficamente los procesos que ocurren para que el organismo obtenga los nutrientes necesarios para el crecimiento mediante la ingesta de distintos tipos de alimentos (Simpson y Raubenheimer 1993, 1995, 1999, Raubenheimer y Simpson 1993, 1994, 1997, Raubenheimer 2011). En este marco teórico, los macronutrientes (proteínas, carbohidratos y lípidos) son representados como dimensiones de un espacio geométrico a través del cual la dieta del organismo describe una trayectoria en cada sesión de alimentación para alcanzar su objetivo de ingesta (intake target, según la denominación en inglés) (Simpson y 
Raubenheimer 1999, Righini 2014). Este proceso se encuentra condicionado por el contenido de macronutrientes, minerales y compuestos secundarios de los alimentos disponibles y la capacidad fisiológica del organismo para procesarlos (e.g.: desaminación, detoxificación). Dicho marco teórico ha sido aplicado para interpretar los patrones de selectividad de alimento en los primates, considerando factores como las variaciones de la disponibilidad de alimento, las defensas químicas de las plantas y el contenido de nutrientes (Lambert y Rothman 2015). El marco teórico geométrico podría constituir un marco teórico adecuado para analizar los patrones de selectividad de alimentos entre las diferentes clases de edad/sexo de los aulladores y respuestas a los cambios espacio-temporales de la disponibilidad de los alimentos.

En cuanto a las estructuras vegetales incluidas en la dieta, las hojas y los frutos representan recursos de calidad diferente, elementos complementarios cuya ausencia o disminución en la disponibilidad de uno u otro, podría resultar crítica para un adecuado balance alimentario. Por esto, el análisis discriminado del consumo de dichas estructuras, puede aportar claridad sobre cambios dietarios a lo largo de las estaciones del año y del gradiente latitudinal seleccionado. A su vez, el grado de asociación con variaciones en la densidad de los aulladores puede ayudar a comprender los factores relacionados con la determinación del límite sur de su distribución.

En referencia a aspectos metodológicos, la observación directa ha sido muy utilizada en estudios de dieta de animales (Chiarello 1998, Dwiyahreni et al. 1999), de hecho gran parte de los estudios de dieta de primates fueron realizados a través de este método (Cullen y Valladares Padua 1997). Sin embargo, este método encuentra dificultades para la observación de animales arborícolas que forrajean donde el dosel es denso, o para la identificación de especies cuando la composición de especies vegetales es compleja (Chiarello 1998, Jones y Krockenberger 2007). Por otro lado, el análisis de heces es considerada una técnica adecuada en ambientes de vegetación densa (Todd y Hansen 1973, Anthony y Smith 1974, Holechek y Vavra 1981, Ellis et al. 1999, Henley et al. 2001) y es utilizado comúnmente en estudios que evalúan el pastoreo por herbívoros terrestres (Norbury 1988ab, Horsup y Marsh 1992, De Boer et al. 2000, Mussa et al. 2003) y la dieta de herbívoros arborícolas diurnos o nocturnos como comadrejas y koalas (Fitzgerald 1984, Pahl 1987, Gaylard y Kerley 1997, Ellis et al. 1999), siendo mucho más escasos en estudios de primates (Bazzalo 2001, Santos et al. 2013). Una desventaja de este método es la digestión diferencial de las cutículas vegetales, por lo que algunas especies, o partes de plantas (ej.: flores) con cutículas frágiles no aparezcan en la muestras o sean subestimadas y especies con 
cutículas resistentes resulten sobre-representadas (Norbury 1988b, Jones y Krockenberger 2007). Lo mencionado anteriormente pone de manifiesto que una combinación de dichos métodos, podría resultar en una identificación más precisa de la composición de la dieta de los aulladores.

Finalmente, para comprender los factores que determinan los cambios en la composición de la dieta, un aspecto clave para considerar, es la relación entre los patrones de utilización de los recursos tróficos y su disponibilidad en el ambiente. Este aspecto, ha sido abordado desde diferentes perspectivas, entre las que se pueden citar estudios de adaptabilidad y selectividad trófica. La adaptabilidad trófica puede ser definida como la capacidad de un organismo para ajustar su dieta a las variaciones ambientales en cuanto a la disponibilidad de recursos (Trujillo Jiménez 2006, Felton et. al. 2009). Estos ajustes son logrados mediante la selectividad en el consumo de los recursos disponibles, pudiendo variar gradualmente entre las estaciones climáticas, así como también a lo largo de la distribución de una especie. Distintos estudios sobre la dieta de los aulladores evidenciaron que el consumo selectivo de un conjunto reducido de especies en relación con las que potencialmente podría consumir. En el extremo norte de su distribución geográfica (Veracruz-México), Alouatta palliata consumió 27 especies de las que sólo 5 (Ficus sp., Nectandra sp., Poulsenia sp., Brosimum sp. y Cecropia sp.) conformaron la mayor parte de la dieta (Estrada 1984). En latitudes tropicales, si bien se registró mayor cantidad de especies consumidas, (33-195 especies), entre 1 y 19 especies constituyeron la mayor parte de la dieta (Tabla I-2). Por lo dicho anteriormente, resulta interesante analizar si la selectividad dietaria de Alouatta caraya se asemeja a las cantidades mencionadas, en un gradiente latitudinal, que a su vez constituye el extremo sur de la distribución de los aulladores, y si la amplitud del nicho trófico en latitudes subtropicales, se relaciona con un deterioro del mismo.

\section{HIPÓTESIS Y PREDICCIONES}

A lo largo de la distribución geográfica más austral de Alouatta caraya, se observará un reducción de espectro trófico de esta especie en función de la menor disponibilidad de especies y estructuras vegetales hacia el sur del gradiente latitudinal.

-Teniendo en cuenta las diferencias en los requerimientos alimentarios entre las clases de edad y sexo de los aulladores y su alto grado de dimorfismo sexual, se predice que los machos maduros mantendrán nichos tróficos más amplios que las hembras maduras e 
individuos inmaduros y que su dieta se verá menos afectada por la reducción en la disponibilidad de recursos.

-Debido al aumento en la estacionalidad climática hacia el sur y su efecto sobre la disponibilidad de recursos, la variabilidad estacional en la dieta de los aulladores será mayor en los sitios ubicados más al sur.

\section{OBJETIVO}

Analizar el comportamiento trófico de Alouatta caraya a través del gradiente latitudinal ubicado en el extremo sur de su distribución poblacional, en relación a las variaciones en la disponibilidad estacional de los recursos alimentarios

\section{Objetivos específicos}

-Conocer el espectro de especies consumidas por Alouatta caraya y evaluar el aporte relativo de las especies más importantes de la dieta.

-Obtener datos sobre el consumo de recursos tróficos, mediante los métodos de observación directa, microhistología y macroscopía.

-Desarrollar una metodología adecuada para el análisis de muestras fecales de aulladores mediante las técnicas de microhistología y macroscopía.

-Estimar del grado de selectividad de las especies vegetales consumidas para folivoría y frugivoría.

-Calcular la similitud de la dieta de los aulladores entre los sitios, entre las estaciones climáticas y entre las categorías de edad/sexo.

-Determinar la amplitud del nicho trófico de Alouatta caraya por cada clase de edad/sexo en cada estación y sitio.

-Obtener un ordenamiento del cambio espaciotemporal de la disponibilidad de los recursos tróficos en el ambiente y de los ítems tróficos incluidos en la dieta.

-Determinar el grado de dependencia de las relaciones de similitud entre las muestras de dieta y las de disponibilidad de recursos. 


\section{MÉTODOS}

\section{Descripción de la composición de la dieta en base al uso de 3 métodos de análisis}

Para el estudio del comportamiento alimentario de los primates, usualmente se utilizan métodos de observación directa, como el de muestreo instantáneo de barrido, con el que se puede obtener la cuantificación del tiempo utilizado para el consumo de los ítems alimentarios (Altmann 1974, Martin y Bateson 1993). Algunas desventajas de este método es la necesidad de un elevado número de observaciones para que la muestra sea representativa, y la dificultad en el reconocimiento visual de la especie consumida, lo que conlleva una pérdida de información sobre la dieta (Bazzalo 2001).

Otro método, generalmente usado para especies herbívoras domésticas, folívoras de gramíneas y de hábito terrestre, es el análisis microhistológico que se basa en la identificación al microscopio de fragmentos vegetales de las heces y/o contenido estomacal (Baumgartner y Martin 1939, Dusi 1949). Por esto, poner a prueba su utilización para analizar la dieta de Alouatta caraya, resulta interesante dadas las particularidades asociadas a su condición de animal silvestre, folívoro-frugívoro y de hábito arborícola. Por otro lado, un método útil para conocer la dieta frugívora, es el análisis macroscópico de las heces, consistente en la identificación bajo lupa de semillas y frutos de cada muestra fecal.

Los análisis microhistológico y macroscópico de las heces posibilitan una determinación cuali-cuantitativa de la dieta del herbívoro, constatando el consumo de especies difíciles de registrar mediante observación directa. Una desventaja es que no se obtienen resultados de tiempos de manipulación del alimento por el animal ni la secuencia diaria de la ingesta.

Por lo mencionado anteriormente, la utilización combinada de los diferentes métodos, permitiría obtener una descripción más precisa de los recursos consumidos, y al mismo tiempo evaluar la complementariedad de los mismos.

A fin de calcular el aporte relativo de las especies más importantes de la dieta, se consideraron aquellas que sumadas, en orden de importancia, constituyeron más del $70 \%$ de la frecuencia de ocurrencia con cada método, y se compararon los resultados obtenidos por cada uno.

El estudio del comportamiento trófico de Alouatta caraya se realizó a través de muestreos mensuales comprendidos entre abril de 2007 y marzo de 2008 en los diferentes sitios del gradiente latitudinal (Tabla I-3). 


\section{OBSERVACIÓN DIRECTA}

Para obtener datos sobre el consumo de recursos tróficos, se realizaron observaciones desde el amanecer hasta el anochecer durante 3 días de muestreo por sitio, durante las campañas correspondientes a los 2 últimos meses de cada estación climática (Tabla I-3), en todo tipo de condiciones climáticas, a excepción de ocurrencia de lluvias torrenciales. Una vez visualizado un grupo de aulladores, se determinó su identidad mediante la composición de clases de edad/sexo y las características particulares de los individuos constituyentes, como se describe en el capítulo I y IV. Posteriormente, se iniciaron las observaciones empleando binoculares (Bushnell y Burries 10 x $42 \mathrm{~mm}$ ) mediante el método de muestreo instantáneo de barrido. Debido a que los aulladores dedican menos del $20 \%$ de su tiempo a la alimentación (Zunino 1986, Di Fiore 1997, Kowalewski 2007), los períodos de observación se restringieron únicamente a las sesiones de alimentación. A intervalos de aproximadamente 20 minutos, se registró la actividad general de forrajeo del grupo (manipulación e ingestión de alimento). Este criterio se basó en el hecho que los individuos dentro de un grupo generalmente tienden a consumir el mismo tipo de recurso durante cada sesión de alimentación (obs. pers.). Durante los barridos se tomó nota de la estructura vegetal (hoja, flor o fruto) de la especie consumida y, cuando fue posible, se realizó un registro fotográfico a fin de analizar con mayor detalle la estructura vegetal y la especie utilizada (Anexo 1). En el curso de un día de muestreo, se llegaron a observar hasta 5 grupos de aulladores. En total se registraron 288 sesiones de alimentación, de las cuales 75 fueron realizadas en Paranacito, 116 en Bella Vista, 97 en Lavalle (23 no se consideraron para los análisis por falta de detalle de la especie consumida o de la clase de edad/sexo del aullador).

A partir de esta información, se calculó la frecuencia de consumo de cada ítem alimenticio dividiendo el número de registros de consumo por el número total de observaciones realizadas en cada muestreo. El Anexo 4 detalla las frecuencias de ocurrencia en la dieta de cada especie, obtenidas con cada uno de los métodos.

De esta forma, el muestreo instantáneo de barrido permitió una aproximación al conocimiento de las especies vegetales consumidas, lo que fue útil al momento de colectar muestras de especies vegetales para emplear posteriormente en los análisis microhistológico y macroscópico de heces. 


\section{Colecta y tratamiento de muestras fecales para los métodos de microhistología y macroscopía}

En cada campaña de muestreo, entre el amanecer y el anochecer, se localizaron de 1 a 5 grupos de aulladores por día y se colectaron heces frescas en el momento de la deposición, procurando una colecta mínima de 5 muestras de individuos de diferente clase de edad y sexo. Las muestras fecales se conservaron dentro de recipientes herméticos individuales, con agregado de sal gruesa dada su propiedad desecante y antifermentativa.

En el laboratorio, cada una de las muestras fecales se disgregó en agua tibia dentro de un filtro para drenar el líquido y evitar la pérdida de fragmentos. Se clarificaron con hipoclorito de sodio ( $\mathrm{NaClO}$ ) diluido al $30 \%$ y se enjuagaron con abundante agua, siguiendo la técnica utilizada por Arriaga (1986). Luego fueron secadas en estufa durante 24 horas a 30 grados centígrados y conservadas en frascos cerrados (Bazzalo 2001).

\section{ANÁLISIS MICROHISTOLÓGICO DE HECES}

El entrenamiento necesario para la aplicación de este método fue realizado durante 6 meses en los laboratorios de Anatomía vegetal del MACN (Museo Argentino de Ciencias Naturales, del IBONE (Instituto de Botánica del Noreste) y de la FHUC-UNL (Facultad de Humanidades y Ciencias-Universidad Nacional del Litoral).

Para la realización de patrones anatómicos de identificación de las especies vegetales consumidas por Alouatta caraya, se utilizaron muestras de las especies del área de estudio, herborizadas y determinadas taxonómicamente (capítulo II).

La obtención de tejido epidérmico foliar, se realizó mediante una maceración suave, colocando las hojas de las plantas colectadas en vasos de precipitado, en una solución de hidróxido de potasio $(\mathrm{KOH})$ o de sodio $(\mathrm{NaOH})$ al $5 \%$ y calentando sobre llama (Dayanandan y Kaufman 1973). Luego se realizó un aclarado con hipoclorito de sodio $(\mathrm{NaClO})$ al $30 \%$, seguido por enjuagues con agua corriente y tinción rápida con safranina al $5 \%$.

Se empleó el método de diafanización de Dizeo de Strittmatter (1973), y las muestras de epidermis se fijaron en portaobjetos, utilizando como medio de montaje gelatina glicerinada con agregado de fenol para evitar la deshidratación y contaminación (D’Ambrosio de Argüeso 1986, Ullrich et al. 1996). Dichos preparados se observaron con un microscopio óptico Wild M20EB utilizando de 100 a 600 aumentos, y se añadió un cristal polarizado para observar la presencia de contenidos en el mesófilo. Se obtuvieron 
fotomicrografías mediante una cámara digital incorporada al microscopio. A partir de la información bibliográfica recabada y de las microfotografías se describieron los caracteres anatómicos de valor diagnóstico (Bazzalo 2001) de las especies consumidas por los aulladores con los que se elaboró un cuadro comparativo y una clave dicotómica (Anexo 2).

Se colectaron 813 muestras fecales, de las cuales en 587 se pudo distinguir a qué tipo de individuo correspondieron en cuanto a clase de edad y sexo. Se trabajó con estas últimas, considerando el sitio de la colecta, la estación climática, realizándose la mezcla de heces de individuos de igual clase para cada sitio a fin de obtener muestras compuestas, en base a la sugerencia de Bonvisutto y Borrelli (2007). De esta forma, se consiguieron 48 muestras compuestas, constituidas (un 70\% de las mismas) por 10 muestras fecales individuales cada una. Las muestras compuestas fueron sometidas a tinción suave con safranina y se preservaron en frascos con alcohol $70^{\circ}$. Los resultados de los análisis dietarios se compararon entre las estaciones climáticas (Tabla III-1).

Tabla III-1. Número de muestras fecales de Alouatta caraya, colectadas por mes y por estación, en 3 sitios de la selva de inundación del río Paraná Medio (Paranacito, Bella Vista y Lavalle) en el período abril 2007-marzo 2008.

\begin{tabular}{|c|c|c|c|c|c|}
\hline Estación & Mes/sitio & Paranacito & Bella Vista & Lavalle & Total \\
\hline \multirow{4}{*}{$\begin{array}{l}\text { Otoño } \\
21 \text { marzo-20 junio }\end{array}$} & Abril & 8 & 10 & 12 & 30 \\
\hline & Mayo & 24 & 12 & 19 & 55 \\
\hline & Junio & 14 & 22 & 26 & 62 \\
\hline & Subtotal & 46 & 44 & 57 & 147 \\
\hline \multirow{4}{*}{$\begin{array}{l}\text { Invierno } \\
21 \text { junio- } 20 \text { setiembre }\end{array}$} & Julio & 12 & 14 & 18 & 44 \\
\hline & Agosto & 14 & 20 & 11 & 45 \\
\hline & Setiembre & 14 & 19 & 16 & 49 \\
\hline & Subtotal & 40 & 53 & 45 & 138 \\
\hline \multirow{4}{*}{$\begin{array}{l}\text { Primavera } \\
21 \text { setiembre-20 diciembre }\end{array}$} & Octubre & 7 & 22 & 23 & 52 \\
\hline & Noviembre & 8 & 21 & 23 & 52 \\
\hline & Diciembre & 10 & 24 & 19 & 53 \\
\hline & Subtotal & 25 & 67 & 65 & 157 \\
\hline \multirow{4}{*}{$\begin{array}{l}\text { Verano } \\
21 \text { diciembre-20 marzo }\end{array}$} & Enero & 5 & 17 & 20 & 42 \\
\hline & Febrero & 18 & 16 & 19 & 53 \\
\hline & Marzo & 19 & 15 & 16 & 50 \\
\hline & Subtotal & 42 & 48 & 55 & 145 \\
\hline \multicolumn{2}{|c|}{ Total anual de heces } & 153 & 212 & 222 & 587 \\
\hline
\end{tabular}

Cada muestra compuesta fue homogeneizada por agitación, se tomó una alícuota y se colocó en un portaobjeto junto a un fijador de gelatina glicerinada (Arriaga et al. 2004), luego se cubrió con un cubreobjetos $(24$ x $48 \mathrm{~mm})$ y se dejó secar. Se obtuvieron así, 5 preparados por muestra con los que se efectuaron las lecturas microscópicas. Una vez montado el preparado al microscopio, se definieron 20 campos desplazando el portaobjeto de manera de cubrir la totalidad del preparado sin repetición de campos (Sparks y Malechek 
1968, Holechek y Gross 1982). Las lecturas se realizaron identificando el fragmento central de materia vegetal en cada campo, utilizando a 100 aumentos y mayores cuando fuese necesario. Para la identificación taxonómica, se utilizaron la clave dicotómica y el cuadro comparativo elaborado (Anexo 2). Se realizó la lectura de 100 campos para cada muestra compuesta $(\mathrm{N}=48)$, acorde a las combinaciones de clase de edad y sexo (4), estación climática (4) y sitio (3), totalizando 4800 lecturas microscópicas.

Se calculó la frecuencia absoluta (número de veces que se registró una determinada especie sobre un total de 100 campos analizados) y la frecuencia relativa (número de campos microscópicos donde está presente cada especie sobre la sumatoria del número de campos microscópicos donde están presentes cada una de las especies) (Holechek y Gross 1982).

\section{ANÁLISIS MACROSCÓPICO DE HECES}

El análisis macroscópico se llevó a cabo mediante la cuantificación y determinación taxonómica de las semillas encontradas en cada una de las muestras fecales procesadas (Anexo 4). Para dicho objetivo, se realizó previamente una colección de referencia de semillas extraídas de muestras provenientes de las especies vegetales del área de estudio. Para la identificación de los frutos consumidos se utilizó material bibliográfico y especímenes del herbario del MACN, del IBONE y de la Facultad de Ciencias Agrarias de la Universidad Nacional del Litoral.

Se revisó bajo lupa cada una de las muestras fecales recolectadas extrayendo todas las semillas con pinzas de disección, las cuales fueron identificadas individualmente al mínimo nivel taxonómico posible (Anexo 3).

Las semillas que no pudieron ser identificadas bajo lupa fueron inducidas a germinación en el laboratorio del IBONE, a fin de procurar su determinación taxonómica una vez obtenida la plántula. Para esto, se ensayaron diferentes técnicas dependiendo del tipo de semilla utilizando un promedio de 20 semillas por especie. En algunas se practicaron escarificaciones superficiales con papel de lija fina y/o incisiones con bisturí para luego ubicarlas en cápsulas de Petri con un sustrato húmedo de germinación, constituido por una capa delgada $(1 \mathrm{~cm})$ de musgo (Sphagnum $\mathrm{sp}$.), o una capa de algodón de 0,5 $\mathrm{cm}$ de grosor y papel secante sobre la misma.

Las cápsulas fueron colocadas en cámara de germinación bajo condiciones ambientales estériles, de luz, humedad y temperatura controladas, durante un período de $1 \mathrm{a}$ 5 meses, dependiendo del cuadro germinativo presentado por cada especie. Las plántulas 
obtenidas fueron colocadas en potes plásticos con tierra fértil y trasladadas a vivero, donde fueron regadas cada 24 horas con agua y mantenidas bajo condiciones de luz y temperatura ambiente (Figura III-1).

A partir de los registros de semillas en las heces, se calculó la frecuencia de ocurrencia de cada especie para cada grupo de muestras de clases de edad/sexo, estación y sitio. Se obtuvo la proporción de heces sin y con semillas, y sobre este último conjunto de datos se calcularon la frecuencias de ocurrencia de cada una de las especies.

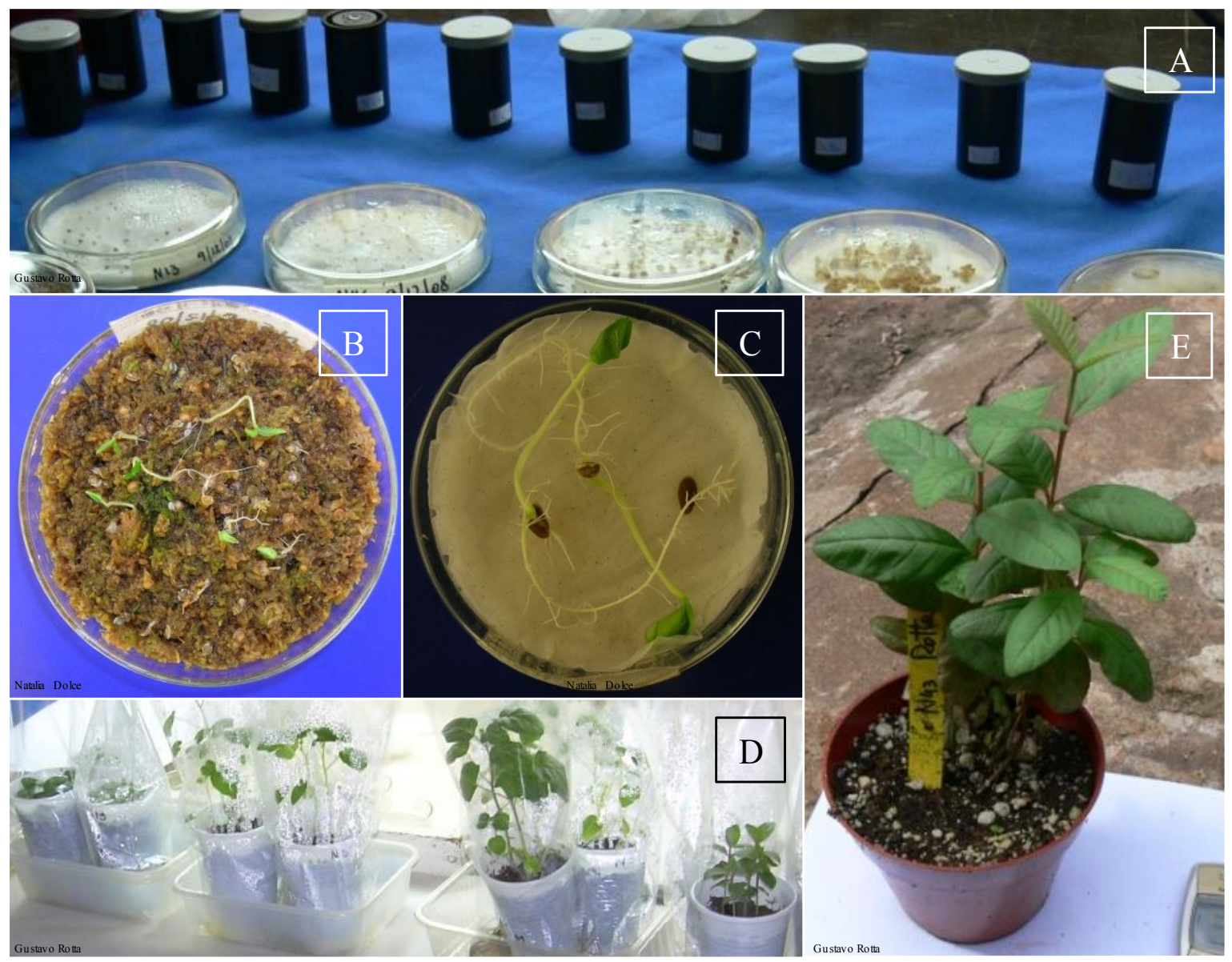

Figura III-1. Semillas extraídas de muestras fecales de Alouatta caraya, dispuestas en recipientes herméticos (A), cápsulas de Petri con sustrato de Sphagnum sp. (B) y algodón/papel secante (C) en cámara de germinación (D) y en macetas con tierra fértil en vivero (E).

\section{ANÁLISIS DE DATOS}

\section{Amplitud de nicho trófico}

A partir de las frecuencias de ocurrencia de las especies vegetales obtenidas en los análisis microhistológico y macroscópico de las heces, se estimó la amplitud del nicho trófico utilizando el índice de Levins (1968): 


$$
\mathrm{B}^{\prime}=\frac{1}{\sum p_{i}{ }^{2}}
$$

Dónde $p_{i}$ es la proporción de la iésima especie en la dieta.

Parar determinar los efectos de los sitios, la estacionalidad y las clases de edad/sexo sobre la variable amplitud de nicho se realizó un ANOVA de 3 vías sin réplica. El ANOVA sin réplica impide la evaluación de todos los tipos de interacciones potenciales entre estos tres factores (Sokal y Rohlf 1979), por este motivo, de acuerdo con la hipótesis de que el cambio en la amplitud de nicho no es la misma para los diferentes sitios, se evaluó la interacción sitio x estación. Las restantes interacciones: sitios x clases de edad/sexo y estación x clase de edad/sexo no fueron consideradas en los análisis. Finalmente, se realizaron test a posteriori para comparar la amplitud de nicho entre las diferentes estaciones dentro de cada sitio.

\section{Variación espaciotemporal de la dieta}

Para comparar la dieta de los aulladores entre los sitios, entre las estaciones climáticas y entre las categorías de edad/sexo (Somlo et al. 1992, Somlo et al. 1994), se calculó el índice de Bray-Curtis (1957) a partir de las frecuencias de ocurrencia de las especies vegetales obtenidas en los análisis microhistológico y macroscópico. A partir de estos resultados, se elaboraron dendrogramas de similitud mediante el método de promedios no ponderados de pares de grupos (UPGMA, según la denominación en inglés), cuyos nodos obtuvieron una significancia estadística determinada por el método de remuestreo de Bootstrap (Felsenstein 1985). Esto consiste en crear una matriz de datos cuyas columnas se van cambiando de forma aleatoria, e incluso se repiten en una misma matriz, y de cada una de las matrices resultantes se crea un árbol, contando al final en cuántos de ellos aparece el nodo a estudiar. Este proceso fue repetido 1000 veces, obteniéndose el porcentaje de veces en que cada nodo del árbol se presentó en las matrices remuestreadas. Al final, todos estos árboles se resumen en uno que representa un consenso donde aparecen los porcentajes de la proporción de cada réplica. Así, si una rama presenta más del 50\% indica que ésta es fiable (Soltis y Soltis 2003).

\section{Selectividad en la dieta}

Como primer índice de selectividad alimentaria se utilizó una prueba de Bondad de ajuste de Chi cuadrado comparando el grado en el cual las abundancias relativas de las especies vegetales en la dieta diferían de aquellas encontradas en el ambiente. La abundancia relativa 
de las especies registradas en las muestras fecales (obtenidas por microhistología y macroscopia de heces) fueron consideradas frecuencias observadas, y las frecuencias esperadas (bajo la hipótesis nula de no selectividad) fueron calculadas partir de las abundancias relativas de las especies vegetales en el ambiente de la siguiente manera:

$$
\text { Abundancia relativa }=N_{i} \times A B_{i} \times \frac{I F_{i}}{N t s p} \times \text { ABt } x \text { IFt } \times \mathrm{Ntm}_{i}
$$

Dónde:

$N_{i}$ : número de individuos de la especie $i$

Ntsp: número total de especies $A B_{i}$ : área basal de la especie $i$ ABt: área basal total $I F_{i}$ : índice fenológico de la especie $i$ IFt: índice fenológico total de especies $\mathrm{Ntm}_{i}$ : número total de campos microscópicos o de semillas en muestras fecales

La estimación del grado de selectividad de las especies vegetales consumidas para folivoría y frugivoría se realizó por comparación de las frecuencias de ocurrencia de tejidos foliares y de semillas en las heces, con la abundancia de las especies en el ambiente, utilizando el índice de selectividad IVLEV (Lechowicz 1982) modificado para incluir el índice fenológico estacional promedio de la especie bajo análisis, como sigue:

$$
I V L E V i=\frac{\left(D_{i}-P_{i} \times I F\right)}{\left(D_{i}+P_{i} \times I F\right)}
$$

Dónde:

$P_{i}$ : porcentaje de la especie $i$ en el ambiente

$D_{i}$ : porcentaje de la especie $i$ en la dieta (campos microscópicos o muestras fecales analizadas)

El índice fenológico (IF) de la especie $i$ (índice subjetivo que varía de 0 a 4 , donde 0 implica la ausencia de la fenofase y 4 la representación máxima de la misma), permite estimar la abundancia de la fenofase de cada especie, representando un índice más adecuado de la disponibilidad de alimento.

El rango de valores de IVLEV fue dividido en tres secciones iguales que indicaron rechazo, no selectividad y preferencia, como sigue:

-de -1 a -0.33: cuando la proporción de la especie $i$ consumida fue inferior a la encontrada en el ambiente, indicando selectividad negativa o rechazo al consumo de dicha especie. 
-de -0.33 a 0.33: cuando la proporción de la especie $i$ consumida fue similar a la encontrada en el ambiente, indicando no selectividad al consumo de dicha especie.

-de 0.33 a 1 : cuando la proporción de la especie $i$ consumida fue superior a la encontrada en el ambiente, indicando selectividad positiva o preferencia al consumo de dicha especie.

Mediante las observaciones microhistológicas y macroscópicas de las estructuras de hojas y frutos de las especies estudiadas y las referidas en la literatura, se reunieron características favorables para su consumo. En el caso de las hojas, se consideró la rápida regeneración del follaje asociada al menor contenido de compuestos secundarios (Estrada 1984), la baja cantidad de tricomas y de cristales, y un menor grosor de la cutícula. A su vez, entre las características favorables para la frugivoría, se consideró la coloración llamativa (rojo, naranja, verde y negro brillante), la mayor carnosidad y el menor tamaño de las semillas (Julliot 1996ab).

\section{Variación espaciotemporal de la disponibilidad de los recursos tróficos y la composición de la dieta}

Para obtener un ordenamiento del cambio espaciotemporal de la disponibilidad de los recursos tróficos en el ambiente y de los ítems tróficos incluídos en la dieta, se aplicó un análisis de correspondencias (Benzécri 1973). Éste es un método de ordenamiento basado en la distancia de Chi cuadrado que ofrece una buena representación de las distancias entre las muestras cuando las especies exhiben distribuciones unimodales y gradientes largos (es decir, gran recambio de especies entre las muestras) (Legendre y Gallagher 2001). Sin embargo, un problema con el análisis de correspondencias es que las especies raras tienen efectos desproporcionados sobre los grandes resultados de ordenación (Legendre y Legendre 1998). Para evitar esto, se utilizó el método empírico de ponderación de las especies raras (Down-weighing) que ofrece el programa CANOCO (Ter Braak y Smilauer 2012).

\section{Asociación entre la disponibilidad de recursos y la composición de la dieta}

A fin de determinar el grado de dependencia de las relaciones de similitud entre las muestras de dieta y de disponibilidad de recursos, se realizó un test de Mantel (Mantel 1967). Este test permite medir la correlación entre dos matrices cuadradas obtenidas a partir de una medida de similitud, y en este contexto, se pudo determinar el grado de asociación entre la composición de la dieta y la disponibilidad de recursos tróficos.

El valor de significancia de la correlación del test de Mantel se obtuvo mediante la permutación aleatoria de los valores de las filas y las columnas de cada una de las matrices 
para luego calcular un índice de correlación. Este proceso fue repetido 1000 veces para obtener la distribución de probabilidades de los coeficientes de correlación entre ambas matrices esperadas por azar. Finalmente, el valor de $p$ se consiguió comparando el coeficiente obtenido entre las matrices reales con la distribución de probabilidades obtenida mediante el método de permutación (Legendre 2000).

Si la correlación entre ambas matrices resulta significativa, indica que las variaciones en la composición de la dieta ocurren en la misma dirección que las variaciones en la composición de recursos alimentarios en el ambiente. Es decir, que aquellos pares de muestras que son más similares en la dieta, también lo son en el ambiente, y aquellos pares de muestras que son más diferentes en la dieta, también lo son en el ambiente.

\section{RESULTADOS}

\section{Descripción de la composición de la dieta en base al uso de 3 métodos de análisis}

Se evidenció el consumo de un total de 36 especies, de las cuales 28 aportaron hojas, 18 aportaron frutos y 4 especies aportaron flores. La dieta folívora incluyó a 19 familias, de las cuales, las más importantes fueron la familia Fabaceae (5 especies), Sapindaceae (3 especies), Lauraceae ( 2 especies) y Flacourtiaceae ( 2 especies). La dieta frugívora incluyó 15 familias, resultando con mayor representación las familias Fabaceae, Lauraceae y Flacourtiaceae, con el registro de 2 especies cada una. El consumo de flores involucró a 4 familias distintas: Fabaceae, Lauraceae, Flacourtiaceae y Euphorbiaceae, con el aporte de una especie cada una. Los resultados arrojados por los 3 métodos mostraron diferencias en la proporción de las especies más importantes, es decir aquellas que conforman el $70 \%$ de los registros dietarios (Figura III-2 y Anexo 4). 


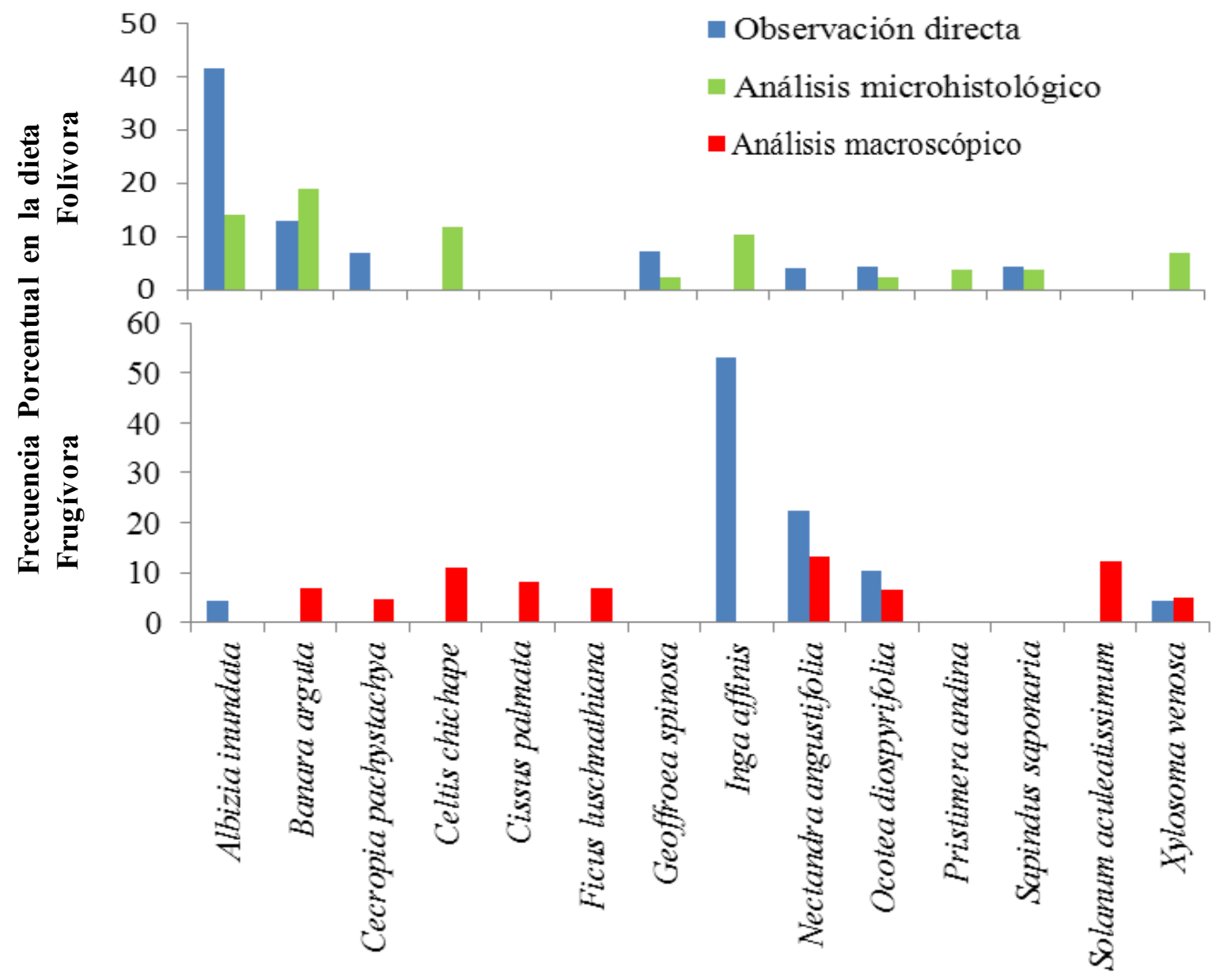

Figura III-2. Frecuencia relativa porcentual de especies componentes del 70\% de la dieta folívora y frugívora de Alouatta caraya determinada por observación directa, análisis microhistológico y macroscópico de heces, en el área de estudio, ubicada en la selva de inundación del río Paraná Medio, en el período abril 2007-marzo 2008.

\section{OBSERVACIÓN DIRECTA}

Se obtuvieron 288 registros de alimentación, en 23 de los cuales no se pudo reconocer la estructura vegetal consumida, resultando 265 los registros completos y útiles para el análisis: 68 correspondieron a Paranacito, 108 a Bella Vista y 89 a Lavalle. Se observó el consumo total de 22 especies (2 No identificadas), 20 de las mismas aportaron hojas, 8 frutos y 4 flores (Anexo 4).

El aporte a la mayor parte de la dieta folívora-frugívora (70\%), estuvo conformada por 4 a 5 especies en toda el área (Figura III-2). Así, para el consumo de hojas, las especies más importantes, en orden decreciente, fueron para Paranacito: Albizia inundata y Geoffroea spinosa, Ocotea diospyrifolia y Sapindus saponaria, para Bella Vista: A. inundata, Banara arguta y Cecropia pachystachya, y para Lavalle: A. inundata, B. arguta y Nectandra angustifolia. En cuanto al consumo de frutos en Paranacito se reportó mayor consumo de $O$. 
diospyrifolia, en Bella Vista de Inga affinis seguida por A. inundata y Xylosma venosa, y en Lavalle las más consumidas fueron Inga affinis y N. angustifolia con valores similares (Anexo 4).

El promedio de tiempo destinado a la alimentación con diferentes estructuras vegetales fue de 74,7 \% para las hojas, 17,7 para los frutos y de 7,6 para las flores. Las frecuencias relativas de consumo de las diferentes estructuras alimentarias, en los 3 sitios de estudio, reflejaron un descenso de $86,7 \%$ a $65,2 \%$ en el consumo de hojas y un incremento del $7,3 \%$ al $28,1 \%$ en el consumo de frutos hacia latitudes superiores, mientras que el consumo de flores fue similar a lo largo del gradiente latitudinal, variando entre 5,8 y 10,2 (Figura III-3).

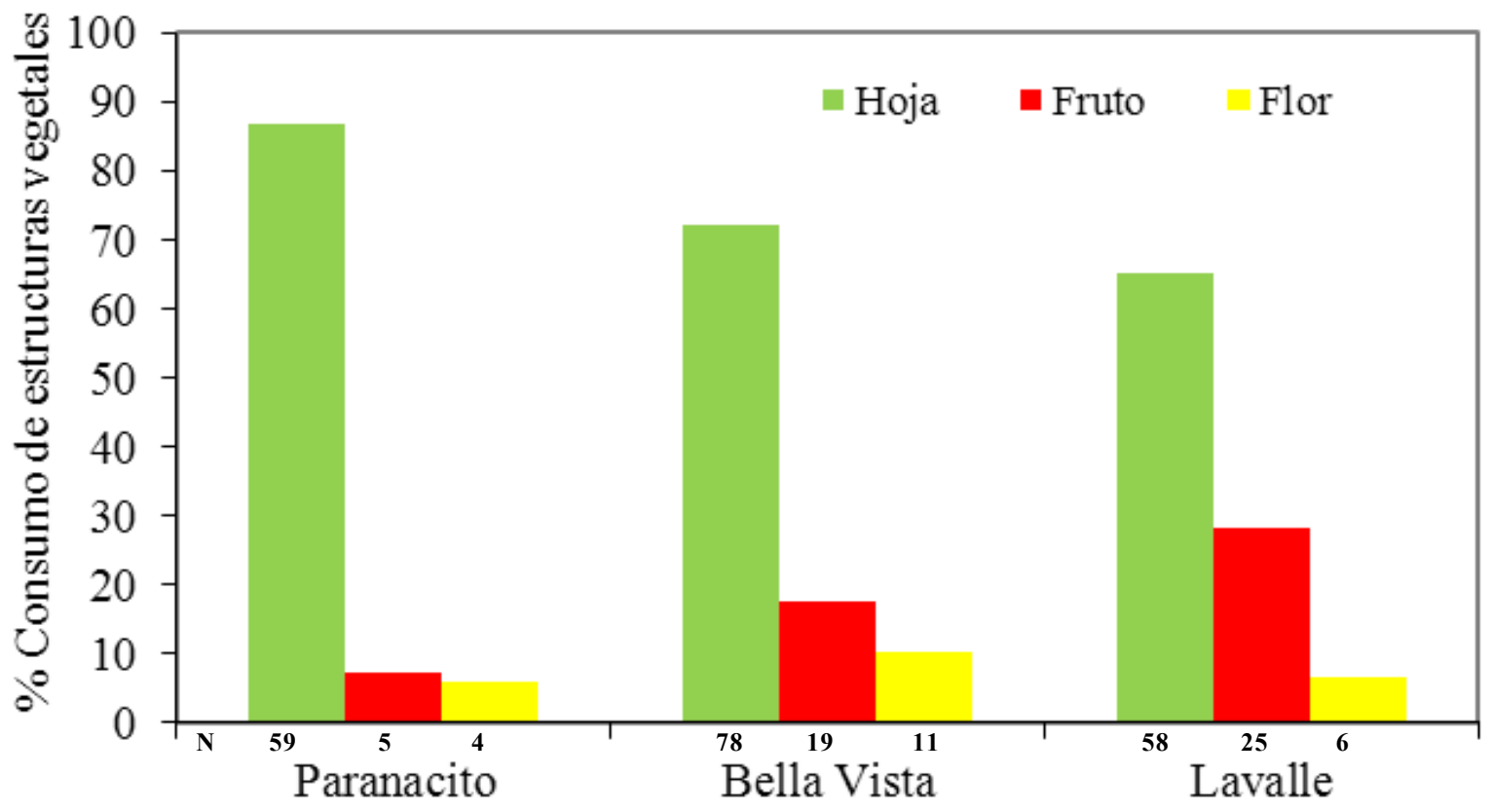

Figura III-3. Consumo porcentual y absoluto (N) anual de estructuras vegetales por Alouatta caraya, registrado por observación directa $(\mathrm{N}=265)$, en 3 sitios de la selva de inundación del río Paraná Medio (Paranacito, Bella Vista y Lavalle) en el período abril 2007-marzo 2008.

\section{Colecta, tratamiento de muestras fecales para los métodos de microhistología y macroscopía}

De las 813 muestras fecales colectadas, 587 fueron analizadas con el método microhistológico de heces debido a que en el resto no se pudo definir sin ambigüedades la clase de edad/sexo. A su vez, mediante el método macroscópico de heces, se utilizaron tanto las muestras con clase de edad/sexo definida, como la totalidad de las mismas. Cabe señalar que todas las clases de edad/sexo, estuvieron generalmente representadas por más de 5 heces por estación climática, quedando sólo un pequeño número de clases, representadas con un mínimo de 3 muestras fecales. 


\section{Amplitud del nicho trófico}

De acuerdo a los resultados del ANOVA de 3 vías, los factores sitio y clase de edad/sexo no mostraron efecto significativo sobre la variable amplitud de nicho. Por su parte, la variable estación mostró un efecto significativo sobre la amplitud de nicho, y también se observó un término de interacción sitio x estación significativo (Tabla III-2). Se observó un aumento significativo de la amplitud del nicho trófico en el verano respecto del invierno y la primavera, presentando el otoño valores intermedios entre éstos (Figura III-4). Estos resultados indican que la variación estacional no ocurre de la misma manera entre los sitios.

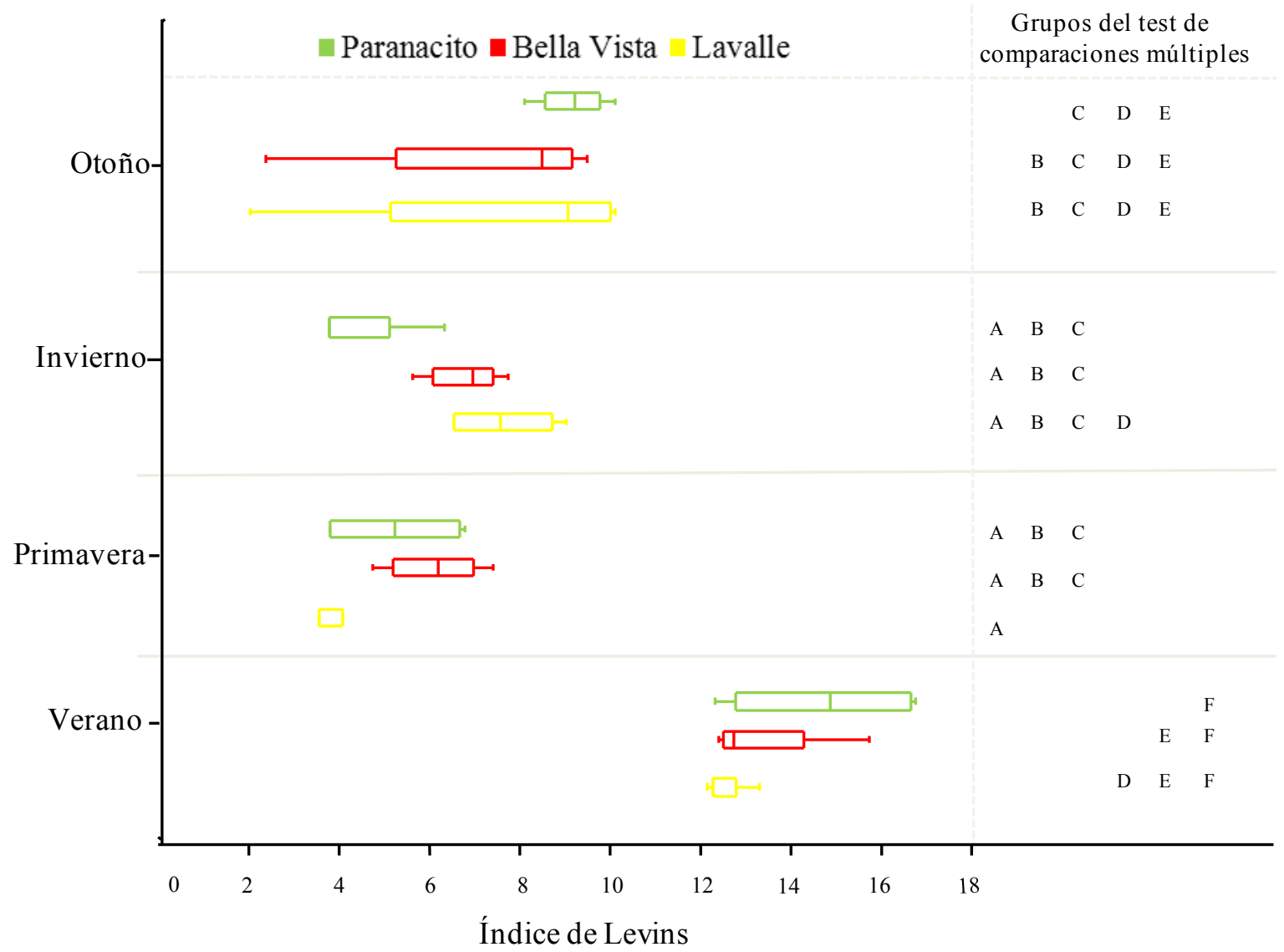

Figura III-4. Amplitud del nicho trófico estacional y latitudinal de individuos de diferentes clases de edad y sexo de Alouatta caraya en 3 sitios de la selva de inundación del río Paraná Medio (Paranacito, Bella Vista y Lavalle) en el período abril 2007-marzo de 2008. Referencias: Test de Tukey: letras diferentes (A, B, C, D, E, F) indican diferencias significativas entre los grupos $(p<0.05)$.

Tabla III-2. Amplitud de nicho trófico de distintas clases de edad/sexo de Alouatta caraya en 3 sitios de la selva de inundación del río Paraná Medio (Paranacito, Bella Vista y Lavalle) en 4 estaciones climáticas comprendidas en el período abril 2007-marzo 2008, según ANOVA. Referencias: GL: Grados de Libertad.

\begin{tabular}{lccccc}
\hline Variable & GL & Suma cuadrados & Cuadrado medio & F de Fisher & $\boldsymbol{p}$ \\
\hline Sitio & 2 & 0,84 & 0,42 & 0,12 & 0,89 \\
Estación & 3 & 466,56 & 155,52 & 44,35 & $<\mathbf{0 . 0 0 0 1}$ \\
Clase edad/sexo & 3 & 9,54 & 3,18 & 0,907 & 0,45 \\
Sitio x Estación & 6 & 51,51 & 8,58 & 2,45 & $\mathbf{0 , 0 4 5}$ \\
\hline
\end{tabular}




\section{ANÁLISIS MICROHISTOLÓGICO DE HECES}

Se identificó un consumo total de hojas de 27 especies, observándose que la mayor parte de la dieta folívora (70\%) estuvo representada por 5 a 8 especies en toda el área, destacándose el consumo común de Albizia inundata, Banara arguta, Celtis chichape e Inga affinis (Figura III-2).

Los aulladores de Paranacito utilizaron 27 especies (3 No identificadas), entre las que Albizia inundata sobresalió como la especie más consumida, seguida por Pristimera andina, Sapindus saponaria, Celtis chichape. En Bella Vista consumieron 20 especies (3 No identificadas), con Banara arguta como especie más importante, seguida por Albizia inundata y otras. Los aulladores de Lavalle usaron como recurso trófico a 18 especies (2 No identificadas), de las que B. arguta se destacó sobre las demás, y fue seguida en orden de importancia por C. chichape, A. inundata (Anexo 4).

\section{Variación espaciotemporal en la composición de la dieta folívora}

La prueba de Bondad de ajuste de Chi cuadrado, arrojó diferencias estadísticamente significativas entre la frecuencia de especies vegetales consumibles en el ambiente y la frecuencia de estas especies registradas en las muestras fecales para cada uno de los 3 sitios: -Paranacito: $\chi 2=105781,03(p<0.001, \mathrm{~N}=21, \mathrm{GL}: 20)$

-Bella Vista: $\chi 2=50063,74(p<0.001, \mathrm{~N}=15$, GL:14)

-Lavalle: $\chi 2=63191,83(p<0.001, \mathrm{~N}=17$, GL:16)

El índice de selectividad IVLEV puso de manifiesto que de las 23 especies vegetales analizadas, 12 fueron seleccionadas positivamente, 6 alternaron entre positiva y negativamente dependiendo del sitio y la estación, 3 tuvieron una selección general con tendencia negativa y 2 especies fueron consumidas de manera no selectiva en relación a su disponibilidad en distintos sitios del gradiente (Figura III-5).

La mayoría de las especies con selectividad positiva, presentaron características consideradas favorables para el consumo (por ej. cutícula delgada, rápida regeneración de follaje, bajo contenido de tricomas y de cristales), como Banara arguta, Xylosma venosa, Celtis chichape, Nectandra angustifolia, Albizia inundata, Geoffroea spinosa, Sapindus saponaria, Ocotea diospyrifolia. Este tipo de relación resultó inconsistente con un grupo de especies, como Peltophorum dubium, Stigmaphyllom bonariense, Ipomoea cairica, Eugenia moraviana, Erythrina crista galli y Paullinia elegans. 
En cuanto a las especies que no mostraron un patrón claro de selectividad, se observó una variación estacional en la selectividad coincidente probablemente con el desarrollo fenológico de las especies (excepto Stigmaphyllom bonariense). Por ejemplo, para algunas especies se observaron índices de selectividad similares entre las estaciones de otoño e invierno por un lado, y primavera y verano por otro lado (ej. Ipomoea cairica, Eugenia moraviana, Paullinia elegans). Para otras especies se observaron patrones de selectividad opuestos en diferentes sitios (ej. Erythrina crista galli, Salix humboldtiana). Finalmente, se observó que el grupo de especies con características consideradas no favorables para el consumo (por ej. cutícula gruesa, alto contenido de tricomas y cristales) fue seleccionado negativamente (Phyllantus chacoensis, Machaonia brasiliensis, Tessaria integrifolia, S. humboldtiana, Croton urucurana y Guadua sp.) (Figura III-5).

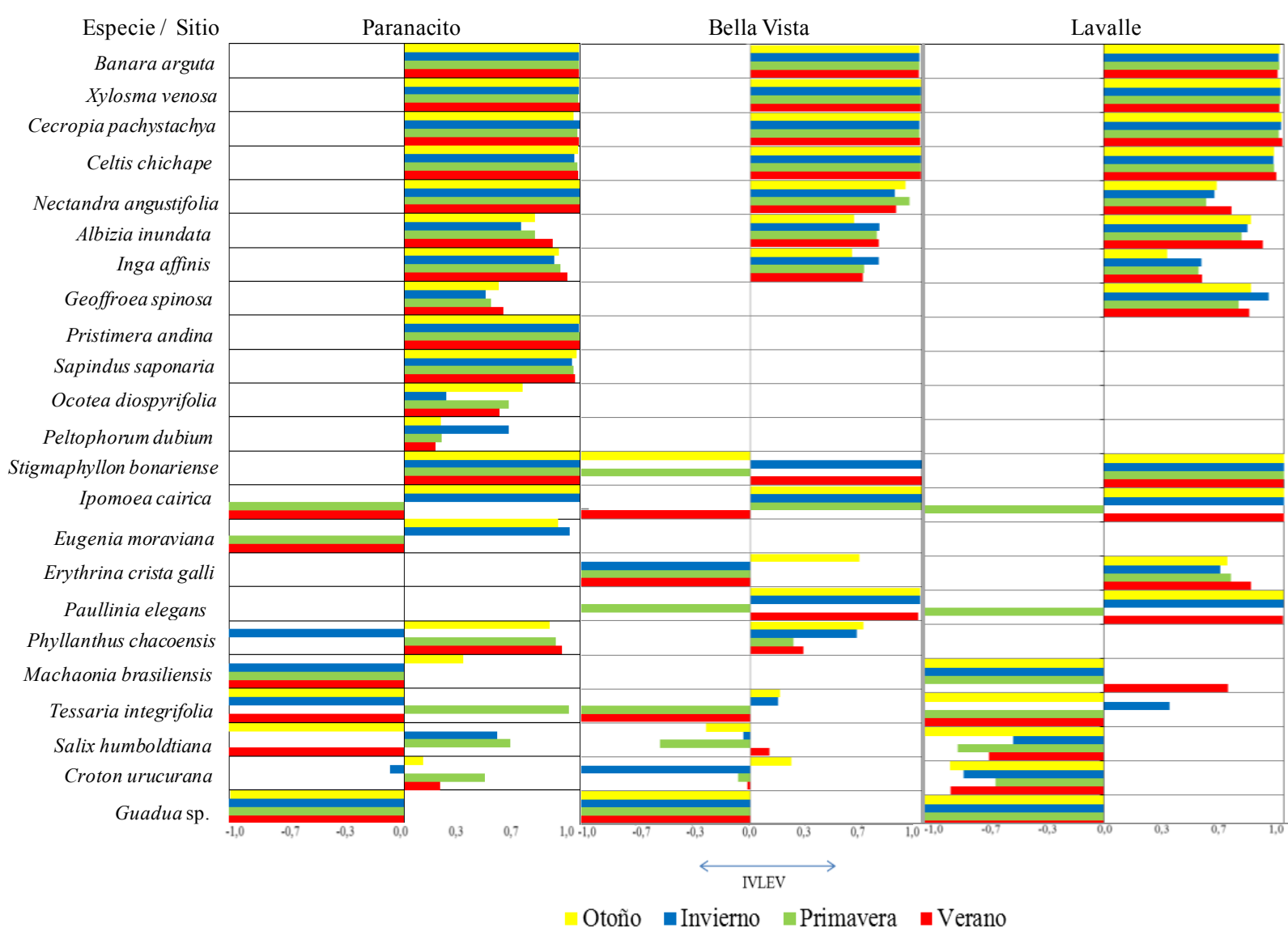

Figura III-5. Selectividad estacional y latitudinal de 23 especies componentes de la dieta folívora de Alouatta caraya en 3 sitios de la selva de inundación del río Paraná Medio (Paranacito, Bella Vista y Lavalle) en el período abril 2007-marzo 2008. Referencias: -1 a -0,33: selectividad negativa, -0,33 a 0,33: no selectividad y 0,33 a 1: selectividad positiva.

\section{Variación espaciotemporal de la dieta folívora}

En los dendrogramas construidos a partir de la composición de la dieta folívora de Alouatta caraya se puso de manifiesto una similitud relativamente alta con la mayoría de los nodos 
ocurriendo entre un $75 \%$ y un $80 \%$. Se observó una mayor similitud entre muestras de diferentes estaciones del mismo sitio, que entre estaciones similares de diferentes sitios. Es decir que las muestras se agruparon primero por sitio y luego por estación climática. Bella Vista y Lavalle resultaron más similares entre sí (77\%), diferenciándose de Paranacito (54\%). Dentro de cada sitio no se observó un patrón claro de similitud entre las estaciones: En Paranacito y Bella Vista las estaciones más similares fueron el verano y la primavera, mientras que en Lavalle lo fueron el otoño y el invierno. La estación más diferente de las restantes fue distinta en cada sitio (Figura III-6).

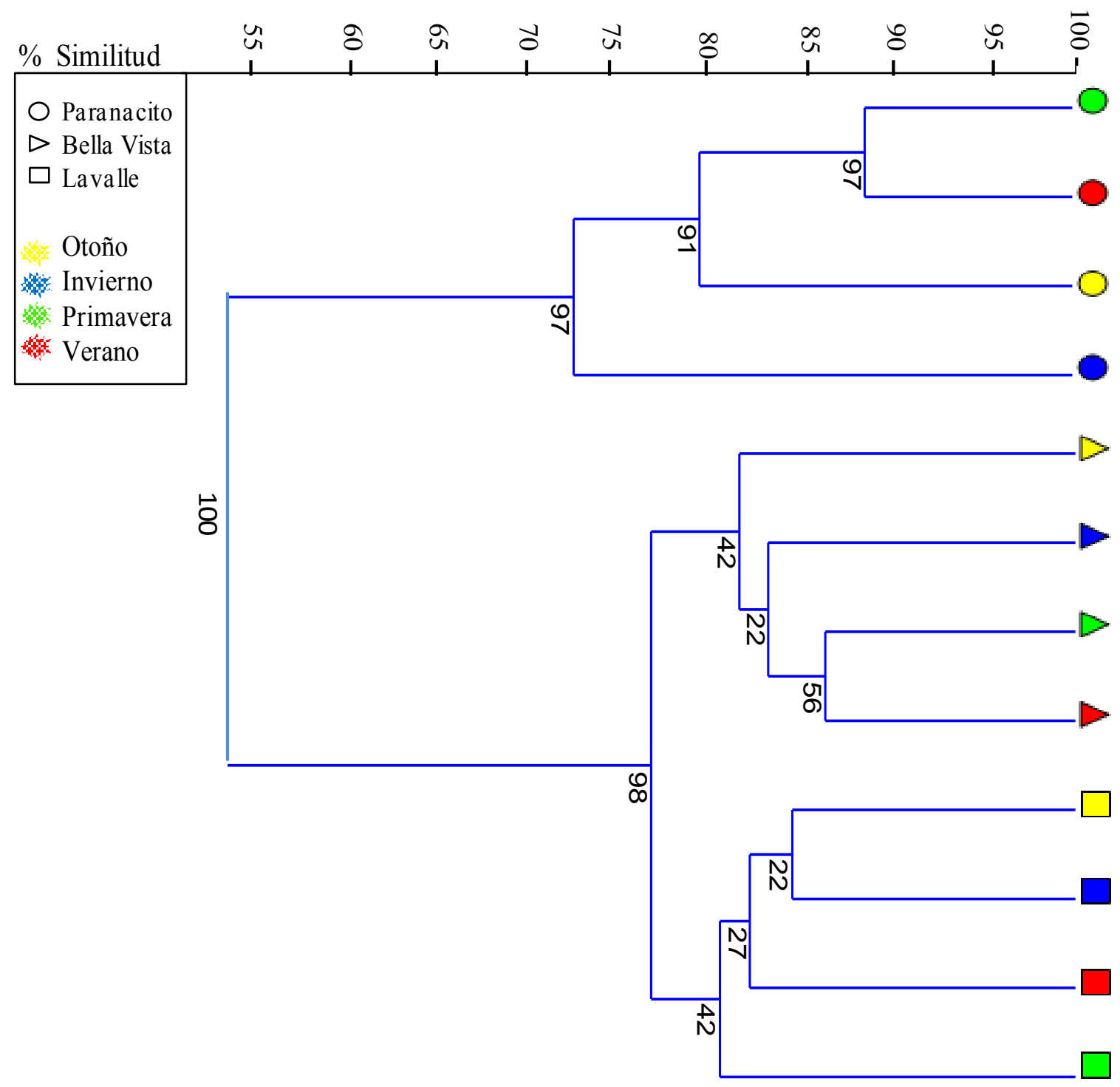

Figura III-6. Dendrograma de similitud porcentual por UPGMA obtenido mediante el índice de BrayCurtis para la dieta folívora estacional de Alouatta caraya en 3 sitios de la selva de inundación del río Paraná Medio (Paranacito, Bella Vista y Lavalle) en el período abril 2007-marzo 2008. Referencias: número debajo de nodos: valores de bootstrap-porcentaje de remuestreos que sustentan el grupo (Felsenstein 1985). 


\section{Variación espaciotemporal de la dieta folívora entre clases de edad/sexo}

El análisis de agrupamiento de la dieta folívora dentro de cada sitio permitió observar que la estación climática es un factor más importante en las relaciones de similitud, que la clase de edad/sexo, es decir que, en líneas generales, las muestras se agruparon primero por estación y después por clases de edad/sexo. Las muestras correspondientes a las diferentes clases de edad/sexo en cada estación climática, presentaron un nivel de similitud menor en Paranacito (65\%) que en Bella Vista y Lavalle (77\%). Dentro de cada estación no se observó un patrón claro en las relaciones de similitud entre las diferentes clases de edad/sexo. Es decir, que las variaciones de la dieta entre los individuos, resultarían independientes de las clases de edad/sexo (Figura III-7). 


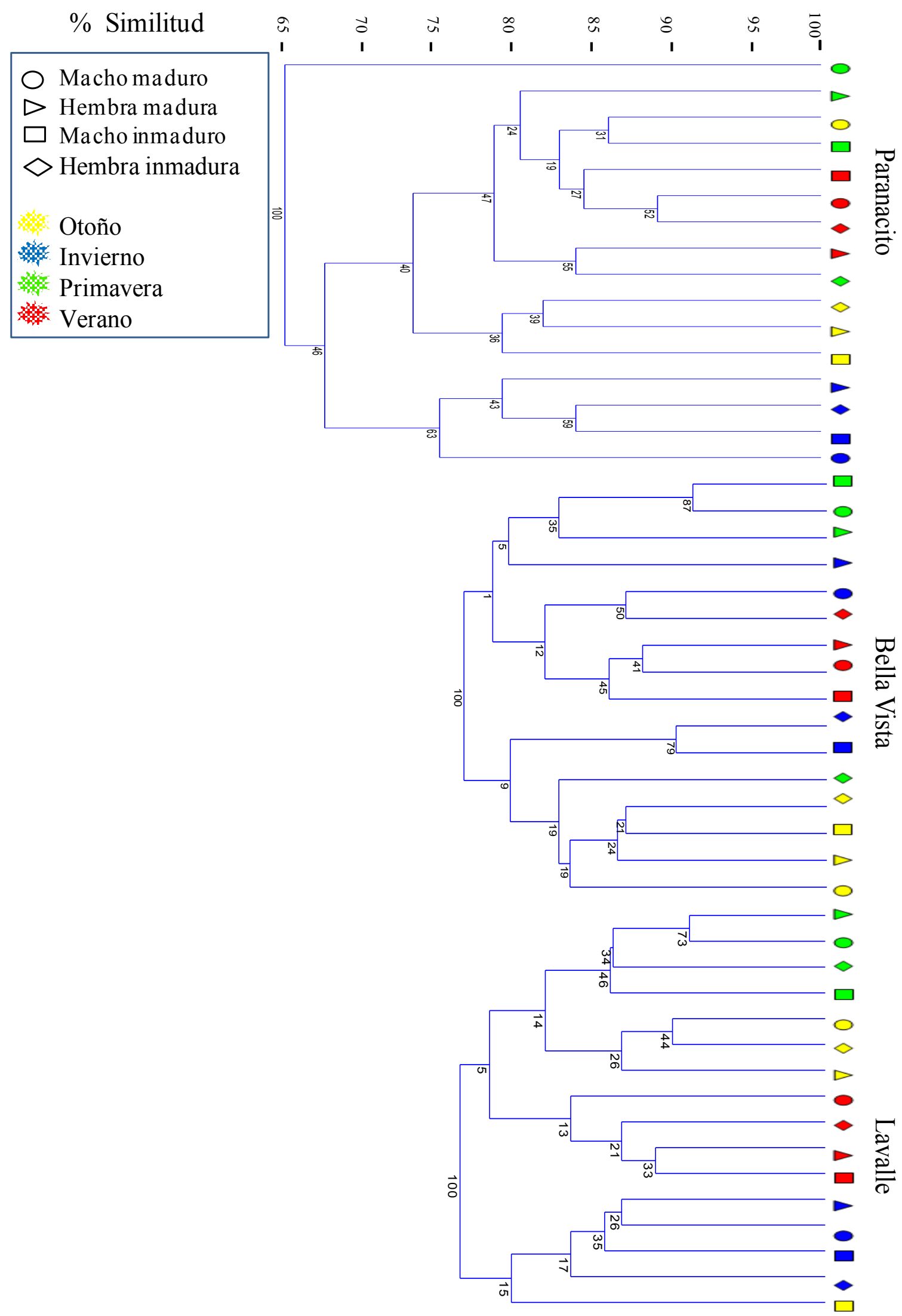

Figura III-7. Dendrograma porcentual de similitud por UPGMA obtenido mediante el índice de Bray-Curtis para la dieta folívora estacional entre clases de edad y sexo de Alouatta caraya en 3 sitios de la selva de inundación del río Paraná Medio (Paranacito, Bella Vista y Lavalle) en el período abril 2007-marzo 2008. Referencias: número debajo de nodos: valores bootstrap-porcentaje de remuestreos que sustentan el grupo (Felsenstein 1985). 


\section{ANÁLISIS MACROSCÓPICO DE HECES}

Se identificó el consumo de frutos de 17 especies, incluyendo a 11 especies en Paranacito, 14 especies en Bella Vista y 11 especies en Lavalle. La mayor parte de la dieta frugívora (70\%) estuvo conformada por: 7 especies en Paranacito, 6 especies en Bella Vista y 5 especies en Lavalle (Figura III-2), resultando las familias Lauraceae y Flacourtiaceae las mejor representadas, con 2 especies cada una (Anexo 4).

\section{Variación espaciotemporal de la frugivoría}

El 45,3\% (460) del total de muestras fecales (813) analizadas presentaron semillas, resultando su frecuencia de ocurrencia mayor en las estaciones de verano y otoño, y menor durante el invierno y la primavera. A su vez, en Lavalle, al sur del gradiente estudiado, se presentó menor cantidad de semillas en las muestras fecales, y durante un período más prolongado que en los sitios ubicados más al norte. De esta forma, se evidenciaría una disminución general de la cantidad heces con semilla detectada por macroscopía en el sur, pasando de porcentajes similares en Paranacito y Bella Vista a $12 \%$ menos de muestras fecales con semillas en Lavalle (Figura III-8).

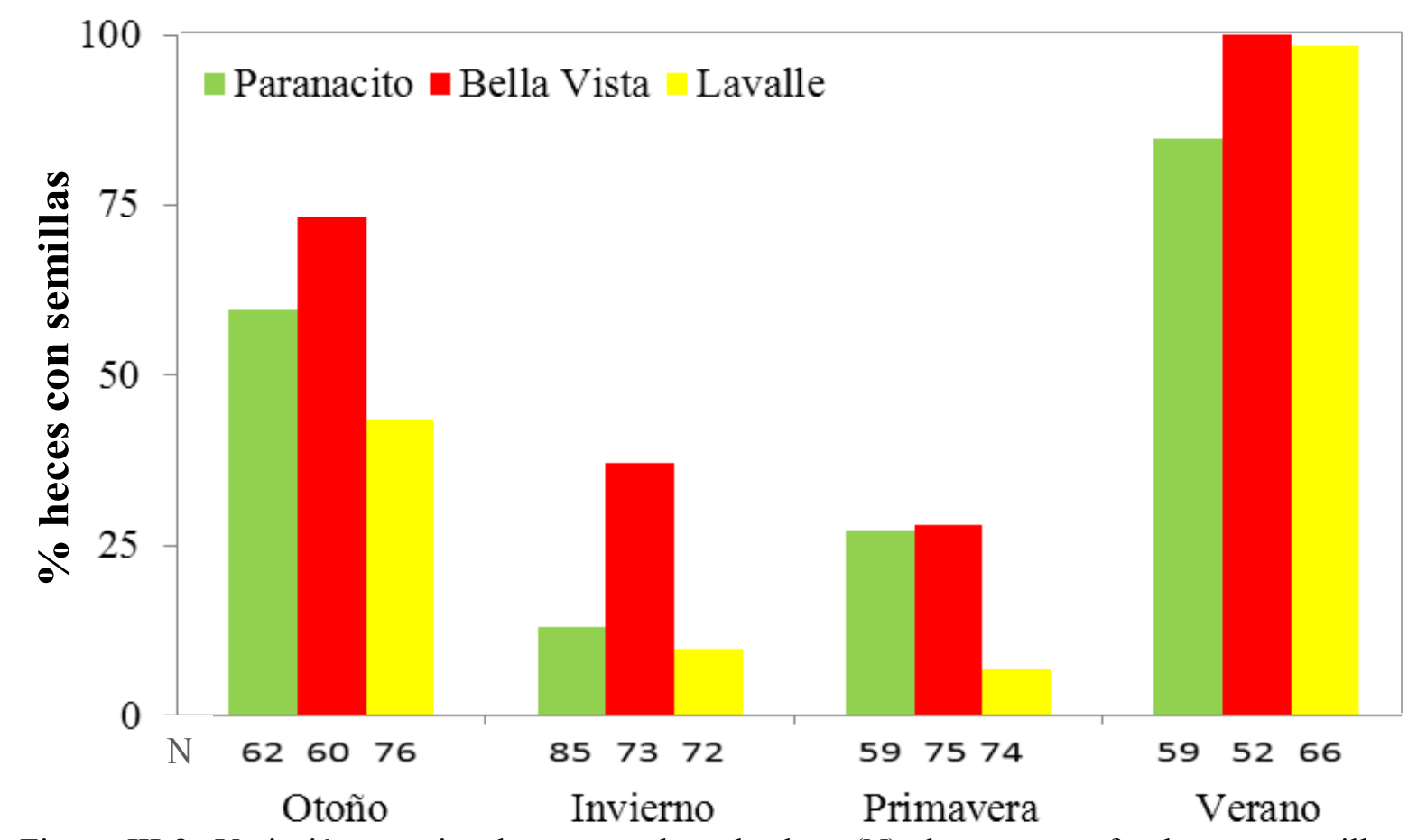

Figura III-8. Variación estacional porcentual y absoluta $(\mathrm{N})$ de muestras fecales con semillas $(\mathrm{N}=813)$, de Alouatta caraya, colectadas en 3 sitios de la selva de inundación del río Paraná Medio (Paranacito, Bella Vista y Lavalle) en el período abril 2007-marzo de 2008. 
La germinación de semillas halladas en las heces permitió determinar taxonómicamente 4 de 11 tipos de semillas no identificados: Melothria candolleana, Solanum aculeatissimum, Cecropia pachystachya y Psidium guajava.

En cada muestra fecal se registró la riqueza de especies y la abundancia de semillas, observándose que la mayoría contuvo semillas de 1 a 3 especies, y que las muestras provenientes del sitio ubicado más al sur contuvieron en promedio mayor cantidad de semillas de 3 a 6 especies (Figura III-9).

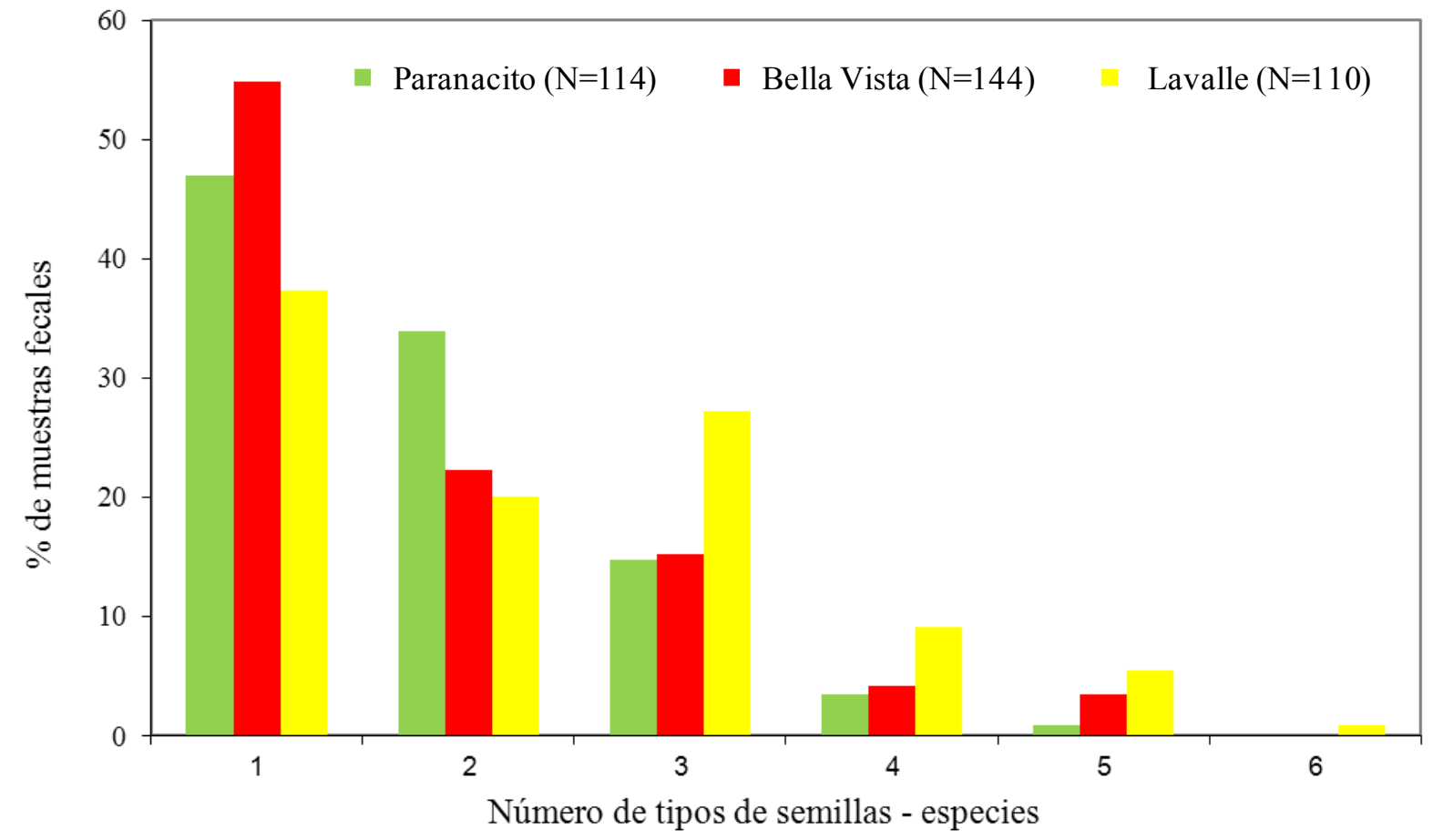

Figura III-9. Frecuencia relativa porcentual del número de semillas-especies halladas en muestras fecales de Alouatta caraya ( $=368)$, colectadas en 3 sitios de la selva de inundación del río Paraná Medio (Paranacito, Bella Vista y Lavalle) en el período abril 2007-marzo 2008.

\section{Variación espaciotemporal en la composición de la dieta frugívora}

La prueba de Bondad de ajuste de Chi cuadrado, arrojó diferencias estadísticamente significativas entre la frecuencia de especies vegetales consumibles en el ambiente y la frecuencia de estas especies registradas en las muestras fecales para cada uno de los 3 sitios: -Paranacito: $\chi 2=4207,77(p<0.001 ; \mathrm{N}=9$; GL: 8)

-Bella Vista: $\chi 2=2212,9(p<0.001 ; \mathrm{N}=8$; GL: 7)

-Lavalle: $\chi 2=2651,38(p<0.001 ; \mathrm{N}=7$; GL: 6)

El índice de selectividad IVLEV de especies consumidas, puso de manifiesto gran variabilidad entre los sitios y las estaciones, observándose un patrón poco definido. De las 10 especies vegetales analizadas, alrededor de la mitad fueron seleccionadas positivamente, un tercio alternaron entre positiva y negativamente dependiendo del sitio y la estación, y 
unas pocas especies se acercaron a la no selectividad en distintos sitios y estaciones del gradiente.

Se manifestó una selectividad positiva para la mayoría de las especies con características de los frutos consideradas favorables para el consumo (carnosidad, colores brillantes, semillas pequeñas), lo que se hizo más evidente en las estaciones de verano y otoño, coincidiendo con el período de maduración de los frutos. Entre dichas especies, se destacó el consumo de Banara arguta, Cecropia pachystachya, Xylosma venosa, Celtis chichape, Ficus luschnathiana, Copernicia alba, Ocotea diospyrifolia. Sin embargo, otras especies presentaron un patrón menos consistente como Paullinia elegans, Inga affinis y Nectandra angustifolia (Figura III-10).

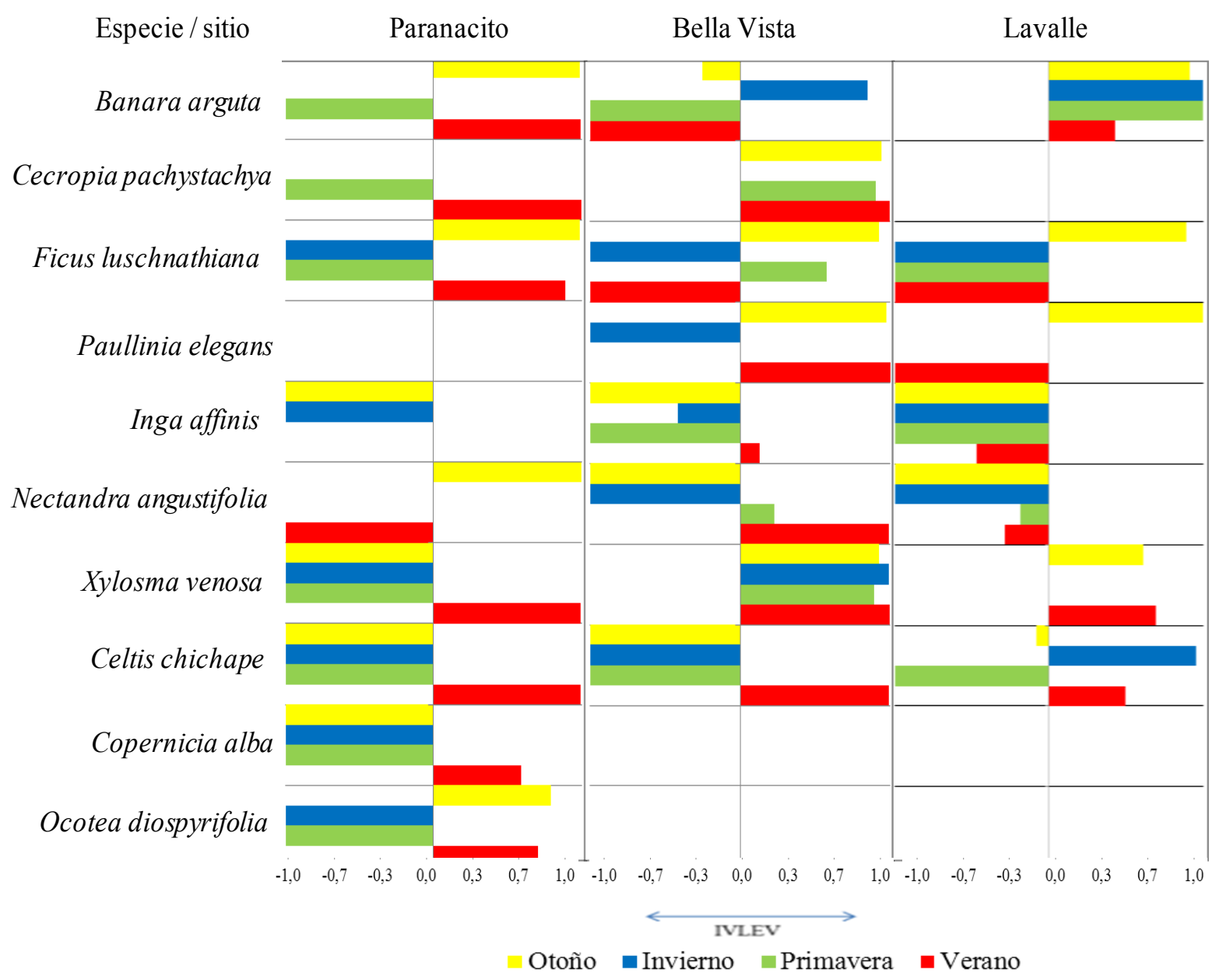

Figura III-10. Selectividad estacional de 10 especies que componen la dieta frugívora de Alouatta caraya en 3 sitios de la selva de inundación del río Paraná Medio (Paranacito, Bella Vista y Lavalle) en el período abril 2007-marzo 2008. Referencias: -1 a -0,33: selectividad negativa, -0,33 a 0,33: no selectividad y 0,33 a 1 : selectividad positiva. 


\section{Variación espaciotemporal en la dieta frugívora}

En comparación con las muestras de folivoría, las de frugivoría mostraron índices de similitud relativamente bajos con la mayoría de los nodos registrándose entre un $15 \%$ y un $20 \%$ de similitud. En líneas generales, se observó una mayor similitud entre estaciones que entre sitios. Por ejemplo, las muestras de una misma estación de Bella Vista y Lavalle fueron más similares entre sí (18\%) que otras del mismo sitio pero de diferente estación. En el caso de Paranacito, las muestras de otoño y verano se agruparon con las de Bella Vista y Lavalle, mientras que las de invierno y primavera formaron cada una un grupo aparte (Figura III-11).

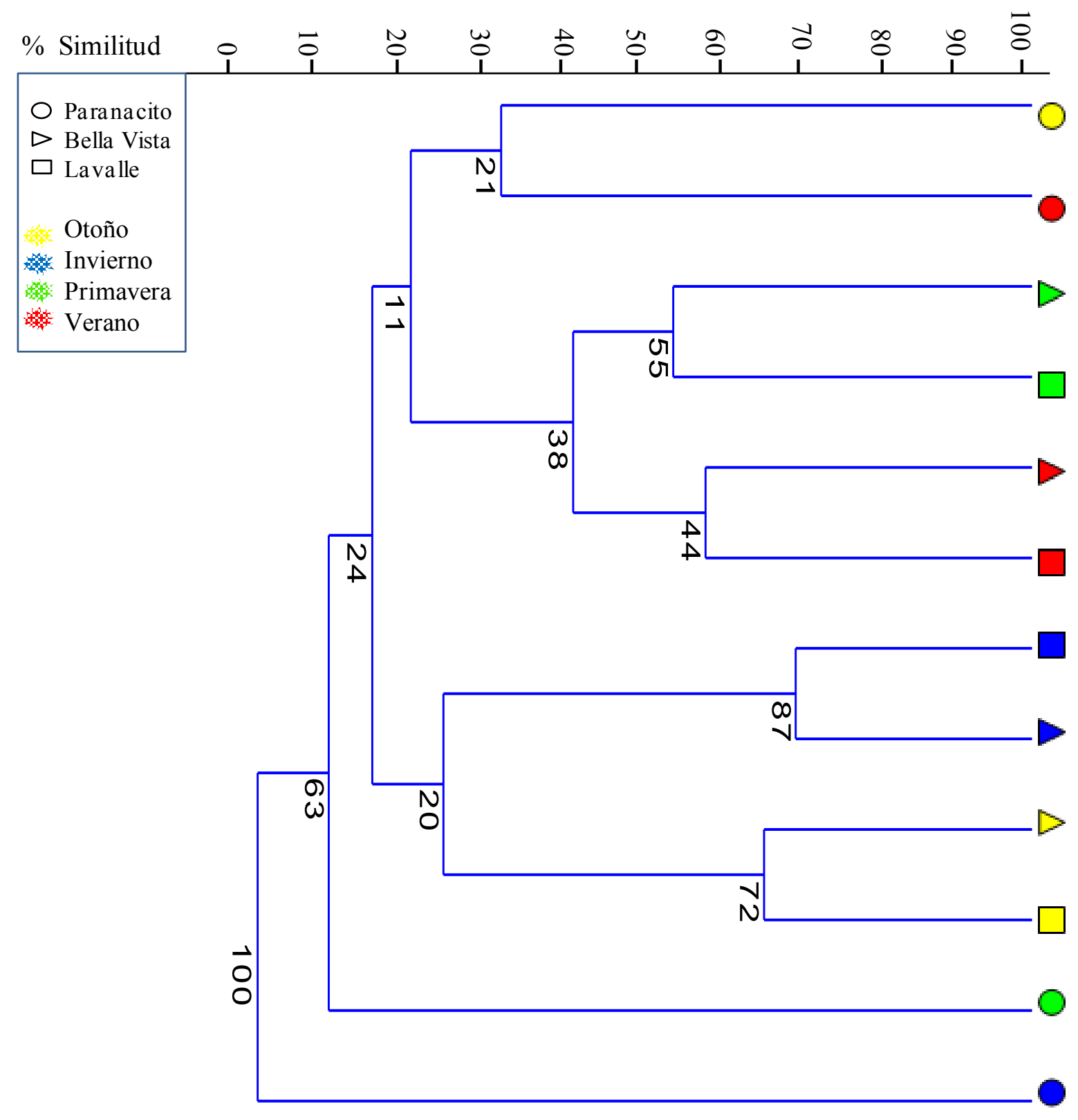

Figura III-11. Dendrograma de similitud por UPGMA obtenido mediante el índice de Bray-Curtis para la dieta frugívora de Alouatta caraya en 3 sitios de la selva de inundación del río Paraná Medio (Paranacito, Bella Vista y Lavalle) en el período abril de 2007-marzo 2008. Referencias: número debajo de nodos: valores de bootstrap-porcentaje de remuestreos que sustentan el grupo (Felsenstein 1985). 


\section{Variación espaciotemporal de la dieta frugívora entre clases de edad/sexo}

El análisis de agrupamiento de la dieta frugívora dentro de cada sitio, permitió observar que en las relaciones de similitud, la estación climática es un factor más importante que la clase de edad/sexo. Es decir que, en líneas generales, las muestras se agruparon primero por estación y después por clases de edad/sexo, al igual que lo observado en la folivoría. Las diferentes clases de edad/sexo presentaron una similitud en la dieta frugívora superior al $40 \%$ dentro de cada estación climática. En Lavalle las muestras de primavera e invierno se agruparon indistintamente con las de otras estaciones, mostrando un bajo nivel de similitud. Esto podría asociarse en parte a la baja ocurrencia de semillas en estas muestras, y a un consecuente incremento en la variabilidad de la composición de especies (Figura III-12). 


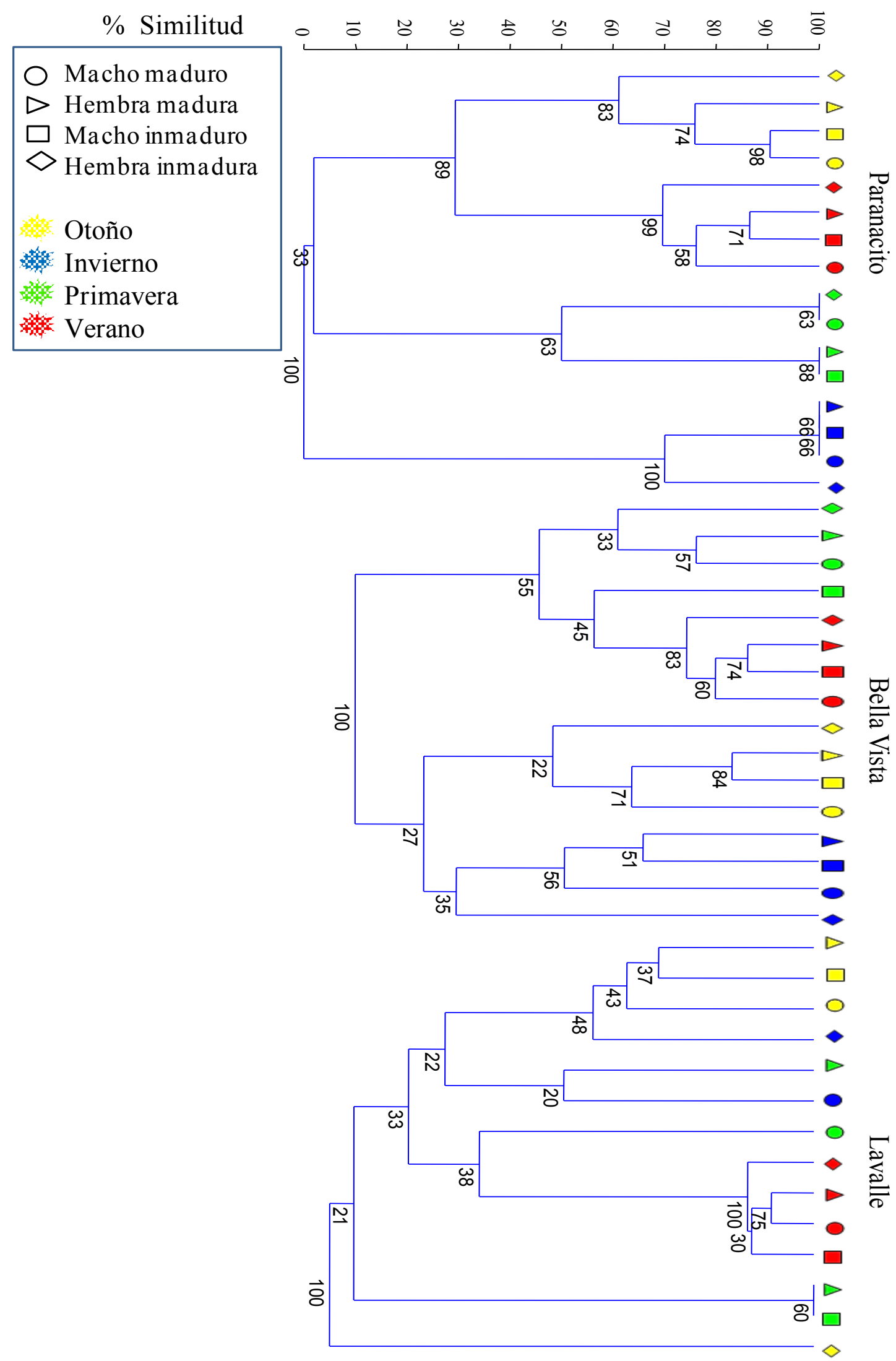

Figura III-12. Dendrograma de similitud por UPGMA obtenido mediante el índice de Bray-Curtis para la dieta frugívora estacional entre clases de edad y sexo de Alouatta caraya en 3 sitios de la selva de inundación del río Paraná Medio (Paranacito, Bella Vista y Lavalle) en el período abril 2007-marzo 2008. Referencias: número debajo de nodos: valores bootstrap-porcentaje de remuestreos que sustentan el grupo (Felsenstein 1985). 


\section{Variación espaciotemporal de la disponibilidad de los recursos tróficos y la composición de la dieta}

El análisis de correspondencias mostró patrones de ordenamiento semejantes para las muestras de dieta y las de disponibilidad de recursos tróficos entre los diferentes sitios y estaciones climáticas. El diagrama de dispersión de las muestras de la composición dietaria, permitió observar una diferenciación espacial entre los sitios a partir del eje 1 (horizontal), con las muestras de Paranacito ubicadas a la derecha y las de Bella Vista y Lavalle a la izquierda del diagrama. Por su parte, el eje 2 (vertical) constituyó un eje de diferenciación temporal que segregó las muestras de consumo de las distintas estaciones, presentándose las muestras de primavera y verano en una posición superior, y las de otoño e invierno en una posición inferior en el diagrama. Esto indicaría un cambio temporal en la composición de la dieta, con trayectorias similares en los 3 sitios estudiados (Figura III-13 B y D).

El análisis de correspondencias realizado a partir de datos de disponibilidad de recursos tróficos reflejó una diferenciación más marcada de las muestras por sitio de estudio y una menor diferenciación en base a las estaciones. El eje 1 puso de manifiesto diferencias marcadas en la composición de especies, nuevamente con las muestras de Paranacito ubicadas a la derecha y las de Lavalle y Bella Vista ubicadas a la izquierda del diagrama. Estos dos últimos grupos de muestras se diferenciaron luego a través del eje 2, con las muestras de Lavalle ubicadas en la porción superior y las de Bella Vista en la porción inferior del diagrama (Figura III-13 A y C).

Al comparar ambos diagramas, se observa una coincidencia en las similitudes de la dieta entre los sitios en base al eje 1 (espacial), y una correspondencia parcial, menos definida, sobre el eje 2 (temporal). Dicho de otro modo, las variaciones en la dieta de los aulladores entre sitios se encontraron en asociación con la variación en la composición de especies a lo largo del gradiente geográfico. Sin embargo, las variaciones temporales observadas en la dieta no se corresponden claramente con las variaciones fenológicas de las especies presentes en cada sitio. A su vez, se observa que la variación temporal registrada en la composición de la dieta sobre el eje 2 es mucho mayor que la variación temporal observada para los datos de disponibilidad (Figura III-13).

En términos generales, las especies mostraron una tendencia comparable sobre el eje 1, tanto para el análisis de los datos de consumo, como para los de disponibilidad. Las especies Sapindus saponaria (hoja), Ocotea diospyrifolia (hoja y fruto), Pristimera andina (hoja), se ubicaron a la derecha de los gráficos, indicando mayor disponibilidad y consumo en Paranacito, y las especies Celtis chichape (hoja), Xylosma venosa (fruto), Banara arguta 
(hoja) se ubicaron a la izquierda del gráfico mostrando mayor disponibilidad y consumo en Bella Vista y Lavalle. En cambio, sobre el eje 2, la distribución de las especies se correspondió sólo parcialmente con los ordenamientos realizados para consumo y disponibilidad (Figura III-13 A y B). 


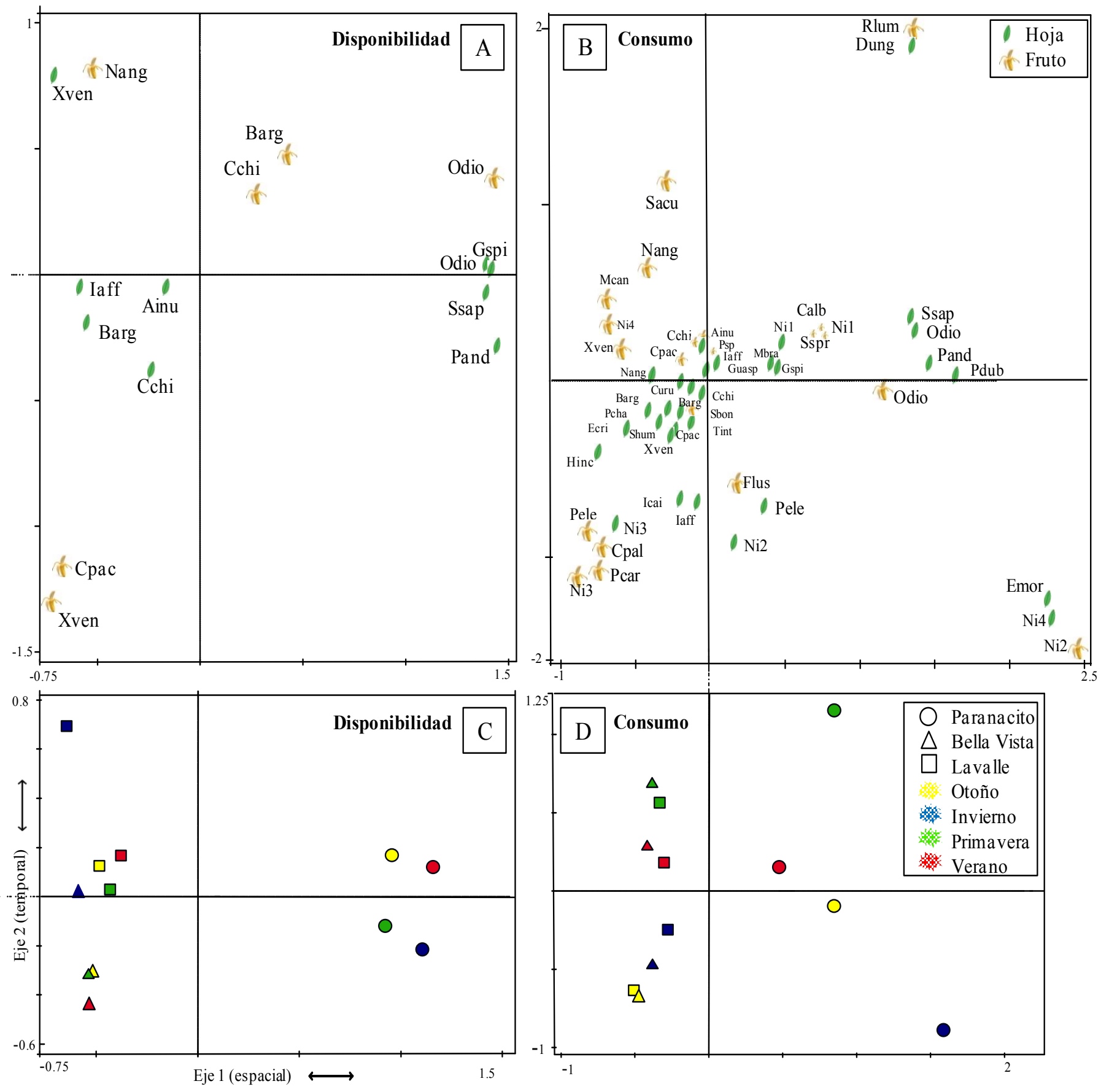

Figura III-13. Similitud del consumo de las especies más importantes de la dieta (70\%) y la disponibilidad estacional de recursos tróficos para Alouatta caraya, en tres sitios de la selva de inundación del río Paraná Medio (Paranacito, Bella Vista y Lavalle) el período abril de 2007-marzo 2008, a partir de análisis de correspondencias. Referencias: Ainu: Albizia inundata, Barg: Banara arguta, Calb: Copernicia alba, Cchi: Celtis chichape, Cpal-Cpal: Cecropia pachystachya, Curu: Croton urucurana, Dung: Dolichandra unguis cati, Ecri: Erythrina crista galli, Emor: Eugenia moraviana, Flus: Ficus luschnathiana, Gspi: Geoffroea spinosa, Guasp: Guadua sp., Hinc: Houssayanthus incanus, Iaff: Inga affinis, Icai: Ipomoea cairica, Nang: Nectandra angustifolia, Mbra: Machaonia brasiliensis, Mcan: Melothria candolleana, Ni1-Ni4: No identificadas 1-4, Odio: Ocotea diospyrifolia, Pand: Pristimera andina, Pcar: Psychotria carthagenensis, Pcha: Phyllanthus chacoensis, Pdub: Peltophorum dubium, Pele: Paullinia elegans, Psp: Panicum sp., Rlum: Rhipsalis lumbricoides, Sacu: Solanum aculeatissimum, Sbon: Stigmaphyllon bonariense, Shum: Salix humboldtiana, Ssap: Sapindus saponaria, Sspr: Sorocea sprucei, Tint: Tessaria integrifolia, Xven: Xylosma venosa. 


\section{Asociación entre la disponibilidad de recursos tróficos y la composición de la dieta}

El test de Mantel puso de manifiesto una correlación estadísticamente significativa $(p=0.001)$ entre la clasificación de las muestras obtenidas a partir de la información dietaria (análisis de heces), y la clasificación generada a partir de los datos de disponibilidad, es decir, entre la variación de los recursos tróficos consumidos por los aulladores y los cambios en la abundancia de dichos recursos en el ambiente. Esto significa que los sitios y las estaciones más similares en cuanto a la disponibilidad, también fueron los más similares en cuanto a la dieta.

El diagrama de dispersión permite observar dos cúmulos de puntos algo alargados horizontalmente. El cúmulo inferior de puntos corresponde a las similitudes entre las muestras de Paranacito y Bella Vista, y las muestras de Paranacito y Lavalle, mientras que el cúmulo superior corresponde a las similitudes entre las muestras de Bella Vista y Lavalle, y las muestras de diferentes estaciones de un mismo sitio. Sin embargo, no se observa un patrón claro dentro de cada conjunto de puntos, manifestándose que las diferencias en la composición dietaria de cada sitio no se corresponden con las diferencias en disponibilidad, tal como fuera observado en el análisis de correspondencias (Figura III-14). 


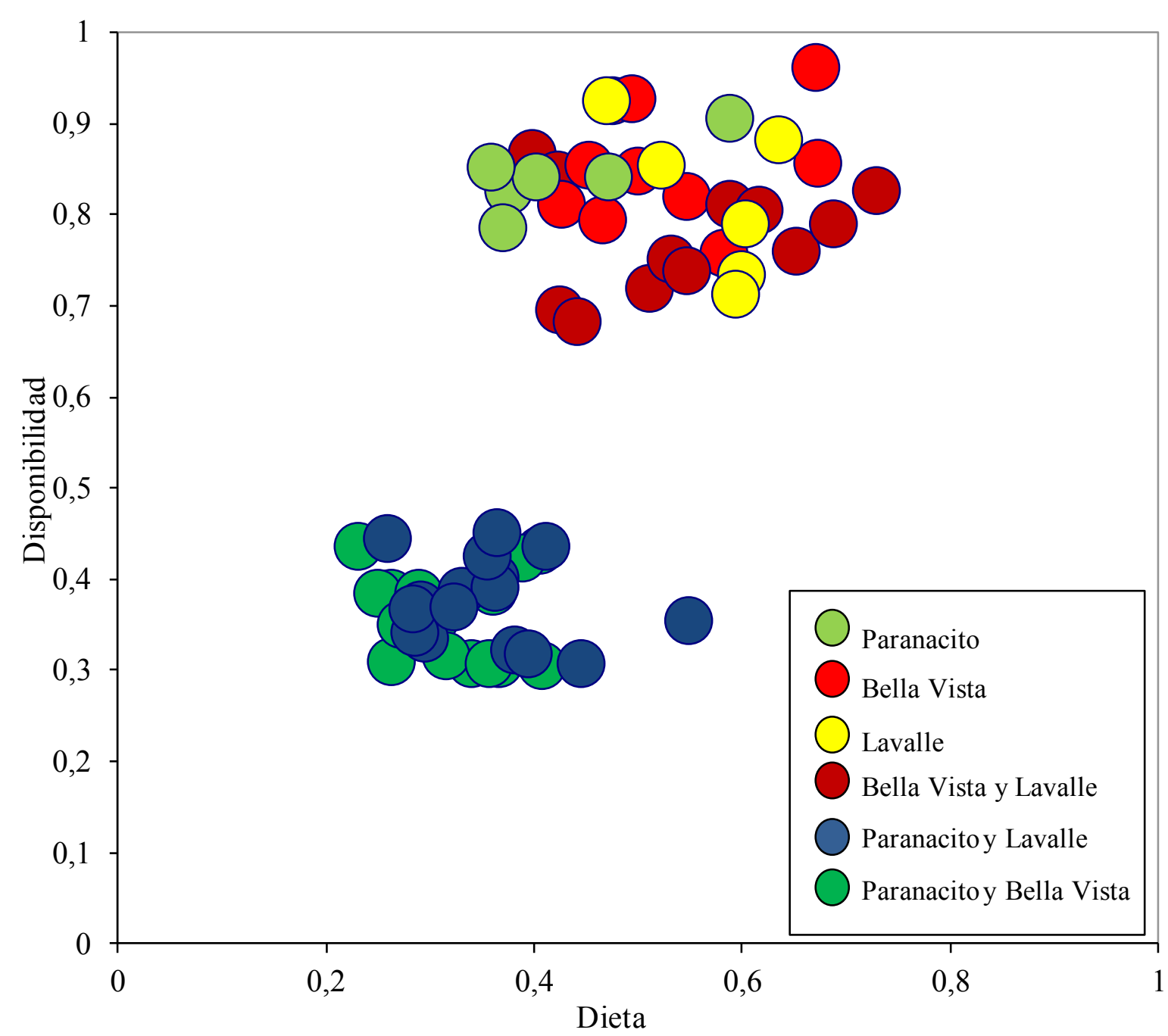

Figura III-14. Gráfico de dispersión de los valores de similitud (Bray-Curtis) de la dieta (eje horizontal) y de disponibilidad de recursos tróficos en el ambiente (eje vertical), en 3 sitios de la selva de inundación del río Paraná Medio (Paranacito, Bella Vista y Lavalle) en el período abril de 2007-marzo 2008. El gráfico muestra una correlación positiva entre la similitud de la dieta y la similitud de la disponibilidad de recursos tróficos que fue probada a partir de un test de Mantel $(\mathrm{r}=0.710, p=0.001, \mathrm{Alfa}=0,05)$.

\section{DISCUSIÓN}

\section{Descripción general de la composición de la dieta}

En el presente capítulo se realizó una descripción exhaustiva de la dieta de los monos aulladores que habitan la porción sur de su área de distribución en la selva de inundación del río Paraná Medio. Los resultados describen el uso de recursos vegetales por parte de los aulladores en un amplio gradiente latitudinal durante un año de muestreo, incluyendo la variación estacional en la disponibilidad de recursos. Las plantas consumidas pertenecieron a 36 especies diferentes, con la utilización de 1 a 3 estructuras vegetales por especie (hojas 
de 28 especies, frutos de 18 especies y flores de 4 especies). Esto representa un total de 50 tipos de recursos diferentes (especie x estructura).

Por el método de observación directa se registró el consumo de 20 especies que suministraron 32 recursos (entre hojas, flores y frutos), mientras que por el método microhistológico se registraron hojas de 27 especies y mediante macroscopía, frutos de 17 especies. Los diferentes métodos utilizados muestran que el análisis microhistológico de heces y la observación directa proveen una descripción coherente en cuanto a la participación de las especies más importantes, fundamentalmente en el consumo de hojas (Figura III-2). El método de observación directa permitió registrar el consumo de frutos que no fueron observados por macroscopía por presentar semillas medianas a grandes, que pueden no ser ingeridas durante el consumo (ej. Inga affinis). El método microhistológico permitió una cuantificación de la abundancia relativa de los recursos consumidos que son difícilmente estimados a través de la medición del tiempo de consumo mediante observación directa, ya que el tiempo de manipulación de un recurso no está necesariamente asociado al volumen consumido. El método de macroscopía permitió detectar especies que no fueron registradas o sólo fueron registradas ocasionalmente por observación directa.

En concordancia con lo expresado por Bazzalo (2001) el método de análisis de heces fue útil para estimar la confiabilidad de los registros de hábitos alimentarios obtenidos por estudios conductuales, y permitió registrar algunos ítems que hubiesen sido difíciles de identificar por observación directa. Si bien los métodos microhistológico y macroscópico requieren de mayor cantidad de tiempo para procesar las muestras en laboratorio, el tiempo de muestreo en campo es mucho menor, lo que hizo posible analizar la dieta de una mayor cantidad de grupos de aulladores con una frecuencia de monitoreo mensual en 3 sitios diferentes a lo largo de 200 kilómetros. En el marco de la presente tesis, el cumplimiento de este esquema de muestreo fue esencial para determinar la variación estacional y latitudinal en el consumo y disponibilidad de recursos, por lo que se considera que la utilización del análisis de heces contribuyó en gran medida a la factibilidad de éste trabajo.

La mayoría de los estudios realizados sobre la ecología trófica del género Alouatta implementaron el método de observación directa. Estos estudios registraron entre 12 y 195 especies diferentes. En Argentina se han llevado a cabo al menos 6 estudios sobre ecología trófica de Alouatta caraya utilizando exclusivamente el método de observación directa (Tabla I-2). De estos estudios, solamente Kowalewski (2007) reportó la utilización de más especies (70 especies) que la presente tesis, lo que pone en relieve que la información 
obtenida mediante el enfoque multi-método utilizado, se encuentra dentro de los parámetros conocidos para la especie.

Entre los primeros estudios realizados en Argentina, Rumiz et al. (1986), compararon la alimentación de poblaciones de Alouatta caraya en la selva de inundación del río Paraná Medio (Isla Guáscara) y de parches de bosques de tierra firme cercanos (a 25 kilómetros al sureste de la ciudad de Corrientes), encontrando diferencias marcadas en la composición dietaria en relación a las diferencias florísticas entre ambos sitios. El sitio de selva de inundación se monitoreó durante 3 meses, mediante observación ad libitum sobre 10 grupos de aulladores, registrando un total de 12 especies, de las cuales 4 fueron (en orden de importancia) las más consumidas: Nectandra falcifolia, lianas no identificadas, Banara arguta, Albizia inundata y Cecropia pachystachya, hecho que coincide con las especies más consumidas registradas en la presente tesis.

En un estudio detallado de la conducta de Alouatta caraya, Kowalewski (2007) analizó el comportamiento alimentario de 2 grupos de aulladores, durante 12 meses, mediante observación directa (abarcando 5 días por mes con cerca de 14.500 registros de alimentación de un total de 77.000 barridos), reportando un total de 70 especies consumidas (18 de árboles, 2 de arbustos, 49 de lianas y epífitas y 1 especie de liquen). En el citado estudio, las 5 especies vegetales más importantes en la dieta (Cecropia pachystachya, Inga affinis, Octoea diospyrifolia, Albizia inundata y Banara arguta), representaron el 74,1\% del tiempo de alimentación total. En la presente tesis estas mismas 5 especies conformaron el $73,3 \%$ del tiempo de alimentación total registrado mediante el método de observación directa, lo que se encuentra en elevada concordancia con lo obtenido por este autor. A pesar del limitado tiempo de observación directa utilizado en esta tesis, estos resultados muestran que la descripción general de la dieta se aproxima mucho a la de estudios más detallados.

En otro estudio, Bravo y Sallenave (2003) analizaron el comportamiento alimentario de los aulladores en el mismo sitio que Kowalewski (2007), pero no reportaron los porcentajes totales del tiempo de consumo por especie, sino que lo hicieron independientemente por estructura, dificultando las comparaciones con los datos aquí obtenidos. Los resultados de este estudio, se discuten más adelante cuando se analizan los resultados de folivoría y frugivoría.

Bazzalo (2001) constituye el único estudio de la dieta folívora de los aulladores en Argentina utilizando el método de análisis de heces. Mediante el análisis microhistológico de 30 muestras fecales colectadas en Isla Brasilera $\left(27^{\circ} 20^{\prime} \mathrm{S}, 58^{\circ} 40^{\prime} \mathrm{O}\right)$ durante el otoño y la primavera de 1997, esta autora registró el consumo de 13 especies de plantas (3 no 
identificadas). De las 10 especies identificadas, 7 coincidieron a nivel de especie, 2 a nivel de género y 1 a nivel de familia con la lista de 27 especies obtenida en la presente tesis mediante este método. Sin embargo, esta autora registró sólo 3 de las 6 especies más importantes del presente estudio y del realizado por Kowalewski (2007), lo que representa una descripción parcial de la dieta. Bazzalo (2001) citó a Cecropia pachystachya, Albizia inundata, Inga affinis, Cissus palmata, Ipomoea Rubens, Iseia luxurians, y 3 especies no identificadas entre los taxones más importantes en la composición de la dieta folívora. Finalmente, al no realizar un análisis macroscópico de las heces, no reporta datos del consumo de frutos.

\section{Alimentación de las diferentes clases de edad y sexo}

Las distintas clases de edad/sexo presentaron una composición dietaria semejante, lo que indica que las diferencias en el desarrollo, metabolismo y crecimiento de los individuos no se manifestarían en la dieta (Pavelka y Knopff 2004, Kowalewski 2007, Prates y Bicca Marques 2008). Es decir, si bien pueden existir diferencias en los requerimientos nutricionales entre las clases de edad/sexo, éstos no se vieron reflejados sistemáticamente en la composición de la dieta. Rothman et al. (2008) observaron que las diferentes clases de edad/sexo de los gorilas (machos lomo plateado, hembras adultas y juveniles) a pesar de tener diferentes requerimientos nutricionales, consumieron iguales proporciones de proteínas, fibras y carbohidratos. En esta especie, la mayor ingesta requerida de proteínas por parte de las hembras y los juveniles no se alcanzaba mediante las selección de alimentos propocionalmente más ricos en proteínas sino a través del consumo de mayor volumen de alimento por kilogramo de masa corporal. Los estudios comparativos del volumen de alimentos consumido de Alouatta spp. no han mostrado diferencias entre las distintas clases de edad/sexo (Glander y Teaford 1995, Pavelka y Knopff 2004, Prates y Bicca Marques 2008).

\section{Folivoría y frugivoría en Alouatta caraya}

Las descripciones realizadas de la alimentación de las distintas especies del género Alouatta muestran una variación en el consumo relativo de hojas y frutos, variando desde dietas mayormente folívoras (ej. Eisenberg et al. 1972, Mendes 1989, Zunino 1986, Chiarello 1993) a dietas con un alto consumo de frutos (ej. Bonvicino 1989, Stevenson et al. 2000, Pinto 2002, Di Fiore y Campbell 2007). En varios estudios sobre la alimentación de Alouatta caraya, el consumo de frutos representó entre el 19 y el 35,5\% del tiempo de forrajeo a lo 
largo del año (reseñados en Rimoli et al. 2008). De acuerdo con el método de observación directa, sólo un 18\% del total de registros $(\mathrm{N}=265)$ correspondió al consumo de frutos, lo que representa el límite inferior del rango conocido para la especie. El análisis macroscópico de las heces reveló la presencia de frutos en un $45,3 \%$ de las muestras. Estos resultados sugieren una dieta fundamentalmente folívora, pero con una utilización frecuente de los frutos como fuente de energía.

En este estudio se registró un incremento gradual hacia los sitios del sur en el porcentaje medio anual del tiempo de forrajeo de frutos, con un 7,35\% en Paranacito, un $17,59 \%$ en Bella Vista, y un 28,09\% en Lavalle. Esto llevaría a pensar que existe un gradiente latitudinal a lo largo del valle aluvial del río Paraná Medio en cuanto al consumo de frutos. Sin embargo en un estudio realizado en un ambiente similar, ubicado a 40 kilómetros al norte del sitio de Paranacito, Bravo y Sallenave (2003) reportaron un 19\% del tiempo alimentario destinado al consumo de frutos, lo que representa un valor semejante al observado en Bella Vista y Lavalle. El menor porcentaje de consumo de frutos observado en Paranacito podría explicarse parcialmente por la menor abundancia de Inga affinis, la especie más importante en el suministro de frutos (Anexo 4). Esta especie presentó un área basal de $0,94 \mathrm{~m}^{2} / \mathrm{ha}$ en Paranacito 3,08 $\mathrm{m}^{2} /$ ha en Bella Vista y $6,75 \mathrm{~m}^{2} /$ ha Lavalle, hecho que podría influir en el tiempo dedicado al consumo de frutos.

Rumiz et al. (1986) reportaron un mayor consumo de frutos en un sitio ubicado en tierra firme respecto de otro cercano ubicado en el valle de inundación del río Paraná, donde se registró un consumo casi nulo de frutos. Sin embargo, estos resultados probablemente presenten un sesgo marcado, dado que el sitio de selva de inundación fue analizado solamente durante el invierno, período que representa según los resultados de esta tesis, una estación con muy baja disponibilidad de frutos. Por ello, el análisis de la frugivoría de los aulladores debe considerar la estacionalidad en la disponibilidad de los mismos.

En estudios previos, se observó que el consumo de hoja suele mantenerse a lo largo del año, mientras que el nivel de frugivoría varía estacionalmente. En este estudio, no fue posible cuantificar la abundancia de frutos con el análisis macroscópico, pero al igual que lo observado por otros autores, la frecuencia de ocurrencia de semillas en las heces presentó una estacionalidad marcada. En concordancia con Kowalewski (2007), el verano fue la estación con mayor consumo de frutos, mientras que en Rumiz et al. (1986) lo fue el otoño. En estos estudios existe una estación donde el consumo de frutos resultó notablemente menor que en las restantes (invierno en Rumiz et al. 1986 y primavera en Kowalewski 2007). En el presente estudio, tanto en la primavera como en el invierno, se evidenció un bajo consumo 
de frutos. Probablemente, estas diferencias se deban a la fenología de las principales especies que aportan frutos [Ficus luschnathiana en Rumiz et al. (1986), y Ocotea diospyrifolia, Cecropia Pachystachya y Banara arguta en Kowalewski (2007)], mientras que en el presente estudio Nectandra angustifolia, Solanum aculeatissimun, Ocotea diospyrifolia y Celtis chichape fueron las especies más consumidas. Otro factor a considerar es, que debido a que el presente estudio se desarrolló más al sur que los estudios arriba citados, el aumento gradual en la estacionalidad climática en sitios de mayor latitud podría afectar la fenología de las especies.

\section{Ecología nutricional de Alouatta caraya}

El marco teórico geométrico requiere el conocimiento del contenido de macronutrientes de los ítems ingeridos, tales como proteínas, lípidos, carbohidratos e iones inorgánicos a fin de interpretar los patrones de selectividad de los alimentos (Rothman et al. 2008). Para primates que ingieren una gran diversidad de recursos, este análisis demanda una gran cantidad de información sobre la composición de nutrientes de las especies vegetales utilizadas y su grado de digestibilidad (Rothman et al. 2008). Por su parte, aunque no fue desarrollado en el marco teórico geométrico, el trabajo de Zunino (1986), es uno de los únicos que analiza el contenido de macronutrientes (proteínas, carbohidratos no estructurales y grasas) en diferentes estructuras (hojas jóvenes y maduras, pecíolos y frutos) en 13 especies vegetales que integraron la dieta de Alouatta caraya en el noroeste de la provincia de Corrientes. Este estudio sugiere que, el contenido protéico que posee cada especie vegetal o cada estructura es un factor crucial que determina los patrones de selectividad de alimento en los aulladores. Durante el verano, cuando los frutos se encuentran disponibles, los aulladores aumentan el consumo proporcional de carbohidratos (43,6\% de carbohidratos, $53,4 \%$ de proteínas), mientras que en invierno, cuando la fuente habitual de proteínas (hoja jóven) es escasa y los frutos no están disponibles, los aulladores mostraron más preferencia por las especies con una alta concentración de proteínas y aumentaron el consumo proporcional de este macronutriente $(29,9 \%$ de carbohidratos, $70,1 \%$ de proteínas). No obstante, en ambas estaciones el consumo total en peso seco de estos dos macronutrientes fue similar ( $82,45 \%$ en verano vs. $84,73 \%$ en invierno) (Zunino 1986). Los resultados del estudio de Zunino (1986) se encuentran en concordancia con las prediciones del marco teórico geométrico. Dado que proteínas y carbohidratos son hasta cierto punto intercambiables (por ej., como fuentes de energía), los requerimientos óptimos se pueden alcanzar utilizando cualquier combinación de los dos nutrientes (Raubenheimer 
et al. 2009), cuando no es posible alcanzar el objetivo de ingesta. Este hecho requeriría de una capacidad para metabolizar los desechos nitrogenados (desaminación, excreción) producto de la utilización de las proteínas con fines energéticos, aspecto que no se ha evaluado en la especie. En la presente tesis, la mayor disponibilidad de frutos observada durante el verano proporcionaría una fuente rica en carbohidratos. Durante el invierno, la menor disponibilidad de frutos demandaría un mayor consumo de hojas para cubrir los requerimientos energéticos, lo que incrementaría la proporción de proteínas incorporadas en la dieta. De este modo, esta especie podría sufrir un estrés metabólico por el procesamiento de proteínas. Como en el extremo sur del gradiente, se observó un periodo más prolongado de escasez de frutos sería esperable que las poblaciones de este sitio presenten mayor estrés metabólico por el procesamiento de los desechos nitrogenados.

\section{Selectividad trófica}

Los estudios sobre la composición de la dieta de los aulladores muestran que existe un número reducido de especies que constituyen la mayor parte de la dieta (Tabla I-2). Considerando que los bosques que habitan los aulladores poseen una elevada diversidad de especies potencialmente utilizables como recursos tróficos, este hecho sugiere que el consumo de recursos ocurre de manera selectiva. La selección de un alimento respondería a múltiples factores y no podría considerarse a la abundancia en el ambiente como la única variable determinante. En el caso de los aulladores, estudios previos han mostrado la preferencia por estructuras vegetales en base no sólo a su contenido energético (Zunino 1987), sino también a un mayor contenido de proteínas y menor contenido de fibra (Milton 1979, Davies et al. 1988, Waterman et al. 1988). Por otra parte, se ha reportado la evasión de estructuras con defensas físicas contra la herbivoría (ej. espinas, tricomas, cristales) y con presencia de compuestos secundarios (ej. taninos condensados) (Oates et al. 1977, Glander 1981, Zunino 1986).

En el presente estudio, la selectividad trófica estuvo asociada a diversas características propias de las estructuras consumidas y a las formas de crecimiento de las plantas. Se observó un consumo selectivo de hojas de especies de mediano y gran porte, con crecimiento foliar relativamente rápido, cutícula delgada y baja densidad de tricomas y cristales, como por ej. Albizia inundata, Banara arguta, Xylosma venosa, Celtis chichape, Geoffroea spinosa, Sapindus saponaria. Por su parte, Inga affinis y Cecropia pachystachya presentaron una selectividad positiva a pesar de poseer defensas antiherbívoros (tricomas en gran cantidad). Si bien Sapindus saponaria, es una especie conocida por contener glucósidos 
de esteroides denominados saponinas localizados en sus frutos, que son tóxicos para los herbívoros (Alvarez de León y Archila Paiz 1988, Iannacone et al. 2013), el consumo de esta especie estuvo limitado a las hojas, que no contendrían esta toxina (Valverde 1999).

Otro aspecto a considerar para interpretar los patrones de selectividad de los aulladores es la accesibilidad al recurso de acuerdo con las formas de crecimiento de las especies vegetales, principalmente el tamaño de los árboles y las características de sus ramas. Las especies que brindan soporte, sobre las cuales los aulladores permanecen durante más tiempo, pueden ser más consumidas debido a su fácil acceso. Este aspecto podría determinar el consumo preferencial de hojas poco palatables, presentes en árboles que proveen soporte, como por ejemplo Inga affinis, entre otras.

A su vez, ciertas especies abundantes en la selva de inundación, como Tessaria integrifolia, Croton urucurana y Guadua sp., fueron escasamente consumidas, lo que resultó en índices de selectividad negativos. Estas especies poseen hojas con características no deseables (gran contenido de tricomas y cutícula gruesa de las dos primeras especies y alto contenido de cristales de sílice de la última) que podrían desalentar el consumo por parte de los aulladores. Si bien se observó un consumo selectivo de especies con rápido desarrollo foliar y menor contenido de componentes secundarios, también hubo un alto grado de consumo de especies con defensas antiherbívoros, lo que sugiere que Alouatta caraya contaría con mecanismos digestivos para contrarrestar el consumo de estructuras defensivas de ciertas especies vegetales.

A diferencia de lo observado para la dieta folívora, donde la selectividad se asoció a un conjunto de especies con patrones similares para todos los sitios y estaciones, para la dieta frugívora la mayoría de las especies evidenció un patrón marcadamente diferente de selectividad entre sitios y estaciones en general. Estas diferencias, pueden deberse a que la producción de hojas tiene una sucesión fenológica más estable y predecible, a diferencia de la producción de frutos, que posee mayor variabilidad fenológica ligada con la biología reproductiva de cada especie y las leves diferencias climáticas entre los sitios. La mayor estabilidad en el consumo de hojas respecto de los frutos puede observarse en los índices de similitud, que variaron aproximadamente entre el 70 y el 90\% para las hojas y entre un $10 \mathrm{y}$ un $70 \%$ para los frutos.

Como los frutos y las flores son recursos marcadamente estacionales, los aulladores muestran un modo de forrajeo de tipo oportunista para estas estructuras (Zunino 1987). Un ejemplo de dicho oportunismo, fue el consumo selectivo de Cecropia pachystachya, Xylosma venosa, Celtis chichape y Ocotea diospyrifolia durante el verano, período en el cual 
estas especies producen frutos en mayor abundancia. A éstos, se suma el consumo general de frutos de Banara arguta, Inga affinis, Albizia inundata, Nectandra angustifolia, Ficus luschnathiana. Por otro lado, a pesar de las características positivas del fruto de Geoffroea spinosa (dulce y carnoso), el mismo no fue registrado en las muestras fecales, lo que puede deberse al gran tamaño de la semilla (Stiles 1992, Fleming et al. 1993) de aproximadamente $30 \mathrm{~mm}$ de diámetro, lo que dificultaría su deglución. Esto último, concuerda con otros estudios dietarios realizados con Alouatta seniculus, donde las semillas registradas en las heces, tuvieron un tamaño menor a 29,8 mm (Alvis Rojas 2012), 15,8 mm (Grafton 2004) y 15,5 mm (Andresen 2005), aunque en A. palliata (en México) se registró la ingesta de frutos con semillas de hasta $40 \mathrm{~mm}$ x $25 \mathrm{~mm}$ (Estrada y Coates Estrada 1986, Julliot 1996a). Finalmente, es importante destacar el consumo de semillas del arbusto Solanum aculeatissimum, las cuales han sido reportadas como tóxicas para el ganado (Braga 1960). Lo mencionado anteriormente, indica una selectividad positiva de Alouatta caraya por especies con frutos coloridos (rojo, naranja, negro o verde brillante), carnosos y con semillas de tamaño relativamente pequeño (Julliot 1996ab), además de cierta capacidad para evitar el consumo de especies tóxicas, así como para neutralizar efectos posiblemente perjudiciales de frutos con componentes secundarios tóxicos.

\section{Variación espaciotemporal en la amplitud del nicho trófico}

La amplitud del nicho trófico de Alouatta caraya, no mostró variaciones importantes entre los sitios, pero mostró grandes variaciones estacionales. Los mayores valores de esta variable se observaron en verano, en coincidencia con la mayor disponibilidad de hoja joven y fruto, lo que contribuiría a un aumento en la diversidad de la dieta. La interacción observada entre el factor sitio y el factor estación estaría indicando que el patrón de cambio estacional en la amplitud del nicho trófico fue diferente entre los sitios estudiados. A partir de estos datos, es sugerente observar que la mayor amplitud del nicho trófico se observó en Paranacito en verano, mientras que la menor amplitud se observó en Lavalle en primavera. Esto último podría indicar la presencia de un período crítico en la estación de primavera en el sitio ubicado más al sur, donde la diversidad de recursos consumidos es menor, debido probablemente a su menor disponibilidad ambiental. 


\section{Composición de la dieta y disponibilidad de recursos tróficos en el extremo sur de la distribución de Alouatta caraya}

Según el análisis de ordenamiento (AC) de las muestras de consumo y disponibilidad de recursos tróficos, y del análisis de correlación entre ambas matrices (test de Mantel), las variaciones en la dieta de los aulladores se relacionaron a los cambios en la composición de especies a lo largo del gradiente espacial, pero no se correspondieron claramente con las variaciones fenológicas de las especies presentes en cada sitio. Esta estructura espacial deriva de las diferencias en la composición de especies entre el sitio Paranacito y los dos sitios ubicados más al sur, lo que se refleja también en la composición de la dieta de los aulladores. En cambio, la carencia de asociación temporal entre la disponibilidad y el consumo indica que los recursos son utilizados en una proporción diferente a la que están en el ambiente. Esto se encuentra en concordancia con la información proporcionada acerca del grado de selectividad de recursos en la dieta de los aulladores (Milton 1980, 1998, Estrada 1984).

La composición dietaria mostró cambios temporales semejantes en los tres sitios estudiados, lo que indicaría que tipos similares de recursos están siendo seleccionados en cada estación. Estos resultados podrían asociarse a la estacionalidad en la disponibilidad de los frutos, donde ciertas especies aparecen únicamente durante la estación de fructificación y desaparecen el resto del año. El análisis macroscópico, reflejó una mayor estacionalidad en la disponibilidad de frutos hacia el sur. El aumento general en cantidad de muestras fecales con semillas en verano y otoño, y la notoria disminución en invierno y primavera, sugiere una menor disponibilidad de frutos en las últimas estaciones. Estos resultados se encuentran en concordancia con estudios dietarios de Alouatta seniculus, donde la ausencia de semillas en las heces se asoció a la variación estacional y disponibilidad de frutos en la selva (Julliot 1996a, Andresen 1999). En Lavalle se registró la menor proporción de heces con semillas de los 3 sitios tanto en otoño, como en invierno y primavera, lo que indicaría una menor presencia del recurso fruto en dicho sitio, durante un período más prolongado. Esta escasez, podría asociarse a una menor calidad ambiental y condicionar la supervivencia de los aulladores en el extremo sur de su distribución.

En resumen, a lo largo del capítulo se observó que las variaciones registradas en la alimentación de los aulladores, pueden brindar algún indicio sobre las causas que determinan el límite sur de la distribución de la especie. Entre las más importantes, se puede mencionar la variación en la disponibilidad alimentaria a lo largo del tiempo y del espacio, destacándose un menor consumo de frutos durante la estación de invierno y primavera hacia el sur del 
gradiente. Por último, cabe destacar que si bien el cambio en la disponibilidad de recursos puede tener efectos sobre la ecología alimentaria y afectar la supervivencia de la especie, también puede tener consecuencias en la organización social, uso del espacio y densidad de la especie, aspectos que a su vez pueden alterar los patrones de utilización de los recursos (Kowalewski 2007), y que se analizarán en el siguiente capítulo. 


\section{CAPÍTULO IV}

\section{VARIACIÓN EN LA ORGANIZACIÓN SOCIAL, USO DEL ESPACIO Y \\ DENSIDAD DE Alouatta caraya EN EL GRADIENTE LATITUDINAL DE LA \\ SELVA DE INUNDACIÓN DEL RÍO PARANÁ MEDIO}

\section{INTRODUCCIÓN}

Se considera unidad social o sociedad a un grupo de animales de la misma especie que interactúan regularmente entre sí, más que con los miembros de otros grupos sociales (Struhsaker 1969). La organización social se define por el tamaño de grupo, la composición etaria-sexual y la cohesión espaciotemporal de los individuos (Kappeler y Van Schaik 2002), puede variar a nivel intraespecífico e interespecífico respondiendo a una variedad de factores ecológicos, incluyendo la presión por depredación y por infanticidio, la disponibilidad de recursos alimentarios, el grado de disturbio ambiental así como también a factores demográficos como la densidad poblacional (Eisenberg et al. 1972, Van Schaik y van Hoff 1983, Ruhiyat 1983, Crockett y Eisenberg 1987, Dunbar 1987, Isbell 1994, Strier 2000, Struhsaker 2000, Watts 2000, Steenbeek et al. 2000, Ostro et al. 2001, Ryan et al. 2008).

Las especies del género Alouatta tienden a formar organizaciones sociales denominadas:

-Unimacho: conformados por un grupo cohesivo de hembras adultas y sus crías y un solo macho adulto, el cual excluye a otros machos adultos del grupo por conducta agonística.

-Multimacho: grupos en los que varios machos adultos conforman un subgrupo definido, dentro del cual se ven comportamientos de afiliación sin existir relaciones de dominancia marcadas entre ellos, pero sí sobre los demás machos de menor edad.

-Machos en gradientes de edades: grupos en los que hay varios machos adultos con un rango de dominancia basado en el grado de madurez, con un solo macho dominante, relacionado a la mayor cantidad de crías, que tolera y estaría emparentado con los machos de menor edad (Eisenberg 1979).

Estos tipos de organizaciones pueden observarse en distintas poblaciones de una misma especie, en la misma población e incluso en un mismo grupo de aulladores, pudiendo además cambiar en el tiempo y geográficamente (Garber et al. 1999, Chapman y Chapman 2000, Ostro et al. 2001, Kowalewski y Zunino 2004). En condiciones de escasez de recursos 
se ha observado una tendencia a la exclusión de los machos subordinados y a la conformación de grupos unimacho (Clarke 1982, Van Hooff y Van Schaik 1994, Bernstein 2007). El tamaño y la composición de los grupos sociales están influenciados por el éxito reproductivo de machos y hembras (Treves 2001), siendo la distribución de las clases de edad/sexo, considerada un buen indicador del estatus de una población (Zucker y Clarke 2003). Sin embargo, aún no están claras las circunstancias ecológicas que favorecen el predominio de un tipo de organización social sobre otra y requiere ser estudiada para un mejor entendimiento de la dinámica poblacional de la especie.

Para Alouatta caraya se reportaron tamaños de grupo variables de acuerdo con su distribución geográfica, presentándose grupos de mayor tamaño en la parte superior (Aguiar et al. 2009) y media del río Paraná (Bravo y Sallenave 2003, Kowalewski y Zunino 2004) que aquellos realizados en otros sitios (Silva y Codenotti 2007) (Tabla IV-1).

Tabla IV-1. Tamaño de grupo de Alouatta caraya, en la selva de inundación del río Paraná Medio/Superior y en otros sitios. Referencias: N: número de grupos.

\begin{tabular}{|c|c|c|c|c|c|}
\hline \multirow{2}{*}{$\begin{array}{l}\text { Sitio-latitud-ubicación } \\
\text { Selva de inundación del río Paraná }\end{array}$} & \multicolumn{4}{|c|}{ Tamaño de grupo } & \multirow{2}{*}{ Fuente } \\
\hline & Media & Rango- & ío estándar & $\mathbf{N}$ & \\
\hline $22^{\circ} 43^{\prime} \mathrm{S}-53^{\circ} 24^{\prime} \mathrm{O}$. Sur de Brasil & 11,5 & $6-18$ & & 13 & 1 \\
\hline $27^{\circ} 20^{\prime} \mathrm{S}-58^{\circ} 40^{\prime} \mathrm{O}$. Noreste de Argentina & 9,7 & $3-15$ & & 27 & 2 \\
\hline $27^{\circ} 20^{\prime} \mathrm{S}-58^{\circ} 40^{\prime} \mathrm{O}$. Noreste de Argentina & 18,5 & $16-21$ & & 2 & 3 \\
\hline $27^{\circ} 20^{\prime} \mathrm{S}-58^{\circ} 41^{\prime} \mathrm{O}$. Noreste de Argentina & 12,4 & & 2,91 & 10 & 4 \\
\hline $27^{\circ} 20^{\prime} \mathrm{S}-58^{\circ} 41^{\prime} \mathrm{O}$. Noreste de Argentina & 11,25 & & 3,02 & 19 & 4 \\
\hline $27^{\circ} 20^{\prime} \mathrm{S}-58^{\circ} 41^{\prime} \mathrm{O}$. Noreste de Argentina & 6,13 & & 2,31 & 12 & 4 \\
\hline $27^{\circ} 20^{\prime} \mathrm{S}-58^{\circ} 41^{\prime} \mathrm{O}$. Noreste de Argentina & 10,2 & $5-15$ & & 11 & 11 \\
\hline $27^{\circ} 36^{\prime}$ S- $58^{\circ} 54^{\prime} \mathrm{O}$. Noreste de Argentina-Paranacito & 10,8 & & 3,0 & 5 & 6 \\
\hline $28^{\circ} 26^{\prime} \mathrm{S}-59^{\circ} 05^{\prime} \mathrm{O}$. Noreste de Argentina-Bella Vista & 12 & & 3,7 & 5 & 6 \\
\hline $29^{\circ} 00^{\prime} \mathrm{S}-59^{\circ} 13^{\prime} \mathrm{O}$. Noreste de Argentina-Lavalle & 14,2 & & 5,3 & 5 & 6 \\
\hline \multicolumn{6}{|l|}{ Tierra firme-otros sitios } \\
\hline $25^{\circ} 40^{\prime} \mathrm{S}-54^{\circ} 26^{\prime} \mathrm{O}$. Noreste de Argentina & 3,5 & & & 3 & 4 \\
\hline $25^{\circ} 54^{\prime} \mathrm{S}-58^{\circ} 13^{\prime} \mathrm{O}$. Noreste de Argentina & 8,5 & & 3,4 & 13 & 7 \\
\hline $27^{\circ} 30^{\prime} \mathrm{S}-58^{\circ} 41^{\prime} \mathrm{O}$. Noreste de Argentina & 5,7 & & 2,25 & 17 & 4 \\
\hline $27^{\circ} 30^{\prime} \mathrm{S}-58^{\circ} 41^{\prime} \mathrm{O}$. Noreste de Argentina & 7 & $2-19$ & & 34 & 8 \\
\hline $29^{\circ} 04^{\prime} \mathrm{S}-53^{\circ} 50^{\prime} \mathrm{O}$. Sur de Brasil & 6,6 & & 2,8 & 22 & 9 \\
\hline $27^{\circ} 30^{\prime} \mathrm{S}-58^{\circ} 41^{\prime} \mathrm{O}$. Noreste de Argentina & 11,25 & & 3,02 & 19 & 5 \\
\hline $26^{\circ} 55^{\prime} \mathrm{S}-59^{\circ} 30^{\prime} \mathrm{O}$. Noreste de Argentina & 8,9 & 3-19 & & 11 & 10 \\
\hline $27^{\circ} 30^{\prime} \mathrm{S}-58^{\circ} 41^{\prime} \mathrm{O}$. Noreste de Argentina & 8,4 & $5-13$ & & 11 & 11 \\
\hline $27^{\circ} 30^{\prime} \mathrm{S}-58^{\circ} 41^{\prime} \mathrm{O}$. Noreste de Argentina & 6,4 & $3-10$ & & 11 & 11 \\
\hline
\end{tabular}

Fuente 1: Aguiar et al. 2009, 2: Kowalewski y Zunino 2004, 3: Bravo y Sallenave 2003, 4: Zunino et al. 2001, 5: González et al. 2002, 6: Este estudio, 7: Juárez et al. 2005, 8: Zunino et al. 2007, 9: Silva y Codenotti 2007, 10: Thorington et al. 1984, 11: Rumiz 1990.

Los bosques inundados a lo largo de los ríos son extremadamente productivos y los aulladores rara vez sufren una reducción marcada en la disponibilidad de alimentos, por lo 
que pueden vivir en mayores densidades y conformando grupos grandes (Ostro et al. 2001, Zunino et al. 2001, Rudran y Fernández Duque 2003), y a su vez de tipo multimacho (Rudran y Fernández Duque 2003, Kowalewski y Zunino 2004, Juárez et al. 2005, Aguiar et al. 2009).

Se ha realizado una considerable cantidad de investigaciones poblacionales de Alouatta caraya, en la región del Chaco y de la selva de inundación del río Paraná Medio (Rumiz 1990, Zunino et al. 2001, Kowalewski y Zunino 2004, Juárez et al. 2005), pero no se han efectuado estudios en sitios más próximos a su límite geográfico poblacional. Dicho límite, se encuentra a $\operatorname{los} 29^{\circ} \mathrm{S}$ aproximadamente, en la selva de inundación del Paraná Medio, donde la especie se hallaría frente a condiciones de marginalidad.

Se han observado variaciones en la disponibilidad de los recursos alimentarios de Alouatta caraya, a lo largo del gradiente latitudinal estudiado (capítulo II), manifestándose valores significativamente menores de riqueza de especies en Esquina y períodos más breves de disponibilidad de estructuras vegetales en los sitios del extremo sur de la distribución de la especie. Se analizaron las modificaciones en el patrón de consumo y selectividad de recursos (capítulo III), como posibles mecanismos compensatorios a los cambios en la disponibilidad de recursos en el ambiente. En base a esto, resulta de interés investigar la ocurrencia de variaciones en la organización social, uso del espacio y densidad poblacional de la especie, a fin de acercarnos al conocimiento de los limitantes de la distribución de $A$. caraya.

\section{HIPÓTESIS Y PREDICCIONES}

A lo largo de la distribución geográfica más austral de Alouatta caraya, su organización social, uso del espacio y densidad poblacional presentarán variaciones en relación a cambios en la rigurosidad ambiental (climática y de disponibilidad alimentaria) que se producen en el gradiente latitudinal.

En respuesta a la disminución de las temperaturas y precipitaciones medias, y de la disponibilidad de recursos alimentarios, Alouatta caraya presentará:

-tamaños de grupo menores y una menor densidad poblacional debido a una menor capacidad de carga del ambiente.

-menor proporción de inmaduro-infantes por hembra madura, debido al efecto de los recursos sobre variables reproductivas. 
-una mayor proporción de grupos unimacho debido a la tendencia de esta especie a la exclusión de machos en condiciones de escasez de recursos.

-una mayor área de acción grupal que le permitirá obtener más recursos alimentarios.

\section{OBJETIVO}

Determinar los cambios en la organización social, uso del espacio y densidad de Alouatta caraya que se producen a lo largo de un gradiente latitudinal creciente de rigurosidad ambiental (climática y de disponibilidad alimentaria) relacionado a la mayor proximidad con el extremo sur de su distribución geográfica poblacional, en la selva de inundación del río Paraná Medio.

\section{Objetivos específicos}

-Describir la variación en la organización social de grupos de Alouatta caraya en cuanto a clases de edad/sexo y tamaño de grupo.

-Analizar el espacio utilizado por los aulladores, considerando el territorio, área de acción y zona de solapamiento.

-Definir la densidad ecológica de aulladores en los diferentes sitios de estudio.

\section{MÉTODOS}

Para determinar las variaciones en la organización social de los grupos de Alouatta caraya en los diferentes sitios del gradiente latitudinal se realizaron muestreos mensuales en el período abril de 2007-marzo de 2008 (Tabla I-2).

Cada sitio de estudio fue recorrido en sesiones que comprendieron 1 jornada completa (desde el amanecer hasta el anochecer), 1 media jornada por la mañana y 1 media jornada por la tarde alcanzando 2 días completos de muestreo por campaña.

Las áreas de selva muestreadas en cada sitio comprendieron 28 ha en Paranacito, 31 ha en Bella Vista y 33 ha en Lavalle. Éstas se recorrieron a pie mediante el uso de caminos predeterminados, 2 veces por muestreo, totalizando 12,8 km de trayecto en Paranacito, 11,1 $\mathrm{km}$ en Bella Vista y $11,5 \mathrm{~km}$ en Lavalle en cada campaña.

En cada sitio, se monitoreó mensualmente la mayor parte de los grupos, sin dejar de registrar a cada uno de los mismos por un lapso superior a 2 meses consecutivos. Se realizó un conteo de cada grupo de aulladores en al menos 8 de las 12 campañas, concretando 40 
conteos de grupo por sitio. Cabe señalar que de los 120 registros realizados en toda el área, un bajo porcentaje de los mismos se consideraron dudosos y fueron excluidos debido a que no se pudo determinar inequívocamente la identidad del grupo de aulladores.

Se cuantificó el número de individuos por grupo, y en caso de existir diferencias en los conteos de individuos, se consideró el de mayor magnitud para los análisis, debido a que algunos individuos pudieron estar separados del grupo u ocultos en el dosel de la selva (Zunino et al. 2007).

El reconocimiento de los individuos se realizó en base a características fenotípicas y marcas naturales (ej. color del pelaje, tamaño corporal, cicatrices) y su clasificación en categorías de edad/sexo, como se describió en el capítulo I. Lo individuos y grupos de aulladores fueron identificados empleando binoculares (Bushnell y Burries 10 x $42 \mathrm{~mm}$ ), y una cámara fotográfica (Panasonic FZ30).

Los individuos se consideraron del mismo grupo cuando fueron observados en estrecha proximidad espacial (en el mismo árbol o en árboles adyacentes), cuando hubo contacto visual entre ellos, exhibieron comportamientos coordinados (ej. locomoción, alimentación, descanso) o respondieron a vocalizaciones de grupos vecinos (Bezanson et al. 2008). Lo mencionado anteriormente permitió la identificación de individuos y grupos, evitando la repetición en el conteo de los mismos.

La organización social de los grupos se definió en base al número de individuos que conformaron las clases de edad/sexo que los componían, en cada sitio de estudio. Cabe señalar que la identificación de la organización social machos en gradiente de edades requiere de un seguimiento temporal de cada grupo para determinar las relaciones sociales y orden de jerarquía entre los machos. Dada la imposibilidad de realizar dicho seguimiento, para el muestreo y el análisis se consideraron 2 de las categorías, unimacho y multimacho, quedando incluida en esta última la organización machos en gradiente de edades (Figura IV$1)$. 


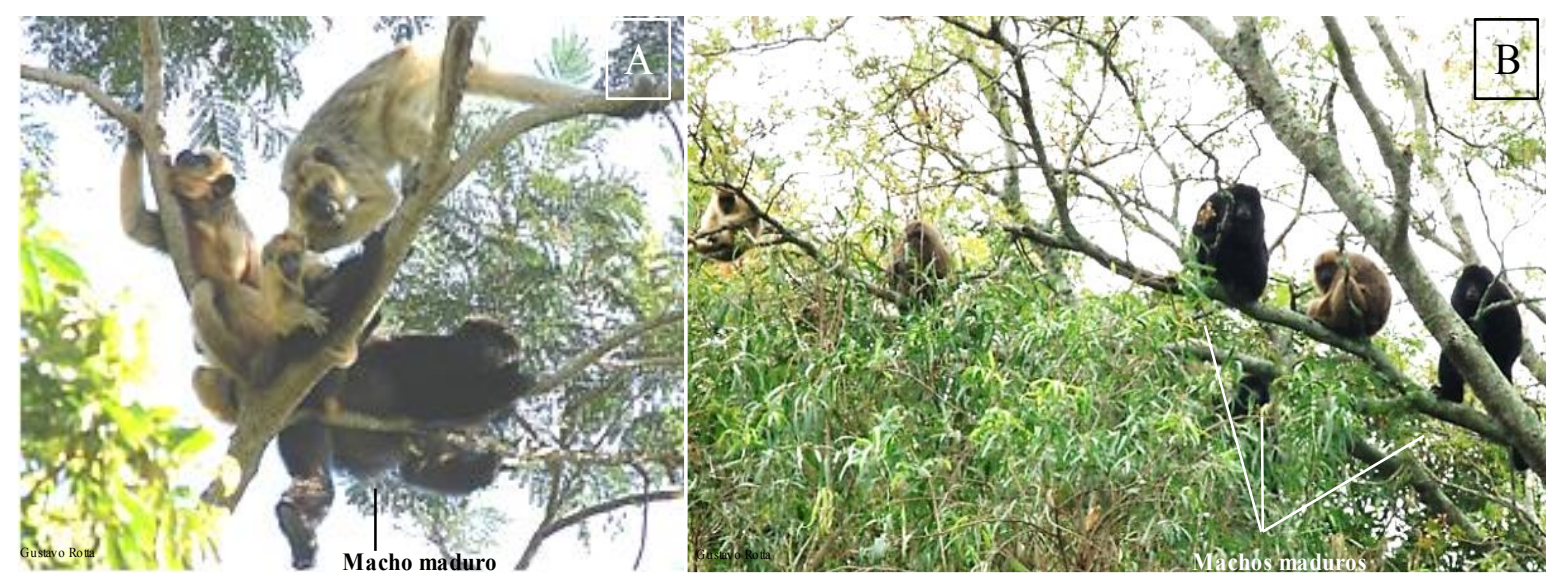

Figura IV-1. Grupos unimacho (A) y multimacho (B) de Alouatta caraya en la selva de inundación del río Paraná Medio.

A fin de evaluar cambios en la organización social de los grupos de Alouatta caraya a lo largo del gradiente latitudinal se compararon 5 grupos de aulladores de cada sitio estudiado. Los grupos de cada sitio fueron tomados como una réplica diferente y considerados como unidades muestrales relativamente independientes, teniendo como supuesto que la organización social se halla asociada en mayor medida a características del ambiente (ej. disponibilidad de recursos), que a la presencia-interacción con grupos vecinos. Otros estudios han reportado diferencias importantes en la organización social entre grupos vecinos habitantes de una misma isla en parches de bosques adyacentes (Bravo Sallenave 2003), indicando que las características del ambiente serían más importantes que la composición de los grupos vecinos en la determinación de la organización social.

Para analizar el espacio utilizado por los aulladores, se tuvieron en cuenta las siguientes definiciones:

-Territorio: áreas defendidas activamente por un grupo, aunque la defensa de la misma no implique necesariamente el uso exclusivo (Jolly 1985). Cuando un grupo detecta la presencia de otro grupo o individuo en el área, inicia una persecución, y el grupo o individuo opositor se desplaza hacia el límite del territorio, donde los grupos comienzan una confrontación de vocalizaciones (Bravo y Sallenave 2003).

-Zona de solapamiento: porción del área de acción de un grupo compartida con otro/s grupo/s.

-Área de acción: es el área que comprende al territorio y la zona de solapamiento entre áreas (Bravo y Sallenave 2003).

Para determinar el área de acción de los grupos de aulladores, juntamente a los seguimientos de cada grupo, se registró la posición, mediante la marcación de puntos de GPS 
(Garmin Etrex 12 channel, precisión: $9 \mathrm{~m}$, DE: $5 \mathrm{~m}$ ). Se elaboraron polígonos sobre imágenes satelitales a partir de la unión de los puntos más externos usados por los aulladores, quedando así delimitada el área de acción de cada grupo.

La zona de solapamiento de los grupos se cuantificó como el porcentaje de área ecológica ocupada por más de un grupo (intersección de las áreas de acción de los grupos). A fin de evitar que el solapamiento entre grupos fuera subestimado, los sitios de estudio fueron recorridos lo suficiente como para tener certeza de que no existían otros grupos además de los registrados.

Por otro lado, el área ecológica en cada sitio, fue definida como la superficie de selva utilizada por todos los grupos, y se calculó la densidad ecológica como el número de individuos por hectárea de selva (Sokal y Rohlf 1979).

Para los cálculos de las superficies mencionados, se utilizó el programa Google Earth Pro versión 6.2.2.6613.

\section{ANÁLISIS DE DATOS}

A fin de observar posibles relaciones entre las variables de composición social y uso del espacio se realizaron análisis de regresión lineal entre el tamaño de grupo, el área de acción y las abundancias de las clases de edad/sexo de los 15 grupos de aulladores registrados. A su vez, para determinar diferencias en la composición social y uso del espacio entre los diferentes sitios, se realizaron ANOVAs con los valores de las proporciones de las distintas clases de edad/sexo, tamaño de grupo y área de acción. Los supuestos de normalidad y homogeneidad de varianza fueron evaluados mediante el test de Shapiro-Wilks y el test de Levene respectivamente realizados sobre los residuos y residuos absolutos de las variables analizadas (Zar 1984).

\section{RESULTADOS}

Se registraron 185 individuos de Alouatta caraya, pertenecientes a 15 grupos, 12 de los cuales presentaron una organización multimacho y 3 una organización unimacho. El tamaño de grupo varió de 6 a 21 individuos (media=12,3; $\mathrm{DE}=3,9 ; \mathrm{N}=15$ ). Los grupos estuvieron conformados por 2,8 machos maduros (DE=1,57), 3,2 hembras maduras ( $\mathrm{DE}=1,37), 2,7$ machos inmaduros $(\mathrm{DE}=0,82), 2,3$ hembras inmaduras $(\mathrm{DE}=0,96)$ y 1,4 infantes $(\mathrm{DE}=0,74)$. 
Se observaron correlaciones positivas entre el número de machos maduros y resto de grupo y del número de hembras maduras y resto de grupo (Figura IV-2A-B). Se evidenció un gradiente en el número máximo de machos maduros por grupo en cada sitio, registrándose grupos con 1 a 3 machos maduros en Paranacito, con 1 a 5 machos maduros en Bella Vista y con 1 a 6 machos maduros en Lavalle (Figura IV-2A).

La abundancia de machos maduros creció proporcionalmente con la abundancia de hembras maduras (Figura IV-2C) observándose mayor rango de valores en los sitios ubicados al sur del gradiente (Bella Vista y Lavalle). La relación entre machos y hembras maduros no se correlacionó con el tamaño de grupo, observándose entre 0,5 y 2 hembras maduras por macho maduro tanto en grupos pequeños como en grupos de mayor tamaño (Figura IV-2D). Esto indica que la proporción de sexos no fue diferente entre grupos pequeños y grandes. A su vez, el área de acción de los grupos mostró un incremento conjunto con el tamaño de grupo (Figura IV-2E) (Tabla IV-2). 

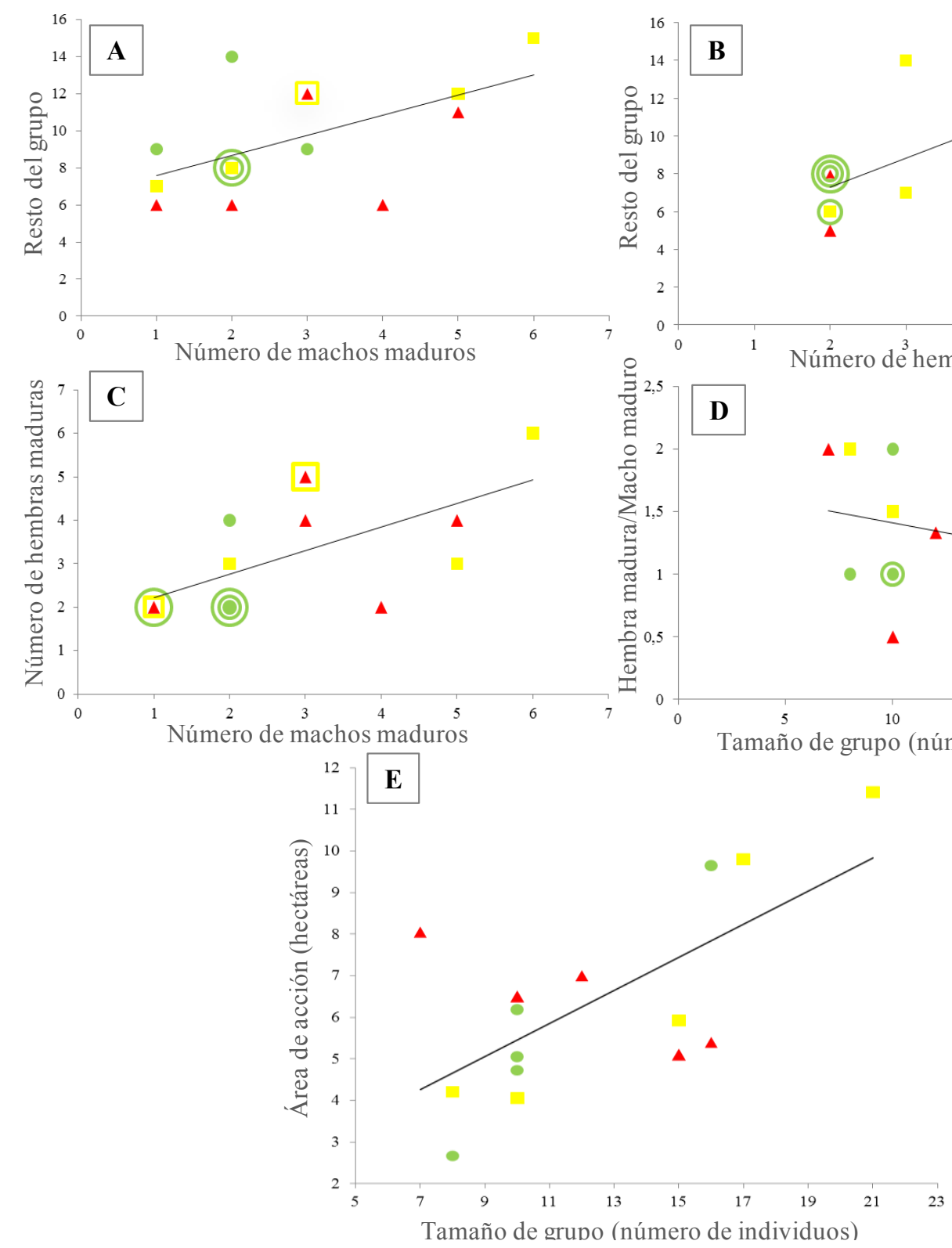
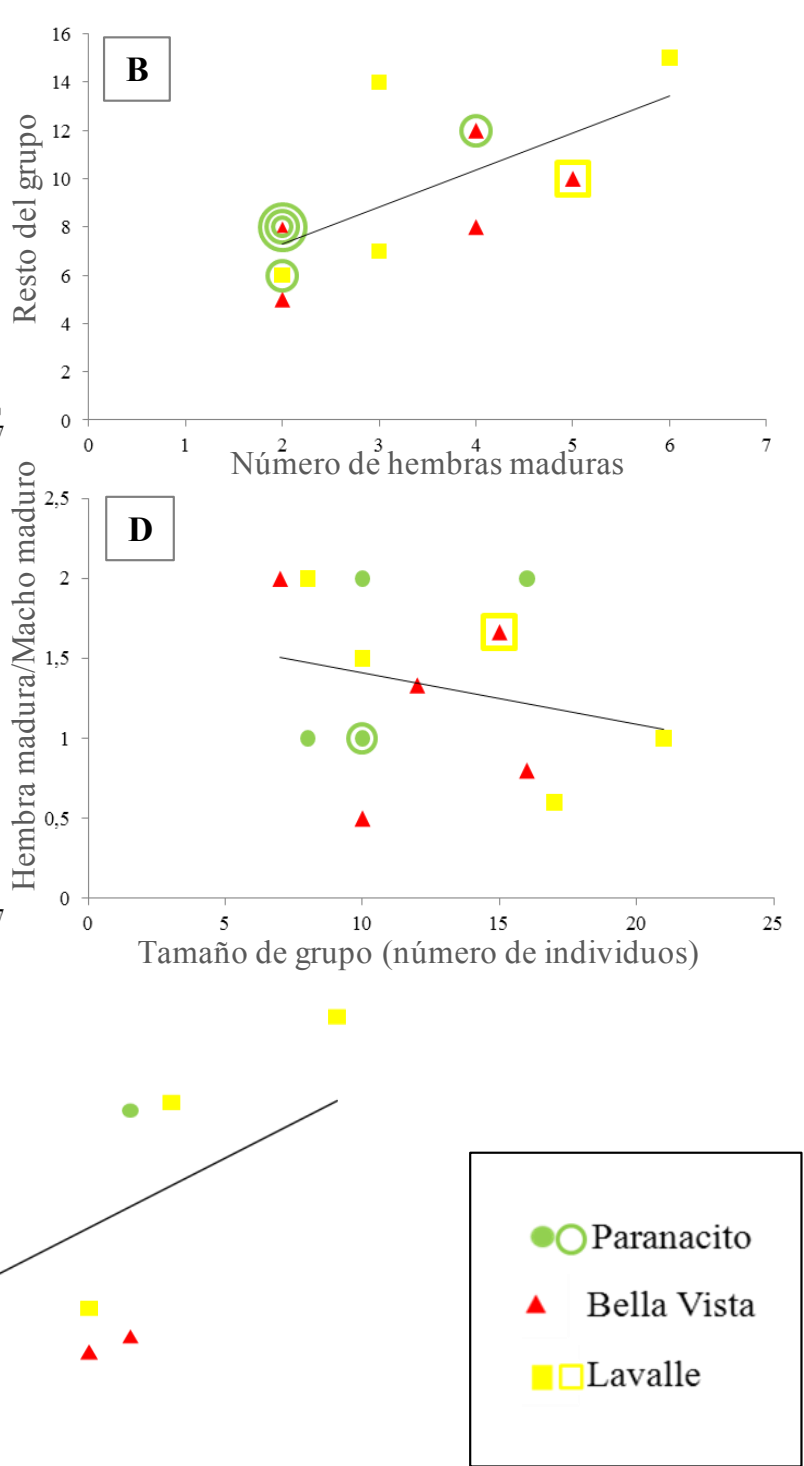

Figura IV-2. Regresiones lineales entre variables de organización/composición social y uso del espacio de 15 grupos de Alouatta caraya, registrados en 3 sitios de la selva de inundación del río Paraná Medio (Paranacito, Bella Vista y Lavalle) en el período abril 2007-marzo 2008. Referencia: cada polígono representa un grupo de aulladores.

Tabla IV-2. Regresiones lineales entre variables de la organización/composición social y uso del espacio de 15 grupos de Alouatta caraya, registrados en la selva de inundación del río Paraná Medio, en el período marzo 2007-abril de 2008. Referencias: GL: grados de libertad.

Figura Variables
A Machos maduros y resto del grupo
B Hembras maduras y resto del grupo
C Machos maduros y hembras maduras
D Tamaño de grupo y hembra madura/macho maduro
E Tamaño de grupo y área de acción

variación explicada

\begin{tabular}{cccc}
34 & 1,13 & 6,63 & $\mathbf{0 , 0 2 3}$ \\
50 & 1,13 & 13,24 & $\mathbf{0 , 0 0 3}$ \\
38 & 1,13 & 8 & $\mathbf{0 , 0 1 4}$ \\
6 & 1,13 & 0,84 & 0,376 \\
45 & 1,13 & 10,54 & $\mathbf{0 , 0 0 6}$ \\
\hline
\end{tabular}


Según los ANOVAs realizados, no se observaron diferencias significativas en el tamaño de grupo ni en el área de acción entre los sitios. Sin embargo estas variables mostraron una tendencia al incremento gradual de los valores medios hacia el sur. Tampoco se registraron diferencias significativas en la proporción de las diferentes clases de edad/sexo por grupo entre los sitios, salvo en la proporción inmaduro-infante/tamaño de grupo, maduro/tamaño de grupo e inmaduro-infante/hembra madura (Figura IV-3, Tabla IV-3).

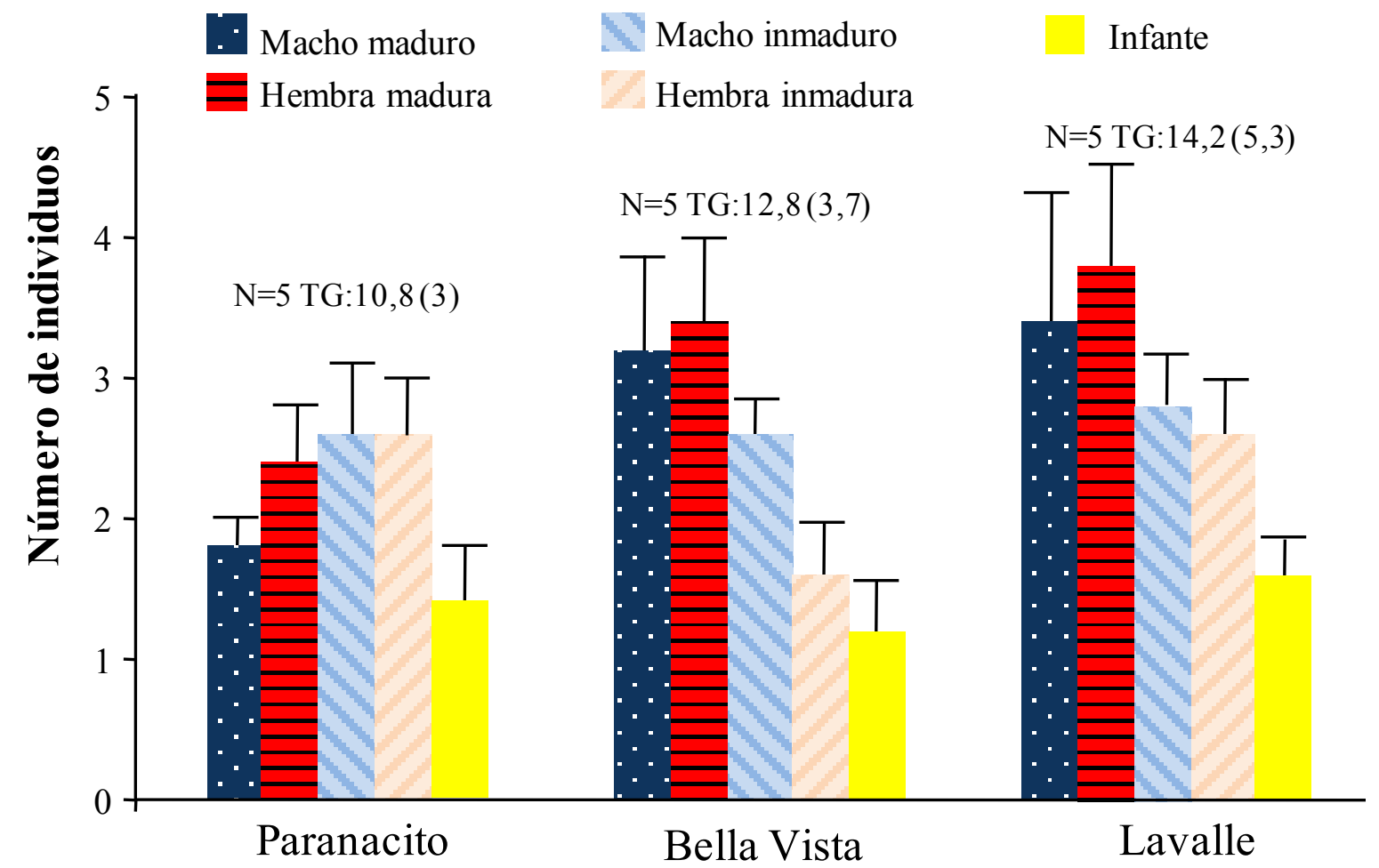

Figura IV-3. Composición social media de Alouatta caraya registrados en 3 sitios de la selva de inundación del río Paraná Medio (Paranacito, Bella Vista y Lavalle) en el período abril 2007-marzo 2008. Referencias: N: número de grupos, TG: tamaño de grupo medio, entre paréntesis: desvío estándar.

Tabla IV-3: Resultados del análisis de la varianza de variables de la organización social comparada de Alouatta caraya de 3 sitios de la selva de inundación del río Paraná Medio (Paranacito, Bella Vista y Lavalle), en el período marzo -abril de 2007. Referencias: GL: grados de libertad.

\begin{tabular}{lccccc}
\hline Variable & $\begin{array}{c}\text { Cuadrado } \\
\text { medio modelo }\end{array}$ & $\begin{array}{c}\text { Cuadrado } \\
\text { medio residuo }\end{array}$ & GL & F & $\boldsymbol{p}$ \\
\hline Tamaño de grupo & 14,867 & 16,800 & 2,12 & 0,885 & 0,438 \\
Hembra madura/tamaño de grupo & 0,005 & 0,003 & 2,12 & 2,044 & 0,172 \\
Macho maduro/tamaño de grupo & 0,009 & 0,006 & 2,12 & 1,496 & 0,263 \\
Inmaduro-infante/tamaño de grupo & 0,028 & 0,005 & 2,12 & 5,424 & $\mathbf{0 , 0 2 1}$ \\
Maduro/tamaño de grupo & 0,028 & 0,005 & 2,12 & 5,424 & $\mathbf{0 , 0 2 1}$ \\
Inmaduro-infante & 3,467 & 3,700 & 2,12 & 0,937 & 0,419 \\
Inmaduro-infante/hembra madura & 1,654 & 3,307 & 2,12 & 5,301 & $\mathbf{0 , 0 2 2}$ \\
Macho maduro/hembra madura & 0,061 & 0,228 & 2,12 & 0,269 & 0,768 \\
Área de acción & 2,530 & 6,417 & 2,12 & 0,394 & 0,682 \\
\hline
\end{tabular}


El cálculo del área de acción media, área y densidad ecológica y de solapamiento del área acción de los grupos de aulladores, produjo índices individuales por cada sitio que no permitieron comparaciones estadísticas y se reportan con fines descriptivos en la tabla IV-3. Estos valores permitieron observar leves tendencias en el uso del espacio de Alouatta caraya a lo largo del gradiente. El área ecológica varió ligeramente entre los sitios, con valores mayores hacia el sur, así como el área de solapamiento entre los grupos fue considerablemente pequeño, oscilando entre el 1 y el $8 \%$ de las áreas de acción de los grupos en cada sitio (con valores mayores hacia el sur), evidenciando territorios segregados para cada grupo. A su vez, la densidad ecológica resultó muy similar entre los sitios, con un leve incremento en Lavalle (Tabla IV-4, Figura IV-6).

Tabla IV-4. Área de acción media, área y densidad ecológica y de solapamiento de área de acción de 5 grupos de Alouatta caraya en 3 sitios de selva de inundación del río Paraná Medio (Paranacito, Bella Vista y Lavalle) en el período abril de 2007-marzo de 2008.

\begin{tabular}{lccc}
\hline Variables / Sitio & Paranacito & Bella Vista & Lavalle \\
\hline Área de acción media (hectáreas-desvío estándar) & $5,7(2,6)$ & $6,4(1,2)$ & $7,1(3,3)$ \\
Área ecológica (hectáreas) & 28 & 31 & 33 \\
Solapamiento de área de acción (\%) & 1,07 & 3,23 & 8,48 \\
Densidad ecológica (individuos/hectárea) & 1,93 & 1,93 & 2,18 \\
\hline
\end{tabular}



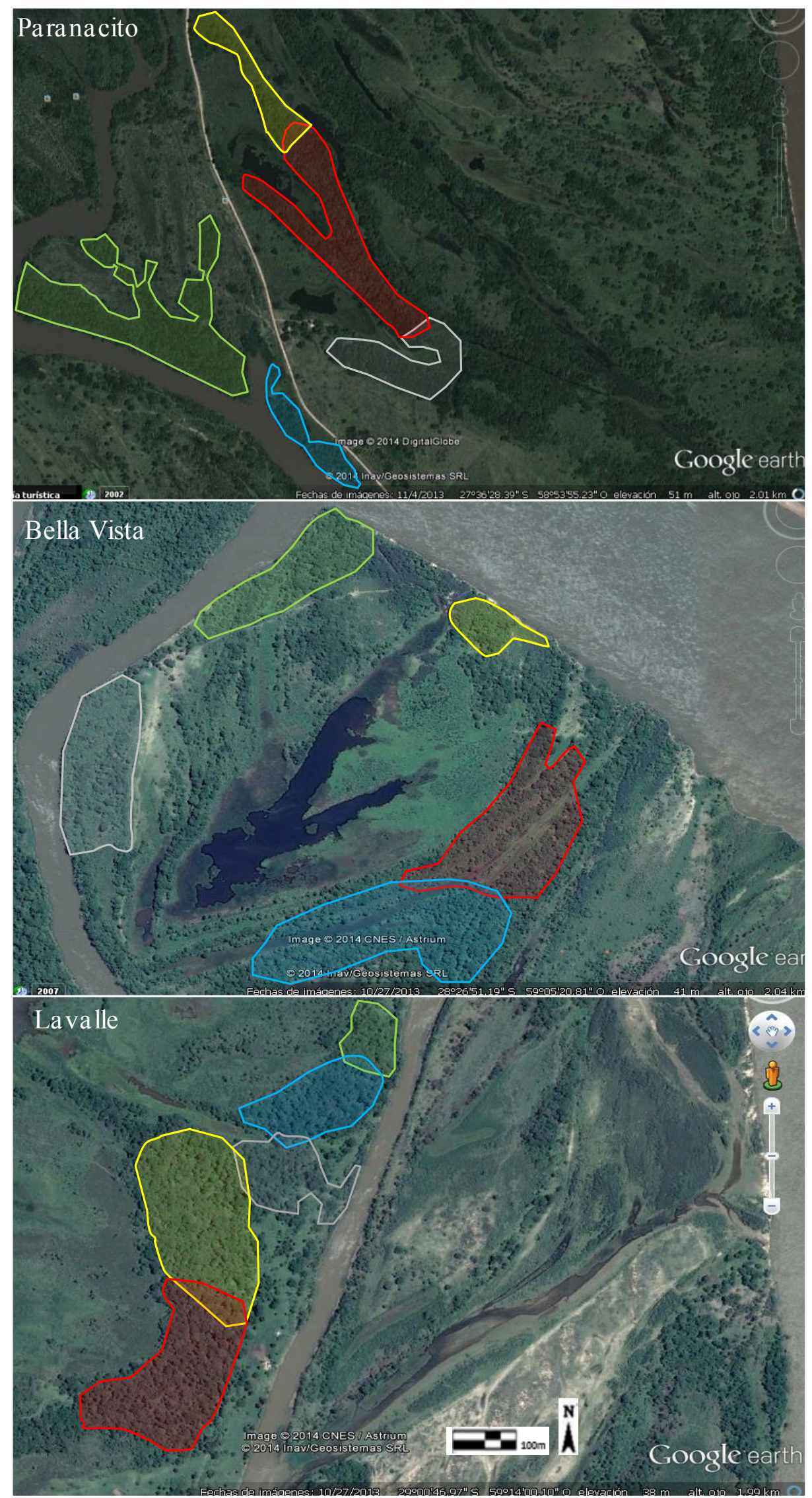

Figura IV-4. Área de acción de 15 grupos de Alouatta caraya en 3 sitios de la selva de inundación del río Paraná Medio (Paranacito, Bella Vista y Lavalle) en el período abril 2007-marzo 2008. Altitud 2 km. Imágenes satelitales del programa Google Earth Pro versión 6.2.2.6613. 


\section{DISCUSIÓN}

En el presente capítulo, se analizó la organización social, el uso del espacio y la densidad de Alouatta caraya a lo largo de un gradiente latitudinal en el extremo sur de su distribución. Los 15 grupos de aulladores estudiados fueron mayormente de tipo multimacho y presentaron un tamaño de grupo medio de 12,3 individuos y un rango de 6 a 21 individuos por grupo. La proporción de sexos siguió una relación aproximada de 1:1 que no varió entre grupos pequeños y grandes. A lo largo del gradiente, no se observaron cambios importantes en la organización social, a excepción del número de inmaduro-infantes por hembra madura, que se redujo hacia el sur. Los indicadores del uso del espacio y la densidad se mostraron estables a lo largo del gradiente estudiado y aumentaron ligeramente hacia el extremo sur de la distribución de la especie, mostrando una escasa respuesta a los cambios latitudinales en las condiciones ambientales descriptas en los capítulos previos.

\section{Tamaño de grupo}

El tamaño de grupo es un componente importante para la descripción de la organización social de los primates. En las distintas especies del género Alouatta el tamaño medio de grupo se encuentra positivamente correlacionado con la densidad poblacional, lo que a su vez depende de factores que afectan la supervivencia como enfermedades, sequías, depredación y disponibilidad de alimento (Crockett y Eisenberg 1987). Se han propuesto varios beneficios asociados al mayor tamaño de grupo, reducción del riesgo de depredación por efecto dilusorio, incremento de la vigilancia, defensa cooperativa y confusión del depredador, como así también costos asociados a una mayor distancia de viaje e incremento en la conflictividad social (Van Schaik 1989, Sterk 1997, Isbell y Young 2002). En referencia a esto último, Kowalewski (2007) sugirió que la conflictividad social (riesgo de infanticidio) y la competencia por el alimento cumplen un rol menor que las estrategias de apareamiento en la determinación de la organización social de Alouatta caraya.

En varias especies de aulladores el tamaño de grupo no parece estar asociado al tipo de bosque habitado (Crockett y Eisenberg 1987, Rudran y Fernández Duque 2003). No obstante, para Alouatta caraya se ha observado un marcado aumento del tamaño de grupo en ambientes de selva de inundación, en asociación a la mayor disponibilidad de recursos en este ambiente (Rumiz 1990, Zunino et al. 2001, Rudran y Fernández Duque 2003, Aguiar et al. 2009). En otros estudios, el tamaño de grupo de $A$. caraya varió entre 2 y 21 individuos (Tabla IV-3) lo que indica que los resultados obtenidos en esta tesis se encuentran dentro del 
rango antes mencionado. A pesar de que el estudio se llevó a cabo en un área marginal de la distribución de la especie, el valor medio de tamaño de grupo registrado (12,3 individuos) fue relativamente alto, aunque se encontró entre los valores observados para otros sitios de la selva de inundación. A lo largo del gradiente estudiado, no se observaron cambios significativos en el tamaño de grupo ni en la densidad poblacional de la especie, lo que sugiere que los cambios en las condiciones climáticas y de disponibilidad de recursos observados, no estarían afectando a estas variables.

\section{Organización social}

Varios estudios han asociado la alta densidad, el mayor tamaño de grupo, la mayor frecuencia de grupos multimacho, y la mayor natalidad de Alouatta caraya en el valle de inundación del río Paraná, a una mayor disponibilidad de recursos alimentarios (Ostro et al. 2001, Zunino et al. 2001, Kowalewski y Zunino 2004). A su vez, A. caraya se destaca por exhibir grupos multimacho con un gran número de machos maduros, pudiendo contener de 2 a 8 machos maduros y de 2 a 8 hembras maduras por grupo, aunque también son comunes los grupos unimacho con 1 a 5 hembras (Rumiz 1990, Kowalewski 2000, Zunino et al. 2001, Kowalewski y Zunino 2004). En estudios realizados en el Paraná Superior y Medio, la mayor cantidad de grupos multimacho y el mayor número de machos por grupo se correspondió con una mayor densidad de individuos (Rudran y Fernández Duque 2003, Juárez et al. 2005, Kowalewski y Zunino 2004, Aguiar et al. 2009). En éste estudio, 12 de los 15 grupos fueron multimacho, presentando de 2 a 6 machos por grupo. Como se describió anteriormente, los valores medios de densidad de individuos (2,05 ind/ha) y el tamaño de grupo (12,3 individuos por grupo) observados en el área de estudio se encuentran cerca del extremo superior conocido para la especie $(3,6$ y 3,25 ind/ha en isla Brasilera, 2,8 ind/ha en isla Guáscara, Zunino et al. 2001, Kowalewski y Zunino 2004).

En la presente tesis se observó una relación de hembras maduras por macho maduro de 1,14:1, en semejanza con lo observado por Kowalewki 2007 (relación 1,13:1) en sitios de selva de inundación. A su vez, Kowalewski y Zunino (2004) observaron un predominio de grupos multimacho en zonas de selva de inundación con árboles altos y un predominio de grupos unimacho en zonas de árboles bajos y bosques de tierra firme, lo que sugiere que el tipo de bosque también afecta la organización social. En éste contexto y en concordancia a lo observado por los autores mencionados, los valores altos de densidad poblacional, la baja proporción de hembras maduras por macho maduro (1,14:1), y la alta proporción de grupos 
multimacho observados en este estudio, parecen ser una propiedad característica de los sitios de selva de inundación.

En el presente estudio, se registró un aumento hacia el sur en el número máximo de machos maduros que poseen los grupos de aulladores, presentándose hasta 3 machos maduros en el sitio ubicado al norte, mientras que en los sitios del sur se observaron grupos con hasta 6 machos. Los análisis de correlación mostraron que el número de machos aumentó gradualmente junto con el tamaño de grupo. Sin embargo, todos los sitios presentaron una gran variación en el número de machos por grupo, indicando que no existen diferencias significativas en esta variable a lo largo del gradiente. Por lo tanto, estos resultados no sustentan la hipótesis enunciada al principio del capítulo de un mayor número de grupos unimacho en los sitios del sur en asociación a la disminución en la abundancia de alimento y un aumento en la conflictividad social por la competencia (Van Schaik 1989).

\section{Relación Inmaduro-infantes por hembra madura}

A lo largo del gradiente estudiado, la proporción de inmaduro-infantes por hembra madura se redujo de 2,8:1 en el sitio ubicado más al norte a 1,68:1 y 2,01:1 en los sitios del sur. Dicha disminución de inmaduro-infantes por hembra madura podría sugerir que la población tiene una menor actividad reproductiva o una menor supervivencia de inmaduroinfantes en los sitios del sur (Heltne et al. 1976). En áreas más centrales de su distribución, los aulladores manifestaron una proporción de inmaduro-infantes por hembra madura menores o iguales a las observadas en este estudio. Para Alouatta palliatta, Heltne et al. (1976) sugirieron que proporciones menores a 0,75:1 son indicadoras de poblaciones de aulladores en decrecimiento o en dificultades. En este contexto, Alvis Rojas (2012) observó una proporción de individuos inmaduros por hembra madura de 1,07:1 en A. seniculus de Colombia y la consideró como indicador de buena salud poblacional. En grupos de $A$. caraya de Isla Brasilera (valle aluvial del río Paraná), Kowalewski y Zunino (2004) reportaron una relación de 1:1, mientras que Zunino et al. (2007) reportaron una relación 1,24:1. Estas comparaciones muestran que las poblaciones estudiadas presentan una tasa de producción de individuos inmaduros superior a las de otros puntos de su área de distribución. Si bien los resultados obtenidos indican una disminución del éxito reproductivo de la especie (estimado por la proporción inmaduro: hembra madura) hacia el extremo sur de su distribución, los valores observados no representan una situación de riesgo o declinación de las poblaciones hacia el sur. 


\section{Uso del espacio}

En el presente estudio, la densidad de Alouatta caraya varió entre 1,93 y 2,18 ind/ha a lo largo del gradiente estudiado, lo que indica que esta variable se mantiene estable y en valores elevados hasta el límite del área de distribución de la especie. En un sector ubicado a $40 \mathrm{~km}$ del extremo norte del área de estudio, Kowalewski y Zunino (2004) observaron densidades notablemente mayores de aulladores en ambientes de selva de inundación (3,25 ind/ha) en comparación con un sitio de tierra firme cercano (0,95 ind/ha). Zunino et al. (2001) hipotetizó que la mayor densidad de aulladores en ambientes de selva de inundación se debe a una mayor disponibilidad de alimento. En este contexto, si la densidad poblacional de aulladores es un indicador de la capacidad de carga del ambiente (Stevenson et al. 2000) la variación observada de la densidad a lo largo del gradiente estudiado no indicaría una disminución de la disponibilidad de recursos alimentarios hacia el extremo sur de la distribución de A. caraya.

\section{Relación área de acción-tamaño de grupo}

El área de acción media de los grupos de aulladores estudiados dentro de cada sitio, varió desde 5,7 ha (Paranacito) a 7,1 ha (Lavalle), con un valor extremo de 11,41 ha en un grupo de 21 individuos registrado en el sitio de Lavalle. Estos resultados se ubican por encima del límite superior de los reportados en otros estudios sobre la especie, que varían desde 1,7-2.2 ha (Bravo y Sallenave, 2003) hasta 5-6 ha (Zunino 1989, Kowalewski 2007). En otras especies de aulladores el área de acción varió de 4 ha a 182 ha, presentando amplias diferencias dentro de una misma especie (Di Fiore y Campbell 2007). En comparación con estos datos y considerando los reportes realizados hasta el presente, Alouatta caraya parece ser una especie con menores requerimientos espaciales que otras especies de aulladores. Los resultados reportados aquí extienden el límite superior conocido del área de acción de la especie.

En este estudio se observó una correlación positiva entre el área de acción y el tamaño de grupo similar a lo observado por otros autores (Jay 1965, Schoener 1971, Berstein 1982). Los mayores requerimientos energéticos de los grupos grandes impulsarían a los individuos a recorrer mayores distancias en busca de alimento (Stallings et al. 1989, Sekulic 1982), resultando en un incremento en el área de acción. De este modo, el valor de área de acción observado, estaría asociado en parte a la presencia de grupos de gran tamaño. Si bien la mayor distancia de viaje puede representar un costo energético para los individuos, se ha estimado que el mismo es de sólo un 0,05\%-0,2\% del presupuesto energético diario (Steudel 
2000). Otros estudios, relacionan el área de acción a la productividad de los parches de bosque habitados por los aulladores (Neville 1972, Gaulin y Gaulin 1982, Crockett y Eisenberg 1987, Stevenson et al. 1991, Palacios y Rodríguez 2001). Sin embargo, la ausencia de diferencias significativas en el área de acción de los grupos y la homogeneidad de la densidad poblacional entre los sitios estudiados sugiere que no existirían diferencias importantes en la disponibilidad de alimentos a lo largo del gradiente latitudinal estudiado.

En conclusión, la información recabada indica que en líneas generales, las poblaciones de aulladores mantienen las características de organización social y el uso del espacio dentro de los valores conocidos en latitudes menores para ambientes de selva de inundación. A lo largo del gradiente considerado, a pesar de la proximidad al extremo sur de la distribución de la especie no se observaron cambios importantes en la densidad local que sugieran una respuesta al paulatino incremento de la rigurosidad ambiental a latitudes mayores. Estos resultados indican que las variables demográficas de la especie se mantienen relativamente estables hasta sitios muy cercanos al límite sur de la distribución de la especie, luego de lo cual las densidades disminuirían de manera abrupta determinando la ausencia de la especie en el sitio ubicado más al sur (Esquina). 


\section{CAPÍTULO V}

\section{DISCUSIÓN GENERAL Y CONCLUSIONES}

\section{FACTORES QUE AFECTAN LA ABUNDANCIA DE LOS AULLADORES EN EL EXTREMO SUR DE SU DISTRIBUCIÓN GEOGRÁFICA}

Según Gaston (2009), una de las principales dificultades para comprender las causas de los límites de distribución de las especies ha sido la falta de integración de los distintos campos de investigación. En esta tesis se abordó el estudio de los factores que determinan el límite sur de distribución de Alouatta caraya, incluyendo el estudio del ambiente (clima y recursos), la alimentación, el uso del espacio y la organización social de la especie. El análisis de los límites de distribución de las especies puede ser considerado como un caso particular de estudio de la variación del tamaño poblacional a través del espacio (Gaston 2009). Las variables demográficas que afectan la abundancia de una población a nivel local son natalidad, mortalidad, inmigración y emigración. De esta manera, los límites de distribución se encuentran determinados por la variación en una o más de estas variables demográficas que producen tendencias poblacionales negativas por una combinación de factores ambientales e interacciones entre especies.

Muchos autores han abordado el estudio de los límites de distribución y los factores que determinan la abundancia local de distintas especies de primates (Horwich y Johnson 1986, Pinto et al 1997, Iwanaga y Ferrari 2002, Navarro Fernandez et al. 2003, Luecke 2004, Baumgarten y Williamson 2007). Dado que las áreas de distribución de todas las especies de aulladores en Sudamérica siguen un patrón fundamentalmente parapátrido (Figura I-3), con escasas áreas de simpatría, se ha argumentado que los límites de distribución estarían delimitados principalmente por interacciones entre especies (Holzmann 2012). Por este motivo, la mayoría de los estudios sobre los límites de distribución de los aulladores se concentraron en las zonas de contacto entre especies, para comprender los factores causantes de la segregación de las áreas (Di Bitetti et al. 1994, Crockett, 1998, Iwanaga y Ferrari 2002, Baumgarten y Williamson 2007, Holzmann 2012). En algunos casos los límites de distribución, se han asociado a diferencias en la preferencia de hábitat entre las especies, fundamentalmente al tipo de bosque ocupado (Baumgarten y Williamson 2007). Sin embargo, es importante tener en cuenta que los límites de distribución de muchas especies son altamente dinámicos y pueden cambiar por factores tales como la ocurrencia de brotes epidémicos, cacería, pérdida y fragmentación de hábitat por desforestación (ej. fiebre 
amarilla; Holzmann 2012). Desde otra perspectiva, los estudios que intentan explicar las variaciones en la abundancia de los aulladores a nivel local podrían ser útiles para comprender los límites de distribución. Cambios relativamente menores en la estructura de los bosques parecen tener un gran impacto en la abundancia de aulladores en ambientes de selva de inundación (Bravo y Sallenave 2003, Kowalewski 2007).

A partir de los datos recabados en la presente tesis y mediante una revisión de la bibliografía es posible valorar la importancia de las diferentes variables demográficas y los factores ambientales que podrían determinar el límite sur de la distribución de Alouatta caraya. A continuación se discute por separado cada una de estas variables demográficas para luego integrarlas en un esquema que permita comprender la variación en el tamaño poblacional de la especie.

\section{Natalidad}

Uno de los factores que podría afectar el límite sur de la distribución de Alouatta caraya, es la disminución de la natalidad en zonas marginales de su rango geográfico. El número de infantes por hembra es comúnmente utilizado como indicador de natalidad en el género Alouatta (Heltne et al. 1976, Kowalewski y Zunino 2004). En el capítulo IV, se observó una disminución en el número de inmaduro-infantes por hembra madura en los sitios del sur, sugiriendo una menor natalidad hacia el límite sur de la distribución de la especie. Los datos recabados en el capítulo II mostraron que la diversidad y abundancia de árboles utilizados como recurso por A. caraya disminuyeron hacia los sitios del sur. A su vez, en el capítulo III se observaron cambios en la dieta que indicarían una mayor estacionalidad y una menor utilización de frutos como recurso en el sitio con presencia de aulladores ubicado más al sur. De acuerdo con estos datos es posible argumentar que los cambios en la disponibilidad de los recursos y en la dieta podrían estar incidiendo en los patrones de natalidad de la especie. En sitios cercanos al área de estudio, se ha observado que los patrones de natalidad de los aulladores se encuentran en asociación con la variabilidad estacional de los recursos. Los ambientes de selva de inundación presentan tasas de nacimientos casi constantes a lo largo del año, en asociación a una baja variación en la disponibilidad de hoja joven y hoja madura. En cambio, en los sitios de tierra firme, los nacimientos se concentran en las épocas de invierno, lo que determina que la época de destete de las crías coincida con la mayor disponibilidad de hoja joven (Kowalewski y Zunino 2004). En base a la información recabada en la presente tesis, no es posible avanzar con este argumento ya que no se dispone 
de datos suficientes para conocer la variación estacional en los índices de natalidad y asociarlo con la variación en los recursos.

La disminución observada en los valores de natalidad podría indicar que las poblaciones del sur sean menos viables y presenten mayores probabilidades de extinción en el tiempo. Sin embargo, los valores de natalidad reportados en el capítulo IV fueron notablemente mayores que otros registrados en áreas más centrales del rango geográfico de la especie. Por este motivo, los datos recabados no indicarían que las variaciones en la natalidad constituyan un factor clave en la distribución de la especie, aunque podrían sugerir una ligera disminución en la aptitud de los aulladores hacia el sur de su área de distribución.

\section{Mortalidad}

\section{Factores que afectan las tasas de mortalidad en el género Alouatta}

El incremento en la mortalidad hacia el límite sur de su área de distribución, fue planteado en esta tesis inicialmente como posible factor determinante del rango geográfico. Dicha hipótesis se basa en que el incremento de la rigurosidad climática y la disminución de los recursos pueden afectar la ecología alimentaria de la especie, impactando negativamente en la supervivencia. Entre los factores asociados al incremento de la mortalidad de los aulladores se han citado enfermedades (ej. fiebre amarilla), depredación, cacería, escasez de alimento, mortalidad directa por frío o intolerancia a bajas temperaturas, sequía (Heltne et al. 1976, Crockett 1985, Holzmann 2012, Arzamendia com. pers., Zunino com. pers.). En cuanto a factores de mortalidad de infantes, esta se ha correlacionado con la disminución de disponibilidad de hojas maduras (Pavé et al. 2012), el reemplazo de machos dominantes e infanticidios asociados (Crockett 2003, Van Belle et al. 2010, Zunino et al. 1986), así como también caídas accidentales, incremento en infecciones parasitarias relacionadas con disturbios ambientales (Kowalewski y Gillespie 2009).

Los análisis de la variación climática permitieron observar que el límite sur de la distribución de Alouatta caraya se asocia con la estacionalidad en la temperatura, mientras que el límite oeste con la estacionalidad en las precipitaciones. Hacia el sur, la disminución de la temperatura media y el aumento de la estacionalidad (capítulo II) podrían dar lugar a períodos críticos para la supervivencia de los individuos, como fue observado para otras especies de mamíferos (Krebs 1985, Lomolino et al. 2005). Sin embargo, la amplia disponibilidad de agua en la llanura aluvial sugiere que la escasez de precipitaciones no sería relevante en la selva de inundación. Adicionalmente, muchos estudios indican una gran tolerancia de la especie al frío (Lindbergh 1976, Giudice y Ascunce 1998, Bruno 2011), que 
es un factor cuya importancia estaría atenuada en el valle aluvial del Paraná por el efecto atemperador de las masas de agua. Finalmente, es importante destacar que los ambientes estudiados carecen de depredadores naturales, y la presión de caza por parte de los pobladores locales es prácticamente inexistente (Pautasso 2008). En relación a la ocurrencia de enfermedades, se han citado casos de epidemia (fiebre amarilla) que pueden causar la extinción local de las poblaciones de aulladores (Holzmann 2012, Zunino com. pers.). Sin embargo, no hay razones para pensar que eventos de fiebre amarilla sean más frecuentes o letales hacia el sur. Hasta el momento, los brotes epidémicos se han registrado en latitudes menores y la enfermedad se asocia fundamentalmente a ambientes tropicales (World Health Organization 2000, Monath 2001).

El análisis de la dieta como evidencia de respuestas adaptativas de la especie en el extremo sur de su distribución

Pocos estudios han abordado la relación entre la disponibilidad y uso de recursos y la supervivencia de los aulladores. Existen algunos reportes sobre la disminución del tamaño poblacional en años donde los bosques tienen menor producción de alimentos (Crockett y Eisenberg 1987). En esta tesis, se analizó el comportamiento alimentario de la especie mediante tres métodos diferentes, permitiendo ampliar notoriamente el espectro trófico conocido para Alouatta caraya, con el registro de 36 especies consumidas, incorporando nuevas al conjunto de registradas por estudios anteriores (Zunino 1987, Bravo y Sallenave 2003, Kowalewski 2007). El consumo de hojas representó el 74,7\% del tiempo alimentario, el de frutos, $17,7 \%$ y el de flores $7,6 \%$, indicando una dieta con una menor representación de los frutos que en estudios anteriores (Zunino 1989, Bicca Marques y Calegaro Marques 1994b, Bravo y Sallenave 2003, Delgado 2006, Kowalewski 2007). A su vez, la gran similitud dietaria entre las clases de edad/sexo observada, se relacionaría con requerimientos nutricionales similares en cuanto al desarrollo sexual y ontogenético de los individuos. Los patrones de selectividad fueron similares entre los sitios indicando la preferencia recurrente por un grupo reducido de especies que mostraron características asociadas a una mayor palatabilidad.

En cuanto al cambio en la disponibilidad de recursos a lo largo del tiempo y del espacio, se observaron períodos de disminución estacional de algunas estructuras vegetales. Sin embargo, la variación estacional en la alimentación no mostró diferencias notorias entre los sitios. De los recursos analizados, los frutos fueron los que mayor variación estacional presentaron, seguidos por las hojas jóvenes y las hojas maduras. Las asociaciones observadas entre los datos de disponibilidad y consumo indican una buena capacidad de ajuste de la 
dieta a la variación estacional y latitudinal en la disponibilidad de recursos. En los sitios del sur, se observó un menor consumo de frutos durante las estaciones de menor disponibilidad (invierno) indicando una reducción en la calidad de la dieta. En años climáticamente desfavorables, estas condiciones de escasez de frutos podrían acentuarse o permanecer durante períodos más prolongados, afectando potencialmente la supervivencia de los aulladores en las poblaciones del sur. Crockett y Eisenberg (1987) mencionaron que las fallas en la producción de frutos y hojas durante períodos desfavorables podría ser una de las razones de la reducción del tamaño de grupo en los aulladores. Aunque existen estudios que indican que los aulladores, a diferencia de otros primates neotropicales, no muestran variaciones poblacionales en asociación a la disponibilidad de frutos (Stevenson et al. 2000), los mismos no contemplaron la estacionalidad térmica de los ambientes ya que fueron realizados en ambientes tropicales. Tomados en conjunto, los datos de ecología alimentaria de la especie indican pequeñas diferencias cualitativas en la dieta y en la disponibilidad de recursos que podrían sugerir la presencia de períodos críticos más intensos en las poblaciones al sur del gradiente.

\section{Inmigración}

Los límites de distribución de las especies pueden establecerse en base a barreras que impiden la dispersión tales como accidentes geográficos (Johns y Skorupa 1987, Peres 1990, Robinson y Bennett 2000). En el valle aluvial del río Paraná, los grandes cursos de agua, en muchos casos de varios kilómetros de extensión, podrían representar barreras para la dispersión de la especie. Por ejemplo, parte del límite entre la distribución de Alouatta pigra y $A$. palliata se ha asociado a la presencia del río Dulce y el lago de Izabal al este de Guatemala (Baumgarten y Williamson 2007). Sin embargo, A. caraya es capáz de nadar (Aguiar et al. 2007b), pudiendo desplazase muchos kilómetros hacia el sur a través del valle aluvial del Paraná luego de grandes inundaciones (Zunino com. pers.). Los desplazamientos de individuos de aulladores entre islas diferentes son comunes (Froehlich y Thorington 1982, Feeley y Terborgh 2005, Gonzalez Socoloske y Snarr 2010). Por este motivo, la capacidad de dispersión de la especie no sería un limitante para colonizar sitios al sur del límite de su distribución.

\section{Emigración}

Los aulladores pueden emigrar hacia otros sitios si no encuentran condiciones adecuadas en el ambiente. Si bien no hay datos concretos sobre los efectos de la emigración en la dinámica 
poblacional de los aulladores, se ha observado que estos primates pueden ser muy selectivos en cuanto al tipo de bosque que habitan. Kowalewski (2007) y Bravo y Sallenave (2003) reportaron marcadas diferencias en la densidad de aulladores entre zonas adyacentes de bosques dentro de una misma isla que sólo mostraban diferencias en la altura de los árboles. A lo largo del gradiente estudiado se observó una disminución en la diversidad, la abundancia y la riqueza de especies vegetales que representan cambios graduales en la estructura del bosque. En el sitio de Esquina se registró una menor abundancia de las especies de árboles de gran porte, que son preferentemente utilizadas como soporte por los aulladores en los otros sitios. Zunino et al. (2001), mencionaron que la densidad de árboles portadores de frutos afecta la abundancia de los aulladores sugiriendo que es el número de árboles (y no el área basal) la variable que podría afectar mayormente a los aulladores.

Los límites observados de la distribución de Alouatta caraya tanto hacia el oeste en las provincias de Chaco y Santa Fe como hacia el sur en la provincia de Corrientes coinciden con gradientes climáticos en las precipitaciones, pero fundamentalmente parecen ser definidos por los cambios fisonómicos de la vegetación (Cabrera 1976, Carnevali 1994, Zunino et al. 1995). Hacia el oeste en la provincia de Chaco se da lugar a los ambientes del Chaco seco y en Santa Fe a los Bajos Submeridionales (con predominio de vegetación herbácea) y hacia el sur de Corrientes el espinal-pastizal correntino, lo que no favorece la presencia de los aulladores, dado su hábito arborícola (Crockett 1998, Einsenberg y Redford 1999). Por esto, los aulladores no extenderían su rango geográfico hacia estos sitios por un proceso de selección de hábitat, al no dispersarse a sitios donde la estructura del bosque no es la adecuada para el establecimiento de la especie o porque el mismo se halla progresivamente más fragmentado. Sin embargo, una evaluación pormenorizada de estas relaciones requiere de estudios más detallados sobre la estructura del bosque y la densidad de aulladores.

\section{Tamaño poblacional}

Los estudios teóricos sobre la variación de la densidad poblacional a lo largo del rango de distribución de las especies prevén una disminución gradual desde el centro del área de distribución hacia los límites del rango geográfico (Hengeveld y Haeck 1982, Brown 1984). Sin embargo los estudios empíricos de un gran número de especies muestran que la densidad poblacional a nivel local no necesariamente disminuye hacia los límites de distribución de las especies, sino más bien, existe un incremento en la fragmentación de las poblaciones (Gaston 2003, Gilman 2006, Yakimowski y Eckert 2007). La disminución en densidad es 
sólo observable cuando se promedian áreas más grandes. Para el caso del río Paraná Medio, la densidad poblacional dentro de islas individuales (que fueron la unidad de trabajo de este estudio), no varió hacia el límite de distribución de la especie. Sin embargo, no existen datos sobre los patrones de ocupación que abarquen un mayor número de islas y permitan establecer un cálculo de la densidad poblacional sobre áreas mayores, un aspecto interesante que podrían abordar futuras investigaciones. También se podría analizar la distribución de las unidades de paisaje potencialmente utilizables por los aulladores a lo largo del valle aluvial del río Paraná Medio. Estos estudios podrían establecer si existe un incremento en la fragmentación de los bosques y en la superficie cubierta por pastizales que podrían impactar negativamente sobre las poblaciones de aulladores.

\section{CONSIDERACIONES FINALES}

En resumen, a lo largo del gradiente estudiado se observaron una serie de cambios paulatinos tanto en los factores ambientales (recursos y condiciones climáticas), en la ecología trófica (composición de la dieta) y en la organización social. Sin embargo, en ninguno de estos factores se observaron diferencias abruptas que indiquen la presencia de un límite definido. Posiblemente, dentro del rango de valores de cada factor que cambia gradualmente (ej. temperatura) exista un umbral de tolerancia de la especie. A su vez, es probable que no exista un único factor, sino un conjunto de factores actuando sinérgicamente que produzcan un efecto limitante sobre las poblaciones (ej.: individuos mal nutridos, afectados por bajas temperaturas, en poblaciones con menor natalidad). Las condiciones progresivamente más rigurosas hacia el sur de la distribución de la especie no sólo condicionarían la natalidad y la mortalidad, sino que desalentarían la dispersión de nuevos individuos hacia esos sitios, reduciendo las probabilidades de recolonización.

El enfoque de estudio utilizado permitió ampliar los conocimientos sobre la ecología trófica de Alouatta caraya. Sin embargo, los resultados sobre los factores que determinan el límite sur de la distribución no fueron concluyentes. De esta manera, esta línea de investigación podría ser suplementada con la aplicación de herramientas de información geográfica que incluyan un conjunto más amplio de factores ambientales y variables ecológicas (Wiens y Graham 2005, Heikkinen et al. 2006, Phillips et al. 2006, Rödder et al. 2008). Además, se requieren estudios intensivos sobre la dinámica poblacional y ecología nutricional de la especie en ambientes favorables y desfavorables y los posibles efectos de las actividades humanas sobre la misma (caza, destrucción y fragmentación de hábitat). La determinación de factores que afectan las variables demográficas de las especies resultan de 
gran interés tanto para comprender el rango actual de distribución de la especies como para encarar medidas de manejo tendientes la conservación de la especie.

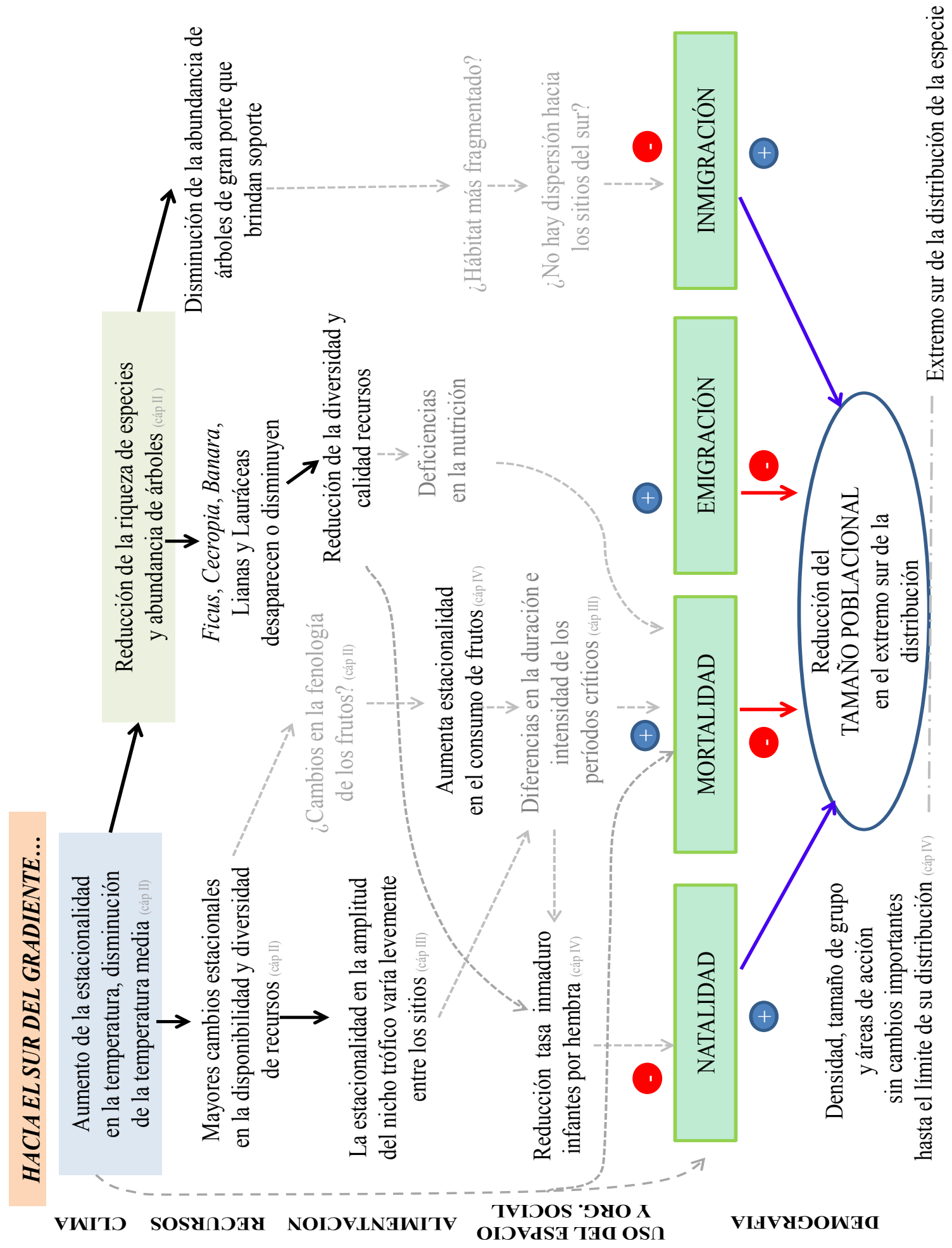

Figura V-1. Diagrama de flujo que integra los procesos que afectan la dinámica poblacional de Alouatta caraya en el extremo sur de su distribución geográfica, en la selva de inundación del río Paraná Medio. El diagrama muestra la relación entre los cambios que ocurren en el clima, los recursos, la alimentación y las variables poblacionales hacia el sur del gradiente latitudinal estudiado. Las flechas en color negro representan relaciones observadas en la tesis y en color gris las inferidas de la bibliografía. Estos conectores denotan asociación pero no establecen causalidad. 


\section{BIBLIOGRAFÍA}

Aguiar LM, Reis NR, Ludwig G, Rocha VJ. 2003. Dieta, área de vida, vocalizações e estimativas populacionais de Alouatta guariba em um remanescente florestal no norte do estado do Paraná. Neotrop Primates 11(2):78-86.

Aguiar LM, Mellek DM, Abreu KC, Boscarato TG, Bernardi IP, Miranda JMD, Passos FC. 2007a. Sympatry of Alouatta caraya and Alouatta clamitans and the rediscovery of free-ranging potential hybrids in southern Brazil. Primates 48:245-248.

Aguiar LM, Ludwig G, Svoboda WK, Hilst CLS, Navarro IT, Passos FC. 2007b. Occurrence, local extinction and conservation of primates in the corridor of the Upper Paraná River, with notes on other mammals. Rev Bras Zool 24:898-906.

Aguiar LM, Ludwig G, Passos FC. 2009. Group size and composition of black-and-gold howler monkeys (Alouatta caraya) on the Upper Paraná River, southern Brazil. Primates 50:74-77.

Altmann J. 1974. Observational study of behavior: sampling methods. Behaviour 49:227-267.

Alvarez de León CI, Archila Paiz AP. 1988. Caracterización física y química del fruto Sapindus saponaria (jaboncillo) y su potencial de industrialización como fuente de saponinas [tesis ingeniero químico]. [Guatemala, Guatemala]; Universidad de San Carlos de Guatemala.

Alvis Rojas NA. 2012. Patron de actividad, dieta, área de actividad y dispersión de semillas de Alouatta seniculus en un fragmento de bosque en San Juan del Carare (Santander) [tesis maestría]. [Ibagué, Tolima, Colombia]: Universidad del Tolima.

Anaya Lira M, Cifuentes Calderón P, Ducoing Watty A, Sánchez Trocino M, Gutiérrez Olvera C. 2010. Determinación de nutrientes en la dieta ofrecida a monos aulladores (Alouatta palliata y A. pigra.) en el Zoológico de Chapultepec. REDVET [Internet] 11(3):[alrededor de 10p.] [consultado 2015 jun 29]. Disponible en: http://www.veterinaria.org/revistas/redvet/n030310/031024.pdf

Andresen E. 1999. Seed dispersal by monkeys and the fate of dispersed seeds in a Peruvian rain forest. Biotropica 31:145-158.

Andresen E. 2005. Interacción entre primates, semillas y escarabajos coprófagos en bosques húmedos tropicales: un caso de diplocoria. Universidad y Ciencia, 2, 73-84.

Anthony RG, Smith NS. 1974. Comparison of rumen and fecal analysis to describe deer diets. J Wildlife Manage 38:535-540.

Arriaga MO. 1986. Metodología adaptada al estudio de hábitos alimentarios en insectos herbívoros. Rev Mus Arg Cienc Nat Bernardino Rivadavia Botánica 11:103-111.

Arriaga MO, Antonijevic V, Stampacchio ML, Faggi AM. 2004. Cauquenes: competidores o comensalistas ovinos? Un estudio de caso para Tierra del Fuego, Argentina [resumen]. En: II Reunión Binacional de Ecología; 2004 Oct 31-Nov 5; Mendoza. Buenos Aires: Asociación Argentina de Ecología. 
Arzamendia V, Giraudo AR. 2009. Influence of large South American rivers of the Plata Basin on distributional patterns of tropical snakes: a panbiogeographical analysis. J Biogeograph 36(9):17391749.

Ascunce MS, Hasson E, Mulligan CJ, Mudry MD. 2007. Mitochondrial sequence diversity of the southernmost extant New World monkey, Alouatta caraya. Mol Phylogen Evol 43:202-215.

Basadonna J. 2002. Complejo Rosafé. El río: desarrollo del interior. En: Borthagaray JM, editor. El Río de la Plata como territorio. Buenos Aires: Ediciones Infinito, FADU, FURBAN. p 247-267.

Baumgarten A, Williamson GB. 2007. Distribution of the black howler monkey (Alouatta pigra) and the mantled howler monkey (A. palliata) in their contact zone in eastern Guatemala. Neotropical Primates 14:11-18

Baumgartner LL, Martin AC. 1939. Plant histology as an aid in squirrel food-habitat studies. J Wildlife Manage 3:266-268.

Bazzalo M. 2001. Estudio de la dieta folívora del mono aullador negro (Alouatta caraya) mediante el método de análisis microscópico de las heces. Rev Mus Arg Cienc Nat n.s. 3(2):147-157.

Belovsky GE. 1978. Diet optimization in a generalist herbivore: the moose. Theor Popul Biol 14(1):105-134.

Belovsky GE. 1984. Herbivore optimal foraging: a comparative test of three models. Am Nat 124(1):97-115.

Beltzer A, Neiff JJ. 1992. Distribución de las aves en el valle del río Paraná: relación con el régimen pulsátil y la vegetación. Ambiente Subtrop 2:77-102.

Bennett C L, Leonard S, Carter S. 2001. Abundance, diversity, and patterns of distribution of primates on the Tapiche River in Amazonian Peru. Am J Primatol 54:119-126.

Benzécri JP. 1973. L'analyse des donées. Volume 2, L'analyse des correspondances. París: Dunod. 619 p.

Bernstein IS. 2007. Social mechanisms in the control of primate aggression. En: Campbell C, Fuentes A, MacKinnon K, Panger M, Bearder S, editors. Primates in perspective. Oxford: Oxford Univ Pr. p $562-571$

Berstein RA. 1982. Foraging - area size and food density: some predictive models. Theor Popul Biol 22:309-323.

Bertonatti C. 1995. El comercio de primates en la República Argentina. Neotrop Primates 3(2):3537.

Bezanson M, Garber PA, Murphy JT, Premo LS. 2008. Patterns of subgrouping and spatial affiliation in a community of mantled howling monkeys (Alouatta palliata). Am J Primatol 70(3):282-293.

Bianchi AR, Cravero SAC, Elena H. [internet]. 2013. SIG climático de Argentina [mapa en internet]. Buenos Aires: [INTA] Instituto Nacional de Tecnología Agropecuaria. [actualizada 2013 mayo 13; consultado 2014 oct 6]. Disponible en: http://geointa.inta.gov.ar/web/index.php/sig-climatico-deargentina/. 
Bianchi RDC, Mendes SL. 2007. Ocelot (Leopardus pardalis) predation on primates in Caatinga Biological Station, southeast Brazil. Am J Primatol 69:1173-1178.

Bicca Marques JC. 1990. A new southern limit for the distribution of Alouatta caraya in Río Grande do Sul State, Brazil. Primates 31(3):449-451.

Bicca Marques JC. 2003. How do howler monkeys cope with habitat fragmentation? En: Marsh LK, editor. Primates in fragments: ecology and conservation. New York: Kluwer Academic/Plenus Pub. p 283-303.

Bicca Marques JC, Calegaro Marques C. 1993. Feeding postures in the black howler monkey, Alouatta caraya. Folia Primatol 60(3):169-172.

Bicca Marques JC, Calegaro Marques C. 1994a. Feeding behavior of the black howler monkey (Alouatta caraya) in a seminatural forest. Acta Biol Leopoldensia 16(2):69-84.

Bicca Marques JC, Calegaro Marques 1994b. Activity budget and diet of Alouatta caraya: an agesex analysis. Folia Primatol 63:216-220.

Bicca Marques JC, Calegaro Marques C. 1995. Locomotion of black howlers in a habitat with discontinuous canopy. Folia Primatol 64:55-61.

Bó RF. 2006. Situación ambiental en la ecoregión delta e islas del Paraná. En: Brown A, Martinez Ortiz U, Acerbi M, Corcuera J, editors. La situación ambiental Argentina 2005. Buenos Aires: Fundación Vida Silvestre Argentina. p 131-143.

Böhm M, Mayhew PJ. 2005. Historical biogeography and the evolution of the latitudinal gradient of species richness in the Papionini (Primata: Cercopithecidae). Biol J Linn Soc 85(2):235-246.

Bonetto AA, Drago E. 1968. Consideraciones faunísticas en torno a la delimitación de los tramos superiores del río Paraná. Physis 27(75):437-444.

Bonetto AA, Hurtado S. 1998. Región 1: cuenca del Plata. En: Canevari P, Blanco DE, Bucher E, Castro G, Davidson I, editors. Los humedales de la Argentina: clasificación, situación actual, conservación y legislación. Buenos Aires: Wetlands International, SRNyDS. Publication 46; p 3372.

Bonetto AA, Orfeo O. 1984. Caracteres sedimentológicos de la carga en suspensión del río Paraná entre Corrientes y Esquina (Rep. Argentina). Rev Asoc Arg Mineral Petrol Sedimentol. 15(3-4):5161.

Bonvicino CR. 1989. Ecologia e comportamento de Alouatta belzebul (Primates: Cebidae) na Mata Atlântica. Rev Nordestina Biol. 6(2):149-179.

Bonvissuto GL, Borrelli L. 2007. Obtención de muestras En: III Jornadas sobre el método microhistológico y su aplicación al análisis de la dieta de herbívoros. 2007 setiembre 6-7; San Carlos de Bariloche. Bariloche: [INTA, EEAA] Insituto Nacional de Tecnología Agropecuaria, Estación Experimental Agropecuaria Bariloche.

Bradbury JW, Vehrencamp SL, editors. 1998. Principles of animal communication. $1^{\text {st }}$ ed. Sunderland (MA): Sinauer Assoc. 881p. 
Braga R. 1960. Plantas do Nordeste, especialmente do Ceará. $2^{\circ}$ ed. Fortaleza (Ceará, Brasil): Imprensa Oficial. $540 \mathrm{p}$.

Bravo SP, Sallenave A. 2003. Foraging behavior and activity patterns of Alouatta caraya in the northeastern Argentinean flooded forest. Int J Primatol 24(4):825-846.

Bravo SP, Zunino GE. 1998. Effects of black howler monkey (Alouatta caraya) seed ingestion on insect larvae. Am J Primatol 45:411-415.

Bravo SP, Zunino GE. 2000. Germination of seeds from three species dispersed by black howler monkeys (Alouatta caraya). Folia Primatol 71:342-345.

Bray JR, Curtis JT. 1957. An ordination of the upland forest communities of southern Wisconsin. Ecol Monogr 27(4):325-349.

Brockett RC, Horwich R, Jones CB. 2000. Female dispersal in the Belizean black howling monkey (Alouatta pigra). Neotrop Primates 8(1):32-34.

Brown A, Zunino GE. 1994. Hábitat, densidad y problemas de conservación de los primates de Argentina. Vida Silvestre Neotrop 3(1):30-40.

Brown JH. 1984. On the relationship between abundance and distribution of species. Am Nat 124(2):255-279.

Brown JH, Lomolino MV. 1998. Biogeography. 2nd ed. Sunderland (MA): Sinaur. 691 p.

Bruno G. 2011. Aportes al conocimiento del aullador negro y dorado (Alouatta caraya): un análisis de historia de vida fuera de su distribución natural [tesis doctoral]. [Buenos Aires]: Universidad de Buenos Aires.

Cabrera A. 1939. Los monos de la Argentina. Physis 16:3-29.

Cabrera A. 1957. Catalogo de los mamíferos de América del Sur. Rev Mus Arg Cienc Nat Bernardino Rivadavia Zool 4(1-2):1-732.

Cabrera A. 1976. Regiones fitogeografías Argentinas. En: Parodi M, Dimitri M, editors. Enciclopedia Argentina de agricultura y jardinería. Tomo 2. 2 edición. Buenos Aires: ACME; Fascículo 1. p 1-85.

Cant JGH. 1980. What limits primates? Primates 21(4):538-544.

Carignan R, Neiff JJ. 1992. Nutrient dynamics in the floodplain ponds of the Paraná River (Argentina) dominated by the water hyacinth Eichhornia crassipes. Biogeochemistry 17:85-121.

Carnevali R. 1994. Fitogeografía de la provincia de Corrientes. Corrientes: Gobierno de la Provincia de Corrientes. 324 p.

Carpenter CR. 1934. A field study of the behavior and social relations of howling monkeys. Comparat Psych Monogr 10(2):1-168.

Case TJ, Holt RD, McPeek MA, Keitt, TH. 2005. The community context of species' borders: ecological and evolutionary perspectives. Oikos 108:28-46.

Caughley G, Grice D, Barker R, Brown B. 1988. The edge of the range. J Anim Ecol 57:771-785. 
Centro Editor de América Latina. 1982. Atlas total de la República Argentina. Vol. I y II. Buenos Aires.

Chapman CA, Balcomb SR. 1998. Population characteristics of howlers: ecological conditions or group history. Int J Primatol 19(3):385-403.

Chapman CA, Chapman LJ. 2000. Determinants of group size in primates: the importance of travel costs. En: Boinski S, Garber PA, editors. How and why animals travel in groups. Chicago: Univ Chicago Pr. p 24-42.

Chapman CA, Chapman LJ, Wangham R, Hunt K, Gebo D, Gardner L. 1992. Estimators of fruit abundance of tropical trees. Biotropica 24(4):527-531.

Chapman CA, Wrangham R, Chapman L. 1994. Indices of habitat-wide fruit abundance in tropical forests. Biotropica 26(2):160-171.

Chapman CA, Gautier-Hion A, Oates JF, Onderdonk DA. 1999. African primate communities: determinants of structure and threats to survival. En: Fleagle JG, Janson C, Reed K, editors. Primate communities. Cambridge: Cambridge Univ Pr. p 1-37.

Chiarello AG. 1993. Activity pattern of the brown howler monkey Alouatta fusca, Geoffroy 1812, in a forest fragment of southeastern Brazil. Primates 34:289-293.

Chiarello AG. 1994. Diet of the brown howler monkey Alouatta fusca in a semi-deciduous forest in southeastern Brazil. Primates 35(1):25-34.

Chiarello AG. 1998. Diet of the Atlantic Forest maned sloth Bradypus torquatus (Xenarthra:Bradypodidae). J Zool 246(1):11-19.

CITES. 1975. Convención sobre el comercio internacional de especies amenazadas de fauna y flora silvestres, entró en vigencia j-ul. 01, 1975, 993 U.N.T.S. 243.

Clarke MR. 1982. Socialization, infant mortality and infant nonmother interactions in howling monkeys (Alouatta palliata) in Costa Rica [tesis doctoral]. [Davis, CA, USA]: University of California.

Clarke MR, Collins DA, Zucker EL. 2002. Responses to deforestation in a group of mantled howlers (Alouatta palliata) in Costa Rica. Int J Primatol 23(2):365-381.

Clutton Brock TH, Harvey PH. 1977. Primate ecology and social organization. J Zool 183:1-39.

Codenotti TL, Silva VM, Albuquerque VJ, Camargo EV, Silveira RMM. 2002. Distribuição e situação atual de conservação de Alouatta caraya (Humboldt, 1812) no Río Grande do Sul, Brasil. Neotrop Primates 10(3):132-140.

Colwell RK, Futuyma DJ. 1971. On the measurement of niche breadth and overlap. Ecology 52:567_ 576.

Condit R. 1998. Tropical forest census plots: methods and results from Barro Colorado Island, Panama and a comparison with other plots. Berlin: Springer. 211 p.

Coppo JA, Resoagli EH. 1978. Etapas de crecimiento en monos carayá (Alouatta caraya). Facena 2:29-39. 
Cordiviola de Yuan E, Giraudo A, Lajmanovich R., Beltzer A, Sottini R. 2001. Ficha informativa de los humedales Ramsar: Jaaukanigás. Santo Tomé (SF): Instituto Nacional de Limnología.

Cortés Ortiz L, Bermingham E, Rico C, Rodríguez Luna E, Sampaio I, Ruiz García M. 2003. Molecular systematics and biogeography of the Neotropical monkey genus, Alouatta. Mol Phylogen Evol 26:64-81.

Cortés Ortiz L, Rylands AB, Mittermeier RA. 2015. The taxonomy of howler monkeys: integrating old and new knowledge from morphological and genetic studies. En: Kowalewski MM, Garber PA, Cortés Ortiz L, Urbani B, Youlatos D, Editors. Howler monkeys: adaptive radiation, systematics, and morphology. New York: Springer. p 55-84.

Crockett CM. 1985. Population studies of red howler monkeys (Alouatta seniculus). Natl Geogr Res 1(2):264-273.

Crockett CM. 1998. Conservation biology of the genus Alouatta. Int J Primatol 19(3):549-578.

Crockett CM. 2003. Re-evaluating the sexual selection hypothesis for infanticide by Alouatta males. En: Jones, CB. Editor. Sexual selection and reproductive competition in primates: new perspectives and directions. (pp. 327-365). Norman (OK): Am Soc Primatol. p 327-365.

Crockett CM, Eisenberg JF. 1987. Howlers: variations in group size and demography. En: Smuts BB, Cheney DL, Seyfarth RM, Wrangham RW, Struhsaker TT, Editors. Primate societies. Chicago: Univ of Chicago Pr. p 54-68.

Crockett CM, Rudran R. 1987. Red howler monkey birth data I: seasonal variation. Am J Primatol 13:347-368.

Cruzate GA, Panigatti JL, Moscatelli G. 2011. Provincia de Corrientes. Precipitación media anual [mapa en internet]. Suelos y ambientes de Corrientes. Buenos Aires: [INTA] Instituto Nacional de Tecnología Agropecuaria. [actualizada 2011 dic 1; consultado 2014 nov 6]. Disponible en: http://inta.gob.ar/imagenes/Corrientes.jpg/view

Cullen JRL, Valladares-Padua C. 1997. Métodos para estudo de ecologia, manejo e conservação de primatas na natureza. En: Valladares-Padua C, Bodmer RE, editors. Manejo e conservação da vida silvestre no Brasil. Brasília: CNPq/Sociedade Civil Mamirauá. p 239-269.

Dallmeier F, Kabel M, Rice R. 1992. Methods for long-term biodiversity inventory plots in protected tropical forest. En: Dallmeier F, editor. Long-term monitoring of biological diversity in tropical forest areas: methods for establishment and inventory of permanent plots. Paris: UNESCO. p 11-46; (MAB Digest: 11).

D’Ambrosio de Argueso A. 1986. Manual de técnicas en histología vegetal. Buenos Aires: Hemisferio Sur. 83 p.

D'Arcy T, Hogue-Hugron S, Lamarre G, Morison S. 2006. Biodiversity and abundance of lianas along two rivers of varying levels of anthropogenic disturbance, in the Parque Natural Metropolitano, Panamá [final internship report, Panama Field Study Semester 2006]. [Montreal]: McGill University. 
Davies AG, Bennett EL, Waterman PG. 1988. Food selection by two South-east Asian colobine monkeys (Presbytis rubicund and Presbytis melalophos) in relation to plant chemistry. Biol J Linn Soc 34(1):33-56.

Dayanandan P, Kaufman PB. 1973. Scanning electron microscopy of plant surfaces - applications. En: Electron Microscopy of America. Proceedings, thirty first annual meeting Electron Microscopy Society of America. San Francisco: San Francisco. p 474-475.

De Boer WF, Ntumi CP, Correia AU, Mafuca JM. 2000. Diet and distribution of elephant in the Maputo Elephant Reserve, Mozambique. Afr J Ecol 38(3):188-201.

De Marques AAB. 2001. Estratégias de uso do espaço por Alouatta guariba clamitans Cabrera, 1940 em hábitats temperado e subtropical no sul do Brasil [tesis doctoral]. [Belo Horizonte, Minas Gerais]: Universidade Federal de Minas Gerais.

De Marques AAB. 2003. Primatas. In: Fontana CS, Bencke GS, Reis RE, editors. Livro vermelho da fauna ameaçada de extinção no Río Grande do Sul. Porto Alegre (Brazil): EDIPUCRS. p 499-506. Defler TR. 2003. Primates de Colombia. Bogotá: Conservación Internacional Colombia. 547 p.

Defler TR. 2004. Primates of Colombia. Rodríguez Mahecha JV, Rylands AB, Mittermeier RA, editors. Bogotá: Conservation International; (Conservation International-tropical field guide series: 5). p 369-395.

Defler TR. 2010. Historia natural de los primates Colombianos. $2^{\mathrm{a}}$ ed. Bogotá: Univ Nac Colombia. Capítulo 9, Familia Atelidae. p 306-383.

Delgado A. 2006. Estudio de patrones de uso de sitios de defecación y su posible relación con infestaciones parasitarias en dos grupos de monos aulladores negros y dorados (Alouatta caraya) en el nordeste argentino [tesis licenciatura]. [Córdoba, Argentina]: Universidad Nacional de Córdoba. Di Bitetti MS. 2003. Outlook for primate conservation in Misiones. En: Galindo Leal C, Câmara IG, editors. The state of the hotspots: the Atlantic Forest of South America: biodiversity status, threats, and outlook. Washington DC: Island Press, Center for Applied Biodiversity Science at Conservation International. p 194-199.

Di Bittetti MS, Placci G, Brown AD, Rode DI. 1994. Conservation and population status of the brown howling monkey (Alouatta fusca clamitans) in Argentina. Neoptrop Primates 2(4):1-4.

Di Fiore A. 1997. Ecology and behavior of lowland woolly monkeys (Lagothrix lagotricha poeppigii, Atelinae) in eastern Ecuador [tesis doctoral]. [Davis, USA]: University of California.

Di Fiore A, Campbell CJ. 2007. The Atelines - variation in ecology, behavior, and social organization. En: Campbell C, Fuentes A, MacKinnon K, Panger M, Bearder S, editors. Primates in perspective. Oxford: Oxford Univ Pr. p 155-185.

Dizeo de Strittmatter, CG. 1973. Nueva técnica de diafanización. Bol Soc Arg Bot 15:126-129.

Duarte Quiroga A, Estrada A. 2003. Primates as pets in Mexico City: an assessment of the species involved, source of origin, and general aspects of treatment. Am J Primatol 61(2):53-60. 
Dunbar RIM. 1987. Demography and reproduction. En: Smuts BB, Cheney DL, Seyfarth RM, Warnghan RW, Struhsaker TT, editors. Primate societies. Chicago: Univ Chicago Pr. p 240-249.

Dusi JL. 1949. Methods for the determination of food habits by plant microtechniques and histology and their application to cottontail rabbit food habits. J Wildlife Manage 13(3):295-298.

Dwiyahreni AA, Kinnaird MF, O’Brien TG, Supriatna J, Andayani N. 1999. Diet and activity of the bear cuscus, Ailurops ursinus, in North Sulawesi, Indonesia. J Mammol 80(3):905-912.

Eisenberg JF. 1979. Habitat, economy and society: some correlation and hypotheses for the Neotropical primates. En: Bernstein S, Smith EO, editors. Primate and human origins: ecological influences on social organization. New York: Garland STPM. p 215-262.

Eisenberg JF, Redford K. 1999. Mammals of the Neotropics, volume 3: the Central Neotropics: Ecuador, Peru, Bolivia, Brazil. Chicago: Univ Chicago Pr. Chapter 9, Order Primates; p 230-278.

Eisenberg JF, Muckenhirn NA, Rudran R. 1972. The relations between ecology and social structure in primates. Science 176(4037):863-874.

Ellis W, Carrick F, Lundgren P, Veary A, Cohen B. 1999. The use of faecal cuticle examination to determine the dietary composition of koalas. Aust Zool 31(1):127-133.

Eskuche U. 2004. La vegetación de la vega del río Paraná Medio superior, Argentina. Fol Bot Geobot Correntesiana 17:1-60.

Estrada A. 1984. Resource use by howler monkeys (Alouatta palliata) in the rain forest of Los Tuxtlas, Veracruz, Mexico. Int J Primatol 5(2):105-132.

Estrada A, Coates-Estrada R. 1986. Frugivory by howling monkeys (Alouatta palliata) at Los Tuxtlas, Mexico: dispersal and fate of seeds. En: Estrada A, Fleming TH, editors. Frugivores and seed dispersal. Dordrecht (Holanda): W. Junk. p 93-104.

Estrada A, Garber PA, Pavelka MSM, Luecke L. 2006. Overview of the Mesoamerican primate fauna, primates studies, and conservation concerns. En: Estrada A, Garber PA, Pavelka MS, Luecke L, editors. New perspectives in the study of Mesoamerican primates: distribution, ecology, behavior, and conservation. New York: Springer-Verlag. p 1-22.

Ezcurra de Drago I, Marchese M, Montalto L. 2007. Benthic Invertebrates. En: Iriondo MH, Paggi JC, Parma MJ, editors. 2007. The Middle Paraná River: limnology of a subtropical wetland. Berlin: Springer. p 251-275.

Fallabrino A, Alonso L, Arévalo AP. 2009. Report of illegal trade of the common marmoset (Callithrix jacchus) in Uruguay. Lab Primate Newsl 48(1):6-34.

Feeley KJ, Terborgh JW. 2005. The effects of herbivore density on soil nutrients and tree growth in tropical forest fragments. Ecology 86(1):116-124.

Felsenstein J. 1985. Confidence limits on phylogenies: an approach using the bootstrap. Evolution 39(4):783-791.

Felton AM, Felton A, Lindenmayer DB, Foley WJ. 2009. Nutritional ecology: nutritional goals of wild primates. Funct Ecol 23:70-78. 
Fernandes Corrêa AF, Furch B. 1992. Investigations on the tolerance of several trees to submergence in blackwater (igapó) and whitewater (várzea) inundation forests near Manaus, Central Amazonia. Amazoniana 12(1):71-84.

Fernández Duque E, Wallace RB, Rylands AB. 2008. Alouatta caraya. In: The IUCN Red List of Threatened Species. Version 2014.2. <www.iucnredlist.org>. Descargó 01 agosto 2014.

Fernández VA, Righini N, Rothman J. 2012. Ecología nutricional de monos aulladores (género Alouatta): aplicación de un nuevo enfoque para la conservación de los primates neotropicales. II Congreso Latinoamericano de Mastozoología y XXV Jornadas Argentinas de Mastozoología; 2012 nov 6-9; Buenos Aires, Argentina. Buenos Aires: [SAREM] Sociedad Argentina para el Estudio de los Mamíferos.

Ferrucci MS. 1998. Sapindaceae. En: Hunziker AT, editor. Flora fanerogámica Argentina. Caja 6, Fascículo 52. Córdoba: [CONICET] Consejo Nacional de Investigaciones Científicas y Técnicas, Programa PROFLORA. 44 p.

Figueiredo RA. 1993. Ingestion of Ficus enormis seeds by howler monkeys (Alouatta fusca) in Brazil: effects on seed germination. J Trop Ecol 9(4):541-543.

Fischer AG. 1960. Latitudinal variations in organic diversity. Evolution 14(1):64-81.

Fitzgerald AE. 1984. Diet of the possum (Trichosurus vulpecula) in three Tasmanian forest types and its relevance to the diet of possums in New Zealand forests. En: Smith AP, Hume ID, editors. Possums and gliders. Chipping Norton (NSW, Australia): Surry Beatty and Sons. p 137-143.

Fleagle JG. 1999. Primate adaptation and evolution. 2nd ed. San Diego: Academic Pr. 596 p.

Fleming TH, Venable DL, Herrera LGM. 1993. Opportunism vs. specialization: the evolution of dispersal strategies in fleshy-fruited plants. Vegetatio 107/108(1):107-120.

Flores Villela O, Ochoa LM, Moreno CE. 2005. Variación latitudinal y longitudinal de la riqueza de especies y la diversidad beta de la herpetofauna mexicana. En: Halffter G, Soberón J, Koleff P, Melic A, editors. M3m: monografías tercer milenio. Volumen 4, Sobre diversidad biológica: el significado de las diversidades alfa, beta, y gamma. Zaragoza (España): [SEA] Sociedad Entomológica Aragonesa. p 143-152.

Ford SM. 1994. Evolution of sexual dimorphism in body weight in platyrrhines. Am J Primatol 34:221-244.

Ford SM, Davis LC. 1992. Systematics and body size: implications for feeding adaptations in New World monkeys. Am J Phys Anthropol 88(4):415-468.

Franceschi E, Lewis JP. 1979. Notas sobre la vegetación de valle Santafesino del río Paraná (República Argentina). Ecosur 6(11):55-82.

Froehlich JW, Thorington RW. 1982. The genetic structure and socioecology of howler monkeys (Alouatta palliata) on Barro Colorado Island. En: Leigh EG, Rand AS, Windsor DM, editors. The ecology of a tropical forest. Washington DC: Smithsonian Institution. p.291-305. 
Fuentes E, Estrada A, Franco B, Magaña M, Decena y, Muñoz D, García Y. 2003. Reporte preliminar sobre el uso de recursos alimenticios por una tropo de monos Aulladores, Alouatta palliata, en El Parque La Venta, Tabasco, México. Neotrop Primates 11(1):24-29.

Galetti M, Pedroni F, Morellato LPC. 1994. Diet of the brown howler monkey Alouatta fusca in a forest fragment in southeastern Brazil. Mammalia 58(1):111-118.

Garber PA. 1984. The proposed nutritional importance of plant exudates in the diet of the Panamanian tamarin, Saguinus oedipus geoffroyi. Int J Primatol 5:1-15.

Garber PA. 1987. Foraging strategies among living primates. Ann Rev Anthropol 16:339-364.

Garber PA, Pruetz JD, Lavallee AC, Lavallee SG. 1999. A preliminary study of mantled howling monkey (Alouatta palliata) ecology and conservation on Isla de Ometepe, Nicaragua. Neotrop Primates 7(4):113-117.

Gaston KJ. 1990. Patterns in the geographical ranges of species. Biol Rev 65(2):105-129.

Gaston KJ. 2003. The structure and dynamics of geographic ranges. Oxford: Oxford Univ Pr. 278 p.

Gaston KJ. 2009. Geographic range limits of species. Proc R Soc B 276:1391-1393.

Gaulin SJC, Gaulin CK. 1982. Behavioral ecology of Alouatta seniculus in Andean cloud forest, Colombia. Int J Primatol 3:1-32.

Gaulin SJC, Knight DH, Gaulin CK. 1980. Local variance in Alouatta group size and food availability on Barro Colorado Island. Biotropica 12(2):137-143.

Gaylard A, Kerley GIH. 1997. Diet of tree hyraxes Dendrohyrax arboreus (Hydracoidea: Procaviidae) in the eastern Cape, South Africa. J Mammal 78(1):213-221.

Gentry, AH. 1991. The distribution and evolution of climbing plants. En: Putz FE, Mooney HA, editors. The biology of vines. Cambridge: Cambridge Univ Pr. p 3-49.

Gerwing JJ, Vidal E. 2002. Changes in liana abundance and species diversity eight years after liana cutting and logging in an eastern Amazonian forest. Conserv Biol 16(2):544-548.

Gilman SE. 2006. The northern geographic range limit of the intertidal limpet Collisella scabra: a test of performance, recruitment, and temperature hypotheses. Ecography 29(5):709-720.

Giraudo AR. 2008. Jaaukanigás y Ramsar: aspectos introductorios. En: Giraudo, AR, editor. Sitio Ramsar Jaaukanigás: biodiversidad, aspectos socioculturales y conservación (río Paraná, Santa Fe, Argentina). 2da ed. Santa Fe (Argentina): Asoc. Cien. Nat. Litoral, Comité Intersectorial de Manejo del Sitio Ramsar Jaaukanigás, Ramsar. p 11-20.

Giudice AM, Ascunce MS. 1998. Presencia de Alouatta caraya fuera de su área de distribución natural. Neotrop Primates 6(3):82-86.

Glander KE. 1975. Habitat and resource utilization: an ecological view of social organization in mantled howler monkeys [tesis doctoral]. [Chicago]: University of Chicago.

Glander KE. 1979. Feeding associations between howling monkeys and basilisk lizards. Biotropica 11(3):235-236. 
Glander KE. 1981. Feeding patterns in mantled howling monkeys. En: Kamil A, Sargent TD, editors. Foraging behavior: ecological, ethological and psychological approaches. New York: Garland STPM. p 231-259.

Glander KE. 1982. The impact of plant secondary compounds on primate feeding behavior. Yearb Phys Anthropol 25:1-18.

Glander KE, Teaford ME. 1995. Seasonal, sexual, and habitat effects on feeding rates of Alouatta palliata. Am Primatol 36:124-125.

Goldberg EE, Lande R. 2007. Species' borders and dispersal barriers. Am Nat. 170(2):297-304.

González V, Zunino GE, Kowalewski MM, Bravo SP. 2002. Densidad de monos aulladores (Alouatta caraya) y composición y estructura de la selva de inundación en una isla del Río Paraná medio. Rev Mus Argent Cienc Nat (Nueva Ser) 4(1):7-12.

Gonzalez Socoloske D, Snarr KA. 2010. An incident of swimming in a large river by a mantles howling monkey (Alouatta palliata) on the north coast of Honduras. Neotrop Primates 17(1):28-31. Gotelli NJ, Entsminger GL. 2001. EcoSim: Null models software for ecology. Version 7.0. Jericho (VT): Acquired Intelligence \& Kesey-Bear.

Grafton BW. 2004. Primates and seed shadows: mapping seed dispersal by red howler monkeys (Alouatta seniculus) using plant DNA fingerprinting [tesis doctoral]. [Kent, OH, USA]: Kent State University.

Gregorin R. 2006. Taxonomia e variaçao geográfica das especies do género Alouatta lacepede (Primates, Atelidae) no Brasil. Rev Bras Zool 23:64-144.

Groves CP. 2001. Primate taxonomy. Washington DC: Smithsonian Institution Pr. p 172-179.

Grytnes JA, Heegaard E, Romdal TS. 2008. Can the mass effect explain the mid-altitudinal peak in vascular plant species richness? Basic Appl Ecol 9:373-382.

Hawkins BA, Diniz-Filho JAF. 2004. 'Latitude' and geographic patterns in species richness. Ecography 27(2):268-272.

Heikkinen RK, Luoto M, Araújo MB, Virkkala R, Thuiller W, Sykes MT. 2006. Methods and uncertainties in bioclimatic envelope modeling under climate change. Prog Phys Geog. 30(6):751777.

Heltne PG, Turner DC, Scott NJ. 1976. Comparisons of census data on Alouatta palliata from Costa Rica and Panama. En: Thorington RW, Heltne PG, editors. Neotropical primates: field studies and conservation. Washington DC: National Academy of Sciences. p 10-19.

Hemingway CA, Bynum N. 2005. The influence of seasonality on primate diet and ranging. En: Brockman DK, Van Schaik CP, editors. Seasonality in primates. Cambridge: Cambridge Univ Pr. p $57-104$.

Hengeveld R, Haeck J. 1982. The distribution of abundance. I. Measurements. J Biogeogr 9(4):303316. 
Henley SR, Smith DG, Raats JG. 2001. Evaluation of 3 techniques for determining diet composition. J Range Manage 54:582-588.

Hernández JCA. 2014. Comparación de los requerimientos de espacio de Alouatta seniculus en fragmentos con diferente intensidad de aprovechamiento de guadua, en el Quindío [tesis maestría]. [Ibagué, Tolima, Colombia]: Universidad del Tolima.

Hershkovitz P. 1977. Living New World monkeys (Platyrrhini), Vol. 1. 1st ed. Chicago: Univ Chicago Pr. p 10.

Heymann EW. 1987. A field observation of predation on a moustached tamarin (Saguinus mystax) by an anaconda. Int J Primatol 8(2):193-195.

Hirsch A, Dias LG., Martins LO, Campos RF, Resende NAT, Landau EC. 2002. BDGEOPRIMdatabase of geo-referenced localities of neoptropical primates. Neotrop Primates 10(2):79-84.

Holdridge LR. 1967. Life zone ecology. San José (Costa Rica): Tropical Science Center. 206 p.

Holechek JL Gross B. 1982. Training needed for quantifying simulated diets from fragmented range plants. J Range Manage 35(5):644-647.

Holechek JL,Vavra M. 1981. The effect of slide and frequency observation numbers on the precision of microhistological analysis. J Range Manage 34(4):337-338.

Holt RD. 2003. On the evolutionary ecology of species' ranges. Evol Ecol Res 5:159-178.

Holzmann I. 2012. Distribución geográfica potencial y comportamiento vocal de dos especies de mono aullador (Alouatta guariba clamitans y Alouatta caraya) [tesis doctoral]. [LaPlata, BA]: Universidad Nacional de La Plata, Facultad de Ciencias Naturales y Museo. 222 p.

Horsup A, Marsh H. 1992. The diet of the allied rock-wallaby, Petrogale assimilis, in the wet-dry tropics. Wildlife Res 19(1):17-33.

Horwich RH, Johnson ED. 1986. Geographical distribution of the black howler (Alouatta pigra) in Central America. Primates 27(1):53-62.

Hubbell SP. 2001. Monographs in population biology. Volumen 32, The unified neutral theory of biodiversity and biogeography. Princeton (NJ): Princeton Univ Pr. 375 p.

Hutchinson MF. 2004. ANUSPLIN version 4.3. Centre for Resource and Environment Studies. The Australian National University. Canberra, Australia.

Iannacone J, La Torre MI, Alvariño L, Cepeda C, Ayala H, Argota G. 2013. Toxicidad de los bioplaguicida Agave americana, Furcraea andina (Asparagaceae) y Sapindus saponaria (Sapindaceae) sobre el caracol invasor Melanoides tuberculata (Thiaridae). Neotrop Helminthol $7(2): 231-241$.

Iriondo MH. 2007. Geomorphology. En: Iriondo MH, Paggi JC, Parma MJ, editors. 2007. The Middle Paraná River: limnology of a subtropical wetland. Berlin: Springer. p 33-52.

Iriondo MH, Paira AR. 2007. Physical geography of the basin. En: Iriondo MH, Paggi JC, Parma MJ, editors. 2007. The Middle Paraná River: limnology of a subtropical wetland. Berlin: Springer. p $7-31$. 
Isbell LA. 1991. Contest and scramble competition: patterns of female aggression and ranging behavior among primates. Behav Ecol 2(2):143-155.

Isbell LA. 1994. Predation on primates: ecological patterns and evolutionary consequences. Evol Anthropol 3(2):61-71.

Isbell LA, Young TR. 2002. Ecological models of female social relationships in primates: similarities, disparities, and some directions for future clarity. Behaviour 139:177-202.

Iwanaga S, Ferrari SF. 2002. Geographic distribution of red howlers (Alouatta seniculus) in southwestern Brazilian Amazonia, with notes on Alouatta caraya. Int J Primatol 23:1245-1256.

Jablonski D, Roy K, Valentine JW. 2006. Out of the tropics: evolutionary dynamics of the latitudinal diversity gradient. Science 314:102-106.

Janson CH, Chapman CA. 1999. Resources and primate communities. En: Fleagle JG, Janson C, Reed K, editors. Primate communities. Cambridge: Cambridge Univ Pr. p 237-267.

Janzen DH. 1978. Complications in interpreting the chemical defenses of trees against tropical arboreal plant-eating vertebrates. En: Montgomery GG, editor. The ecology of arboreal folivores. Washington D.C.: Smithsonian Institute. p 73-84.

Jay P. 1965. Field studies. En : Schrier AM, Harlow HF, Stollnitz F, editors. Behavior of nonhuman primates: modern research trends. Vol 2. New York: Academic. p 534-553.

Jeffree EP, Jeffree CE. 1994. Temperature and the biogeographical distribution of species. Funct Ecol 8:640-650.

Jetz W, Rahbek C. 2002. Geographic range size and determinants of avian species richness. Science 297:1548-1551.

Johns AD, Skorupa JP. 1987. Responses of rain-forest primates to habitat disturbance: a review. Int J Primatol 8:157-191.

Johnson AE, Molyneux RJ, Merrill GB. 1985. Chemistry of toxic range plants: variation in pyrrolizidine alkaloid content of Senecio, Amsinckia, and Crotalaria species. J Agric Food Chem 33(1):50-55.

Jolly A. 1985. The evolution of primate behavior. 2nd ed. New York: Macmillan. 526 p.

Jones KMW, Krockenberger AK. 2007. Determining the diet of cryptic folivores: an assessment of diet analysis techniques using the green ringtail possum (Pseudochirops archeri) as a case study. Wildlife Res 34(5):352-358.

Juárez CP, Dvoskin R, Fernández-Duque E. 2005. Structure and composition of wild black howler troops (Alouatta caraya) in gallery forests of the Argentinean Chaco. Neotrop Primates 13:19-22.

Julliot C. 1996a. Fruit choice by red howler monkeys (Alouatta seniculus) in tropical rain forest. Am J Primatol 40:261-284.

Julliot C. 1996b. Seed dispersal by red howling monkeys (Alouatta seniculus) in the tropical rain forest of French Guiana. Int J Primatol 7(2):238-258. 
Julliot C, Sabatier D. 1993. Diet of the red howler monkey (Alouatta seniculus) in French Guiana. Int J Primatol 14(4):527-550.

Kappeler PM, Van Schaik CP. 2002. Evolution of primate social systems. Int J Primatol 23(4):707740.

Kaspari M, O’Donnell S, Kercher JR. 2000. Energy, density, and constraints to species richness: ant assemblages along a productivity gradient. Am Nat 155(2):280-292.

Katinas L. 2001. El herbario significado, valor y uso. La Plata (Argentina): Facultad de Ciencias Naturales y Museo, Universidad Nacional de La Plata. 11 p; (Serie Técnica y Didáctica - ProBiota: 1).

Kinzey WG, editor. 1997. New World primates: ecology, evolution, and behavior. New York: Walter de Gruyter. Chapter 11, Alouatta; p 174-185.

Kirkpatrick M, Barton NH. 1997. Evolution of a species’ range. Am Nat 150(1):1-23.

Koleff P, Gaston KJ. 2001. Latitudinal gradients in diversity: real patterns and random models. Ecography 24:341-51.

Kowalewski MM. 2000. Birth seasonality in black howler monkeys (Alouatta caraya) in an island system in northern Argentina [tesis de maestría]. [Stony Brook, NY, USA]: State University of New York at Stony Brook.

Kowalewski MM. 2007. Patterns of affiliation and co-operation in howler monkeys: an alternative model to explain social organization in non-human primates [tesis doctoral]. [Urbana-Champaign, USA]: University of Illinois.

Kowalewski MM, Garber PA. 2010. Mating promiscuity and reproductive tactics in female black and gold howler monkeys (Alouatta caraya) inhabiting an island on the Parana river, Argentina. Am J Primatol 72(8):734-748.

Kowalewski MM, Zunino GE. 2004. Birth seasonality in Alouatta caraya in northern Argentina. Int J Primatol. 25(2):383-400.

Krebs CJ. 1985. Ecología: estudio de la distribución y la abundancia. 2nd ed. Correa JB, translator. México: Harla. 753 p.

Lambert JE, Rothman JM. 2015. Fallback foods, optimal diets and nutritional targets: primate responses to varying food availability and quality. Annu Rev Anthropol 44:493-512.

Lawton JH. 1993. Range, population abundance and conservation. Trends Ecol Evol 8(11):409-413. Lechowicz, MJ. 1982. The sampling characteristics of electivity indices. Oecología 52:22-30.

Leemans R. 1990. Global data sets collected and compiled by the Biosphere Project [working paper] [Internet]. Laxenburg, Austria: [IIASA] International Institute for Applied Systems Analysis. [actualizada 2006 jun 15; consultado 2013 enero 18]. Disponible en: http://iridl.ldeo.columbia.edu/SOURCES/.ECOSYSTEMS/.Holdridge/.present/

Legendre P. 2000. Comparison of permutation methods for the partial correlation and partial Mantel tests. J Statist Comput Simul 67:37-73. 
Legendre P, Gallagher ED. 2001. Ecologically meaningful transformations for ordination of species data. Oecologia 129:271-280.

Legendre P, Legendre L. 1998. Numerical ecology. 2nd Eng ed. Amsterdam: Elsevier Sci. 852 p. Lehman SM. 2000. Primate community structure in Guyana: effects of habitat use and diet on geographic distribution. Int J Primatol 25:1225-1242.

Levins R. 1968. Evolution in changing environments. Princeton (NJ): Princeton Univ Pr. 120 p.

Lewis JP, Franceschi EA. 1979. Notas sobre la dinámica de la vegetación del valle del río Paraná. Ecosur 6(12):145-163.

Lindbergh S. 1976. Natural social structures and feeding procedures in the acclimatisation of South American primates. Int Zoo Yearbook 16:146-149.

Lomolino MV. 2001. Elevation gradients of species-density: historical and prospective views. Global Ecol Biogeogr 10(1):3-13.

Lomolino MV, Riddle B, Brown JH. 2005. Biogeography. 3rd ed. Sunderland (MA): Sinauer. 845 p.

Londoño JM, Gómez-Posada C. 2003. Dieta del mono aullador (Alouatta seniculus) en una selva subandina, Quindío, Colombia [resumen]. En: XXXVIII Congreso Nacional de Ciencias Biológicas; 2003 Oct; Armenia. Armenia (Quindío, Colombia): Asociación Colombiana de Ciencias Biológicas. López Villalba JA, Sterrett WR, McDonald MJ. 1987. Árboles comunes del Paraguay, ñande yvyra mata kuera. Washington, DC: Peace Corps (U.S.). Information Collection and Exchange. 425 p. Ludwig G, Aguiar LM, Miranda JMD, Teixeira GM, Svoboda WK, Malanski LS, Shiozawa MM, Hilst CLS, Navarro IT, Passos FC. 2007. Cougar predation on black-and-gold howlers on Mutum Island, southern Brazil. Int J Primatol 28(1):39-46.

Ludwig G, Aguiar LM, Svoboda WK, Hilst CLS, Navarro IT, Vitule JRS, Passos FC. 2008. Comparison of the diet of Alouatta caraya (Primates: Atelidae) between a riparian island and mainland on the Upper Parana River, southern Brazil. Rev Bras Zool 25(3):419-426.

Luecke L. 2004. Distribution of the black howler monkey (Alouatta pigra) in Mesoamerica: A GIS analysis. Am J Primatol 62(Suppl 1):75-76.

Lundberg P, Palo RT. 1993. Resource use, plant defenses, and optimal digestión in ruminants. Oikos 68(2):224-228.

Lynch Alfaro JW, Matthews L, Boyette AH, Macfarlan SJ, Phillips KA, Falótico T, Ottoni E, Verderane M, Izar P, Schulte M, y otros. 2011. Anointing variation across wild capuchin populations: a review of material preferences, bout frequency and anointing sociality in Cebus and Sapajus. Am J Primatol 74(4):299-314.

Lynch Alfaro JW, Boubli JP, Olson LE, Di Fiore A, Wilson B, Gutiérrez-Espeleta GA, Chiou KL, Schulte M, Neitzel S, Ross V, y otros. 2012. Explosive Pleistocene range expansion leads to widespread Amazonian sympatry between robust and gracile capuchin monkeys. J Biogeogr 39(2):272-288. 
MacArthur RH, Wilson EO. 1967. The theory of island biogeography. Princeton (NJ): Princeton Univ Pr. 203 p.

Machado ABM, Martins CS, Drummond GM. 2005. Lista da fauna brasileira ameaçada de extinção: incluindo as espécies quase ameaçadas e defícientes em dados. Belo Horizonte: Fundação Biodiversitas. $160 \mathrm{p}$.

Manly BFJ. 1986. Randomization and regression methods for testing for associations with geographical, environmental and biological distances between populations. Res Popul Ecol 28(2):201-218.

Mantel N. 1967. The detection of disease clustering and a generalized regression approach. Cancer Res 27(2):209-220.

Marchetti ZY, Aceñolaza PG. 2012. Pulse regime and vegetation communities in fluvial systems: the case of the Parana River floodplain, Argentina. Flora 207(11):795-804.

Marchetti ZY, Latrubesse EM, Pereira MS, Ramonell CG. 2013. Vegetation and its relationship with geomorphologic units in the Paraná River floodplain, Argentina. J South Am Earth Sci 46:122-136. Marsh, LK. 1999. Ecological effects of the black howler monkey (Alouatta pigra) on fragmented forests in the Community Baboon Sanctuary, Belize [tesis doctoral]. [St. Louis, MO, US]: Washington University.

Martin P, Bateson PPG. 1993. Measuring behaviour: an introductory guide. Cambridge: Cambridge Univ Pr. 222 p.

Martinez Mota R. 2004. Comparacion de cortisol fecal de monos aulladores (Alouatta pigra) que habitan en un bosque fragmentado y continuo como medida para determinar estrés [tesis maestría]. [Xalapa, Veracruz, México]: Instituto de Ecología AC.

Martins MM. 2009. Lianas as a food resource for brown howlers (Alouatta guariba) and southern muriquis (Brachyteles arachnoides) in a forest fragment. Anim Biodivers Conserv 32(1):51-58.

Matteucci SD, Colma A. 1982. Metodología para el estudio de la vegetación. Washington DC: Secretaría General de la Organización de los Estados Americanos. 154 p; (Serie de Biología, Monografía Científica $\mathrm{N}^{\circ} 22$ ).

McWilliam JR. 1978. Response of pasture plants to temperature. En: Wilson,JR, editor. Plant relations in pastures. East Melbourne: [CSIRO] Commonwealth Scientific and Industrial Research Organisation. p 17-34.

Mendes SL. 1989. Estudo ecológico de Alouatta fusca (Primates: Cebidae) na Estação Biológica de Caratinga, MG. Rev Nordestina Biol 6(2):71-104.

Mendes Pontes AR. 1999. Environmental determinants of primates abundance in Maracá Island, Roraima, Brazilian Amazonia. J Zool 247(2):189-199.

Milton K. 1979. Factors influencing leaf choice by howler monkeys: a test of some hypotheses of food selection by generalist herbivores. Am Nat 114(3):362-378. 
Milton K. 1980. The foraging strategy of howler monkeys: a study in primate economics. New York: Columbia Univ Pr. 165 p.

Milton K. 1984. The role of food-processing factors in primate food choice. En: Rodman P, Cant J, editors. Adaptations for foraging in nonhuman primates. New York: Columbia Univ Pr. p 249-279. Milton K. 1996. Effects of bot fly (Alouattamyia bueria) parasitism on a free-ranging howler monkey (Alouatta palliata) population in Panama. J Zool 239(1):39-63.

Milton K. 1998. Physiological ecology of howlers (Alouatta): energetic and digestive considerations and comparison with the Colobinae. Int J Primatol 19(3):513-548.

Milton K. 2006. Picking up the pace: nutritional ecology as an essential research tool in primatology.

En: Hohmann G, Robbins MM, Boesch C, editors. Feeding ecology in apes and other primates. Cambridge: Cambridge Univ Pr. p 381-396.

Miner BG, Sultan SE, Morgan SG, Padilla DK, Relyea RA 2005. Ecological consequences of phenotypic plasticity. Trends Ecol Evol 20(12):685-692.

Miranda JMD, Bernardi IP, Abreau KC, Passos FC. 2005. Predation on Alouatta guariba clamitans (Cabrera) (Primates, Atelidae) by Leopardus pardalis (Linneaus) (Carnivora, Felidae). Rev Bras Zool 22(3):793-795.

Monath TP. 2001. Yellow fever: an update. Lancet Infect Dis 1(1):11-20.

Morellato LPC, Leitão Filho HF. 1996. Reproductive phenology of climbers in a southeastern Brazilian forest. Biotropica 28(2):180-191.

Muñoz D, Estrada A, Naranjo E. 2005. Monos aulladores (Alouatta palliata) en un plantación de cacao (Theobroma cocao) en Tabasco, México: aspectos de la ecología alimentaria. Univ Cienc Esp II:35-44.

Mussa PP, Aceto P, Abba C, Sterpone L, Meineri G. 2003. Preliminary study on the feeding habits of roe deer (Capreolus capreolus) in the western Alps. J Anim Physiol An N 87(3-4):105-108.

Navarro Fernández E, Pozo de la Tijera C, Escobedo Cabrera E. 2003. Afinidad ecológica y distribución actual de primates (Cebidae) en Campeche, México. Rev Biol Trop 51(2):591-600.

Neiff JJ, Reboratti, HJ. 1989. Estructura y dinámica de bosques de Tessaria interifolia II: análisis de crecimiento y productividad. Bol Soc Arg Bot 26(1-2):39-43.

Neiff JJ, Reboratti HJ, Gorleri MC, Basualdo M. 1985. Impacto de las crecientes extraordinarias sobre los bosques fluviales del Bajo Paraguay. Buenos Aires: Cámara de Diputados de la Nación. Boletín de la Comisión Especial del Río Bermejo No. 4. p 13-30.

Neville MK. 1972. The population structure of red howler monkeys (Alouatta seniculus) in Trinidad and Venezuela. Folia Primatol 17:56-86.

Neville MK, Glander KE, Braza F, Rylands AB. 1988. The howling monkeys, genus Alouatta. En: Mittermeier RA, Rylands AB, Coimbra-Filho AF, da Fonseca GAB, editors. Ecology and behavior of Neotropical primates. Volume 2. Washington DC: World Wildlife Fund. p 349-438. 
Norbury GL. 1988a. A comparison of stomach and fecal samples for diet analysis of grey kangaroos. Aust Wildlife Res 15(3):349-255.

Norbury GL. 1988b. Microscopic analysis of herbivore diets - a problem and a solution. Aust Wildlife Res 15(1):51-57.

Nowak RM. 1999. Walker's mammals of the World. $6^{\text {th }}$ edition. Baltimore: John Hopkins Univ Pr. p 537-556.

Oates JF, Swain T, Zantovska J. 1977. Secondary compounds and food selection by colobus monkeys. Biochem Syst Ecol 5:317-321.

Oftedal OT, Whiten A, Southgate DAT, Van Soest P. 1991. The nutritional consequences of foraging in primates: the relationship of utrient intakes to nutrient requirements [and discussion]. Philos $\mathrm{T}$ Roy Soc B 334(1270):161-170.

Ojeda RA, Chillo V, Diaz Isenrath GB, editors. 2012. Libro rojo de los mamíferos amenazados de la Argentina 2012. Buenos Aires: [SAREM] Sociedad Argentina para el Estudio de los Mamíferos. 257 p.

Olson DM, Dinerstein E, Wikramanayake ED, Burgess ND, Powell GVN, Underwood EC, D'Amico JA, Itoua I, Strand HE, Morrison JC, and others. 2001. Terrestrial ecoregions of the world: a new map of life on earth. BioScience 51(11):933-938.

Orfeo O. 1995. Sedimentología del río Paraná en el área de confluencia con el río Paraguay [tesis doctoral]. [LaPlata, BA]: Universidad Nacional de La Plata, Facultad de Ciencias Naturales y Museo. $290 \mathrm{p}$.

Orfeo O, Stevaux, J. 2002. Hydraulic and morphologic characteristics of middle and upper reaches of the Paraná River (Argentina and Brazil). Geomorphology 44(3/4):309-322.

Orihuela Lopez G, Terborgh J, Ceballos N. 2005. Food selection by a hyperdense population of red howler monkeys (Alouatta seniculus). J Trop Ecol 21(4):445-450.

Ostro LET, Silver SC, Koontz FW, Horwich RH, Brockett R. 2001. Shifts in social structure of black howler (Alouatta pigra) groups associated with natural and experimental variation in population density. Int J Primatol 22(5):733-748.

Owen Smith N, Novellie P. 1982. What should a clever ungulate eat? Am Nat 119(2):151-178.

Pahl LI. 1987. Feeding-behavior and diet of the common ringtail possum, Pseudocheirus-Peregrinus, in eucalyptus woodlands and leptospermum thickets in southern Victoria. Aust J Zool 35(5):487506.

Palacios E, Rodriguez A. 2001. Ranging pattern and use of space in a group of red howler monkeys (Alouatta seniculus) in a southeastern Colombian rainforest. Am J Primatol 55:233-251.

Paoli C, Iriondo M, García N. 2000. Características de las cuencas de aporte. In: Paoli C, Schreider M, editors. El río Paraná en su tramo medio. Santa Fe (Argentina): Univ Nac Litoral. p 27 -68.

Paoli C, Iriondo M, García N. 2000. Características de las cuencas de aporte. In: Paoli C, Schreider M, editors. El río Paraná en su tramo medio. Santa Fe (Argentina): Univ Nac Litoral. p 27-68. 
Parmesan C, Gaines SD, Gonzalez L, Kaufman DM, Kingsolver JG, Peterson AT, Sagarin, R. 2005. Empirical perspectives on species borders: from traditional biogeography to global change. Oikos 108:58-75.

Pautasso AA. 2008. Mamíferos de la província de Santa Fe, Argentina. Comunicaciones del Museo Provincial de Ciencias Naturales "Florentino Ameghino" 13(2):1-248.

Pavé R, Kowalewski MM, Garber PA, Zunino GE, Fernández VA, Peker S. 2012. Infant mortality in black-and-gold howlers (Alouatta caraya) living in a flooded forest in northeastern Argentina. Int J Primatol 33(4):937-957.

Pavelka M, Knopff H. 2004. Diet and activity in black howler monkeys (Alouatta pigra) in southern Belize: does degree of frugivory influence activity level? Primates 45:105-111.

Pensiero JF, Gutiérrez HF, Luchetti AM, Exner E, KernV, Brnich E, Oakley L, Prado D, Lewis JP. 2005. Flora vascular de la provincia de Santa Fe, claves para el reconocimiento de familias y géneros: catálogo sistemático de especies. Santa Fe (Argentina): Ediciones UNL, Universidad Nacional del Litoral. $403 \mathrm{p}$.

Peres CA. 1990. Effects of hunting on western Amazonian primate communities. Biol Conserv 54(1):47-59.

Peres CA. 1997. Primate community structure at twenty western Amazonian flooded and unflooded forests. J Trop Ecol 13(3):381-405.

Peres CA, Janson CH. 1999. Species coexistence, distribution, and environmental determinants of neotropical primate richness: a community-level zoogeographic analysis. En: Fleagle JG, Janson CH, Reed K, editors. Primate communities. Cambridge: Cambridge Univ Pr. p 55-74.

Phillips SJ, Anderson RP, Schapire RE. 2006. Maximum entropy modeling of species geographic distributions. Ecol Model 190:231-259.

Pianka E. 1966. Latitudinal gradients in species diversity: a review of the concepts. Am Nat 100(910):33-46.

Pianka E. 1976. Competition and niche overlap: a method of measuring them. Ecology 53:687-692.

Piantanida M, Puig S, Nani N, Cavanna L, Mazzuccelli S, Gil A, Rossi F. 1984. Introducción al estudio de la ecología y etología del mono aullador (Alouatta caraya) en condiciones naturales. Rev Mus Arg Cienc Nat Bernardino Rivadavia Ecol 3(3):163-192.

Pielou EC. 1966. The measurements of diversity in different types of biological collections. J Theor Biol 13:131-144.

Pina ALCB. 1999. Dinâmica socio-ecológica em uma população de guaribas das mãos vermelhas (Alouatta belzebul) na Estação Científica Ferreira Penna, PA [masters thesis]. [Belém, Pará]: Universidade Federal do Pará.

Pinto ACB. 2001. Padrão de atividades, dieta e dispersão de sementes pelo macaco guariba Alouatta belzebul em floresta com exploração madeireira e não-explorada na Amazônia oriental [masters thesis]. [Belém, Pará]: Universidade Federal do Pará. 
Pinto LP. 2002. Dieta, padrão de atividades e área de vida de Alouatta belzebul discolor (Primates, Atelidae) em Paranaíta, norte de Mato Grosso [masters thesis]. [Campinas, São Paulo]: Universidade Estadual de Campinas.

Pinto LP, Rylands AB. 1997. Geographic distribution of the golden-headed lion tamarin, Leontopithecus chrysomelas: implications for its management and conservation. Folia Primatol 68(3-5):161-180.

Placci LG. 1995. Estructura y comportamiento fenológico en relación a un gradiente hídrico en bosques del este de Formosa [doctoral thesis inedit]. [La Plata]: Universidad Nacional de La Plata.

Prates HM, Bicca Marques JC. 2008. Age-sex analysis of activity budget, diet, and positional behavior in Alouatta caraya in an orchard forest. Int J Primatol 29:703-715.

Prates JC, Gayer SMP, Kunz LF, Buss G. 1990. Feeding habits fo the brown howler monkey Alouatta fusca clamitans (Cabrera, 1940) (Cebidae, Alouattinae) in the Itapuã State Park: a preliminary report. Acta Biol Leopoldensia 12(1):175-188.

Printes RC, Liesenfeld MVA, Jerusalinsky L. 2001. Alouatta guariba clamitans Cabrera, 1940: a new southern limit for the species and for Neotropical primates. Neotrop Primates 9(3):118-121.

Quirós R, Bechara JA, de Resende EK. 2007. Fish diversity and ecology, habitats and fisheries for the un-dammed riverine axis Paraguay-Parana-Rio de la Plata (southern South America). Aquatic Ecosys Health Mgmt 10(2):1-14.

Rahbek C. 1995. The elevational gradient of species richness: a uniform pattern? Ecography 18(2):200-205.

Ramírez N. 2009. Correlaciones entre la fenología reproductiva de la vegetación y variables climáticas en los altos llanos centrales venezolanos. Acta Bot Venez 32(2):333-362.

Randall D, Burggren W, French K. 2002. Eckert animal physiology. $5^{\text {a }}$ ed. New York: Freeman.752 p.

Raubenheimer D. 2011. Toward a quantitative nutritional ecology: the right-angled mixture triangle. Ecol Monogr 81(3):407-427.

Raubenheimer D, Simpson SJ. 1993. The geometry of compensatory feeding in the locust. Anim Behav 45(5): 953-964.

Raubenheimer D, Simpson SJ. 1994. The analysis of nutrient budgets. Funct Ecol 8(6):783-791.

Raubenheimer D, Simpson SJ. 1995. Constructing nutrient budgets.Entomol Exp Appl 77(1):99104.

Raubenheimer D, Simpson S. 1997. Integrative models of nutrient balancing: application to insects and vertebrates. Nutr Res Rev 10(10):151-179.

Raubenheimer D, Simpson SJ, Mayntz D. 2009. Nutrition, ecology and nutritional ecology: toward an integrated framework. Funct Ecol 23(1):4-16. 
Righini N. 2014. Primate nutritional ecology: the role of food selection, energy intake, and nutrient balancing in Mexican black howler monkey (Alouatta pigra) foraging strategies [tesis doctoral]. [Urbana-Champaign, USA]: University of Illinois.

Rímoli AO, Valdivino EM, Rímoli J, Ferrari SF. 2008. Behavior patterns of a group of black howler monkeys Alouatta caraya (Humboldt, 1812) in a forest fragment in Terenos, Mato Grosso do Sul: a seasonal analysis. En: Ferrari SF, Rímoli J, editors. A Primatologia no Brasil-9. Aracaju: Sociedade Brasileira de Primatologia, Biologia Geral e Experimental-UFS. p 179-191.

Robinson JG, Bennett EL, editors. 2000. Hunting for sustainability in tropical forests. New York: Columbia Univ Pr. 1000 p.

Rödder D, Veith M, Lötters S. 2008. Environmental gradients explaining the prevalence and intensity of infection with the amphibian chytrid fungus: the host's perspective. Anim Conserv 11(6):513517.

Root T. 1988. Environmental factors associated with avian distributional boundaries. J Biogeogr 15:489-505.

Rosenzweig ML. 1995. Species diversity in space and time. Cambridge: Cambridge Univ Pr. 460 p. Rothman JM, Dierenfeld ES, Hintz HF, Pell AN. 2008. Nutritional quality of gorilla diets: consequences of age, sex, and season, Oecologia 155(1):111-122.

Rudran R. 1978. Socioecology of the blue monkeys (Cercopithecus mitis stuhlmanni) of the Kibale forest, Uganda. Washington DC: Smithsonian Inst Pr. 88 p; (Smithsonian contributions to zoology, no. 249).

Rudran R, Fernández-Duque E. 2003. Demographic changes over thirty years in a red howler population in Venezuela. Int J Primatol 24:925-947.

Ruhiyat Y. 1983. Socio-ecological study of Presbytis aygula in West Java. Primates 24(3):344-359. Rumiz DI. 1990. Alouatta caraya: population density and demography in northern Argentina. Am J Primatol 21(4):279-294.

Rumiz DI, Zunino GE, Obregozo ML, Ruiz JC. 1986. Alouatta caraya: habitat and resource utilization in northern Argentina. En: Taub DM, King FA, editors. Current perspectives in primate social dynamics. New York: VanNostrand-Reinhold. p 175-193.

Ryan SJ, Starks PT, Milton K, Getz WM. 2008. Intersexual conflict and group size in Alouatta palliata: a 23-year evaluation. Int J Primatol 29:405-420.

Rylands AB, Mittermeier RA. 2009. The diversity of the New World primates (Platyrrhini): an annotated taxonomy. En: Garber PA, Estrada A, Bicca Marques JC, Heymann EW, Strier KB, editors. South American primates, developments in primatology: progress and prospects. New York: Springer. p 23-54.

Rylands AB, Mittermeier RA, Silva JS. 2012. Neotropical primates: taxonomy and recently described species and subspecies. Int Zoo Yearbook 46(1):11-24. 
Salvatori G, Salvatori M, Schmidt I. 2002. Grandes obras en el Río: dragado e hidrovía. En: Borthagaray JM, editor. El río de la Plata como territorio. Buenos Aires: Ediciones Infinito, FADU, FURBAN. p 395-420.

Santamaría Gómez AM. 1999. Ecologia e comportamento de Alouatta seniculus em uma mata de terra firma na Amazônia Central [masters thesis]. [Belo Horizonte, Minas Gerais]: Universidade Federal de Minas Gerais.

Santos GASD, Bianchini E, Reis NR. 2013. Seasonal variation of consumption of the species used as fruit source by brown howler monkeys (Alouatta clamitans) in southern Brazil. Biota Neotrop 13(3):148-153.

Schemske DW. 2002. Ecological and evolutionary perspectives on the origins of tropical diversity.

En: Chazdon R, Whitmore T, editors. Foundations of tropical forest biology: classic papers with commentaries. Chicago: Univ Chicago Pr. p 163-173.

Schneider H. 2000. The current status of the New World monkey phylogeny. An Acad Bras Cienc $72: 165-172$.

Schneider H, Canavez FC, Sampaio I, Moreira MÂM, Tagliaro CH, Seuánez HN. 2001. Can molecular data place each Neotropical monkey in its own branch? Chromosoma 109:515-523.

Schoener TW. 1971. Theory of feeding strategies. Annu Rev Ecol Syst 2:369-404.

Schön Ybarra MA. 1986. Loud calls of adult male red howling monkeys (Alouatta seniculus). Folia Primatol 47(4):204-216.

Sekulic R. 1982. Daily and seasonal patterns of roaring and spacing in four red howler Alouatta seniculus troops. Folia Primatol 39:22-48.

Sekulic R. 1983. The effect of female call on male howling in red howler monkeys (Alouatta seniculus). Int J Primatol 4(3):291-305.

Silva JS. 2001. Especiação nos macacos-prego e caiararas, gênero Cebus Erxleben, 1777 (Primates, Cebidae) [tesis doctoral]. [Rio de Janeiro]: Universidade Federal do Rio de Janeiro.

Silva VM, Codenotti TL. 2007. Mapeamento das areas de ocorrência de Alouatta caraya em fragmentos florestais de Tupanciretã, Río Grande do Sul. En: Bicca Marques JC, editor. A primatologia no Brasil. Volume 10. Porto Alegre: Sociedade Brasileira de Primatologia. p 181-191. Silver SC, Ostro LET, Yeager CP. 1998. Feeding ecology of the black howler monkey (Alouatta pigra) in northern Belize. Am J Primatol 45:263-279.

Simmen B, Sabatier D. 1996. Diets of some French Guianan primates: food composition and food choices. Int J Primatol 17(5):661-693.

Simpson GG. 1964. Species density of North American recent mammals. Syst Zool 13(2):57-73.

Simpson SJ, Raubenheimer D. 1993. A multi-level analysis of feeding behaviour: the geometry of nutritional decisions. Phil Trans R Soc Lond B 342:381-402.

Simpson SJ, Raubenheimer D. 1995. The geometric analysis of feeding and nutrition: a user's guide. J Insect Physiol 41(7):545-553. 
Simpson SJ, Raubenheimer D. 1999. Assuaging nutritional complexity: a geometrical approach. P Nutr Soc 58(4):779-789.

Smith-Ramírez C, Armesto JJ. 1994. Flowering and fruiting patterns in the temperate rainforest of Chiloé, Chile - ecologies and climatic constraints. J Ecol 82(2):353-365.

Snaith TV, Chapman CA. 2007. Primate group size and socioecological models: do folivores really play by different rules? Evol Anthropol 16:94-106.

Sokal RR, Rohlf FJ 1979. Biometría: principios y métodos estadísticos en la investigación biológica. Madrid: H. Blume Ediciones. 832 p.

Soltis PS, Soltis DE. 2003. Applying the bootstrap in phylogeny reconstruction. Stat Sci 2(18):256267.

Somlo R, Bonvissuto G, Sbriller A, Bonino N, Moricz E. 1992. Diet relationships among sheep and sympatric herbivores in northwest Patagonia, Argentina. En: [AAPA] Asociación Argentina de Producción Animal, editor. Congreso mundial de ovinos y lanas - conferencias; 1992 ago 9-16; Buenos Aires. Buenos Aires: AAPA. p 93-109.

Somlo R, Bonvissuto G, Sbriller A, Bonino N, Moricz E. 1994. La influencia de la condición del pastizal sobre la dieta estacional de los herbívoros y el pastoreo múltiple, en sierras y mesetas occidentales de Patagonia. Rev Arg Prod Anim 14(3-4):187-207.

Sparks D, Malechek J. 1968. Estimating percentage dry weight in diets using a microscopic technique. J Range Manage 21:264-265.

Stallings JR, West L, Hahn W, Gamarra I. 1989. Primates and their relation to habitat in the Paraguayan Chaco. En: Redford KH, Eisenberg J, editors. Advances in Neoptropical mammalogy. Gainsville (FL, USA): Sandhill Crane. 605 p.

Steenbeek R, Sterck EHM, de Vries H, van Hooff JARAM. 2000. Costs and benefits of the onemale, age-graded, and all-male phases in wild Thomas's langur groups. En: Kappeler PM, editor. Primate males: causes and consequences of variation in group composition. Cambridge: Cambridge Univ Pr. p 130-145.

Sterck EHM. 1997. Determinants of female dispersal in Thomas langurs. Am J Primatol 42(3):179198.

Steudel K. 2000. The physiology and energetics of movement: effects on individuals and groups. En:

Boinski S, Garber PA. editors. On the move: how and why animals travel in groups. Chicago: Univ Chicago Pr. p 9-23.

Stevens GC. 1992. The elevational gradient in altitudinal range: an extension of Rapoport's latitudinal rule to altitude. Am Nat 140(6):893-911.

Stevenson PR, Quiñones MJ, Ahumada J. 1991. Relación entre la abundancia de frutos y las estrategias alimenticias de cuatro especies de primates en el río Duda, Macarena. Informe inédito presentado a la Fundación para la Promoción de la Investigación y la Tecnología, Banco de la República. Bogotá, Colombia. 
Stevenson PR, Quiñones M, Ahumada J. 2000. Influence of fruit availability on ecological overlap among four Neotropical primates at Tinigua National Park, Colombia. Biotropica 32(3):533-544.

Stevenson PR, Castellanos MC, Cortés AI, Link A. 2008. Flowering patterns in a seasonal tropical lowland forest in western Amazonia. Biotropica 40(5):559-567.

Stiles E. 1992. Animals as seed disperser. En: Fenner M. editor. Seeds: the ecology of regeneration in plant communities. $1^{\mathrm{a}}$ ed. Wallingford, UK: CABI. p 87-104.

Stoner KE. 1996. Habitat selection and seasonal patterns of activity and foraging of mantled howling monkeys (Alouatta palliata) in northeastern Costa Rica. Int J Primatol 17(1):1-30.

Strier KB. 2000. From binding brotherhoods to short-term sovereignty: the dilemma of male Cebidae. En: Kappeler PM, editor. Primate males: causes and consequences of variation in group composition. Cambridge: Cambridge Univ Pr. p 72-83.

Strier KB, Mendes, SL, Santos RR. 2001. Timing of births in sympatric brown howler monkeys (Alouatta fusca clamitans) and northern muriquis (Brachyteles arachnoides hypoxantus). Am $\mathrm{J}$ Primotol 55:87-100.

Struhsaker TT. 1969. Correlates of ecology and social organization among African Cercopithecines. Folia Primatol 11(1/2):80-118.

Struhsaker TT. 2000. Variation in adult sex ratios of red colobus monkey social groups: implicatins for interspecific comparisons. En: Kappeler PM, editor. Primate males: causes and consequences of variation in group composition. Cambridge: Cambridge Univ Pr. p 108-119.

Sun C, Kaplin BA, Kristensen KA, Munyaligoga V, Mvukiyumwami J, Kajondo KK, Moermond TD. 1996. Tree phenology in a tropical montane forest in Rwanda. Biotropica 28(4b):668-681.

Talora DC, Morellato P. 2000. Fenologia de espécies arbóreas em floresta de planície litorânea do sudeste do Brasil. Rev Bras Bot 23(1):13-26.

Tello NS, Huck M, Heymann EW. 2002. Boa constrictor attack and successful group defence in moustached tamarins, Saguinus mystax. Folia Primatol 73(2-3):146-148.

ter Braak CJF, Šmilauer P. 2012. Canoco reference manual and user's guide: software for ordination, version 5.0. Ithaca (NY): Microcomputer Power. 496 p.

Terborgh J. 1986. Keystone plant resources in the tropical forest. En: Soulé ME, editor. Conservation biology: the science of scarcity and diversity. Sunderland (MA, USA): Sinauer. p 330-334.

Thorington RW, Ruiz JC, Eisenberg JP. 1984. A study of a black howling monkey (Alouatta caraya) population in northern Argentina. Am J Primatol 6:357-366.

Todd JW, Hansen RM. 1973. Plant fragments in the feces of bighorns as indicators of food habits. J Wildlife Manage 32:275-279.

Treves A. 2001. Reproductive consequences of variation in the composition of howler monkey (Alouatta spp.) groups. Behav Ecol Sociobiol 50(1):61-71. 
Trujillo Jiménez P, Espinosa de los Monteros Viveros E. 2006. La ecología alimentaria del pez endémico Girardinichthys multiradiatus (Cyprinidontiformes: Goodeidae), en el Parque Nacional Lagunas de Zempoala, México. Rev Biol Trop 54(4):1247-1255.

Tundisi JG. 1994. Tropical South America: present and perspectives. En: Margalef R, editor. Limnology now: a paradigm of planetary problems. Amsterdam: Elsevier. p 353-424.

Ullrich TG, Castellaro G, Wackwitz B, Ferrando G, Parraguez V, Raggi L. 1996. Utilización de la técnica microhistológica para la determinación de la composición botánica de la dieta de herbívoros. En: Acuña Pomiez H, [SOCHIPA] Sociedad Chilena de Producción Animal, editors. XXI Reunión anual de la Sociedad Chilena de Producción Animal AG; 1996 Nov 12-14; Coyhaique, Chile. Temuco (Chile): SOCHIPA. p 3-4.

UNEP - WCMC. 2013. UNEP - WCMC species database: CITES - listed species [internet]. Cambridge (United Kingdom): United Nations Environment Programme-World Conservation Monitoring Centre; [consultado 23 Mar 2013]. Disponible en: http://www.unep-wcmcapps.org/isdb/CITES/Taxonomy/tax-species-result.cfm/isdb/CITES/Taxonomy/tax-speciesresult.cfm?displaylanguage $=$ eng $\&$ Genus $=$ Alouatta $\&$ Species .

Valdovinos C, Navarrete SA, Marquet PA. 2003. Mollusk species diversity in the Southeastern Pacific: why are there more species towards the pole? Ecography 26(2):139-144.

Valverde, O. 1999. Gavilán (Pentaclethra macroloba) [afiche]. Revista Forestal Centroamericana 26.

Van Belle S, Kulp AE, Thiessen-Bock R, Garcia M, Estrada A. 2010. Observed infanticides following a male inmigration event in black howler monkeys, Alouatta pigra, at Palenque National Park, Mexico. Primates 51(4):279-284.

Van Hooff JARAM, Van Schaik CP. 1994. Male bonds: affilliative relationships among nonhuman primate males. Behaviour 130(3):309-337.

Van Schaik CP. 1989. The ecology of social relationships amongst female primates. En: Standen V, Foley RA, editors. Comparative socioecology: the behavioural ecology of humans and other mammals. Oxford: Blackwell Scientific. p 195-218.

Van Schaik CP, van Hooff JARAM. 1983. On the ultimate causes of primate social systems. Behaviour 85(1/2):91-117.

Villalba JS, Prigioni CM, Sappa AC. 1995. Sobre la posible presencia de Alouatta caraya en Uruguay. Neotrop Primates 3(4):173-174.

Von Ihering H. 1914. Os bugios do gênero Alouatta. Rev Mus Paulista 9:231-280.

Wallace AR. 1878. Tropical nature and other essays. London: Macmillan. 356 p.

Wallace RB, Rumiz D. 2010. Atelidae. En: Wallace RB, Gómez H, Porcel ZR, Rumiz DI, editors. Distribución, ecología y conservación de los mamíferos medianos y grandes de Bolivia.Santa Cruz de la Sierra, Bolivia: Centro de Ecología Difusión Simón I. Patiño. p 305-330. 
Waterman PG, Ross JAM, Bennett EL, Davies AG. 1988. A comparison of the floristics and leaf chemistry of the tree flora in two Malaysian rain forests and the influence of leaf chemistry on populations of colobine monkeys in the Old World. Biol J Linn Soc 34(1):1-32.

Watts DP. 2000. Causes and consequence of variation in male mountain gorilla life histories and group membership. En: Kappeler PM, editor. Primate males: causes and consequences of variation in group composition. Cambridge: Cambridge Univ Pr. p 169-179.

Westoby M. 1978. What are the biological bases of varied diets? Am Nat 112:627-631.

Whitehead JM. 1989. The effect of the location of a simulated intruder on responses to long-distance vocalizations of mantled howling monkeys, Alouatta palliata palliata. Behaviour 108(1/2):73-103.

Whiteman PC. 1980. Tropical pasture science. New York: Oxford Univ Pr. p 242-276.

Whittaker RH, Willis KJ, Field R. 2001. Scale and species richness: towards a general, hierarchical theory of species diversity. J Biogeogr 28:453-470.

Wiens JJ, Graham CH. 2005. Niche conservatism: integrating evolution, ecology, and conservation biology. Annu Rev Ecol Evol Syst 36:519-539.

Williams Guillén K. 2003. The behavioral ecology of mantled howling monkeys (Alouatta palliata) living in a Nicaraguan shade coffee plantation [tesis doctoral]. [New York]: New York University. Willig MR, Kaufman DM, Steven RD. 2003. Latitudinal gradients of biodiversity: pattern, process, scale, and synthesis. Ann Rev Ecol Evol Syst 34:273-309.

World Health Organization. 2000. Yellow fever, 1998-1999. Wkly Epidemiol Rec 75(4):322-328. Yakimowski SB, Eckert CG. 2007. Threatened peripheral populations in context: geographical variation in population frequency and size and sexual reproduction in a clonal woody shrub. Conserv Biol 21(3):811-822.

Zar JH. 1984. Biostatiscal analysis. 2nd ed. Upper Saddle River (NJ, USA): Prentice-Hall. 718 p.

Zucker EL, Clarke M. 2003. Longitudinal assessment of immature to adult ratios in two groups of Costa Rican Alouatta palliata. Int J Primatol. 24:87-101

Zuidwijk A. 2002. Navegación y puertos argentinos en la cuenca del Plata. En: Borthagaray JM, editor. El río de la Plata como territorio. Buenos Aires: Ediciones Infinito, FADU, FURBAN. p 215245.

Zunino GE. 1986. Algunos aspectos de la ecología y etología del mono aullador negro (Alouatta caraya) en hábitat fragmentados [tesis doctoral]. [Buenos Aires]: Universidad de Buenos Aires.

Zunino GE. 1987. Nutrición en primates folívoros: la dieta de Alouatta caraya en vida silvestre. Bol Primatol Arg 5(1):278-290.

Zunino GE. 1989. Hábitat, dieta y actividad del mono aullador negro (Alouatta caraya) en el noreste de Argentina. Bol Primatol Lat 1(1):74-97.

Zunino GE. 1996. Análisis de nacimientos en Alouatta caraya (Primates, Cebidae), en el noreste de la Argentina. Mus Arg Cienc Nat Extras n.s. 133:1-10. 
Zunino GE, Mudry MD, Delprat MA. 1995. Estado actual del conocimiento de las poblaciones silvestres de primates de la Argentina. Treballs Societat Catalana de Biologia 46:177-188.

Zunino GE, Bravo S, Ferreira FM, Reisenman C. 1996. Characteristics of two types of habitat and the status of the howler monkey (Alouatta caraya) in northern Argentina. Neotrop Primates 4(2):48 -50 .

Zunino GE, González V, Kowalewski MM, Bravo SP. 2001. Alouatta caraya, relations among habitat, density and social organization. Primate Rep 61:37-46.

Zunino GE, Kowalewski MM, Oklander L, González V. 2007. Habitat fragmentation and population size of the black and gold howler monkey (Alouatta caraya) in a semideciduous forest in northern Argentina. Am J Primatol 69:1-10.

Zyalalov A. 2004. Water flows in higher plants: physiology, evolution, and system analysis. Russ J Plant Physl 51(4):547-555. 
ANEXO 1. Registro fotográfico de forrajeo de recursos tróficos de Alouatta caraya, en el período abril 2007-marzo 2008, en la selva de inundación del río Paraná Medio
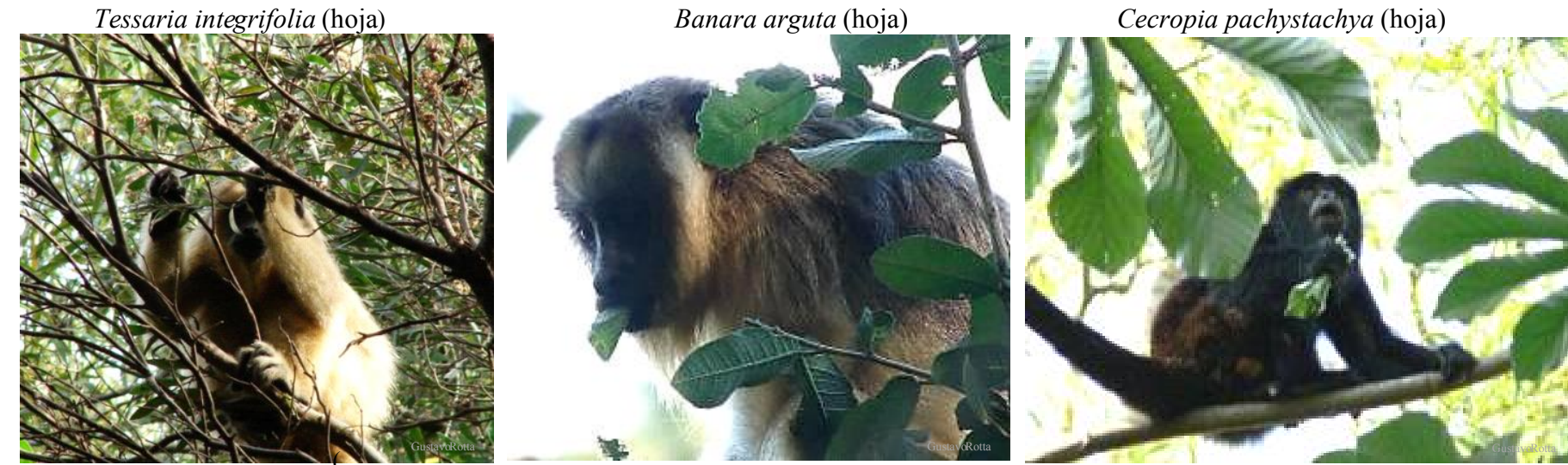
Guadua sp. (hoja)

Albizia inundata (hoja)

Ocotea diospyrifolia (fruto)
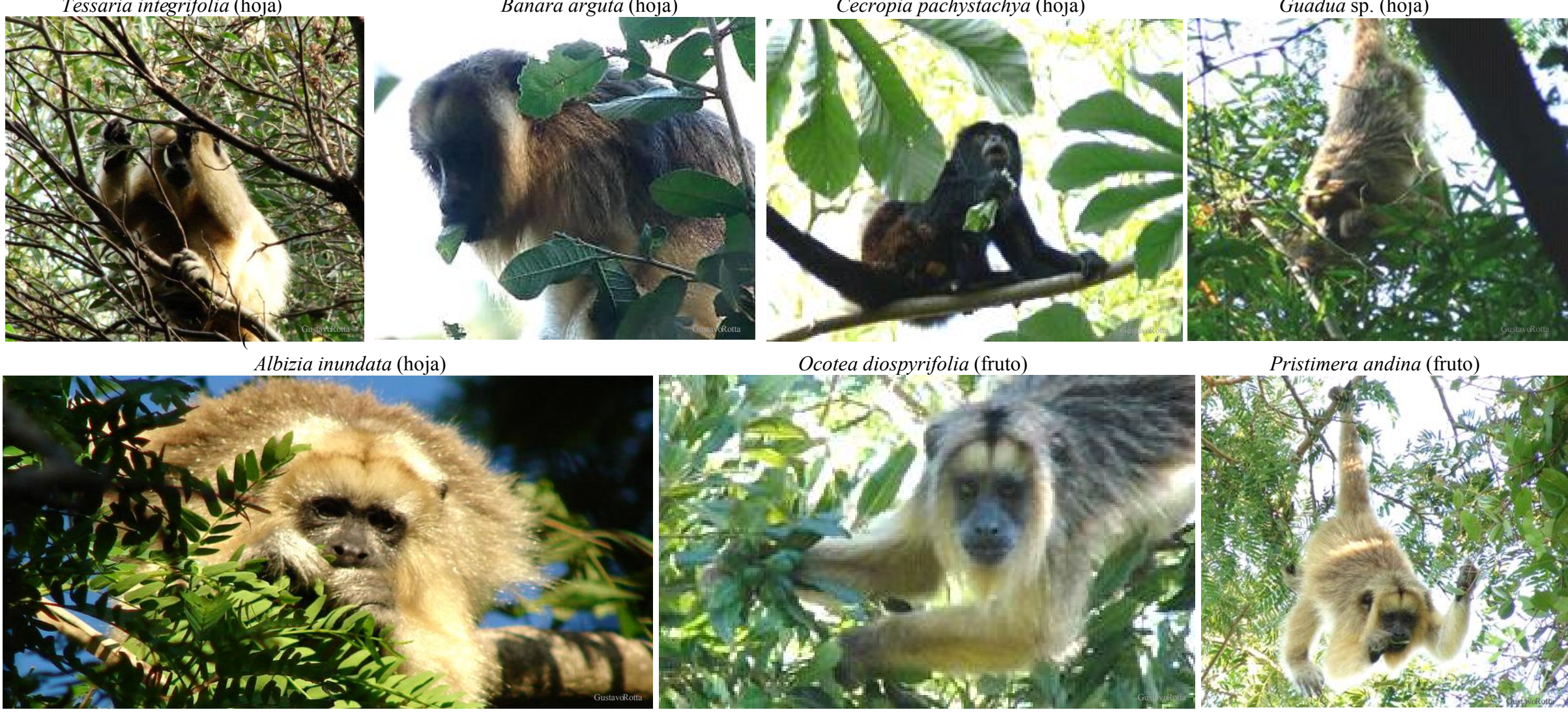

Pristimera andina (fruto)

Xylosma venosa (fruto) Croton urucurana (fruto)

And
Inga affinis (fruto)
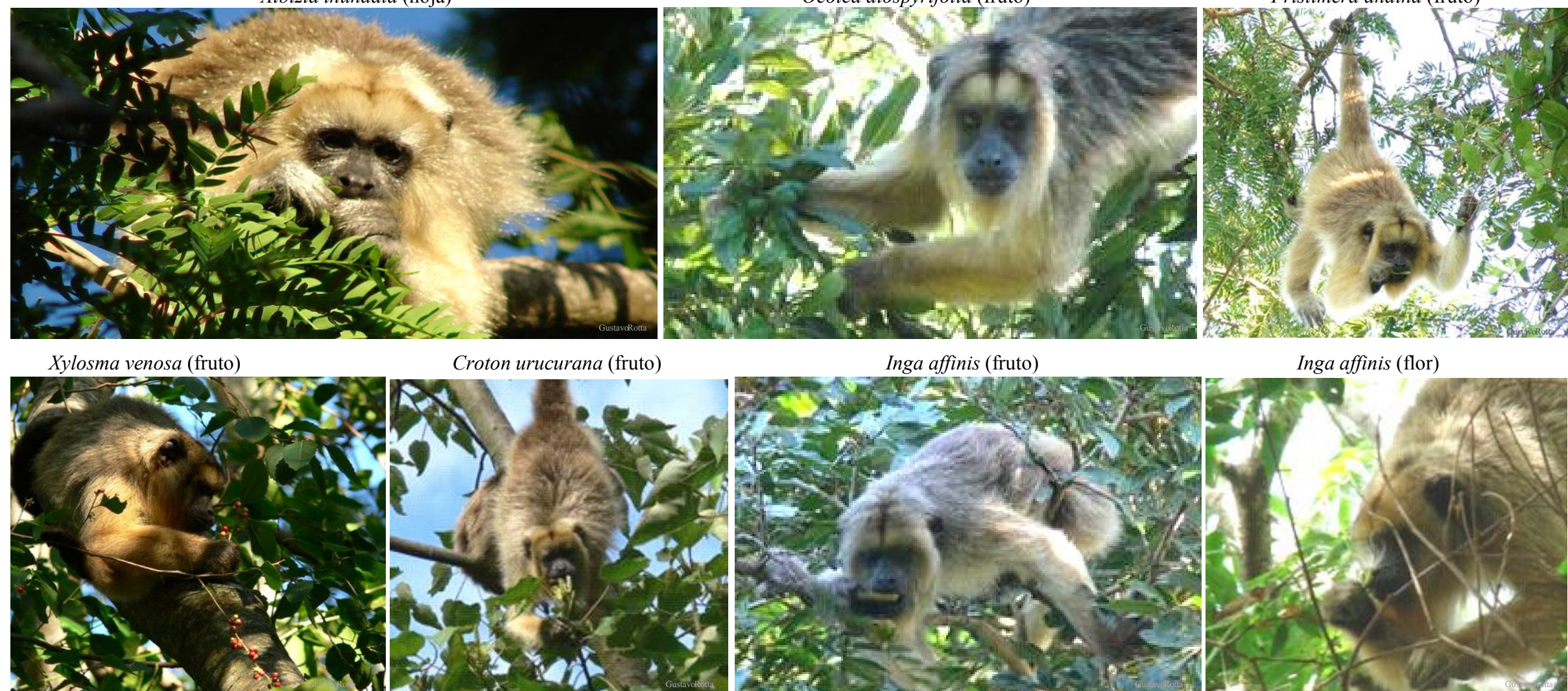
ANEXO 2. Caracteres vegetales anatómicos foliares, cuadro comparativo, clave dicotómica y microfotografías para la determinación por microhistología de 26 especies consumidas por Alouatta caraya en la selva de inundación del río Paraná Medio.

a) Tipo y forma:

- Simple: tortuoso, lanuginoso, cónico, aguijón o ahusado.

- Ramificado: 2 ramas, 3 o más ramas, tipo T, malpigiáceo o estrellado.

b) Ornamentación de la cutícula: lisa, verrucosa, con torsión, con puntuación y/o labración.

c) Cantidad de células: unicelular o multicelular.

d) Cantidad de series celulares: uniseriado, biseriado o multiseriado.

e) Longitud: tipo $1(0-0,1 \mathrm{~mm})$, tipo $2(0,1-0,2 \mathrm{~mm})$ o tipo $3(0,2-0,5 \mathrm{~mm})$.

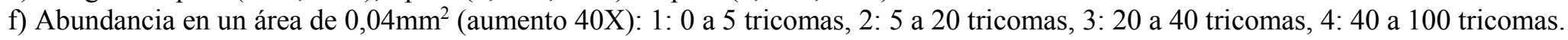

\section{Estomas}

a) Ubicación: en pecíolo, en superficie foliar abaxial (lámina hipostomática), en superficie adaxial (lámina epistomática) o en ambas superficies (lámina anfistomática).

b) Tipo: paracítico, anomocítico, actinocítico o anisocítico.

c) Distribución: dispersos, agrupado o alineados.

d) Textura de cutícula:

- Reticulada. -Granulosa. -Verrucosa. - Con rebordes. - Estriada (estrías largas o cortas, orientadas al azar, alas junto a estomas, o en círculos alrededor de estomas).

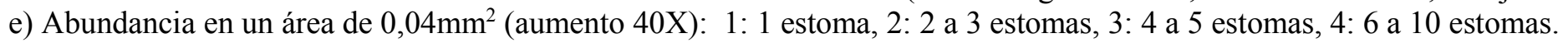

a) Contorno celular en vista superficial:

- Tipo 1: Recto.

- Tipo 2: Ondulado levemente curvado.

- Tipo 3: Sinuoso U amplios.

- Tipo 4: Sinuoso V amplios.

\section{Células epidérmicas}

-Tipo 5: Sinuoso v angostos bajos curvos concentrados.

-Tipo 6: Sinuoso v angostos romos

-Tipo 7: Sinuoso v angosto altos agudos

-Tipo 8: Sinuoso similar al carácter Omega.

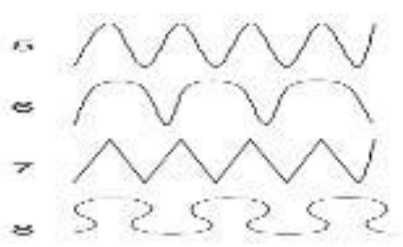

- Irregular, cuadrado, rectangular, triangular, circular, cantidad de lados

c) Grosor cutícula: tipo 1 (1 a $2 \mu \mathrm{m})$, tipo 2 ( 2 a $3,5 \mu \mathrm{m})$ o tipo 3 (3,5 a $5 \mu \mathrm{m})$.

d) Textura de cutícula: - Reticulada, granulosa, rugosa, crestada, verrucosa y estriada.

La de tipo estriada se diferenció de acuerdo a características de sus estrías:

+ de longitud corta o larga.

+ de abundancia baja (1), media (2) o alta (3).

+ con disposición al azar, alas o círculos junto a estomas.

+ con marcación leve (1), media (2) o alta (3).

\section{Idioblastos y contenidos celulares}

a) Cristales: tipo prismático (tetraédrico, tetrapiramidal, romboédrico, cúbico), drusa, rafidio o cistolito.

b) Distribución: homogénea, agrupada, en hilera, en roseta, en venas, en la lámina o en el pecíolo.

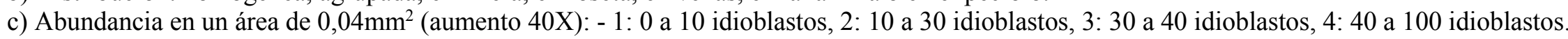


Cuadro para la identificación por microhistología de especies consumidas por Alouatta caraya.

(Referencias: abdcia: abundancia, long: longitud, unicel: unicelular, multicel: multicelular, cs: células)

\begin{tabular}{|c|c|c|c|c|c|c|c|c|c|}
\hline $\begin{array}{c}\text { Especie } \\
\text { Epidermis }\end{array}$ & Albizia inundata & Banara arguta & Croton urucurana & $\begin{array}{c}\text { Geoffroea } \\
\text { spinosa }\end{array}$ & Guadua sp. & Inga affinis & $\begin{array}{c}\text { Nectandra } \\
\text { angustifolia }\end{array}$ & $\begin{array}{c}\text { Ocotea } \\
\text { diospyrifolia }\end{array}$ & $\begin{array}{c}\text { Peltophorum } \\
\text { dubium }\end{array}$ \\
\hline \multicolumn{10}{|l|}{ Adaxial } \\
\hline $\begin{array}{l}\text { Contorno } \\
\text { celular en } \\
\text { vista } \\
\text { superficial }\end{array}$ & $\begin{array}{l}\text { Tipo 1, isodiamétrico, } \\
\text { 4-5 lados }\end{array}$ & $\begin{array}{l}\text { Tipo 2, } \\
\text { isodiamétrico, 3-5 } \\
\text { lados }\end{array}$ & \begin{tabular}{|l} 
Tipo 1 y 2, \\
isodiamétrico - \\
irregular, 4-6 lados
\end{tabular} & $\begin{array}{l}\text { Tipo 1, } \\
\text { isodiamétrico, 4-5 } \\
\text { lados }\end{array}$ & $\begin{array}{l}\text { Tipo } 1 \text { y } 6, \\
\text { rectangular, } 4 \text { lados }\end{array}$ & $\begin{array}{l}\text { Tipo } 2 \text { y 5, } \\
\text { isodiamétrico 3-4 } \\
\text { lados }\end{array}$ & $\begin{array}{l}\text { Tipo 2, isodiamétrico, } 4 \\
\text { lados }\end{array}$ & $\begin{array}{l}\text { Tipo 1, } \\
\text { isodiamétrico, } 4 \\
\text { lados }\end{array}$ & $\begin{array}{l}\text { Tipo 1, isodiamétrico, } \\
4 \text { lados }\end{array}$ \\
\hline Estoma & No se observó & Paracítico, abdcia 2-3 & Paracítico, abdcia 1-2 & No se observó & \begin{tabular}{|l|} 
Paracítico, con 2 cs \\
anexas cortas y 2 \\
anexas largas \\
longitudinales, \\
dispuestos en hileras \\
paralelas, abdcia 2 \\
\end{tabular} & No se observó & No se observó & No se observó & Paracítico, abdcia 1 \\
\hline Cutícula & Lisa, grosor 1 & $\begin{array}{l}\text { Estriada, alas } \\
\text { perpendiculares a } \\
\text { ostílo en cs } \\
\text { oclusivas e } \\
\text { irregulares en cs } \\
\text { restantes, grosor } 2 \\
\end{array}$ & \begin{tabular}{|l|} 
Estriada, alas \\
perpendiculares a \\
ostíolo en cs \\
oclusivas y lisa en cs \\
restantes, grosor 1
\end{tabular} & Lisa, grosor 2 & Lisa, grosor 3 & Lisa, grosor 2 & Lisa, grosor 2 & Lisa, grosor 3 & Lisa, grosor 3 \\
\hline Tricomas & $\begin{array}{l}\text { Simple unicel. con } \\
\text { cutícula verrucosa, en } \\
\text { borde de la lámina, } \\
\text { abdcia } 2\end{array}$ & \begin{tabular}{|l|} 
Simple unicel., \\
cutícula estriada con \\
torsiones, abdcia 2
\end{tabular} & $\begin{array}{l}\text { Con } 5 \text { o más ramas, } \\
\text { tipo estrellado, } \\
\text { abdcia } 3\end{array}$ & No se observó & No se observó & $\begin{array}{l}\text { Simple unicel. } \\
\text { long. 3-4 con } \\
\text { cutícula verrucosa, } \\
\text { abdcia 3 } \\
\end{array}$ & No se observó & $\begin{array}{l}\text { Simple unicel. liso, } \\
\text { long. 1-2-3, abdcia } 1\end{array}$ & $\begin{array}{l}\text { Simple unicel. liso, } \\
\text { long. 2, abdcia } 1\end{array}$ \\
\hline \multicolumn{10}{|l|}{ Abaxial } \\
\hline $\begin{array}{l}\text { Contorno } \\
\text { celular en } \\
\text { vista } \\
\text { superficial }\end{array}$ & $\begin{array}{l}\text { Tipo } 1 \text { y } 2, \\
\text { isodiamétrico, } 4 \text { lados }\end{array}$ & $\begin{array}{l}\text { Tipo 2, isodiamétrico } \\
\text { - irregular, } 4 \text { lados }\end{array}$ & $\begin{array}{l}\text { Tipo } 2 \text { y } 4 \text {, } \\
\text { isodiamétrico, } \\
\text { irregular }\end{array}$ & $\begin{array}{l}\text { Tipo } 2 \text {, irregular, } \\
4-5 \text { lados }\end{array}$ & $\begin{array}{l}\text { Tipo } 1 \text { y } 6, \\
\text { rectangular, } 4 \text { lados }\end{array}$ & $\begin{array}{l}\text { Tipo } 2 \text { y } 5 \text {, } \\
\text { rectangular, } 4 \text { lados }\end{array}$ & $\begin{array}{l}\text { Tipo 2, isodiamétrico, } \\
\text { cuadrado-rectangular, 4- } \\
5 \text { lados }\end{array}$ & \begin{tabular}{|l} 
Tipo 1 y 2, \\
isodiamétrico - \\
cuadrado, 4 lados
\end{tabular} & $\begin{array}{l}\text { Tipo 2, isodiamétrico, } \\
\text { 4-7 lados }\end{array}$ \\
\hline Estoma & $\begin{array}{l}\text { Paracítico, abdcia } 2 . \\
\text { Anomocítico, hundido } \\
\text { respecto de cs } \\
\text { epidérmicas, oclusivas } \\
\text { rodeadas por } 5 \text { o más cs } \\
\text { anisoédricas, abdcia } 2 \\
\end{array}$ & Paracítico, abdcia 3 & Paracítico, abdcia 2-3 & $\begin{array}{l}\text { Paracítico, abdcia } \\
2-3\end{array}$ & \begin{tabular}{|l|} 
Paracítico, con 2 cs \\
anexas cortas y 2 \\
anexas largas \\
longitudinales, \\
dispuestos en hileras \\
paralelas, abdcia 2-3 \\
\end{tabular} & $\begin{array}{l}\text { Paracítico, abdcia } \\
3-4\end{array}$ & Paracítico, abdcia 3 & Paracítico, abdcia 3 & Paracítico, abdcia 1 \\
\hline Cutícula & Lisa, grosor 1 & $\begin{array}{l}\text { Estriada 2, alas } \\
\text { perpendiculares a } \\
\text { ostíolo en cs } \\
\text { oclusivas e } \\
\text { irregulares en cs } \\
\text { restantes, grosor } 2 \\
\end{array}$ & $\begin{array}{l}\text { Estriada 2, alas } \\
\text { perpendiculares a } \\
\text { ostílo en cs } \\
\text { oclusivas e } \\
\text { irregulares en cs } \\
\text { restantes, grosor 1-2. }\end{array}$ & Lisa, grosor 2 & Lisa, grosor 3 & Lisa, grosor 2 & Lisa, grosor 2 & Lisa, grosor 3 & Lisa, grosor 3 \\
\hline Tricomas & $\begin{array}{l}\text { Simple unicel. con } \\
\text { cutícula verrucosa, long. } \\
2 \text { abdcia } 1 \text {. Glandular } \\
\text { multicel. con pie de } 3 \mathrm{cs} \\
\text { y cabezuela alargada, } \\
\text { long. } 2 \text {, abdcia } 1\end{array}$ & $\begin{array}{l}2 \text { ramas, tipo } \mathrm{T}- \\
\text { malpighiaceo, abdcia } \\
3\end{array}$ & $\begin{array}{l}\text { Con } 5 \text { o más ramas, } \\
\text { tipo estrellado, } \\
\text { abdcia } 4\end{array}$ & $\begin{array}{l}\text { Simple unicel., } \\
\text { long } 2 \text {, abdcia } 1\end{array}$ & No se observó & $\begin{array}{l}\text { Simple unicel. } \\
\text { long. } 3 \text {, abdcia } 3 \text {. } \\
\text { Glandular multicel. } \\
\text { con cel. basal y pie } \\
\text { multicel. } \\
\text { uniseriado, long } 1 \text {, } \\
\text { abdcia 1 }\end{array}$ & No se observó & No se observó & No se observó \\
\hline
\end{tabular}




\begin{tabular}{|c|c|c|c|c|c|c|c|c|c|}
\hline Pecíolo & & & & & & & & & \\
\hline $\begin{array}{l}\text { Contorno } \\
\text { celular en } \\
\text { vista } \\
\text { superficial }\end{array}$ & $\begin{array}{l}\text { Tipo 1, isodiamétrico - } \\
\text { rectangular }\end{array}$ & $\begin{array}{l}\text { Tipo 1, isodiamétrico } \\
\text { - rectangular }\end{array}$ & $\begin{array}{l}\text { Tipo 1-2, } \\
\text { isodiamétrico 4-6 } \\
\text { lados }\end{array}$ & $\begin{array}{l}\text { Tipo } 1 \text { y } 2 \text {, } \\
\text { rectangular }\end{array}$ & $\begin{array}{l}\text { Tipo } 1 \text { y } 5 \text {, } \\
\text { rectangular }\end{array}$ & $\begin{array}{l}\text { Tipo } 2 \text { y } 5 \text {, } \\
\text { rectangular }\end{array}$ & $\begin{array}{l}\text { Tipo } 2 \text {, isodiamétrico, } 4 \\
\text { lados cuadrado - circular }\end{array}$ & $\begin{array}{l}\text { Tipo } 1 \text { y } 2,4 \text { lados } \\
\text { rectangular -circular }\end{array}$ & $\begin{array}{l}\text { Tipo 2, rectangular } \\
\text { irregular- 4-5lados }\end{array}$ \\
\hline Estoma & $\begin{array}{l}\text { Paracítico, hundido } \\
\text { respecto de cs } \\
\text { epidérmicas, abdcia 1-2 }\end{array}$ & No se observó & No se observó & No se observó & Paracítico, abdcia 2-3 & Paracítico, abdcia 3 & No se observó & No se observó & No se observó \\
\hline Cutícula & Lisa, grosor 3 & Lisa, grosor 2 & Estriada 2, grosor 1-2 & Lisa, grosor 2 & Lisa, grosor 3 & Lisa, grosor 2 & Lisa, grosor 2 & Lisa, grosor 3 & Lisa, grosor 3 \\
\hline $\begin{array}{l}\text { Mesófilo, } \\
\text { contenidos } \\
\text { celulares. }\end{array}$ & $\begin{array}{l}\text { Prismáticos } \\
\text { tetrapiramidales en } \\
\text { venas de lámina y } \\
\text { pecíolo, abcia } 2-3 \text {. } \\
\text { Drusas dispersas, abdcia } \\
1\end{array}$ & $\begin{array}{l}\text { Drusas en hilera en } \\
\text { pecíolo y dispersas } \\
\text { homogéneamente en } \\
\text { lámina, abdcia } 2\end{array}$ & $\begin{array}{l}\text { Drusas dispersas } \\
\text { homogéneamente en } \\
\text { lámina y pecíolo, } \\
\text { abdcia } 2\end{array}$ & $\begin{array}{l}\text { Prismáticos } \\
\text { alargados } \\
\text { tetraédricos, abdcia } \\
1\end{array}$ & No se observó & $\begin{array}{l}\text { Prismáticos } \\
\text { tetraédricos en } \\
\text { venas, abdcia } 3\end{array}$ & $\begin{array}{l}\text { Drusas en pecíolo, } \\
\text { abdcia } 1\end{array}$ & No se observó & No se observó \\
\hline
\end{tabular}

\begin{tabular}{|c|c|c|c|c|c|c|c|c|}
\hline $\begin{array}{c}\text { Especie } \\
\text { Epidermis }\end{array}$ & Pristimera andina & Salix humboldtiana & Sapindus saponaria & Xylosma venosa & Stigmaphyllon bonariense & Tessaria integrifolia & Cecropia Pachystachya & Celtis chichape \\
\hline \multicolumn{9}{|l|}{ Adaxial } \\
\hline $\begin{array}{l}\text { Contorno } \\
\text { celular en vista } \\
\text { superficial }\end{array}$ & $\begin{array}{l}\text { Tipo } 1 \text { y } 2 \text {, irregular, } \\
\text { 3-5 lados }\end{array}$ & $\begin{array}{l}\text { Tipo 2, irregular, 3-5 } \\
\text { lados }\end{array}$ & $\begin{array}{l}\text { Tipo 1, irregular, 3-5 } \\
\text { lados }\end{array}$ & $\begin{array}{l}\text { Tipo 2, } \\
\text { isodiamétrico, 4-6 } \\
\text { lados }\end{array}$ & $\begin{array}{l}\text { Tipo 2, isodiamétrico, 10-14 } \\
\text { lados }\end{array}$ & $\begin{array}{l}\text { Tipo } 1 \text { y } 2 \text {, isodiamétrico- } \\
\text { rectangular, } 4 \text { lados }\end{array}$ & $\begin{array}{l}\text { Tipo 1-2, isodiamétrico, } 4-5 \\
\text { lados }\end{array}$ & $\begin{array}{l}\text { Tipo 1, isodiamétrico, } 4 \text { o } 5 \\
\text { lados }\end{array}$ \\
\hline Estoma & $\begin{array}{l}\text { Actinocíticos, } \\
\text { rodeados por } 4 \mathrm{cs} \\
\text { vecinas en } 2 \text { hileras } \\
\text { concéntricas, abdcia } 1\end{array}$ & Paracítico, abdcia 4 & No se observó & No se observó & No se observó & Anomocíticos, abdcia 2-3 & No se observó & No se observó \\
\hline Cutícula & Lisa, grosor 2 & Estriada, grosor 2 & Reticulada, grosor 2 & Estriada, grosor 2 & Lisa, grosor 1 & Lisa, grosor 2 & Lisa, grosor 2 & Lisa, grosor 1-2 \\
\hline Tricomas & No se observó & $\begin{array}{l}\text { Simple unicel., liso } \\
\text { ahusado, en vena, long. } \\
2 \text {, abdcia 1. Simple } \\
\text { unicel., forma de } \\
\text { aguijón, liso, long. 1, } \\
\text { abdcia 1. Simple unicel } \\
\text { tabicado, liso, long. 3, } \\
\text { abdcia } 2\end{array}$ & $\begin{array}{l}\text { Simple, multicel., } \\
\text { uniseriado, long. } 2 \text {, } \\
\text { abdcia } 1\end{array}$ & $\begin{array}{l}\text { Simple, unicel., } \\
\text { long. 1, abdcia } 2 .\end{array}$ & $\begin{array}{l}\text { Con } 2 \text { ramas bifurcado, } \\
\text { unicel., cutícula labrada y } \\
\text { punteada, abdcia } 2 \text {. }\end{array}$ & $\begin{array}{l}\text { Glandular multicel. en } \\
\text { roseta, con pedicelo unicel. } \\
\text { y cabezuela de } 4-6 \mathrm{cs}, \\
\text { abdcia } 2\end{array}$ & $\begin{array}{l}\text { Simple Unicel. lanuginoso, } \\
\text { long. 3, abdcia } 4\end{array}$ & $\begin{array}{l}\text { Simple de base estrellada- } \\
\text { redondeada, long } 3-4 \text {, con } \\
\text { cutícula grosor } 3 \text {, abdcia } 2 \text {. } \\
\text { Glandular de pie corto de } 2- \\
3 \text { cs y cuerpo cónico, } \\
\text { abdcia } 1\end{array}$ \\
\hline
\end{tabular}




\begin{tabular}{|c|c|c|c|c|c|c|c|c|}
\hline \multicolumn{9}{|l|}{ Abaxial } \\
\hline $\begin{array}{l}\text { Contorno } \\
\text { celular en vista } \\
\text { superficial }\end{array}$ & $\begin{array}{l}\text { Tipo } 1 \text { y } 2 \text {, } \\
\text { isodiamétrico - } \\
\text { rectangular, 4-5 lados }\end{array}$ & $\begin{array}{l}\text { Tipo 2, isodiamétrico, } \\
\text { 3-5 lados }\end{array}$ & $\begin{array}{l}\text { Tipo 2. isodiamétrico, } \\
\text { 5-6 lados }\end{array}$ & $\begin{array}{l}\text { Tipo 1-2, } \\
\text { isodiamétrico, 4-6 } \\
\text { lados }\end{array}$ & $\begin{array}{l}\text { Tipo } 3 \text { y } 8 \text {, isodiamétrico - } \\
\text { circular, irregular (cs que } \\
\text { rodean a cs anexas con } \\
\text { contorno tipo } 8 \text { ) }\end{array}$ & $\begin{array}{l}\text { Tipo } 1 \text { y } 2 \text {, isodiamétrico - } \\
\text { rectangular }\end{array}$ & Tipo 3, irregular 6-14 lados & $\begin{array}{l}\text { Tipo } 1 \text { y } 2 \text {, isodiamétrico, } 6 \\
\text { lados }\end{array}$ \\
\hline Estoma & $\begin{array}{l}\text { Actinocítico, } \\
\text { rodeados por } 4 \mathrm{cs}, \\
\text { abdcia } 2\end{array}$ & Paracítico, abdcia 2 & Anomocítico, abdcia 3 & Paracítico, abdcia 3 & $\begin{array}{l}\text { Paracítico, } 2 \text { cs anexas que no } \\
\text { cubren los ápices de las } \\
\text { oclusivas, abdcia } 3\end{array}$ & Anomocítico, abdcia 3 & Anomocítico, abdcia 3 & $\begin{array}{l}\text { Anomocítico, abdcia 3-4. } \\
\text { Anisocítico, abdcia } 3\end{array}$ \\
\hline Cutícula & Lisa, grosor 2 & $\begin{array}{l}\text { Estriada, marcación } 3 \\
\text { en cs subsidiarias de } \\
\text { estomas y estriada } \\
\text { marcación } 1 \text { en cs } \\
\text { restantes. grosor } 1-2\end{array}$ & $\begin{array}{l}\text { Estriada, marcación } 2 \\
\text { en cs subsidiarias de } \\
\text { estomas y lisa en cs } \\
\text { restantes. Grosor } 2\end{array}$ & $\begin{array}{l}\text { Estriada marcación } \\
3 \text {, grosor } 2-3\end{array}$ & Lisa, grosor 1 & Lisa, grosor 2 & Lisa, grosor 2 & Lisa, grosor 1-2 \\
\hline Tricomas & No se observó & $\begin{array}{l}\text { Simple unicel., sinuoso, } \\
\text { long, } 4 \text {, abdcia } 2\end{array}$ & $\begin{array}{l}\text { Simple unicel., long. } 3 \text {, } \\
\text { cutícula labrada y } \\
\text { punteada, abdcia } 2 . \\
\text { Glandular con pedicelo } \\
\text { multicel, y cabezuela } \\
\text { multicel, abdcia } 4\end{array}$ & No se observó & $\begin{array}{l}\text { Con } 2 \text { ramas bifurcado, } \\
\text { unicel., cutícula labrada y } \\
\text { punteada, abdcia } 4\end{array}$ & $\begin{array}{l}\text { Glandular multicel. en } \\
\text { roseta, con pie unicel. y } \\
\text { cabezuela de } 4-6 \text { cs, abdcia } \\
2\end{array}$ & $\begin{array}{l}\text { Simple unicel. lanuginoso, } \\
\text { long. } 3 \text {, abdcia } 4\end{array}$ & $\begin{array}{l}\text { Simple de base estrellada- } \\
\text { redondeada, long. } 3-4 \text {, con } \\
\text { cutícula grosor } 3 \text {, abdcia } 2 \text {. } \\
\text { Glandular de pie corto de } 2- \\
3 \text { cs y cuerpo cónico, } \\
\text { abdcia } 1\end{array}$ \\
\hline \multicolumn{9}{|l|}{ Pecíolo } \\
\hline $\begin{array}{l}\text { Contorno } \\
\text { celular en vista } \\
\text { superficial }\end{array}$ & $\begin{array}{l}\text { Tipo 1-2 } \\
\text { isodiamétrico- } \\
\text { irregular, 4-5 lados }\end{array}$ & \begin{tabular}{|l|} 
Tipo 2 y 3, \\
isodiamétrico, cuadrado \\
- circular, 4 lados
\end{tabular} & $\begin{array}{l}\text { Tipo } 1 \text { y 2, rectangular - } \\
6 \text { lados }\end{array}$ & \begin{tabular}{|l|} 
Tipo 1, \\
isodiamétrico, 3 o 4 \\
lados
\end{tabular} & Tipo 1 y 2, circular, 4 lados & $\begin{array}{l}\text { Tipo 1,2, isodiamétrico, } \\
\text { cuadrado - circular e } \\
\text { irregular }\end{array}$ & Tipo 1, rectangular & $\begin{array}{l}\text { Tipo } 1 \text { y 2, 4-5 lados - } \\
\text { circular }\end{array}$ \\
\hline Estoma & No se observó & No se observó & Anomocítico, abdcia 2 & No se observó & No se observó & Anomocítico, abdcia 2 & No se observó & No se observó \\
\hline Cutícula & Lisa, grosor 3 & Lisa, grosor 2-3 & $\begin{array}{l}\text { Reticulada, grosor. } \\
\text { Lisa, grosor } 2\end{array}$ & Lisa, grosor 2 & Lisa, grosor 1 & $\begin{array}{l}\text { Estriada, marcación 1, } \\
\text { grosor } 1\end{array}$ & Lisa, grosor 2 & Lisa, grosor 2 \\
\hline Tricomas & No se observó & $\begin{array}{l}\text { Simple unicel., long. 3, } \\
\text { abdcia } 2\end{array}$ & $\begin{array}{l}\text { Simple multicel. de } 3,4 \\
\text { cs, long 3-4, uniseriado, } \\
\text { abdcia } 2\end{array}$ & $\begin{array}{l}\text { Simple unicel., } \\
\text { long. 1, abdcia } 3\end{array}$ & $\begin{array}{l}\text { Con } 2 \text { ramas bifurcado, } \\
\text { unicel., cutícula labrada y } \\
\text { punteada, abdcia } 3 \text {. }\end{array}$ & $\begin{array}{l}\text { Glandular multicel. en } \\
\text { roseta, con pedicelo unicel. } \\
\text { y cabezuela de } 4-6 \text { cs, } \\
\text { abdcia } 3\end{array}$ & $\begin{array}{l}\text { Simple unicel. lanuginoso, } \\
\text { long 3, abdcia } 4\end{array}$ & $\begin{array}{l}\text { Simple de base estrellada- } \\
\text { redondeada notoria, long. } 3 \text { - } \\
4, \text { con cutícula grosor } 3 \\
\text { abdcia } 2 \text {. }\end{array}$ \\
\hline $\begin{array}{l}\text { Mesófilo, } \\
\text { contenidos } \\
\text { celulares. }\end{array}$ & $\begin{array}{l}\text { Drusas de a pares, } y / 0 \\
\text { dispersas o en venas, } \\
\text { abdcia } 4\end{array}$ & $\begin{array}{l}\text { Prismáticos en venas, } \\
\text { abdcia 2. Drusas, abdcia } \\
2\end{array}$ & $\begin{array}{l}\text { Prismáticos en venas, } \\
\text { abdcia } 3\end{array}$ & $\begin{array}{l}\text { Prismáticos, abdcia } \\
3\end{array}$ & Drusas dispersas, abdcia 1 & No se observó & $\begin{array}{l}\text { Drusas dispersas } \\
\text { homogéneamente, abdcia } 1\end{array}$ & $\begin{array}{l}\text { Drusas dispersas } \\
\text { homogéneamente, abdcia } 2 \text {, } \\
\text { en venas, abdcia } 3 \text {. }\end{array}$ \\
\hline
\end{tabular}




\begin{tabular}{|c|c|c|c|c|c|c|c|c|c|}
\hline $\begin{array}{c}\text { Especie } \\
\text { Epidermis }\end{array}$ & $\begin{array}{l}\text { Paullinia } \\
\text { elegans }\end{array}$ & $\begin{array}{l}\text { Ipomoea } \\
\text { cairica }\end{array}$ & $\begin{array}{l}\text { Phyllanthus } \\
\text { chacoensis }\end{array}$ & $\begin{array}{c}\text { Erythrina crista } \\
\text { galli }\end{array}$ & $\begin{array}{l}\text { Machaonia } \\
\text { brasiliensis }\end{array}$ & Eugenia moraviana & $\begin{array}{c}\text { Sorocea } \\
\text { sprucei }\end{array}$ & $\begin{array}{c}\text { Houssayanthus } \\
\text { incanus }\end{array}$ & $\begin{array}{c}\text { Dolichandra } \\
\text { unguis cati }\end{array}$ \\
\hline \multicolumn{10}{|l|}{ Adaxial } \\
\hline $\begin{array}{l}\text { Contorno } \\
\text { celular en } \\
\text { vista } \\
\text { superficial }\end{array}$ & $\begin{array}{l}\text { Tipo 3, } \\
\text { isodiamétrico, } 4 \\
\text { lados }\end{array}$ & $\begin{array}{l}\text { Tipo 4, } \\
\text { isodiamétrico, } \\
\text { 8-12 lados }\end{array}$ & $\begin{array}{l}\text { Tipo 1, isodiamétrico, 4-5 } \\
\text { lados }\end{array}$ & $\begin{array}{l}\text { Tipo } 1 \text { y } 2, \\
\text { isodiamétrico, 3-4 } \\
\text { lados }\end{array}$ & $\begin{array}{l}\text { Tipo } 1 \text { y } 2, \\
\text { isodiamétrico, 4- } \\
5 \text { lados }\end{array}$ & Tipo 5, isodiamétrico, 18-26 lados & $\begin{array}{l}\text { Tipo 2, } \\
\text { isodiamétrico, 4-5 } \\
\text { lados }\end{array}$ & $\begin{array}{l}\text { Tipo 2, isodiamétrico, 3-6 } \\
\text { lados }\end{array}$ & $\begin{array}{l}\text { Tipo 6, } \\
\text { isodiamétrico, } \\
\text { 10-14 lados }\end{array}$ \\
\hline Estoma & $\begin{array}{l}\text { Anomocíticos, } \\
\text { abdcia } 1\end{array}$ & $\begin{array}{l}\text { Anomocíticos, } \\
\text { abdcia } 1\end{array}$ & No se observó & No se observó & $\begin{array}{l}\text { Paracítico, } 2 \mathrm{cs} \\
\text { anexas que no } \\
\text { cubren los } \\
\text { ápices de un } \\
\text { extremo de las } \\
\text { oclusivas, } \\
\text { abdcia 1 }\end{array}$ & No se observó & No se observó & No se observó & $\begin{array}{l}\text { Paracítico, } \\
\text { abdcia } 1\end{array}$ \\
\hline Cutícula & Lisa, grosor 2 & $\begin{array}{l}\text { Estriada, } \\
\text { grosor 2-3 }\end{array}$ & Lisa, grosor 2 & Lisa, grosor 3 & Lisa, grosor 2 & Lisa, grosor 2-3 & Lisa, grosor 3 & Lisa, grosor 2 & Lisa, grosor 1 \\
\hline Tricomas & $\begin{array}{l}\text { Simple unicel. } \\
\text { ahusado, liso, } \\
\text { long.1 y } 3 \text {, abdcia } \\
2-3\end{array}$ & $\begin{array}{l}\text { Simple unicel. } \\
\text { cónico liso } \\
\text { long. 1, abdcia } \\
1 \text {, glandular } \\
\text { capitado long. } \\
1 \text {, abdcia 1 }\end{array}$ & No se observó & No se observó & No se observó & No se observó & $\begin{array}{l}\text { Simple unicel., } \\
\text { long 1-3, abdcia } \\
\text { 2-4. Glandular } \\
\text { multicel, con } \\
\text { célula base y } 2 \\
\text { distales, long. 1, } \\
\text { abdcia 1 }\end{array}$ & $\begin{array}{l}\text { Simple unicel. liso, abdcia } \\
\text { 2-3. Glandular con pie } \\
\text { multicelular y cabezuela de } \\
2-3 \mathrm{cs}\end{array}$ & $\begin{array}{l}\text { Simple } \\
\text { multicel. } \\
\text { uniseriado de } \\
4-6 \text { cs, long. } \\
2-3, \text { cutícula } \\
\text { verrucosa, } \\
\text { abdcia 2-3 }\end{array}$ \\
\hline \multicolumn{10}{|l|}{ Abaxial } \\
\hline $\begin{array}{l}\text { Contorno } \\
\text { celular en } \\
\text { vista } \\
\text { superficial }\end{array}$ & $\begin{array}{l}\text { Tipo } 2 \text { y } 3, \\
\text { irregular }\end{array}$ & $\begin{array}{l}\text { Tipo 4, } \\
\text { irregular 6-10 } \\
\text { lados }\end{array}$ & Tipo 2, irregular 3-6 lados & $\begin{array}{l}\text { Tipo } 1 \text { y } 2 \text {, } \\
\text { isodiamétrico - } \\
\text { circular, 3-4 lados }\end{array}$ & $\begin{array}{l}\text { Tipo } 1 \text { y } 2, \\
\text { isodiamétrico, } 4- \\
5 \text { lados }\end{array}$ & Tipo 5, isodiamétrico, 18-26 lados & $\begin{array}{l}\text { Tipo 5, } \\
\text { isodiamétrico - } \\
\text { rectangular }\end{array}$ & $\begin{array}{l}\text { Tipo 2, isodiamétrico } \\
\text { cuadrado - rectangular }\end{array}$ & $\begin{array}{l}\text { Tipo 5, } \\
\text { isodiamétrico, } \\
\text { 6-8 lados }\end{array}$ \\
\hline Estoma & $\begin{array}{l}\text { Anomocítico, } \\
\text { abdcia } 2\end{array}$ & $\begin{array}{l}\text { Anomocítico, } \\
\text { abdcia } 3\end{array}$ & Paracítico, abdcia 3 & $\begin{array}{l}\text { Paracítico, abdcia } \\
2-3\end{array}$ & \begin{tabular}{|l|} 
Paracítico, 2 cs \\
anexas, que no \\
cubren los \\
ápices de un \\
extremo de las \\
oclusivas, \\
abdcia 2 \\
\end{tabular} & Paracítico, abdcia 2 & $\begin{array}{l}\text { Paracítico, } \\
\text { oclusivas } \\
\text { rodeadas por } 2 \mathrm{cs,} \\
\text { abdcia } 4\end{array}$ & Anomocítico, abdcia 2-3 & $\begin{array}{l}\text { Paracítico, } \\
\text { abdcia } 1-2\end{array}$ \\
\hline Cutícula & Lisa, grosor 2 & $\begin{array}{l}\text { Estriada, } \\
\text { grosor 1-2 }\end{array}$ & Lisa, grosor 2 & Lisa, grosor 2 & Lisa, grosor 2 & Lisa, grosor 2 & Lisa, grosor 2 & Lisa, grosor 2 & Lisa, grosor 1 \\
\hline Tricomas & No se observó & $\begin{array}{l}\text { Simple unicel. } \\
\text { cónico, liso, } \\
\text { long. 1, abdcia } \\
\text { 1. Glandular, } \\
\text { capitado, long. } \\
\text { 1, abdcia } 1\end{array}$ & No se observó & No se observó & No se observó & No se observó & $\begin{array}{l}\text { Simple unicel., } \\
\text { long. 1-3, abdcia } \\
\text { 2-4. Glandular } \\
\text { multicel, con } \\
\text { célula base y } 2 \\
\text { distales, long.1, } \\
\text { abdcia 1 }\end{array}$ & $\begin{array}{l}\text { Simple unicel. liso, long. } 2 \text {, } \\
\text { abdcia } 2-3 \text {. Glandular con } \\
\text { pie multicel y cabezuela de } \\
2 \text { cs, long. } 2 \text {, abdcia } 2\end{array}$ & $\begin{array}{l}\text { Simple } \\
\text { multicel., } \\
\text { uniseriado de } \\
4-6 \text { cs, long. } \\
2-3 \text {, cutícula } \\
\text { verrucosa, } \\
\text { abdcia 2-3 }\end{array}$ \\
\hline
\end{tabular}




\begin{tabular}{|c|c|c|c|c|c|c|c|c|c|}
\hline \multicolumn{10}{|l|}{ Pecíolo } \\
\hline $\begin{array}{l}\text { Contorno } \\
\text { celular en } \\
\text { vista } \\
\text { superficial }\end{array}$ & $\begin{array}{l}\text { Tipo 1, 4-5 lados - } \\
\text { circular }\end{array}$ & $\begin{array}{l}\text { Tipo 2, } \\
\text { irregular, 5-7 } \\
\text { lados }\end{array}$ & $\begin{array}{l}\text { Tipo 1, rectangular, 4-5 } \\
\text { lados }\end{array}$ & Tipo 1, rectangular & $\begin{array}{l}\text { Tipo } 1 \text { y } 2, \\
\text { isodiamétrico, 4- } \\
5 \text { lados }\end{array}$ & Tipo 1, isodiamétrico & $\begin{array}{l}\text { Tipo } 1 \text { y } 2,4-6 \\
\text { lados }\end{array}$ & Tipo 1, rectangular & $\begin{array}{l}\text { Tipo } 1, \\
\text { rectangular }\end{array}$ \\
\hline Estoma & $\begin{array}{l}\text { Anomocítico, } \\
\text { abdcia } 3\end{array}$ & No se observó & No se observó & No se observó & No se observó & No se observó & No se observó & Anomocítico, abdcia 1 & No se observó \\
\hline Cutícula & Lisa, grosor 2 & $\begin{array}{l}\text { Estriada, } \\
\text { grosor 1-2 }\end{array}$ & Lisa, grosor 2-3 & Lisa, grosor 3 & Lisa, grosor 2 & Lisa, grosor 1 & Lisa, grosor 2 & Lisa, grosor 2 & Lisa, grosor 2 \\
\hline Tricomas & $\begin{array}{l}\text { Simple unicel., } \\
\text { ahusado, liso, long. } \\
\text { 3, abdcia 2-3 }\end{array}$ & No se observó & $\begin{array}{l}\text { Simple unicel. liso, ápice } \\
\text { romo, long. 3, abdcia } 2\end{array}$ & No se observó & No se observó & No se observó & $\begin{array}{l}\text { Simple unicel. } \\
\text { liso, long. } 1, \\
\text { abdcia } 4\end{array}$ & $\begin{array}{l}\text { Glandular con pie multicel. } \\
\text { y cabezuela de } 2 \mathrm{cs} \text {, long. } \\
2 \text {, abdcia } 1\end{array}$ & \begin{tabular}{|l|} 
Simple \\
multicel. \\
uniseriado de \\
$4-6$ cs, long. \\
$2-3$, cutícula \\
verrucosa, \\
abdcia $2-3$ \\
\end{tabular} \\
\hline $\begin{array}{l}\text { Mesófilo, } \\
\text { contenidos } \\
\text { celulares. }\end{array}$ & $\begin{array}{l}\text { Prismáticos } \\
\text { romboédricos, } \\
\text { abdcia } 2-3\end{array}$ & $\begin{array}{l}\text { Drusas en } \\
\text { nervadura } \\
\text { principal, } \\
\text { abdcia } 2\end{array}$ & Prismáticos, abdcia 2 & $\begin{array}{l}\text { Prismáticos en } \\
\text { pecíolo, abdcia } 1 . \\
\text { Drusas en pecíolo, } \\
\text { abdcia } 1\end{array}$ & No se observó & $\begin{array}{l}\text { Prismáticos romboédricos, abdcia } 1 . \\
\text { Drusas, abdcia } 1\end{array}$ & $\begin{array}{l}\text { Prismáticos en } \\
\text { venas, abdcia } 4 . \\
\text { Drusas dispersas } \\
\text { homogéneamente, } \\
\text { abdcia } 1\end{array}$ & Cúbicos, abdcia 1 & $\begin{array}{l}\text { Prismáticos, } \\
\text { abdcia 1. } \\
\text { Ráfides } \\
\text { dispersos, } \\
\text { abdcia 1. } \\
\text { Ráfides en } \\
\text { roseta, abdcia } 1 \\
\end{array}$ \\
\hline
\end{tabular}


A - Hojas glabras

B - Anfistomática, con estomas Actinocíticos

Pristimera andina

B' - Anfistomática o Hipostomática, con estomas Paracíticos

C - Anfistomática, sin cristales

C'- Hipostomática, con Cristales

Machaonia brasiliensis

$\mathrm{D}$

D - Con drusas

$\mathrm{D}^{\prime}$ - Con drusas y cristales prismáticos

Nectandra angustifolia

E - Contorno celular en superficie tipo 5, isodiamétrica de 18-26 lados

$E^{\prime}$ - Contorno celular en superficie tipo 1-2, isodiamétrica de 3-4 lados redondeados

$\mathrm{A}^{\prime}$ - Hojas pubescentes

F - Pubescentes anfistomática

$\mathrm{F}^{\prime}$ - Pubescentes hipostomática

$\mathrm{G}$ - Con estomas anomocíticos

$\mathrm{H}$ - Epidermis estriada

$\mathrm{H}^{\prime}$ - Epidermis lisa

I - Tricoma glandular en roseta, pie unicelular y cabezuela multicelular

I' - Tricoma simple

$\mathrm{G}^{\prime}$ - Con estomas paracíticos

$\mathrm{J}$ - Con tricomas ramificados

$\mathrm{K}$ - Con más de 5 ramas, estrellados

$\mathrm{K}^{\prime}$ - Con 2 ramas, malpigiáceos

$\mathrm{J}^{\prime}$ - Con tricoma no ramificado

L - Con cutícula epidérmica estriada

L' - Con cutícula epidérmica lisa

LL - Con cristales prismáticos, en roseta y ahusados

LL'- Sin cristales

Eugenia moraviana

Erythrina crista galli

G

$\mathrm{N}$

$\mathrm{H}$

Ipomoea cairica

Tessaria integrifolia

Paullinia elegans

Croton urucurana

Banara arguta

Salix humboldtiana

LL

Dolichandra unguis cati

$\mathrm{M}$ 


\section{M - Contorno celular en superficie tipo 1, 5 y 6 rectangular 4 lados, con células oclusivas osteiforme}

$\mathrm{M}^{\prime}$ - Contorno celular en superficie tipo 2 isodiamétrico 4 a 7 lados, sin células oclusivas osteiformes

$\mathrm{N}$ - Con estomas paracíticos y anomocíticos

$\mathrm{N}^{\prime}$ - Con estomas anomocíticos o paracíticos

$\tilde{\mathrm{N}}$ - Com estomas anomocíticos

$\tilde{\mathrm{N}}^{\prime}$ - Con estomas paracíticos

$\mathrm{O}$ - Con drusas

$\mathrm{P}$ - Con tricomas lanuginosos

$\mathrm{P}^{\prime}$ - Con tricomas simples de base estrellada

$\mathrm{O}^{\prime}$ - Con cristales prismáticos y cúbicos

Q- Con cutícula estriada o reticulada

Q'- Con cutícula lisa

$\mathrm{R}$ - Con cutícula estriada

$\mathrm{R}^{\prime}$ - Con cutícula lisa

$\mathrm{S}$ - Tricomas con 2 ramas

$\mathrm{S}^{\prime}$ - Tricomas simples y/o glandulares

$\mathrm{T}$ - Tricomas simples unicelulares lisos

$\mathrm{U}$ - Sin cristales, tricomas en epidermis adaxial

U' - Con cristales prismáticos

$\mathrm{V}$ - Tricomas en epidermis abaxial de longitud 2 y abundancia 1

$\mathrm{V}^{\prime}$ - Tricomas en epidermis de pecíolo de longitud 3, con ápice romo y abundancia 2

$\mathrm{T}^{\prime}$ - Tricomas simples y glandulares

W - Tricomas simples unicelulares de longitud 3 y abundancia 3 , y glandulares multicelulares, con célula basal y pie multicelular uniseriado

W'- Tricomas simples unicelulares de longitud 1-3 y abundancia 2-4, y glandulares multicelulares, con célula basal y 2 distales
Guadua sp.

Peltophorum dubium

Albizia inundata

$\tilde{\mathrm{N}}$

R

O

$\mathrm{P}$

Cecropia pachystachya

Celtis chichape

Q

Sapindus saponaria

Houssayanthus incanus

Xylosma venosa

$\mathrm{S}$

Stigmaphyllon bonariense

$\mathrm{T}$

U

Ocotea diospyrifolia

V

Geoffroea spinosa

Phyllanthus chacoensis

W

Inga affinis

Sorocea sprucei 
Microfotografías para la identificación por microhistología de especies consumidas por Alouatta caraya

Epidermis adaxial
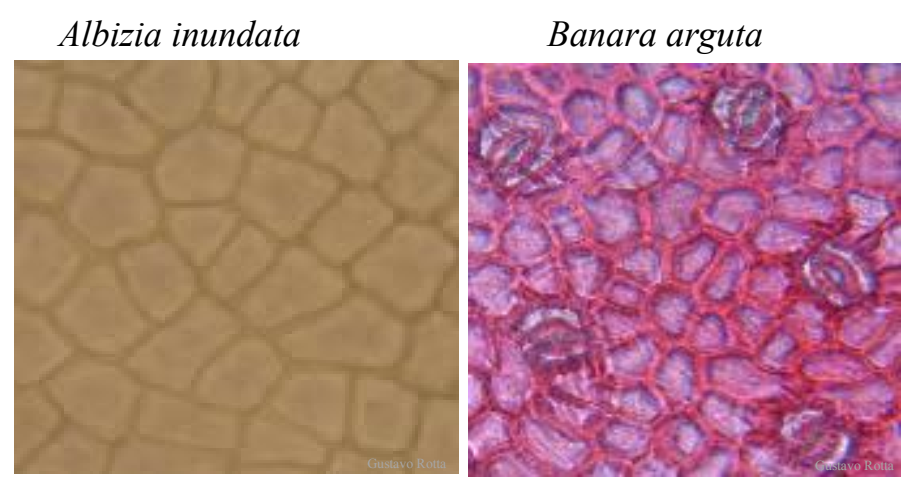

Croton urucurana
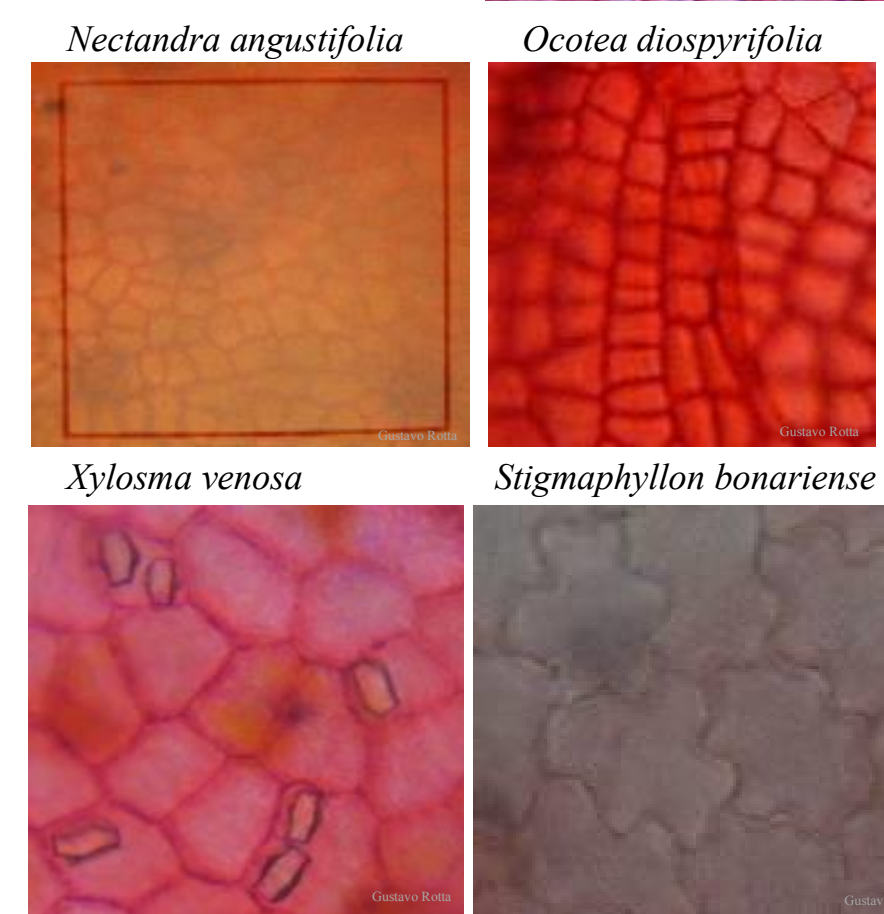

Stigmaphyllon bonariense

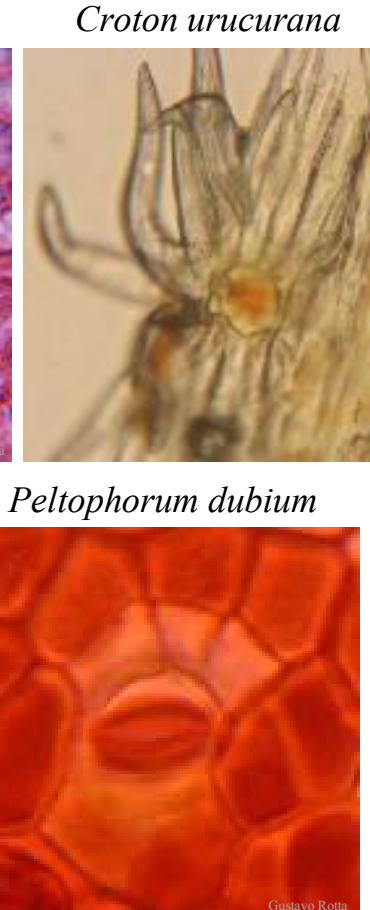

Geoffroea spinosa
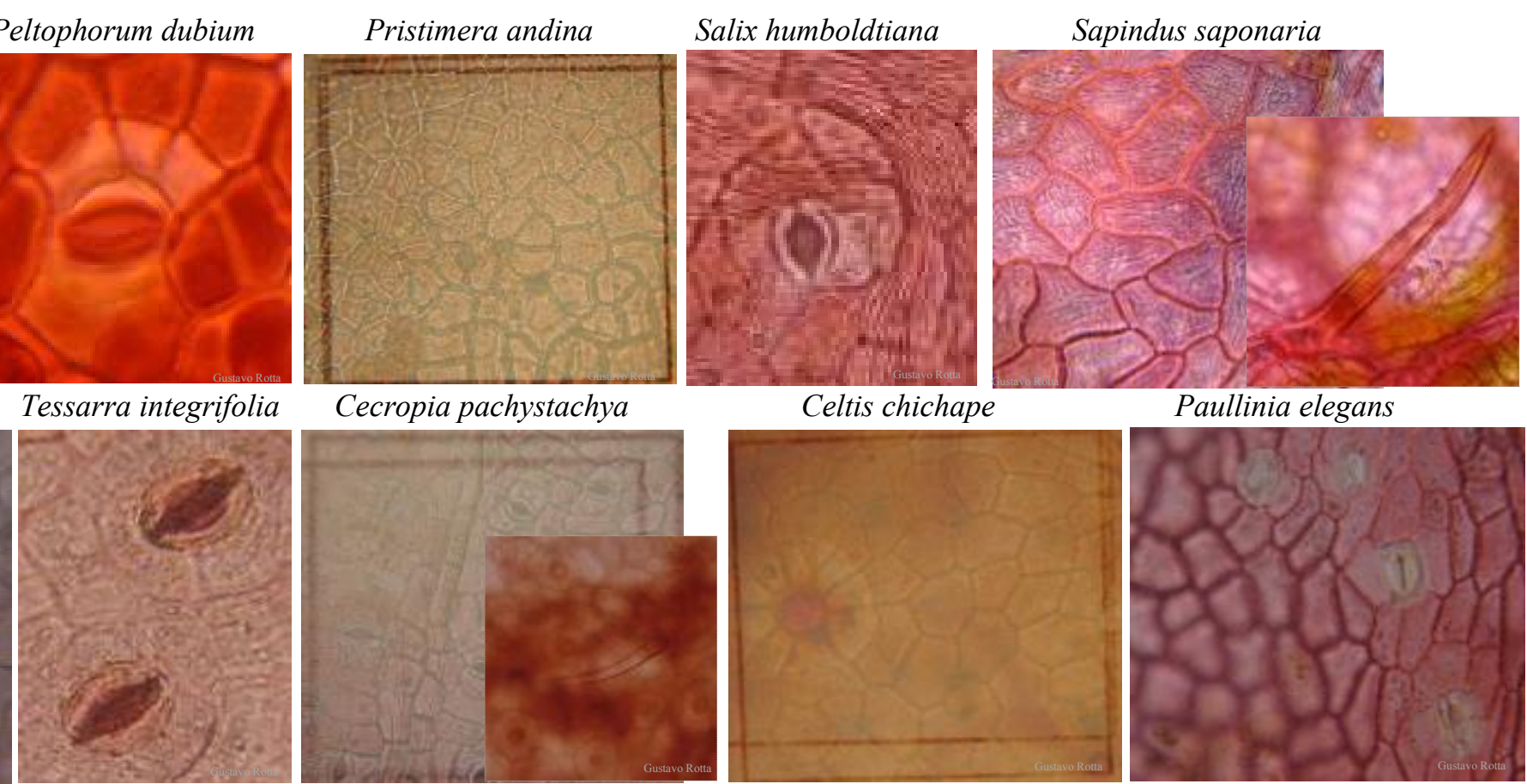

Celtis chichape

Paullinia elegans

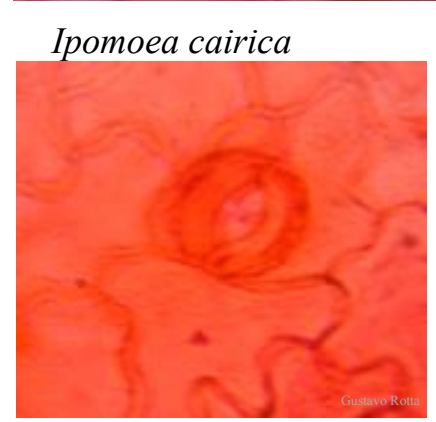

Phyllanthus chacoensis

Machaonia brasiliensis

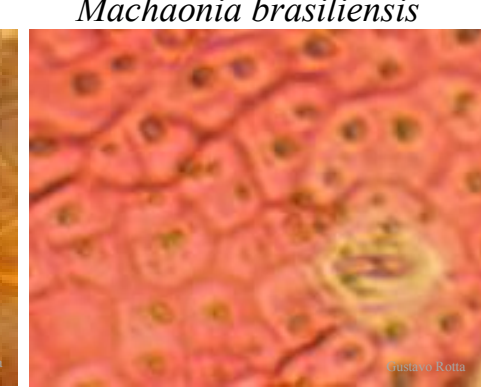

Sorocea sprucei

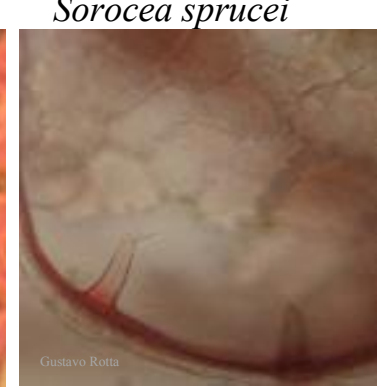

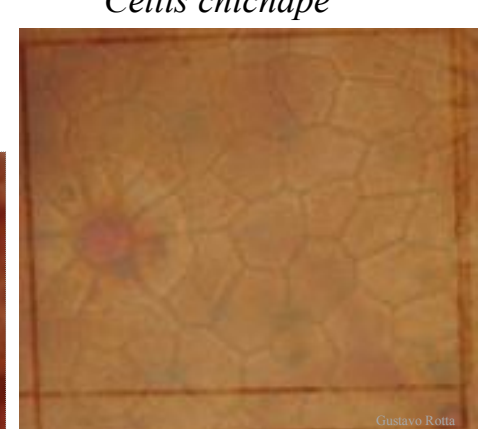

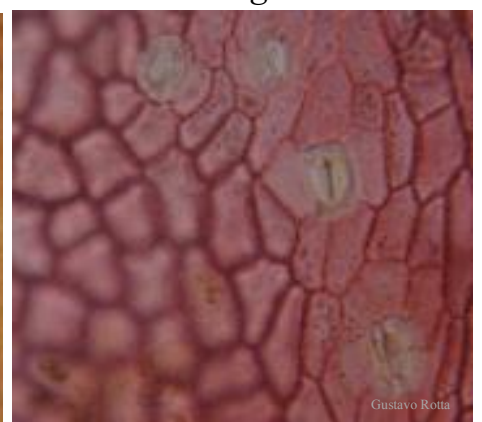

Houssayanthus incanus

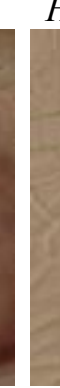

Dolichandra unguis cati

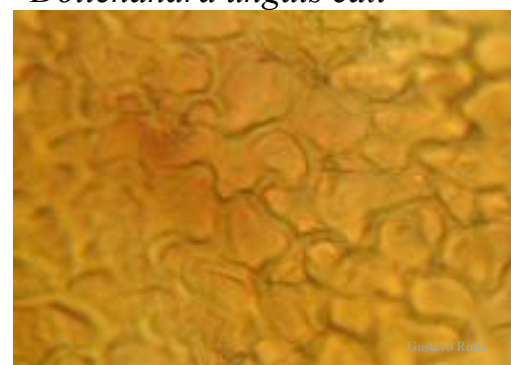



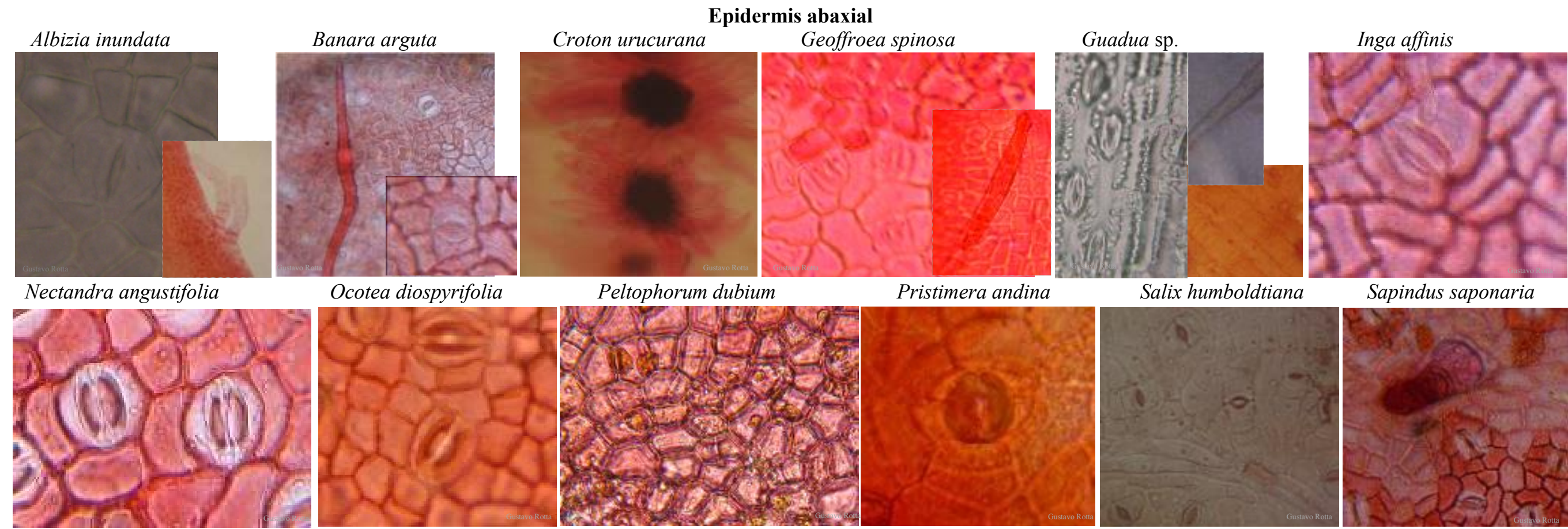

Pristimera andina

Salix humboldtiana

Sapindus saponaria
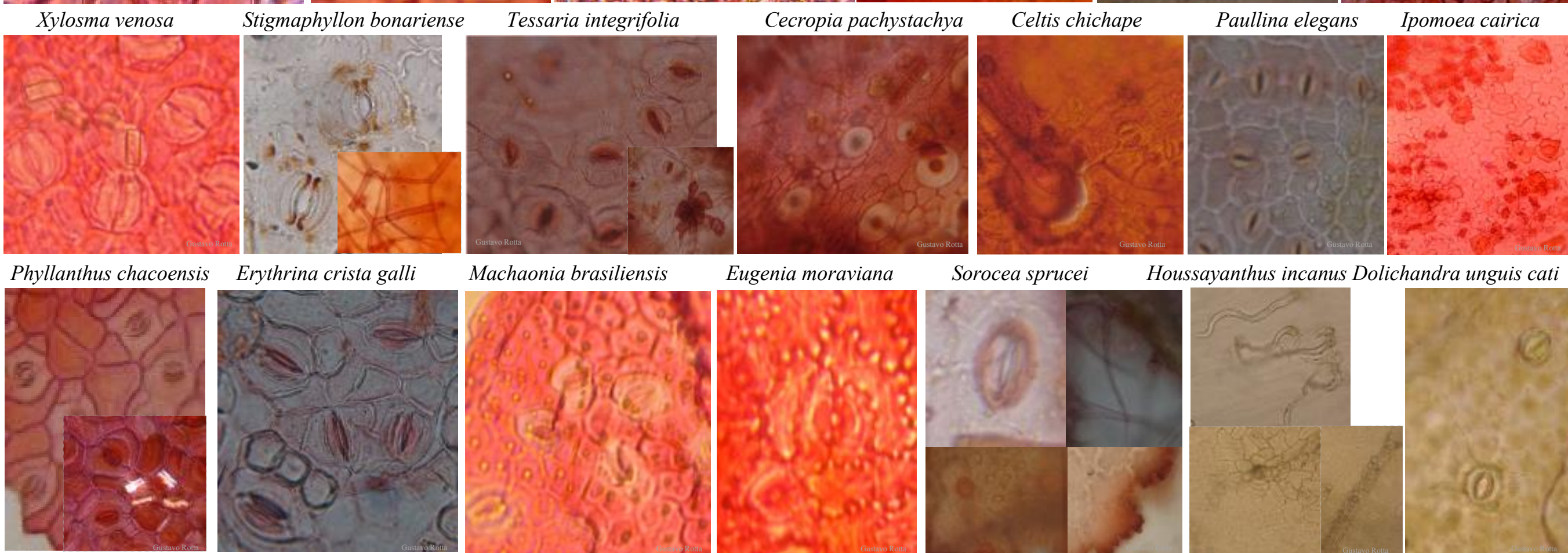

Eugenia moraviana

Sorocea sprucei

Houssayanthus incanus Dolichandra unguis cati
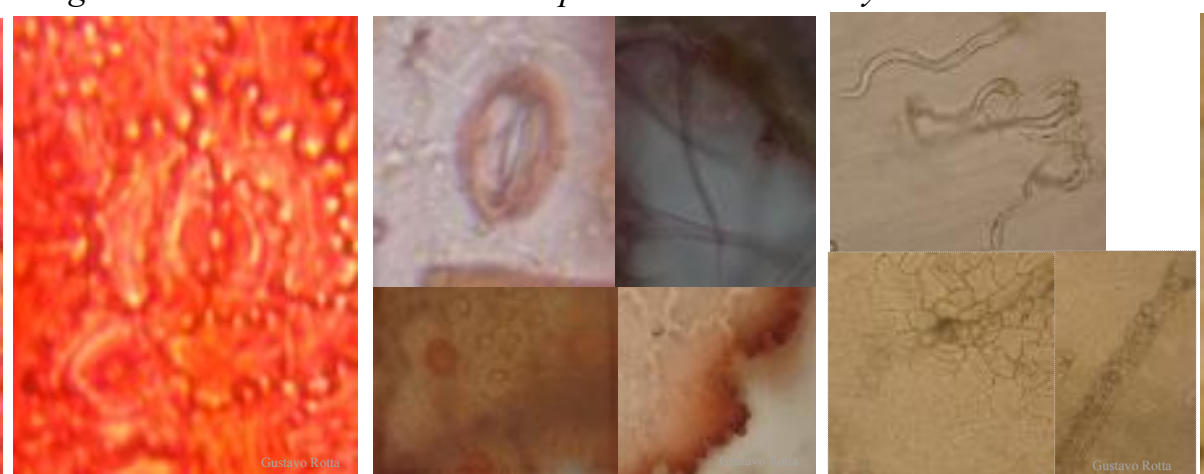


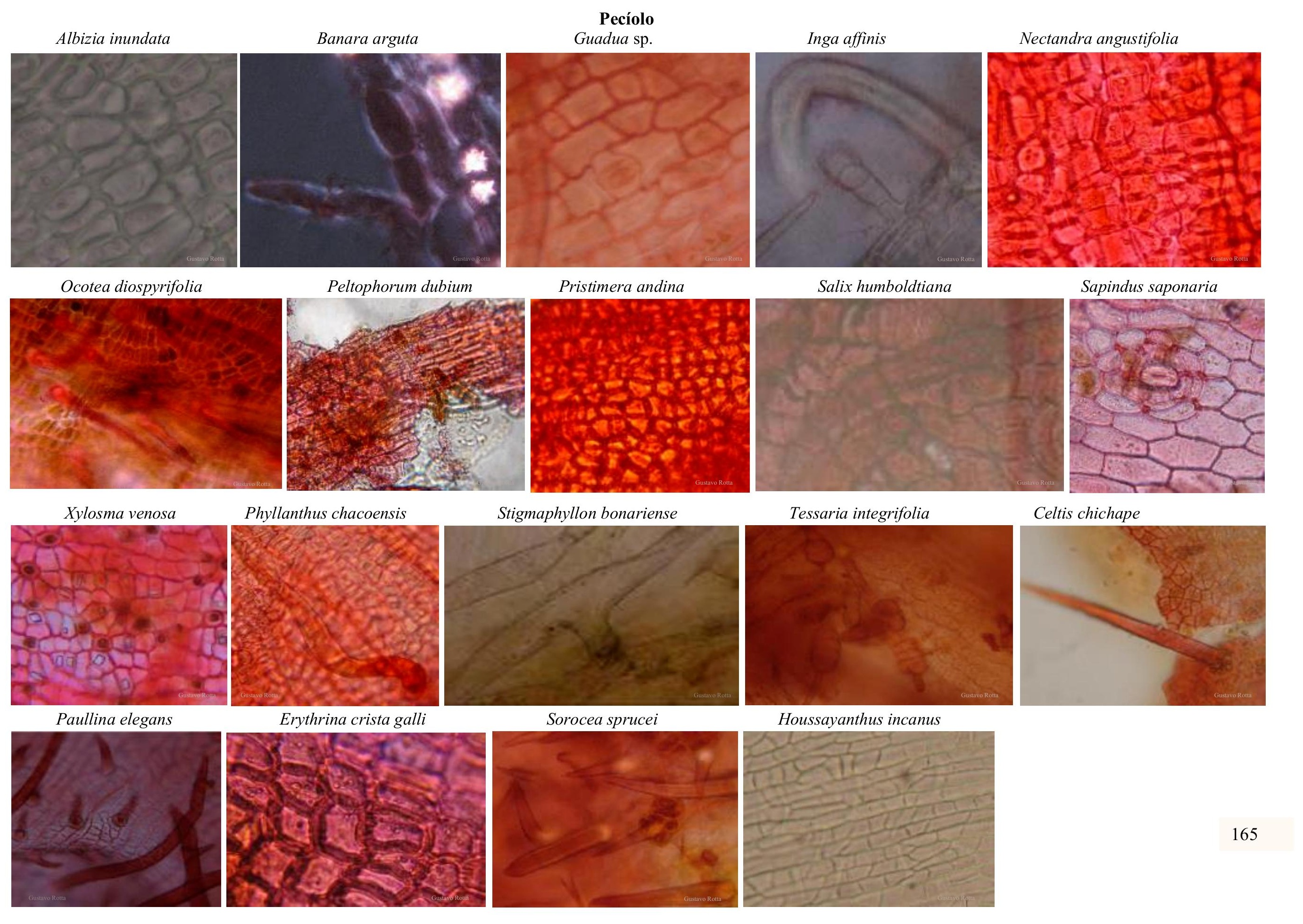


ANEXO 3. Semillas de especies consumidas por Alouatta caraya, detectadas por macroscopía de muestras fecales obtenidas en la selva de inundación del río Paraná Medio.

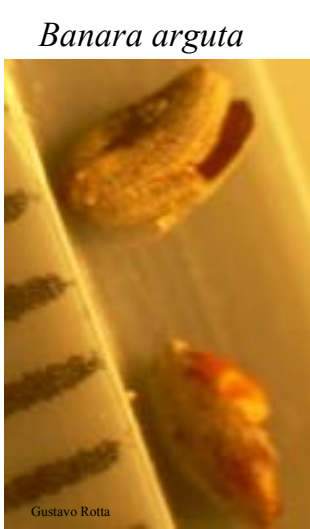

Nectandra angustifolia

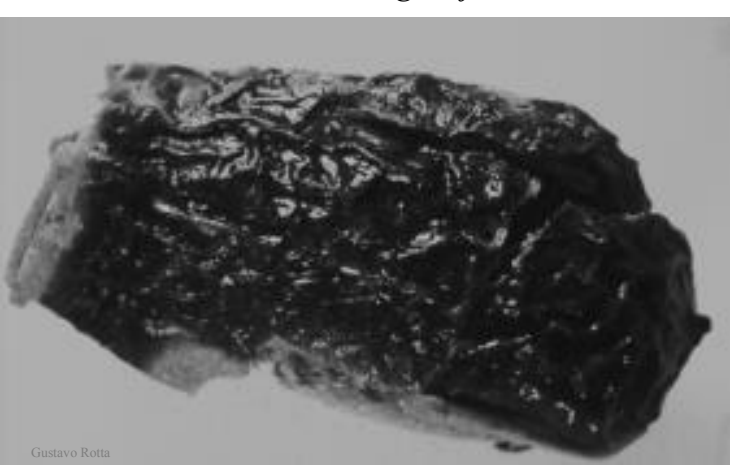

Ficus luschnathiana

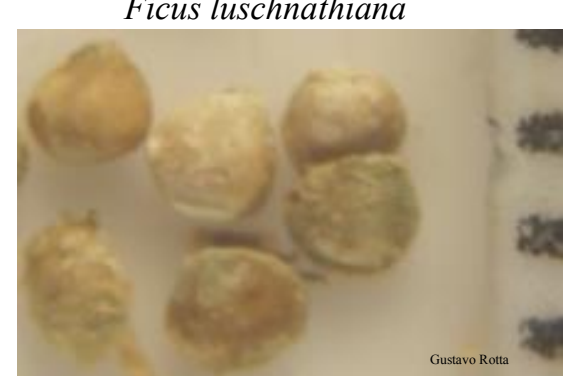

Panicum sp.
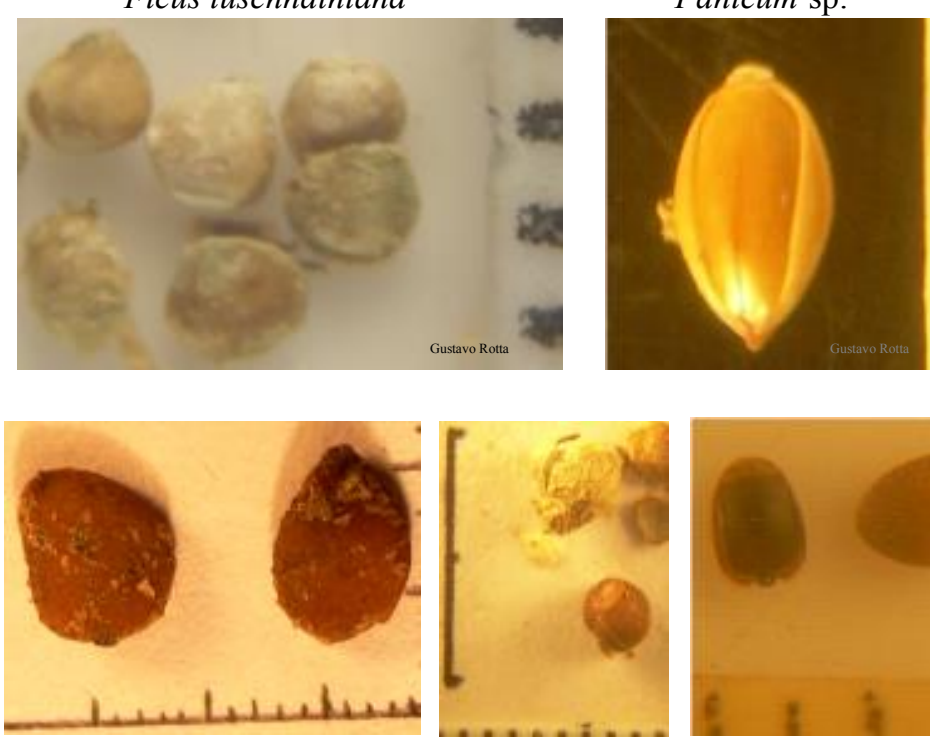

Celtis chichape

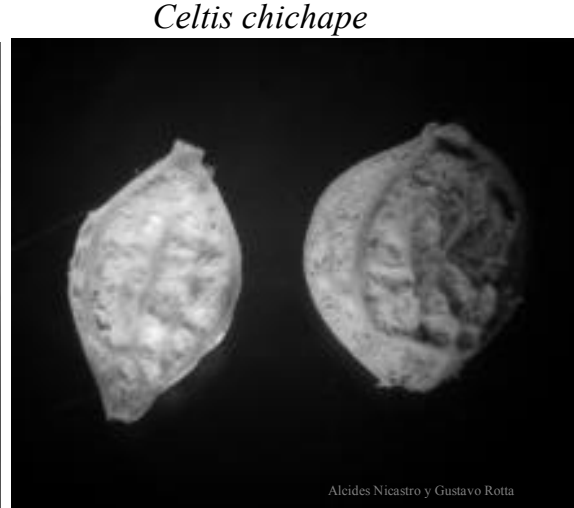

Rhipsalis lumbricoides

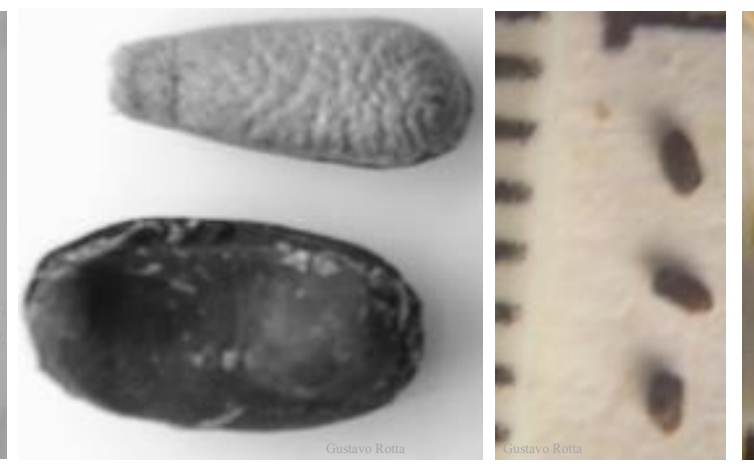

Psychotria carthagenensis
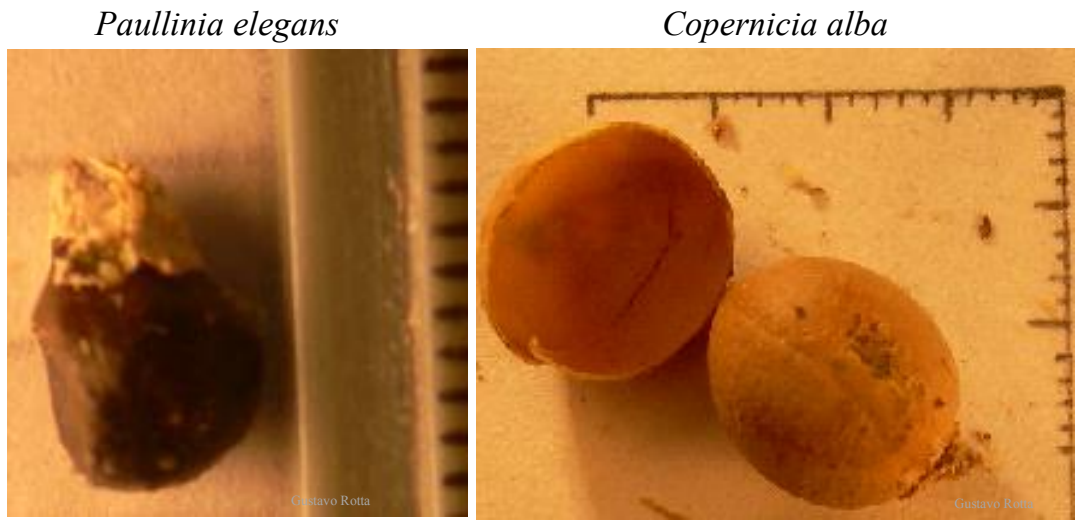

Cecropia pachystachya

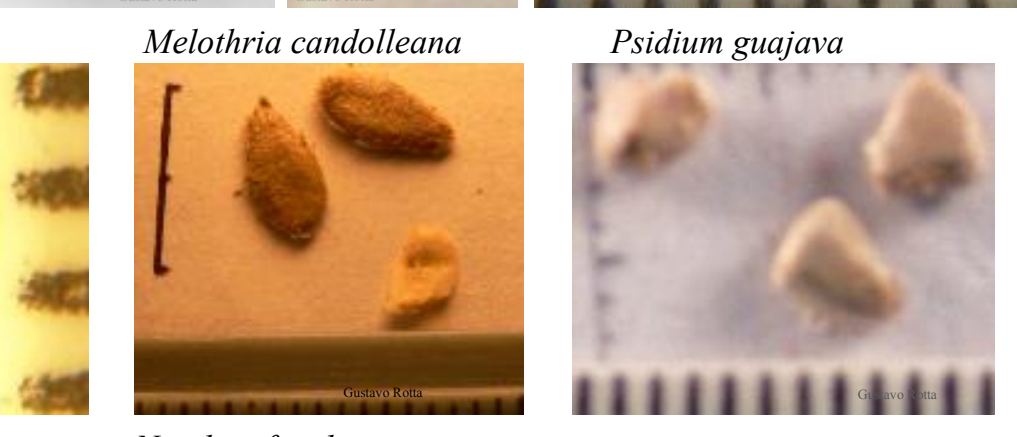

No identificadas
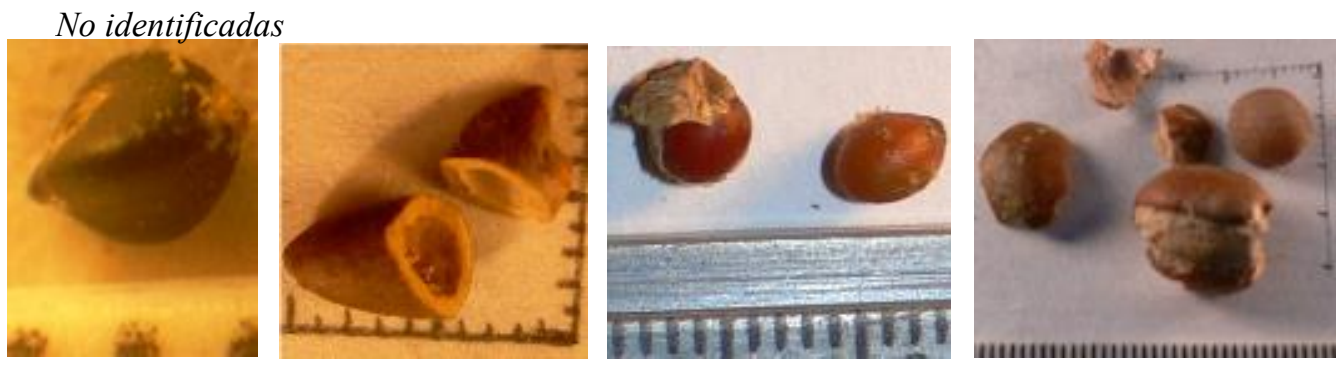


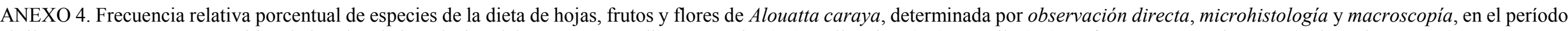

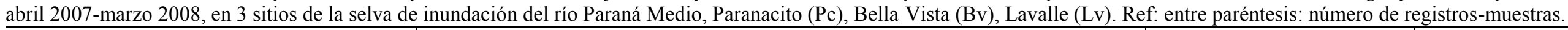

\begin{tabular}{|c|c|c|c|c|c|c|c|c|c|c|c|c|c|c|c|c|}
\hline & Método & & & & bservaci & ón Direct & & & & & & crohistolo & gía & & Iacroscop & \\
\hline Fomilis & Sitio (muestras) & & Pc (68) & & & Bv (108) & & & Lv (89) & & Pc (1600) & Bv (1600) & Lv (1600) & Pc (79) & Bv (117) & $\mathbf{L v}(95)$ \\
\hline FamIIIa & Especie / Estructura & Hoja(59) & Fruto (5) & Flor(4) & $\operatorname{Hoja}(78)$ & Fruto(19) & Flor(11) & Hoja(58) & Fruto(25) & Flor (6) & & Hoja & & & Fruto & \\
\hline Fabaceae & Inga affinis & 1,7 & - & - & 3,9 & 63,2 & 90,9 & 10,3 & 56,0 & 83,3 & 9,3 & 11,4 & 10,7 & 0,0 & 5,3 & 6,5 \\
\hline Lauraceae & Ocotea diospyrifolia & 13,6 & 100 & 100 & - & - & - & - & - & - & 6,8 & 0,0 & 0,0 & 23,9 & 0,0 & 0,0 \\
\hline Fabaceae & Albizia inundata & 28,8 & - & - & 53,9 & 10,5 & - & 37,9 & - & - & 13,3 & 16,3 & 13,2 & - & - & - \\
\hline Flacourtiaceae & Banara arguta & 1,7 & - & - & 16,7 & 5,3 & - & 20,7 & - & 16,7 & 6,5 & 27,0 & 23,4 & 11,3 & 4,0 & 11,5 \\
\hline Lauraceae & Nectandra angustifolia & 3,4 & - & - & 2,6 & - & - & 13,8 & 44,0 & - & 4,2 & 8,0 & 8,1 & 4,2 & 15,8 & 17,1 \\
\hline Celtidiaceae & Celtis chichape & - & - & - & - & - & - & 8,6 & - & - & 9,9 & 10,1 & 14,8 & 13,4 & 2,6 & 22,6 \\
\hline Cecropiaceae & Cecropia pachystachya & 1,7 & - & - & 16,7 & 5,3 & - & - & - & - & 1,6 & 4,1 & 1,8 & 4,9 & 7,9 & 0,0 \\
\hline Fabaceae & Geoffroea spinosa & 23,7 & - & - & - & - & - & - & - & - & 6,9 & 0,0 & 5,9 & - & - & - \\
\hline Solanaceae & Solanum aculeatissimum & - & - & - & - & - & - & - & - & - & - & - & - & 4,2 & 18,0 & 11,5 \\
\hline Sapindaceae & Sapindus saponaria & 13,6 & & - & - & - & - & - & - & - & 11,4 & 0,0 & 0,0 & - & - & - \\
\hline Moraceae & Ficus luschnathiana & - & - & - & - & - & - & - & - & - & - & - & - & 14,8 & 7,0 & 2,8 \\
\hline Vitaceae & Cissus palmata & - & - & - & - & - & - & - & - & - & - & - & - & 0,0 & 12,3 & 10,1 \\
\hline Sapindaceae & Paullinia elegans & - & - & - & - & 5,3 & & - & - & - & 1,6 & 1,1 & 1,0 & 0,0 & 6,1 & 3,2 \\
\hline Hippocrateaceae & Pristimera andina & 3,4 & - & - & - & - & - & - & - & - & 11,1 & 0,0 & 0,0 & - & - & - \\
\hline Euphorbiaceae & Croton urucurana & - & - & - & 1,3 & - & 9,1 & - & - & - & 1,0 & 2,4 & - & - & - & - \\
\hline Convolvulaceae & Ipomoea cairica & 1,7 & - & - & 1,3 & - & - & - & - & - & 0,6 & 1,1 & 1,9 & - & - & - \\
\hline Asteraceae & Tessaria integrifolia & 1,7 & - & - & 1,3 & - & - & 3,5 & - & - & 0,1 & 0,1 & 0,1 & - & - & - \\
\hline Arecaceae & Copernicia alba & 1,7 & - & - & - & - & - & - & - & - & - & - & 0,4 & 2,1 & 0,0 & 0,0 \\
\hline Salicaceae & Salix humboldtiana & - & - & - & - & - & - & 1,7 & - & - & 0,2 & 0,9 & 1,1 & - & - & - \\
\hline Cactaceae & Rhipsalis lumbricoides & - & - & - & - & - & - & - & - & - & - & - & - & 3,5 & 0,0 & 0,0 \\
\hline Fabaceae & Peltophorum dubium & - & - & - & - & - & - & - & - & - & 3,3 & 0,0 & 0,0 & - & - & - \\
\hline Poaceae & Panicum sp. & - & - & - & - & - & - & - & - & - & - & - & - & 1,4 & 1,8 & 0,0 \\
\hline Rubiaceae & Psychotria carthagenensis & - & - & - & - & - & - & - & - & - & - & - & - & 0,0 & 1,8 & 0,5 \\
\hline Phyllanthaceae & Phyllanthus chacoensis & - & - & - & - & - & - & - & - & - & 0,3 & 1,9 & 0,0 & - & - & - \\
\hline Bromeliaceae & Tillandsia meridionalis & 1,7 & - & - & - & - & - & - & - & - & - & - & - & - & - & - \\
\hline Myrtaceae & Psidium guajava & - & - & - & - & - & - & - & - & - & - & - & - & 0,0 & 1,8 & 0,0 \\
\hline Cucurbitaceae & Melothria candolleana & - & - & - & & - & - & - & - & - & - & - & - & 0,0 & 0,9 & 0,5 \\
\hline Rubiaceae & Machaonia brasiliensis & - & - & - & 1,3 & - & - & - & - & - & 0,1 & 0,0 & 0,1 & - & - & - \\
\hline Myrtaceae & Eugenia moraviana & - & - & - & - & - & - & - & - & - & 1,1 & 0,0 & 0,0 & - & - & - \\
\hline Fabaceae & Erythrina crista galli & - & - & - & - & - & - & - & - & - & 0,0 & 0,1 & 0,4 & - & - & - \\
\hline Poaceae & Guadua sp. & - & - & - & - & - & - & - & - & - & 0,1 & 0,1 & 0,0 & - & - & - \\
\hline Sapindaceae & Houssayanthus incanus & - & - & - & - & - & - & - & - & - & 0,0 & 0,2 & 0,0 & - & - & - \\
\hline
\end{tabular}


ANEXO 5. Índice de Disponibilidad (IDi) de especies utilizadas como recurso alimentario por Alouatta caraya, según las estructuras vegetales (hoja joven, hoja madura, fruto y flor), en el período abril 2007-marzo 2008, en 4 sitios de la selva de inundación del río Paraná Medio (Paranacito, Bella Vista, Lavalle y Esquina).

Hoja joven

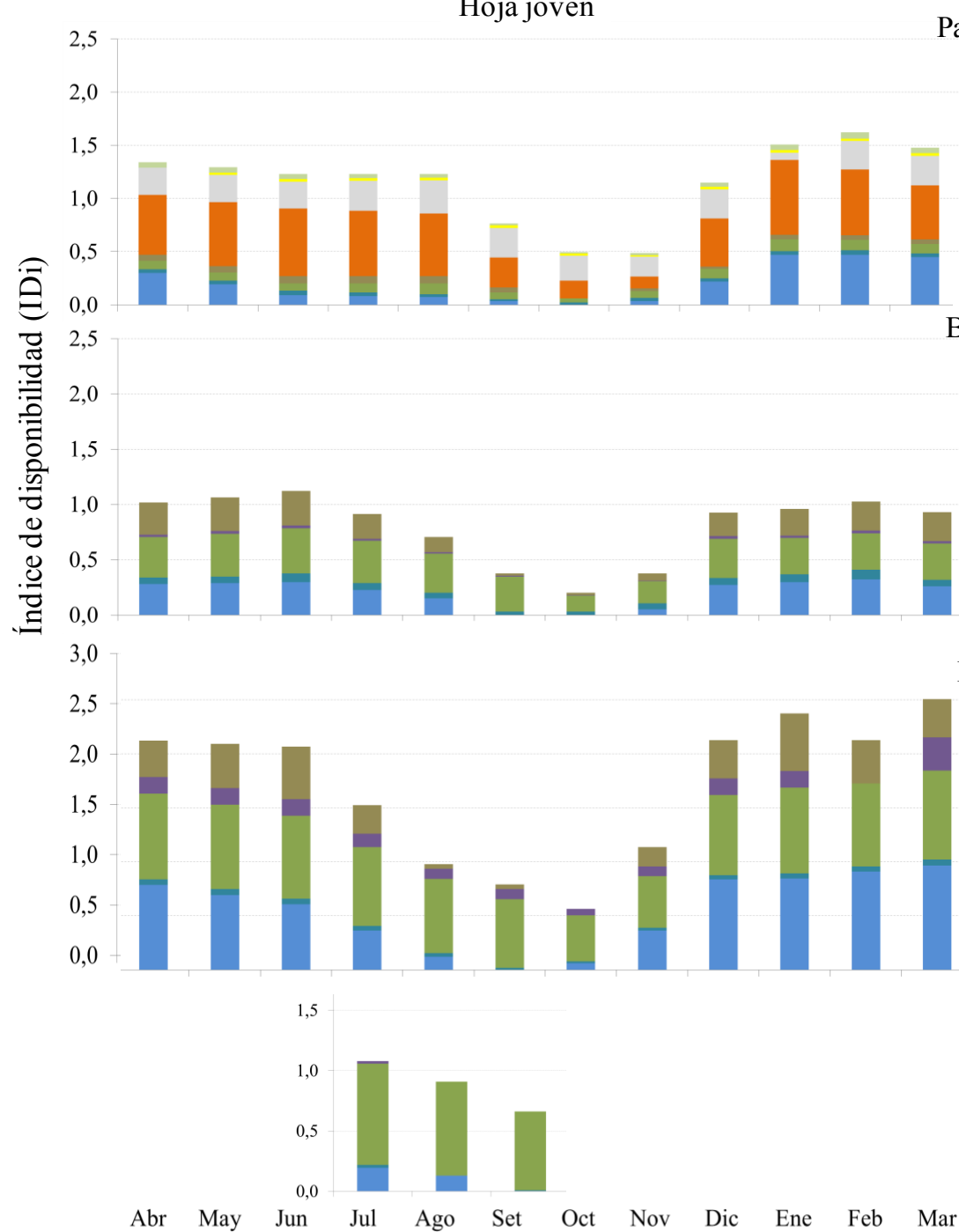

Paranacito

Hoja madura

Bella Vista
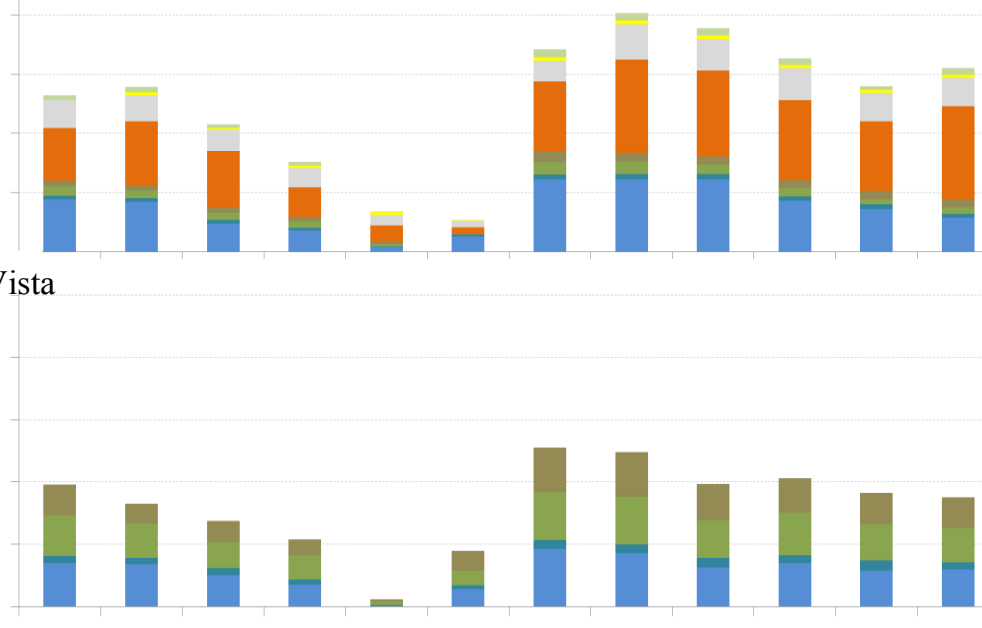

Lavalle

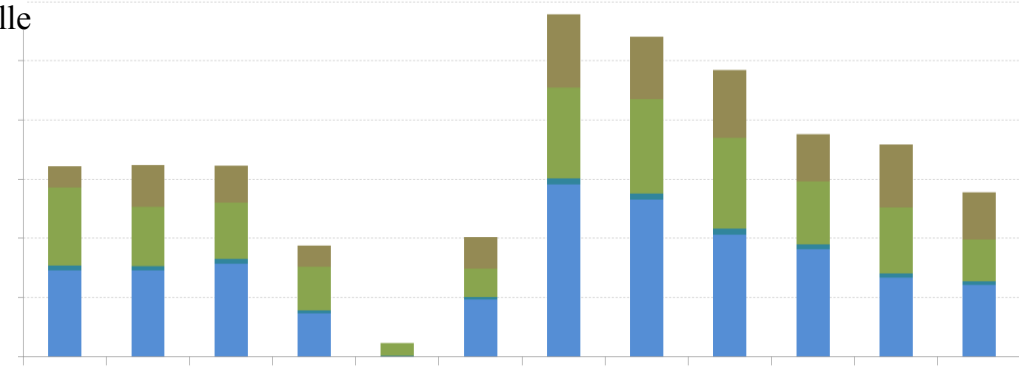

Esquina

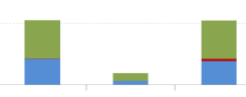

Abr May Jun Jul Ago Set Oct Nov Dic Ene Feb Mar

Referencias-Especies: $\square$ Sapindus saponaria

Pristimera andima

Inga affinis
- Ocotea diospiryfolia

- Celtis chichape
- Geoffroea spinosa Banara arguta

albizia inundata 


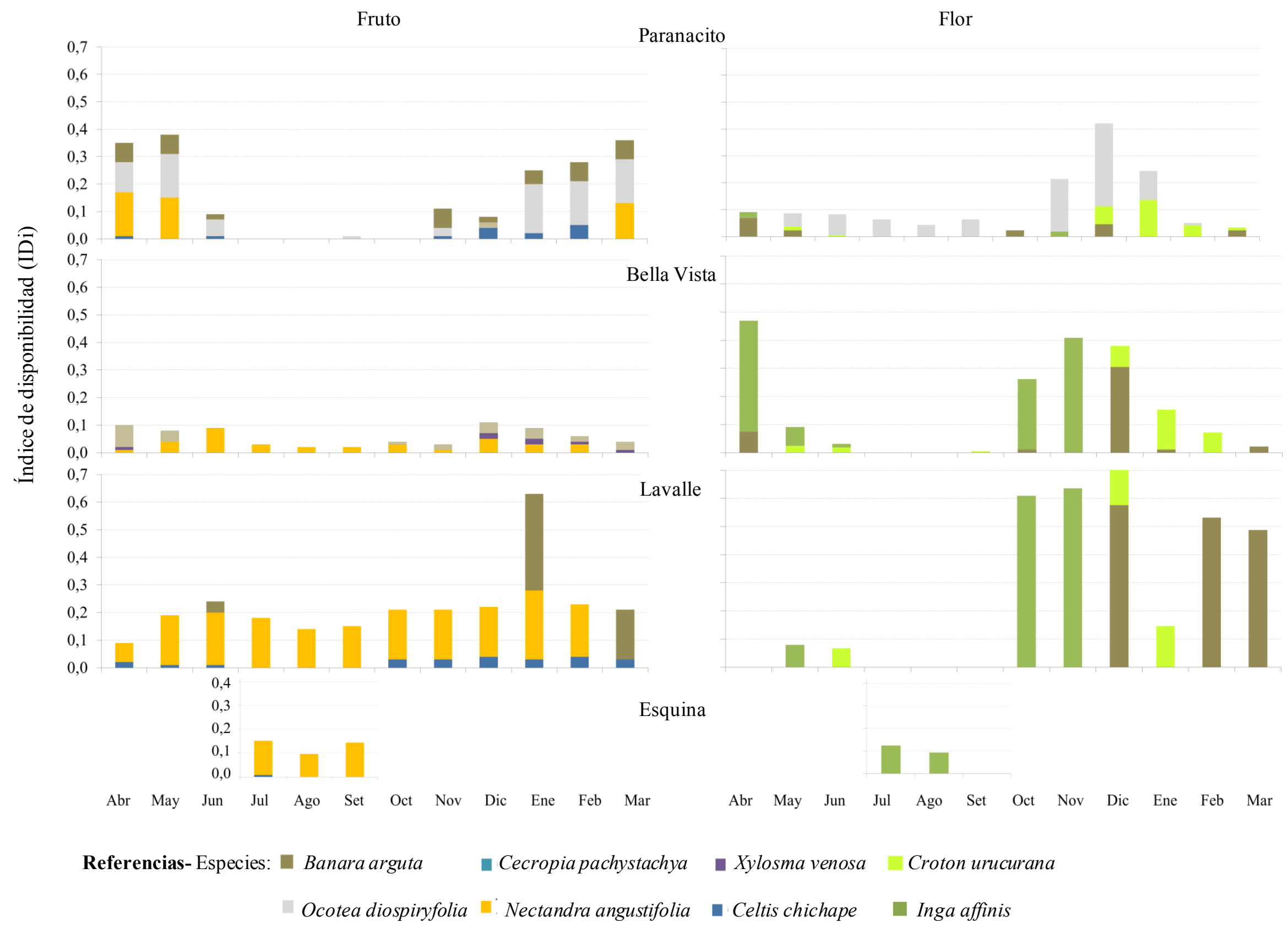

